MAURO CANZIAN

\title{
Análise qualitativa e semiquantitativa de parâmetros morfológicos em biópsias pulmonares cirúrgicas e autópsias: valor preditivo e impacto no prognóstico de pacientes com infiltrado pulmonar difuso
}

\author{
Tese apresentada à Faculdade de Medicina da \\ Universidade de São Paulo para obtenção do \\ titulo de Doutor em Ciências \\ Área de concentração: Patologia \\ Orientadora: Prof. Dra. Vera Luiza Capelozzi
}

São Paulo

2005 
Dedico este trabalho a meus pais, Vicentina de Oliveira Canzian e Sergio Canzian, pois a eles devo toda a minha formação educacional como profissional, como cidadão e como ser humano.

Dedico também a minha esposa, Maria José da Silva Fernandes, e a meu filho, Francisco Fernandes Canzian, pelo amor, carinho, companbeirismo e paciência incondicionais, fundamentais para a realização deste.

Não poderia deixar de também dedicar este trabalho ao brasileiro, o mais bumilde, que busca no serviço público de saúde o alivio para seus sofrimentos. 


\section{AGRADECIMENTOS}

À querida Profa. Dra. Vera Luiza Capelozzi, minha orientadora, pelo grande exemplo de dedicação, de perseverança, de luta incansável pelo progresso da ciência neste país, mas, sobretudo, de respeito e carinho ao próximo.

À Profa. Dra. Carmen Silvia Valente Barbas, uma das mentoras deste estudo, que em muito nos auxiliou com seus conselhos, opiniões e explicações principalmente de questões ligadas à prática clínica.

Ao Prof. Dr. Paulo Hilário Nascimento Saldiva, pela possibilidade de desenvolver este estudo no Departamento de Patologia da FMUSP.

Ao Prof. Dr. Gyorgy Böhm, mentor científico do grupo de Patologia Pulmonar da FMUSP.

À Profa Dra. Maria de Lourdes Higuchi, pelo grande incentivo e pelas concessões à realização deste estudo em concomitância a minha atividade profissional no Laboratório de Anatomia Patológica do Instituto do Coração do HCFMUSP.

Ao Prof. Dr. Francisco Vargas Suso, pelo crédito e grande respeito com que me acolheu nas atividades do Departamento de Pneumologia da FMUSP.

Ao Prof. Dr. Alberto Cukier, pelo importante incentivo à minha atividade profissional e desenvolvimento na subespecialidade de Patologia Pulmonar, tornando possível a realização deste.

Aos colegas e amigos, médicos do Laboratório de Anatomia Patológica do InCor - HCFMUSP, Jussara Bianchi Castelli, Léa Maria Macruz Ferreira Demarchi, Luiz Alberto Benvenuti, Paulo Sampaio Gutierrez, Renata Bacic Palhares e Vera Demarchi Aiello, pelo grande auxílio ao transmitir-me suas experiências, mas também pelas discussões e sugestões, em doses homeopáticas ao longo desses anos, e, sobretudo pela minha substituição em atividades de rotina, possibilitando-me tempo disponível para a conclusão deste.

Ao amigo Dr. Marcos Samano, pelas correções e pareceres relacionados à prática cirúrgica. 
Ao Acadêmico da FMUSP, aluno de Iniciação Científica, Alexandre de Matos Soeiro pelo enorme auxílio na árdua coleta de dados de prontuários.

Ao estatístico Marcel Frederico de Lima Taga pela sua disponibilidade e interesse em discutir, criticar construtivamente, sugerir alterações em toda a esfera estatística deste estudo.

À estatística Cecília Farhat pelo auxílio na análise dos dados.

Ao amigo Dr. Alexandre Muxfeldt Ab'Saber, por suas opiniões na revisão dos casos, assim como na redação deste.

Ao amigo Dr. Edwin Roger Parra, pela troca de informações relevantes durante a realização de nosso estudo.

À Profa. Dra. Maria de Fátima Araújo, de quem me considero discípulo, responsável pelo meu interesse e minha escolha em especializar-me em Anatomia Patológica.

Ao funcionário do Departamento de Patologia da FMUSP, Reginaldo Silva do Nascimento, e ao funcionário do Laboratório de Anatomia Patológica do InCor - HCFMUSP, Marcio Rodrigues Martins, pelo auxílio na busca e arquivamento de lâminas e blocos de parafina.

Às funcionárias do Serviço de Histologia do Departamento de Patologia da FMUSP, em especial à Sra. Cassia Arruda, pela elaboração de lâminas.

A todos os funcionários do Laboratório de Anatomia Patológica do InCor HCFMUSP, que sempre me auxiliaram direta ou indiretamente nesta empreitada.

Ao funcionário do Serviço de Verificação de Óbito, Nilton Fontes Neuman, pelo levantamento de registros de casos autopsiados.

Aos funcionários dos Serviços de Arquivamento Médico e Estatístico do InCor - HCFMUSP e do Instituto Central do HCFMUSP, em especial às funcionárias Sandra Regina Diniz Souza e Clarice Aparecida Milani, pelo levantamento de casos e busca de prontuários.

À FAPESP, entidade científica patrocinadora deste estudo. 


\section{ÍNDICE}

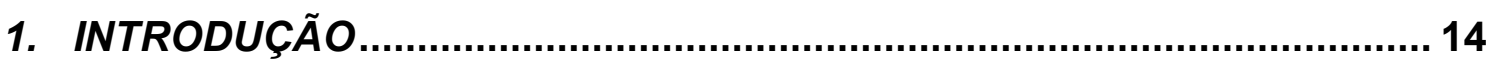

1.1. DEFININDO INFILTRADOS PULMONARES DIFUSOS E A

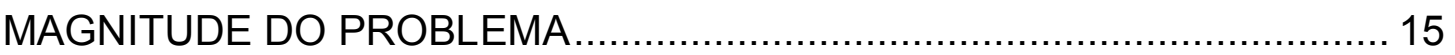

1.1.1. MAGNITUDE DO PROBLEMA .............................................. 18

1.2. IMPLICAÇÕES DA ORGANIZAÇÃO HISTOANATÔMICA DO

APARELHO RESPIRATÓRIO NO ESTUDO DOS INFILTRADOS

PULMONARES DIFUSOS.

1.3. IMPLICAÇÕES DA QUEBRA DOS MECANISMOS DE DEFESA NO

ESTUDO DOS INFILTRADOS PULMONARES DIFUSOS …..................... 27

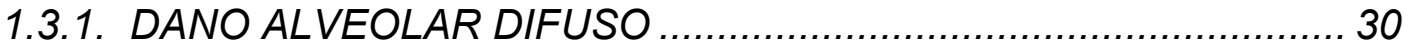

1.3.2. SÍNDROMES HEMORRÁGICAS ALVEOLARES ........................ 31

1.3.3. PNEUMONIA EM ORGANIZAÇÃO (PADRÃO OP) ...................... 31

1.3.4. PNEUMONIA INTERSTICIAL USUAL (UIP) ............................... 32

1.3.5. PNEUMONIA ALVEOLAR MACROFÁGICA ............................. 32

1.3.6. INFILTRADOS CELULARES LINFÓIDES .................................. 33

PERIBRONNQUICOS E INTERSTICIAIS ............................................... 33

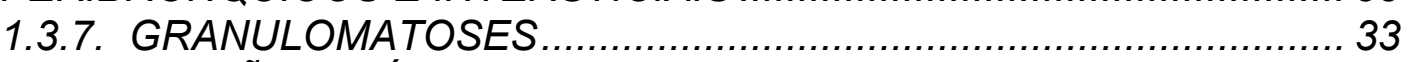

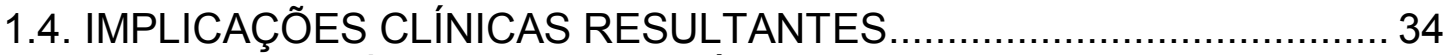

1.4.1. INSUFICIÊNCIA RESPIRATÓRIA ....................................... 34

1.5. IMPLICAÇÕES DA BIÓPSIA PULMONAR NOS INFILTRADOS

PULMONARES DIFUSOS - PERSPECTIVAS HISTÓRICAS …................... 37

1.5.1. PROCEDIMENTOS BRONCOSCÓPICOS ................................. 39

1.5.2. PROCEDIMENTOS CIRÚRGICOS...................................... 42

1.6. JUSTIFICANDO A PROPOSTA DE ANALISAR QUANTITATIVAMENTE

OS PARÂMETROS HISTOLÓGICOS NOS INFILTRADOS PULMONARES

DIFUSOS.

1.7. EMBASAMENTO CIENTÍFICO PARA ESTUDAR INFILTRADOS

PULMONARES DIFUSOS - QUESTÕES NÃO RESOLVIDAS 52

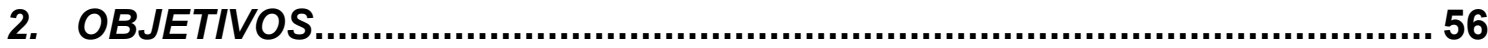

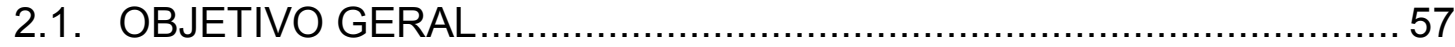

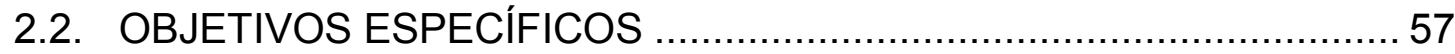

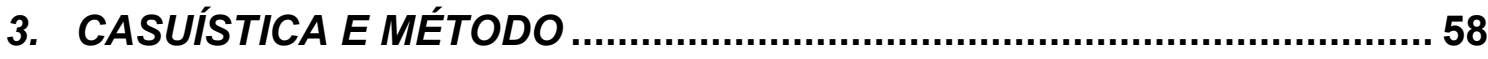

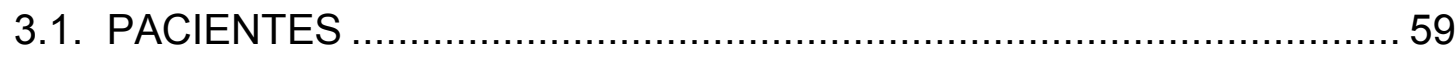

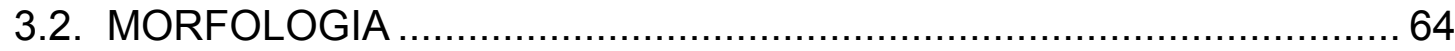

3.3. DETERMINAÇÃO DOS "ÍNDICES HISTOPATOLÓGICOS" ................ 71

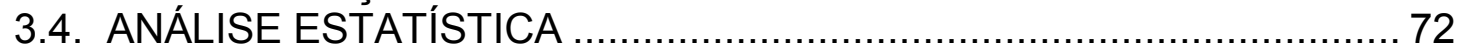

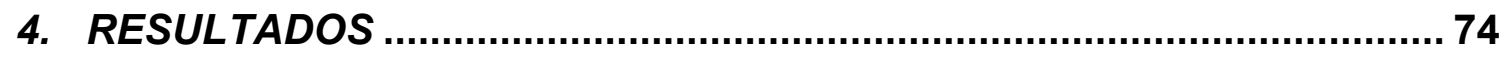

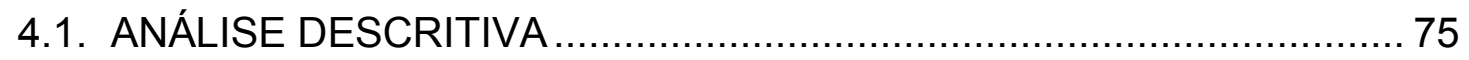




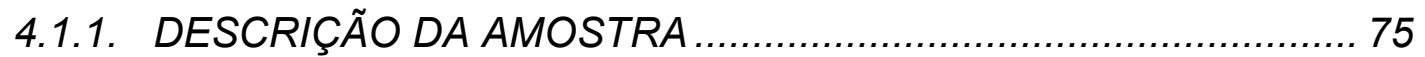

4.1.1.1. Análise descritiva de variáveis epidemiológicas e .................. 75

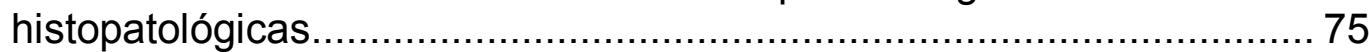

4.2. CONCORDÂNCIAS ENTRE OS DIAGNÓSTICOS …......................... 81

4.3. RELAÇÕES DAS VARIÁVEIS COM A SOBREVIDA HOSPITALAR ..... 92

4.3.1. RELAÇÃO DOS ÍNDICES HISTOPATOLÓGICOS ...................... 99

AGUDOS E CRÔNICOS COM A SOBREVIDA HOSPITALAR ................. 99

4.3.1.1. Combinação das variáveis com a sobrevida ........................ 102

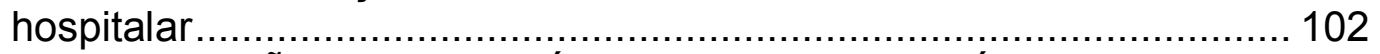

4.4. COMPARAÇÃO ENTRE ANÁLISES HISTOPATOLÓGICAS DE

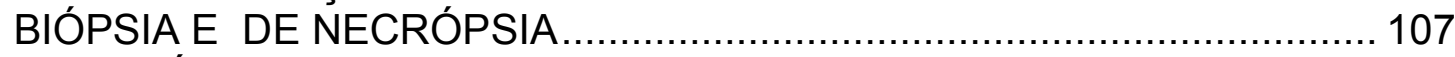

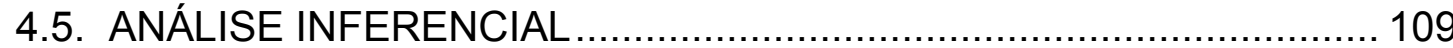

4.5.1. ASSOCIAÇÃO DAS VARIÁVEIS COM A SOBREVIDA............... 109

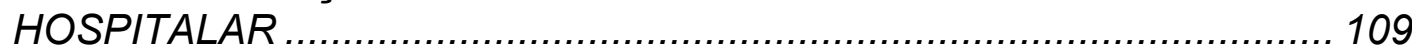

4.5.2. COMPARAÇÃO ENTRE ANÁLISES HISTOPATOLÓGICAS ....... 110

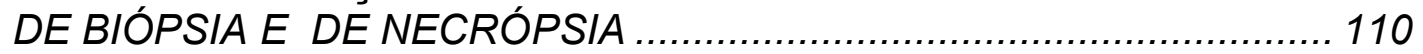

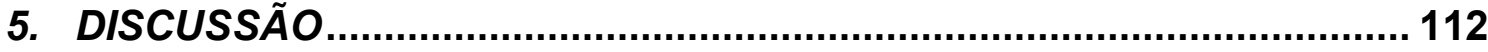

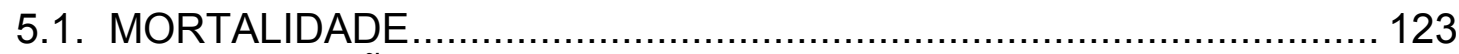

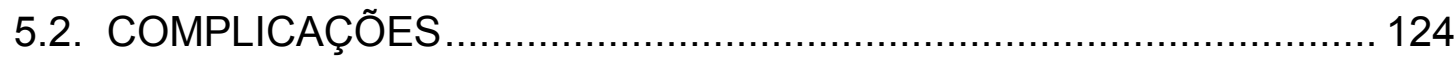

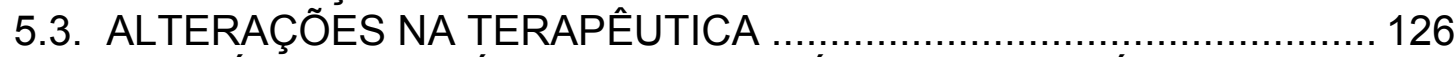

5.4. ACURÁCIA DIAGNÓSTICA E DIAGNÓSTICO ESPECÍFICO ........... 127

5.5. CONCORDÂNCIA ENTRE ACHADOS HISTOPATOLÓGICOS DE

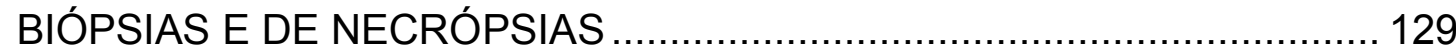

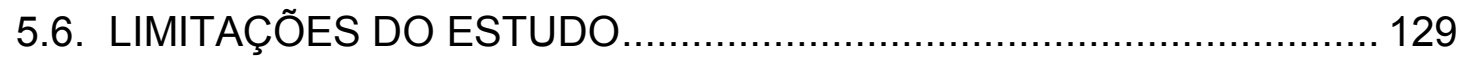

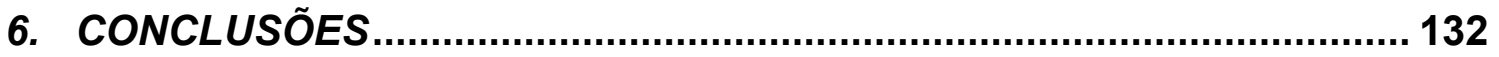

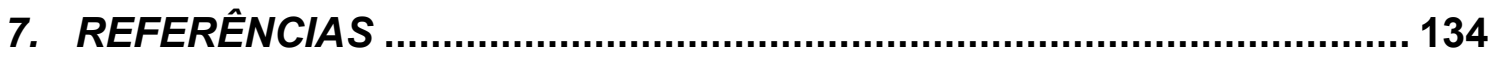

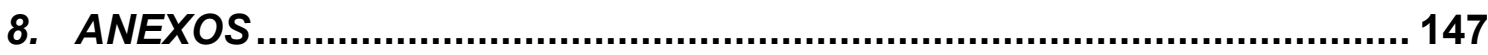

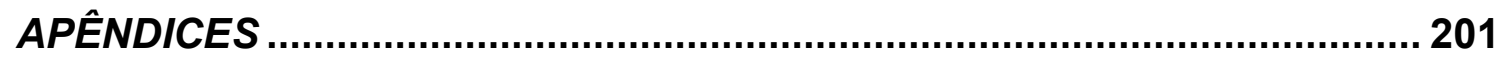




\section{LISTA DE SIGLAS E ABREVIATURAS}

\begin{tabular}{ll} 
ALI & "Acute lung injury" \\
AM & Amiloidose \\
AMP & Pneumonia alveolar macrofágica \\
AVCI & Acidente vascular cerebral isquêmico \\
BALT & Tecido linfóide associado ao brônquio \\
BAVT & Bloqueio atrioventricular total \\
Bcp & Broncopneumonia \\
CEC & Carcinoma espinocelular \\
CMV & Citomegalovírus \\
CPC & Congestão passiva crônica \\
CV & Capilarites / vasculites \\
DAD & Dano alveolar difuso \\
DC & Distúrbios circulatórios \\
DIP & Pneumonia intersticial descamativa \\
DM & Diabetes mellitus \\
FiO & Fração inspirada de oxigênio \\
FIP & Fibrose intersticial pulmonar \\
FIPI & Fibrose intersticial pulmonar idiopática \\
GVHD & Doença enxerto-contra-hospedeiro \\
GW & Granulomatose de Wegener \\
\hline
\end{tabular}


HAS Hipertensão arterial sistêmica

HIV Vírus da imunodeficiência humana

HP Hipertensão pulmonar

HX Histiocitose $X$

IAM Infarto agudo do miocárdio

ICC Insuficiência cardíaca congestiva

IOT Intubação orotraqueal

IRA Insuficiência renal aguda

IRC Insuficiência renal crônica

ITU Infecção do trato urinário

LAM Linfangioleiomiomatose

LES Lupus eritematoso sistêmico

LF L Linfoma

LH Linfoma de Hodgkin

LIP Pneumonia intersticial linfóide

LLA Leucemia linfóide aguda

LMC Leucemia mielóide crônica

LNH Linfoma não-Hodgkin

CA Carcinomas

NSIP Pneumonia intersticial não específica

OP Pneumonia organizante

PGNI Pneumopatia granulomatosa não infecciosa 


\begin{tabular}{ll}
$\mathrm{PH}$ & Pneumonia por hipersensibilidade \\
$\mathrm{PI}$ & Pneumopatias infecciosas \\
$\mathrm{PIT}$ & Pneumonias intersticiais \\
$\mathrm{PaO}_{2}$ & Pressão parcial de oxigênio \\
$\mathrm{PCO}_{2}$ & Pressão parcial de dióxido de carbono \\
$\mathrm{PO}_{2}$ & Pressão parcial de oxigênio \\
$\mathrm{QT}$ & Quimioterapia \\
$\mathrm{SARA}$ & Síndrome da angústia respiratória aguda \\
$\mathrm{Sat} \mathrm{O}_{2}$ & Saturação de oxigênio \\
SIDA & Síndrome da imunodeficiência adquirida \\
SK & Sarcoma de Kaposi \\
SNC & Sistema nervoso central \\
Tbc & Tuberculose \\
TEP & Tromboembolismo pulmonar \\
TGI & Trato gastrointestinal \\
TMO & Transplante de medula óssea \\
TVP & Trombose venosa profunda \\
Tx & Transplante \\
UIP & Pneumonia intersticial usual \\
VA & Doenças de vias aéreas \\
VEF & volume expiratório forçado no 1º segundo \\
\hline
\end{tabular}




\section{RESUMO}

CANZIAN M. Análise qualitativa e semiquantitativa de parâmetros morfológicos em biópsias pulmonares cirúrgicas e autópsias: valor preditivo e impacto no prognóstico de pacientes com infiltrado pulmonar difuso. São Paulo, 2005. [Tese de Doutorado - Faculdade de Medicina da Universidade de São Paulo].

Objetivo: Ainda que a biópsia pulmonar cirúrgica tenha sido amplamente estudada em distintas populações, alterações teciduais detalhadas foram até hoje muito pouco exploradas. Dessa forma, realizou-se estudo com o objetivo de estudar o impacto da biópsia pulmonar cirúrgica em pacientes portadores de pneumopatias difusas, procurando-se aplicar e validar um sistema de escore histopatológico, explorando-se a sua relação semiquantitativa com fatores epidemiológicos e evolução dos pacientes. Métodos: foram examinadas as biópsias pulmonares cirúrgicas de 63 pacientes maiores de 18 anos de idade, portadores de infiltrado pulmonar difuso, internados entre os anos de $1982 \mathrm{e}$ 2003. As alterações histopatológicas foram divididas segundo compartimentos anatômicos (interstício, vias aéreas, vasos e alvéolos) e avaliadas semiquantitativamente através de um sistema de escore variando de zero a 4 . Dessa forma, "índices" histopatológicos agudo e crônico foram estabelecidos. Resultados: associação estatisticamente significante foi observada entre 4 dos diversos parâmetros estudados e a sobrevida hospitalar: sexo, a presença de comorbidade, a presença de dano alveolar difuso e o "sistema de escore". O risco de óbito foi 6 vezes maior para os homens em relação às mulheres, 33 vezes maior para os portadores de dano alveolar difuso e 25 vezes maior para os portadores de comorbidade em relação aos não portadores e foi observado risco de óbito 3 vezes menor para cada unidade acrescida no "índice crônico". Conclusões: a avaliação detalhada de espécimes pulmonares cirúrgicos permite o estabelecimento de um sistema de escores histopatológicos que pode fornecer mais dados do que a avaliação puramente diagnóstica com possíveis 
implicações prognósticas Novos estudos randomizados prospectivos, com maior casuística, poderiam confirmar e complementar nossas conclusões.

Palavras-chave: pulmão; patologia; biópsia; autópsia; insuficiência respiratória; valor preditivo; prognóstico. 


\section{SUMMARY}

CANZIAN M. Qualitative and semiquantitative analyses of morphological parameters of open lung biopsies and autopsies: predictive value and impact on prognosis of patients with diffuse pulmonary infiltrate. São Paulo, 2005. [Tese de Doutorado - Faculdade de Medicina da Universidade de São Paulo].

Background: Open lung biopsy has been studied in distinct populations, mostly concerning only histopathological diagnostic information in diffuse pulmonary disease, beyond clinical data. As detailed tissue analyses in diffuse infiltrates has been barely exploited, the aim of this study is apply a scoring system to evaluate if analyses of intensity and extension of pathologic process through a semiquantitative approach could provide important prognostic information.

Methods: we examined open lung biopsies of 63 patients older than 18 years, with diffuse infiltrates, from 1982 to 2003 . Pulmonary specimens were divided into 4 anatomical compartments - interstitium, vessels, airways and alveolar spaces. Severity of each pathological alteration was semiquantitatively rated following an histological score system varying from 0(zero) to 4. "Acute" and "chronic" "indices" were then histologically established. Results: Statistically significant association occurred between four variables with hospital survival: sex, diffuse alveolar damage, comorbidity and "scoring system". Death risk for men was six times greater of women's risk. Occurrence of diffuse alveolar damage and comorbidity increases respectively death risk 33 times and 25 times when compared to the absence of these parameters. Each unity increased in "chronic index" decreases 3 times the risk of death. Conclusions: detailed histological analysis of histological specimens can provide more than nosological diagnosis, bringing valuable information concerning prognosis. Greater study in a randomized and prospective trial could finalize end confirm this conclusion. 
Key words: lung; pathology; biopsy; autopsy; respiratory failure; predictive value; prognosis 
1. INTRODUÇÃO 


\section{INTRODUÇÃO}

\subsection{DEFININDO INFILTRADOS PULMONARES DIFUSOS E A MAGNITUDE DO PROBLEMA}

O termo "infiltrado difuso" é definido como o acúmulo acima do normal e com distribuição anatômica contínua de quantidades de substâncias ou células no interstício ou no alvéolo pulmonares, porém sem necessariamente haver o envolvimento completo dos pulmões ou de outros tecidos ou estruturas torácicas (TUDDENHAM 1984).

O quadro de infiltrado difuso pode ser observado em mais de 150 entidades pulmonares, a maior parte destas acometendo a parede alveolar, seja o interstício septal, o epitélio alveolar ou o endotélio. As alterações funcionais refletem restrição ao fluxo aéreo que podem se manifestar por redução da expansão do parênquima pulmonar, da capacidade total, da capacidade vital, do volume residual e da complacência pulmonar (GODWIN 1995).

As doenças intersticiais ou infiltrativas, que podem ser agudas ou crônicas, ao lado das doenças que acometem a parede torácica ou o espaço pleural, constituem o grande grupo de doenças pulmonares restritivas (GODWIN 1995). 
As doenças infiltrativas agudas são, em sua maior parte, representadas pelo edema intersticial que pode se formar pelo aumento da pressão da microvasculatura pulmonar ou pelo próprio aumento da permeabilidade microvascular, em virtude de lesões da barreira alvéolo-capilar. O protótipo deste grupo de afecções seria a síndrome da angústia respiratória aguda (SARA) (GODWIN 1995).

A SARA foi descrita em 1967 (ASHBAUGH 1967) e desde então vem sendo objeto de diversos estudos. Alterações como a elevação da pressão microvascular e a lesão da barreira têm sido associadas não somente ao edema, mas também ao acúmulo de exsudato protéico, formação de membranas hialinas em espaços alveolares, congestão e hemorragia. Parte dos pacientes acometidos evolui com o desenvolvimento de fibrose intersticial aguda, alguns dos quais não sobrevivem.

A definição da SARA pela Conferência de Consenso AmericanaEuropéia (BERNARD e col. 1994) inclui o estabelecimento de infiltrado pulmonar bilateral, relação resultante entre a pressão parcial de oxigênio no sangue arterial e a fração de oxigênio no ar inspirado $\left(\mathrm{PaO}_{2} / \mathrm{FiO}_{2}\right)$ menor de 200 mmHg e ausência de hipertensão atrial esquerda. Ainda que tal definição seja uma tentativa de limitar a patologia ao dano alveolar difuso (DAD), seja em sua fase aguda, seja em sua fase proliferativa, e embora na prática clínica os termos SARA e DAD sejam muitas vezes confundidos e até mesmo utilizados como sinônimos, numerosos padrões histológicos de base como pneumonias infecciosas, pneumonia organizante (OP), pneumonia eosinofílica aguda e 
capilarite pulmonar podem corresponder a esta síndrome e serem tratadas de diferentes maneiras. Porém, a freqüência com que patologias diferentes do DAD ocorrem em uma população de pacientes com SARA não é conhecida. Ainda que linhas mestras de conduta clínica tenham sido definidas para a SARA, não está claro se esta síndrome é uma entidade homogênea que pode ser tratada de maneira uniforme. Dessa forma, o papel da biópsia pulmonar cirúrgica na condução de casos de SARA permanece frustro (PATEL e col. 2004).

O dano alveolar difuso é uma forma de lesão pulmonar aguda que se caracteriza histologicamente por uma fase exsudativa, em que ocorre necrose de pneumócitos e endoteliócitos, edema e formação de membranas hialinas, evoluindo para uma fase proliferativa, com a organização do exsudato intraalveolar, que se torna fibrótico e é incorporado ao septo alveolar levando o alvéolo ao colapso, com aposição de paredes, e proliferação de pneumócitos do tipo 2. Em aproximadamente $50 \%$ dos casos o processo se resolve com o restabelecimento da arquitetura pulmonar normal, porém, em certo percentual de casos, ocorre progressão para uma consolidação fibrótica levando ao padrão de faveolamento (GODWIN 1995; TRAVIS e col. 2002).

A resolução da fase aguda pode sobrepor-se as alterações crônicas já estabelecidas, como por exemplo, as observadas na pneumonia intersticial usual (fibrose intersticial pulmonar). No entanto, grande parte das pneumopatias intersticiais crônicas podem originar-se em quadros de alveolite (GODWIN 1995). 
O dano alveolar difuso denota um padrão histológico observado em lesões pulmonares acarretadas pelas mais diversas etiologias, sendo a SARA a sua expressão clínica (TRAVIS e col. 2002).

Embora pacientes com DAD sejam hipoxêmicos, são muitas vezes refratários a oxigenioterapia em virtude da própria toxicidade promovida pelo oxigênio (GODWIN 1995).

As doenças infiltrativas crônicas perfazem um grupo de doenças pulmonares que embora apresentem características clínicas e radiológicas em comum, têm etiologia e quadros patológicos distintos. A maior parte destes quadros cursam com infiltrado intersticial associado a certa quantidade de exsudato intra-alveolar e apresentam hipertensão pulmonar em suas fases evolutivas tardias, em função da destruição do leito capilar. Aproximadamente $25 \%$ deste grupo é formado pelas doenças produzidas pela interação com o meio ambiente (pneumonia por hipersensibilidade, por exemplo), seguido pela sarcoidose (aproximadamente 20\%) e pelas pneumonias intersticiais crônicas idiopáticas (aproximadamente 13\%) (GODWIN 1995).

\subsubsection{MAGNITUDE DO PROBLEMA}

Os infiltrados pulmonares refletem graves problemas de saúde, ocupando lugar de destaque na clínica médica, em virtude de sua morbidade. Estima-se que no momento do diagnóstico $50 \%$ dos pacientes já apresentam 
doença bilateral com insuficiência respiratória progressiva (CARRINGTON e col. 1978; TURNER-WARWICK e col. 1980a; KING 1991).

Como fatores desencadeantes no desenvolvimento dos infiltrados pulmonares difusos (IPD) podem estar em jogo componentes imunológicos, genéticos e ou virais (DREISEN 1978). Provavelmente, o processo surge em indivíduos "susceptíveis" após contato com determinado estímulo. Este estímulo inicial leva a uma cascata de eventos que envolve controles inflamatório, imunológico e fibrótico pulmonar. Nos países norte-americanos, estudos sugerem uma prevalência de IPD de 80,9 por 100.000 homens, comparada com 67,2 por 100.000 mulheres (KING 1991). Similarmente, a incidência geral de IPD é mais comum em homens (31,5 por 100.000/ano) do que em mulheres (26,1 por 100.000/ano) aumentando com idade. (KING 1991). A sobrevida média relatada é de aproximadamente 4 anos. Estudo realizado em nosso meio cita uma sobrevida média de $33 \pm 32$ meses (BARROSO 1992).

O que diminuiria a mortalidade por IPD? Eliminar os fatores ambientais, a sua detecção precoce, habilidade em detectar a atividade da doença ou tratar todos os casos com esteróides têm sido algumas das alternativas.

Apesar de apresentarem características semelhantes, os vários IPD têm aspectos individuais fazendo com que cada um deles seja estudado separadamente. A gravidade das doenças envolvidas e a evolução clínica comumente insatisfatória da maioria delas têm desencadeado pesquisas quanto à patogênese. Estudos histológicos, ultra-estruturais, funcionais e do lavado 
bronco-alveolar (TURNER-WARWICK 1980b; RAGHU 1987; KING 1991; DRENT e col. 1996; GAY e col. 1998) há décadas são realizados em pacientes acometidos e em modelos experimentais, objetivando através de um melhor conhecimento dos mecanismos evolutivos, o aprimoramento dos métodos diagnósticos e o estabelecimento de novas terapêuticas. Se por um lado, essas técnicas têm permitido conhecer melhor o comportamento de tais doenças, por outro têm dado razões para o aparecimento de questões, muitas das quais sem resposta até o momento. Para os patologistas isto se tem refletido no aparecimento de múltiplas e complicadas classificações, dependendo de qual for a técnica empregada para examinar o tecido. Para os clínicos esta explosão de conhecimentos tem aberto novos caminhos para o desenvolvimento de protocolos de tratamento. Protocolos terapêuticos atualmente existentes dependem diretamente da caracterização histológica do processo inflamatório e fibrótico. Daí verifica-se a importância de um sistema de classificação no reconhecimento dos vários padrões histológicos.

O conhecimento da distribuição das lesões pulmonares é importante para o diagnóstico e requer amplo conhecimento da organização histoanatômica do aparelho respiratório. 


\subsection{IMPLICAÇÕES DA ORGANIZAÇÃO HISTOANATÔMICA DO APARELHO RESPIRATÓRIO NO ESTUDO DOS INFILTRADOS PULMONARES DIFUSOS}

A principal função dos pulmões é a troca gasosa que depende de uma ação sincrônica e coordenada que envolve o sistema nervoso central, a musculatura diafragmática e da parede torácica, e o sistema circulatório. Todo o volume de sangue do corpo passa pelos pulmões a cada minuto, distribuído por uma superfície de troca que perfaz aproximadamente $80 \mathrm{~m}^{2}$, o que equivale às dimensões de uma quadra de tênis (GODWIN 1995). Cada um dos pulmões pesa entre 300 e 400 gramas e apenas $10 \%$ de seu volume é ocupado por tecido sólido. As estruturas funcionais do pulmão podem ser divididas em vias condutoras e porção de troca gasosa (GODWIN 1995).

Desde a traquéia até o alvéolo, a via aérea sofre aproximadamente 23 dicotomizações e, embora ocorra progressiva redução no diâmetro individual da via aérea, há um grande aumento no diâmetro da totalidade destas, permitindo diminuição da resistência periférica ao fluxo aéreo (GODWIN 1995).

O campo de enfoque deste estudo é o menor compartimento anatômico pulmonar que pode ser observado macroscopicamente: o lóbulo. Trata-se de estrutura anatômica bem definida, com formato poligonal, que se compõe de 3 a 5 bronquíolos terminais e suas estruturas distais. Suas dimensões estão entre 1 e $2 \mathrm{~cm}$. de diâmetro, sendo delimitado pelo tecido conjuntivo do septo 
interlobular (GODWIN 1995). É em sua porção central que se observa o eixo bronco-vascular, ao redor do qual se dispõem os ácinos, onde ocorrem as trocas gasosas, em número que varia entre 3 e 30 (TRAVIS e col. 2002). O ácino pulmonar é a unidade funcional pulmonar responsável pela troca gasosa, sendo formado pelo bronquíolo respiratório, o ducto alveolar, o saco alveolar e o alvéolo, medindo aproximadamente $0,75 \mathrm{~mm}$. de diâmetro. Existem 2 a 5 gerações de bronquíolos respiratórios, que são revestidos por epitélio cubóide e providos de parede muscular, atuando predominantemente na condução aérea, sendo mínima a sua função de troca gasosa. A parede dos ductos alveolares por sua vez é formada pelos próprios alvéolos, sendo revestidos por camada única de células escamosas de espessura bastante reduzida, assim como ocorre nos sacos alveolares e alvéolos (GODWIN 1995).

As vias aéreas são revestidas por células de origem endodérmica que apresentam peculiaridades funcionais de acordo com a região em que se encontram, propiciando proximalmente a produção e expelição de muco e distalmente as trocas gasosas. Vias aéreas condutoras são revestidas predominantemente por células colunares ciliadas pseudoestratificadas e, em menor número, por células caliciformes, ambas derivadas das células basais, sendo paulatinamente substituídas em pequenas vias aéreas por revestimento celular cubóide. As células caliciformes podem aumentar muito em número face à lesão aguda, intensificando a produção de muco, em associação às glândulas submucosas, que atua na prevenção do ressecamento da mucosa e como importante mecanismo de defesa, auxiliando na remoção de partículas 
exógenas, em associação ao movimento ciliar. Estados patológicos que alterem a composição do epitélio, como, por exemplo, a hiperplasia de células caliciformes ou a sua substituição por epitélio metaplásico, levarão a uma maior ou menor produção de muco, assim como o seu eventual acúmulo. Vale lembrar que, além da própria condução do ar, as vias aéreas também atuam na filtração de partículas estranhas do ar inspirado (GODWIN 1995).

No epitélio bronquiolar são também observadas as células de Clara, responsáveis por uma secreção proteinácea aquosa que atua na limpeza e redução da tensão superficial de pequenas vias aéreas (GODWIN 1995).

São considerados bronquíolos as vias aéreas menores de $1 \mathrm{~mm}$ de diâmetro, desprovidas de revestimento cartilaginoso e de glândulas submucosas e revestidas por musculatura lisa. O termo "pequenas vias aéreas" é utilizado para vias aéreas menores do que $2 \mathrm{~mm}$ de diâmetro, incluindo, dessa forma, pequenos brônquios e bronquíolos (TRAVIS e col. 2002).

Ainda que os pneumócitos do tipo I representem apenas $40 \%$ das células epiteliais alveolares, são responsáveis pelo revestimento de aproximadamente 95\% da superfície, em virtude de sua morfologia plana e de sua diminuta espessura. São responsáveis pelo controle do fluxo de fluidos entre o interstício e o espaço alveolar e não possuem potencial regenerativo. Assim, uma vez lesadas, ocorre acúmulo de fluido nos espaços aéreos (GODWIN 1995; TRAVIS e col. 2002).

As trocas gasosas entre o ar inspirado e o sangue se fazem através de uma membrana que, a partir do interior do espaço alveolar se constitui do 
citoplasma dos pneumócitos do tipo I, as membranas basais e o citoplasma da célula endotelial do capilar septal. A parede alveolar possui duas membranas basais, sendo uma associada ao epitélio e outra associada a células endotelial, que se fundem em determinados pontos da parede alveolar, facilitando a troca gasosa (GODWIN 1995; TRAVIS e col. 2002).

Pneumócitos do tipo II perfazem $60 \%$ das células epiteliais, mas revestem apenas $3 \%$ da superfície alveolar. Contrariamente aos do tipo I, são células de formato cubóide, aspecto proeminente, são providas de potencial regenerativo, sendo responsáveis pela produção de surfactante e de substituição de pneumócitos do tipo I quando lesados. Embora constituam um pequeno percentual das células alveolares, os macrófagos, principal constituinte do chamado "componente descamativo", são os principais responsáveis pelo mecanismo de defesa celular, mostrando-se proliferados quando a resposta imune se faz necessária, no caso de fagocitar partículas exógenas que escapam aos mecanismos de filtração traqueobrônquicos (GODWIN 1995; TRAVIS e col. 2002).

Alvéolos adjacentes comunicam-se através numerosas conexões denominadas "poros de Kohn". Embora permitam primordialmente a ventilação colateral, também propiciam a passagem de outros materiais, sejam sólidos ou líquidos. Semelhante sistema de comunicação é observado entre os bronquíolos terminais e os alvéolos de suas adjacências denominados "canais de Lambert" (GODWIN 1995). Estes, embora de difícil visualização em pulmões 
normais, são responsáveis pela metaplasia colunar peribronquiolar (lambertose) observada na fase resolutiva de processos inflamatórios (TRAVIS e col. 2002).

O pulmão apresenta um duplo sistema de irrigação sangüínea formado pelo sangue venoso proveniente da artéria pulmonar (pequena circulação) e pelo sangue arterial proveniente das artérias brônquicas (grande circulação ou circulação sistêmica) A circulação pulmonar é composta por artérias elásticas calibrosas e por arteríolas musculares, que acompanham o eixo brônquico e bronquiolar em direção à periferia, ramificando-se progressivamente e chegando à rede capilar da parede alveolar, onde ocorrem as trocas gasosas com o ar inspirado. A circulação sistêmica responsável pelo suprimento sangüíneo arterial do tecido pulmonar constitui-se de ramos das artérias brônquicas com origem na aorta ou nas artérias intercostais, formando um plexo na parede brônquica que se estende distalmente até o nível de bronquíolos respiratórios, e proximalmente até a traquéia. Os ramos das artérias brônquicas também suprem a pleura visceral e parte do tecido conjuntivo intersticial (GODWIN 1995; TRAVIS e col. 2002).

O sistema venoso, por sua vez, surge do plexo alveolar periférico e se dirige aos septos interlobulares, onde são habitualmente observados em cortes histológicos (TRAVIS e col. 2002).

Artérias pulmonares possuem dupla membrana elástica (interna e externa), ao passo que em veias uma única membrana elástica é observada. A localização de um vaso em preparados microscópicos revela-se de grande 
importância em determinados estados patológicos, uma vez que veias podem arterializar-se, passando a exibir dupla camada elástica (TRAVIS e col. 2002).

Vasos linfáticos aparecem ao nível de pequenos bronquíolos distais e aumentam de calibre à medida que se aproximam dos linfonodos da região hilar (GODWIN 1995). A rede linfática, embora complexa, é muitas vezes inaparente sendo somente observada em estados patológicos tais como o edema pulmonar e a linfangite carcinomatosa. Acompanha estruturas broncovasculares, sendo geralmente observada nas zonas septais interlobulares e na pleura (TRAVIS e col. 2002).

O tecido linfóide, denominado "tecido linfóide associado ao brônquio" (ou pela sigla "BALT", de acordo com sua denominação em inglês "bronchusassociated lymphoid tissue") está normalmente presente na submucosa da arvore brônquica, mas é principalmente observado na presença de estimulação antigênica, ao longo de estruturas linfáticas, em geral, em locais de ramificação de vias aéreas. Embora o termo "BALT" seja utilizado para o tecido linfóide relacionado à via aérea, em estados reacionais a hiperplasia linfóide é observada ao longo da drenagem linfática, incluindo septos interlobulares e pleura. A íntima relação do "BALT" com estruturas aéreas pode, quando hiperplásico, levar até mesmo a estados de suboclusão destas (TRAVIS e col. 2002).

O sistema neuroendócrino pulmonar é formado por células com projeções dendríticas situadas na camada basal. As células neuroendócrinas, também conhecidas como células de Kulchitsky, são encontradas nas 
proximidades das glândulas de secreção brônquicas e também no epitélio superficial. São metabolicamente ativas e contém densos grânulos citoplasmáticos formados por hormônios peptídicos como a serotonina, a calcitonina e a bombesina. Já, os chamados corpos neuroepiteliais são estruturas presentes nos alvéolos e nos bronquíolos respiratórios formadas por agregados de células neuroendócrinas que atuam como sensores de oxigênio, aumentando a perfusão alveolar na ocorrência de queda da ventilação (GODWIN 1995; TRAVIS e col. 2002).

O arcabouço intersticial, que no pulmão normal é somente observado ao longo do eixo bronco-vascular, ao redor de veias e nos septos interlobulares, é constituído de fibras colágenas, fibras elásticas, células mesenquimais ("células alongadas"), e por reduzido número de células inflamatórias (GODWIN 1995).

\subsection{IMPLICAÇÕES DA QUEBRA DOS MECANISMOS DE DEFESA NO ESTUDO DOS INFILTRADOS PULMONARES DIFUSOS}

O infiltrado pulmonar difuso é o resultado final bastante estereotipado das diferentes expressões histopatológicas decorrentes da agressão aos vários compartimentos pulmonares.

Ao longo da evolução biológica, à medida que os animais deixaram de ser aquáticos e se tornaram terrestres, o aparelho que mais teve de adaptar-se foi o aparelho respiratório, devendo funcionar como um filtro de um lado, e de 
outro, manter hígidas as propriedades de troca gasosa. Considerando que a cada incursão respiratória a quantidade de partículas indesejáveis inaladas que não devem atingir a barreira alveolocapilar é muito grande, o equilíbrio entre função de filtro e troca gasosa foi conseguido através do desenvolvimento de mecanismos de defesa altamente especializados às agressões constantes.

O primeiro mecanismo de defesa adotado pelo aparelho respiratório foi a organização anatômica. Desta forma, a medida tomada pela natureza foi dividir o aparelho respiratório em dois grandes compartimentos: condução do ar e respiratório.

A segunda medida tomada pela natureza foi a organização histoanatômica dos compartimentos de condução e respiratório. Tal organização histoanatômica foi concebida com intuito de: 1) aquecer e umidificar o ar inspirado através da vascularização da submucosa; 2) diminuir o fluxo do ar inspirado através das dicotomizações pelo aumento do diâmetro total das vias aéreas; 3) reter o material particulado / microrganismos através da camada de muco e dicotomizações e 4) eliminar material particulado / microrganismos através do batimento ciliar, tecido linfóide, muco e tosse.

Ao nível dos ácinos pulmonares, macrófagos preenchem os espaços alveolares e são responsáveis pela defesa imunológica do compartimento distal do trato respiratório. A função do ácino pulmonar é basicamente permitir a difusão dos gases.

Embora existam diferentes expressões histopatológicas dessas doenças, a seqüência dos eventos patológicos decorrentes dos mecanismos de agressão 
aos compartimentos de condução e troca gasosa é bastante estereotipada. Inicialmente, existe uma fase predominantemente inflamatória, com infiltração celular expressiva, acompanhada de reatividade do epitélio de revestimento. Esta fase é seguida por deposição de colágeno no interstício axial, septal ou periférico, secundária à ativação dos fibroblastos, que são estimulados por diversos fatores de crescimento liberados pelas células inflamatórias no microambiente das vias aéreas e alvéolos. Mantida a estimulação secretora dos fibroblastos, o território alveolar e bronquiolar passa por uma fase de remodelação, onde as áreas colapsadas do parênquima são cicatrizadas de modo desfavorável, à semelhança de um osso com fratura e desvio que é engessada sem a adequada redução. A fase de remodelação representa um evento tardio decorrente dos mecanismos de agressão, levando à coexistência de regiões de colapso e espessamento fibroso ao lado de áreas acentuadamente dilatadas, císticas, conhecidas pelos patologistas como pulmão em "favo de mel" ou faveolamento.

Os padrões de reação pulmonar resultantes da agressão pulmonar mais comuns são mostrados na Tabela 1.1. (CAPELOZZI 1998) 
Tabela 1.1: Padrões básicos de reações à agressão pulmonar

\begin{tabular}{l}
\hline Dano alveolar difuso (padrão DAD) \\
Hemorragia alveolar \\
Pneumonia organizante (padrão OP) \\
Pneumonia intersticial usual (padrão UIP) \\
Pneumonia alveolar macrofágica (padrão AMP) \\
Infiltrado celular linfóide (padrão LIP) \\
Granulomatoses \\
\hline
\end{tabular}

\subsubsection{DANO ALVEOLAR DIFUSO}

Corresponde a um padrão histológico de agressão muito comum (e não um diagnóstico específico) encontrado nas doenças intersticiais agudas, particularmente em pacientes com SARA, como previamente referido, e nos imunossuprimidos. O dano alveolar difuso, cujo quadro histopatológico foi previamente relatado, é observado em infecções, inalação de tóxicos, drogas, colagenoses, radioterapia, reações alérgicas agudas (pneumonia por hipersensibilidade), síndromes hemorrágicas agudas e na pneumonia intersticial aguda (síndrome de Hamman-Rich) (CAPELOZZI 1998). 


\subsubsection{SÍNDROMES HEMORRÁGICAS ALVEOLARES}

Nas hemorragias crônicas, encontra-se grande número de macrófagos contendo hemossiderina nos espaços aéreos. Nas agudas, o quadro histológico é dominado pela "capilarite", representada por grande número de neutrófilos ao longo dos septos alveolares e ao redor das pequenas veias pulmonares. As principais causas incluem a síndrome de Goodpasture, vasculites (granulomatose de Wegener, por exemplo), colagenoses (lupus eritematoso sistêmico, por exemplo), hemossiderose pulmonar idiopática, drogas e leptospirose, além de uma forma idiopática (CAPELOZZI 1998).

\subsubsection{PNEUMONIA EM ORGANIZAÇÃO (PADRÃO OP)}

Antiga bronquiolite obliterante com pneumonia em organização (BOOP). Trata-se de um padrão histológico de reação muito comum em diversas entidades, principalmente no dano alveolar difuso em organização e na OP idiopática, também conhecida com pneumonia organizante criptogênica. A característica histológica mais evidente é o envolvimento focal dos espaços aéreos por rolhas de tecido de granulação no interior dos bronquíolos, ductos alveolares e alvéolos. Causas mais comuns incluem infecções em organização, dano alveolar difuso em organização, drogas e inalantes tóxicos, colagenoses, alveolite alérgica extrínseca, pneumonia eosinofílica crônica, reação periférica a 
abscessos, infartos, granulomatose de Wegener e a forma idiopática (CAPELOZZI 1998).

\subsubsection{PNEUMONIA INTERSTICIAL USUAL (UIP)}

Acompanha-se de alterações permanentes e irreversíveis da arquitetura pulmonar conhecidas como faveolamento. A fibrose pulmonar idiopática (FIPI) é o protótipo de pneumonia intersticial usual e caracteriza-se pelo aspecto variegado que inclui regiões de tecido pulmonar normal, áreas de faveolamento e zonas de fibrose ativa. Histologicamente inclui a pneumonia intersticial usual, pneumonia intersticial linfocítica, colagenoses, drogas, pneumoconioses, sarcoidose, histiocitose de células de Langerhans, infecções crônicas, aspiração crônica, pneumonia por hipersensibilidade crônica, radioterapia crônica etc (CAPELOZZI 1998).

\subsubsection{PNEUMONIA ALVEOLAR MACROFÁGICA}

Refere-se à lesão constituída por aumento do número de macrófagos alveolares e alterações inflamatórias das paredes alveolares. Os principais exemplos são a pneumonia intersticial descamativa (DIP) propriamente dita, bronquiolite respiratória do fumante, histiocitose de células de Langerhans, 
hemorragia alveolar crônica, reações crônicas a drogas e pneumoconioses. Os aspectos citológicos dos macrófagos variam consideravelmente e podem auxiliar no diagnóstico diferencial. Na bronquiolite do fumante, a pigmentação castanho-amarelada é bem evidente; nas reações à amiodarona, pneumonias obstrutivas, pneumonia lipoídica e doenças de depósito, os macrófagos aparecem xantomizados; nas pneumoconioses por metais pesados os macrófagos formam células gigantes multinucleadas (CAPELOZZI 1998).

\subsubsection{INFILTRADOS CELULARES LINFÓIDES}

\section{PERIBRÔNQUICOS E INTERSTICIAIS}

Linfócitos e plasmócitos associados a discreto grau de fibrose e conservação da histoarquitetura pulmonar são muito comuns, porém auxiliam pouco no diagnóstico diferencial (CAPELOZZI 1998).

\subsubsection{GRANULOMATOSES}

Algumas pneumonias intersticiais mostram quadro histopatológico dominado por granulomas sarcoídicos, necrosantes ou não. As mais importantes incluem sarcoidose, alveolite alérgica extrínseca, reações a drogas, infecções granulomatosas, talcose intravenosa, pneumoconioses, síndrome de 
Sjögren, pneumonia aspirativa, linfomas, granulomatose de Wegener e granulomatose broncocêntrica. Nesses casos e com base na distribuição anatômica e nas características qualitativas das lesões, alguns elementos ajudam no diagnóstico. Grupos de células gigantes com material birrefringente

na bainha vascular são característicos da talcose intravenosa. Sarcoidose e beriliose exibem conglomerados de granulomas ao longo dos linfáticos, contendo ao redor colágeno denso, lamelar e birrefringente (CAPELOZZI 1998).

\subsection{IMPLICAÇÕES CLÍNICAS RESULTANTES}

\subsubsection{INSUFICIÊNCIA RESPIRATÓRIA}

Do ponto de vista clínico, a maioria dos infiltrados pulmonares cursa com graus variáveis de insuficiência respiratória.

Define-se insuficiência respiratória como uma síndrome resultante de diversas doenças, em que o sistema respiratório deixa de cumprir suas funções fundamentais na oxigenação sangüínea ou na eliminação do dióxido de carbono $\left(\mathrm{CO}_{2}\right)$ (GRIPPI 1998).

O estabelecimento da síndrome pode se dar de forma aguda, com alterações gasométricas do sangue arterial e do próprio equilíbrio ácido-base implicando em risco de morte, ou crônica, cujas manifestações clínicas são mais indolentes e, por vezes, inaparentes (GRIPPI 1998). 
A insuficiência respiratória pode ser classificada em hipercápnica, quando a pressão arterial parcial de $\mathrm{CO}_{2}\left(\mathrm{PaCO}_{2}\right)$ é maior do que $45 \mathrm{mmHg}$, ou hipoxêmica, quando a $\mathrm{PaO}_{2}$ é menor do que $55 \mathrm{mmHg}, \mathrm{FiO}_{2}$ maior ou igual a $60 \%$. Na insuficiência respiratória aguda hipercápnica, além de uma $\mathrm{PaCO}_{2}$ maior do que $45 \mathrm{mmHg}$, observa-se acidemia, definida como $\mathrm{pH}$ sangüíneo menor do 7,30. O efeito do aumento repentino da $\mathrm{PaCO}_{2}$ depende do nível do sérico de bicarbonato. Em pacientes com "insuficiência respiratória" hipercápnica crônica, a lenta elevação da $\mathrm{PaCO}_{2}$ permite a compensação renal, através da elevação do nível sérico de bicarbonato (GRIPPI 1998).

Dados gasométricos podem não ser suficientes para a distinção entre os estados crônico e agudo da insuficiência respiratória hipoxêmica, devendo-se levar em consideração sinais e sintomas que forneçam indícios de doença de longa evolução ou de eventos abruptos (GRIPPI 1998).

Ainda que a própria definição de insuficiência respiratória esteja baseada na medida da $\mathrm{PaO}_{2}$, a hipoxemia arterial pode levar a uma inadequada oxigenação tecidual sem necessariamente promover a insuficiência respiratória. A oxigenação tecidual depende do débito cardíaco assim como da capacidade de transporte gasoso pelo sangue. Assim sendo, fatores que alterem o débito cardíaco, a concentração sangüínea de hemoglobina ou que dificultem a dissociação entre oxigênio e hemoglobina no tecido promovem hipóxia tecidual, insuficiência respiratória seria conseqüência de um processo relativamente mais prolongado de hipóxia tecidual (GRIPPI 1998). 
Alterações em cada um dos componentes dos mecanismos fisiológicos da respiração - sistema nervoso central (farmacológicas, estruturais e metabólicas), sistema nervoso periférico (neuropatias, doenças neuromusculares), musculatura respiratória, parede torácica (alterações anatômicas da caixa torácica), vias aéreas (distúrbios obstrutivos tais como epiglotite, aspiração de corpos estranhos, estreitamento fibrótico da traquéia, asma, fibrose cística) e alvéolos (edema pulmonar, pneumonia difusa, hemorragias pulmonares maciças, aspiração do conteúdo gastresofagiano, afogamento) - podem levar a insuficiência respiratória (GRIPPI 1998).

Em grande número de enfermidades a hipoxemia se produz através de 4 principais mecanismos: hipoventilação alveolar, desequilíbrio da ventilação / perfusão, "shunt" e limitação da difusão (GRIPPI 1998).

Discretas alterações na ventilação alveolar modificam significativamente a $\mathrm{PaCO}_{2}$, ao contrário do que ocorre em relação a $\mathrm{PaO}_{2}$, em que as alterações são mínimas, principalmente em níveis acima de 55 a 60 mmHg (GRIPPI 1998).

Normalmente, o suprimento ventilatório excede em muito a sua demanda e é por isso que o aumento da necessidade ventilatória que ocorre durante a atividade física pode se dar sem o estabelecimento de hipercapnia (GRIPPI 1998).

As entidades que levam a insuficiência respiratória podem ser também classificadas de acordo com o componente do sistema respiratório ao qual se relaciona (GRIPPI 1998). 


\subsection{IMPLICAÇÕES DA BIÓPSIA PULMONAR NOS INFILTRADOS PULMONARES DIFUSOS - PERSPECTIVAS HISTÓRICAS}

Dada a sua complexidade, o diagnóstico dos infiltrados pulmonares difusos muitas vezes demanda a realização de exames histopatológicos de material colhido por biópsias.

A primeira tentativa na obtenção de material pulmonar para análise através de aspiração por agulha foi realizada por Leyden (1883) (citado por MACKENZIE e RILEY 1991 e por FERNANDEZ e col. 2002) há mais de 120 anos e pouco tempo após Ménétrier (1886) (citado por FERNANDEZ e col. 2002) conseguiria o primeiro diagnóstico de tumor pulmonar através desta mesma técnica. A inadequação da técnica pioneira para a obtenção de tecido pulmonar foi logo revelada pelos freqüentes relatos de complicações e de óbitos. Desde então diversas técnicas têm sido inventadas, testadas e aperfeiçoadas até o estabelecimento dos procedimentos em uso corrente atualmente: as técnicas de biópsia transtorácicas (punção aspirativa por agulha, e biópsia percutânea por agulha), as broncoscópicas (lavado e escovado brônquicos e biópsia transbrônquica) e as cirúrgicas (biópsia cirúrgica e biópsia por videotoracoscopia).

Em 1940, Tripoli e Holland (citados por MACKENZIE e RILEY 1991) relatou a utilização de uma agulha cortante ("cutting needle") para biópsias pulmonares cuja utilização rotineira não se deu em virtude de freqüentes 
complicações. Duas décadas após, uma nova e efêmera modalidade de biópsia, realizada com o auxílio de uma broca ("drill biopsy"), foi relatada por Deeley (1960) (citado por MACKENZIE e RILEY 1991).

A biópsia percutânea por agulha não tardou a ganhar extensa aceitação, sendo adotada muitas vezes como rotina em lesões periféricas solitárias, através de agulhas do tipo "tru-cut ®", em casos de massas tumorais localizadas e em tumores com infiltração da parede torácica por tratar-se de procedimento de simples realização, com baixa morbidade (MATTHAY e MORITZ 1981) e com alto índice de sucesso diagnóstico, reduzindo a utilização de toracotomias. No entanto, não há unanimidade em relação à abordagem de lesões nodulares de distribuição difusa ou a tumores sem envolvimento pleural, principalmente em função de um percentual relativamente alto de falsos negativos apontados por alguns autores (LOCICERO e SHIELDS 1989) A crescente sofisticação dos métodos de imagem vêm permitindo a freqüente utilização da punção-biópsia aspirativa por agulha fina, cuja principal indicação se faz principalmente em lesões difusas ou em lesões periféricas solitárias (MATTHAY e MORITZ 1981; LOCICERO e SHIELDS 1989). Tal método permanece, no entanto, contra-indicado na presença de hipertensão pulmonar, quando há suspeitas de fístula arteriovenosa, em doenças císticas e bolhosas pulmonares, na presença de diátese hemorrágica ou na própria falta de cooperação do paciente. A complicação observada com maior freqüência é o pneumotórax, em geral de pequena intensidade, que pode ocorrer em 
aproximadamente 10 a $25 \%$ dos casos (MATTHAY e MORITZ 1981; LOCICERO e SHIELDS 1989).

\subsubsection{PROCEDIMENTOS BRONCOSCÓPICOS}

A história da broncoscopia se inicia nos primórdios do século $X X$ com Killian (citado por KITAMURA 1990), em 1902, que lançou mão de um aparelho rígido para a retirada de corpos estranhos aspirados de vias aéreas superiores. Deve-se a Jackson (1905) (citado por KITAMURA 1990) o aperfeiçoamento do que poderia ser chamado do primeiro broncoscópio rígido, permitindo sua utilização com uma ferramenta diagnóstica. Seis décadas foram necessárias para o desenvolvimento do primeiro broncoscópio flexível, permitindo o acesso a regiões pulmonares previamente inacessíveis (KITAMURA 1990).

A biópsia transbrônquica foi inicialmente descrita por Andersen e Fontana (1965), que buscavam uma alternativa com menor morbidade que a biópsia transtorácica. Sete anos mais tarde os mesmos autores descreviam os resultados obtidos com 450 biópsias realizadas em pacientes com infiltrado difuso, relatando a obtenção de amostras satisfatórias em $84 \%$, com baixo índice de complicações, representadas principalmente por pneumotórax, enfisema mediastinal e sangramento (ANDERSEN e FONTANA 1972). 
Na década de 60, a invenção do broncoscópio flexível por fibras óticas por Ikeda (citado por MATTHAY e MORITZ 1981 e por KITAMURA 1990) revolucionou a técnica, tornando possível a avaliação da árvore brônquica desde os brônquios lobares até brônquios subsegmentares de 4a. ordem. Desde então, tal método vem sendo aperfeiçoado, podendo ser hoje realizado com finalidades terapêuticas e diagnósticas com maior facilidade, segurança e conforto para o paciente (KITAMURA 1990).

Uma das mais importantes técnicas de coleta de material possibilitada pelo advento da broncoscopia é o lavado brônquico ou bronco-alveolar, permitindo a identificação de agentes infecciosos e elementos neoplásicos (POLETTI e col. 2004). A sua utilização, em conjunto com a coleta de espécimes através de fórceps e de escovas, ampliou em muito a possibilidade diagnóstica (MATTHAY e MORITZ 1981; KITAMURA 1990), principalmente com o advento da síndrome da imunodeficiência adquirida (SIDA), em que a acurácia diagnóstica é de 70 a $80 \%$, podendo chegar a $100 \%$ em pacientes com linfangite carcinomatosa e tuberculose miliar (KITAMURA 1990). Em estudo comparativo prévio com 53 pacientes a biópsia transbrônquica revelouse diagnóstica em 38\%, comparados aos $924 \%$ da biópsia pulmonar cirúrgica (WALL e col. 1980). Conforme a classificação histológica utilizada, a investigação broncoscópica fornece diagnóstico em 38\% a 85\% dos pacientes, enquanto que o produto diagnóstico da biópsia cirúrgica varia entre 80\% e 94\% (UTZ e col. 1992). 
Estes dados não são compartilhados por SMITH e col. (1977) que relataram uma acurácia diagnóstica por parte da biópsia transbrônquica de $85 \%$, em doenças pulmonares difusas.

Dentre todos os procedimentos de biópsia pulmonar, a via transbrônquica é a que apresenta a mais baixa taxa de mortalidade, além de ser a menos traumática e a menos custosa (GAENSLER e CARRINGTON 1980).

As suas maiores desvantagens estão na impossibilidade de seleção do material que, em geral, é obtido de regiões imediatamente adjacentes ao brônquio, apresentando dimensões diminutas e com freqüentes artefatos por esmagamento do tecido(GAENSLER e CARRINGTON 1980). FRAIRE e col. (1992) identificaram uma associação diretamente proporcional e estatisticamente significante entre o estabelecimento de um diagnóstico histopatológico específico de infecção e o número de espaços alveolares amostrados em espécimes pulmonares. Além disso, também foi demonstrado que o número de fragmentos amostrados tem influência sobre o produto diagnóstico (DESCOMBES e col. 1997; CURLEY e col. 1998).

A tendência a sangramentos profusos (pacientes com contagem plaquetária menor do que $50.000 / \mathrm{mm}^{3}$ ), a insuficiência respiratória ou cardíaca severas, a uremia, o cor pulmonale e o estado de convalescença de ataque cardíaco estão dentre os principais fatores que contra-indicam a realização de uma biópsia transbrônquica (KITAMURA 1990). A biópsia transbrônquica tem sido comumente limitada a pacientes em ventilação autônoma, porém a sua 
factibilidade durante a ventilação assistida tem sido avaliada (PAPAZIAN e col. 1998).

As mais freqüentes complicações da biópsia transbrônquica são o pneumotórax ( 1 a $10 \%$ dos casos) e o sangramento profuso ( $1,5 \%$ dos casos), de acordo com a casuística de KITAMURA 1990).

A biópsia aspirativa por agulha transbroncoscópica é uma variação do método que permite o acesso à lesões adjacentes a traquéia, a brônquios principais ou a brônquios lobares, em que não é observada nenhuma alteração luminal. É mais freqüentemente utilizada em casos suspeitos de neoplasia primária ou metastática, de sarcoidose e de linfoma (KITAMURA 1990).

Embora os métodos broncoscópicos tenham aumentado em muito a freqüência com que se chega ao diagnóstico, principalmente quando comparados à análise de amostras de escarro e à radiografia, são ainda de uso limitado em casos com infiltrado pulmonar difuso, sendo as dificuldades ainda maiores quando há imunocomprometimento. Estima-se que em tal situação, mesmo com a utilização da biópsia cirúrgica, em aproximadamente $30 \%$ dos pacientes o diagnóstico etiológico não é obtido (JAFFE e MAKI 1981).

\subsubsection{PROCEDIMENTOS CIRÚRGICOS}


A técnica da biópsia cirúrgica foi inicialmente descrita por Klassen (1949) (citado por MATTHAY e MORITZ 1981 e por MACKENZIE E RILEY 1991), tendo sofrido modificações, como fora relatado por VENN e col. (1985).

Ainda que a anestesia local tenha também sido sugerida para o referido procedimento (GAENSLER e col. 1964), esta, além de não permitir a liberdade de se aumentar a incisão quando necessária, dificulta a reinsuflação e pode dificultar a utilização de anestesia geral, caso se faça necessária durante o procedimento. Assim, exige-se o uso de anestesia geral e intubação orotraqueal, além da utilização de dreno torácico por período mínimo de 24 horas, pois, por menor que seja a lesão pleural, há sempre uma tendência à exsudação. No passado, freqüentes complicações como pneumotórax, enfisema subcutâneo, atelectasias foram observadas em virtude de drenagem pós-operatória inadequada (GAENSLER e col. 1964).

Klassen (1949) (citado por MATTHAY e MORITZ 1981 e por MACKENZIE E RILEY 1991) preconizou a realização de incisão anterior, com 7 a $15 \mathrm{~cm}$., no 2o. ao 5o. espaço intercostal. A incisão posterolateral, previamente utilizada, é ainda preferida em casos em que há linfadenopatia hilar, ou quando se observa assimetria do padrão de infiltrado ao exame de imagem. Embora a incisão cirúrgica possa ser realizada em qualquer região do tórax, a incisão anterior no 5o. espaço intercostal é a escolhida na maior parte dos pacientes, uma vez que permite excelente exposição do pulmão e mínimo desconforto pós-operatório (LOCICERO e SHIELDS 1989). Ainda que diminuta, a incisão cirúrgica permite a palpação de tecidos pulmonar e pleural, o que se mostra 
vantajoso em relação a outros procedimentos de biópsia (LOCICERO e SHIELDS 1989).

A obliteração aérea e hemostática adequadas do tecido pulmonar após a biópsia tornou-se possível com a utilização do grampeador ("stapler"), corrigindo principalmente pequenos escapes de ar que permaneciam por horas após a cirurgia com as suturas tradicionais (KIRBY e FELL 1995).

Até recentemente postulava-se como uma das maiores desvantagens da biópsia cirúrgica, quando comparada à transbrônquica, a impossibilidade de sua realização em regime ambulatorial. Pouco mais de uma década após RUSKIN e col. (1990) terem demonstrado que a biópsia pulmonar cirúrgica poderia ser realizada com segurança em unidades de terapia intensiva, evitando o deslocamento de pacientes que habitualmente requerem um aparato de manutenção ventilatória, BLEWETT e col. (2001) provaram que tal procedimento pode até mesmo ser efetivado em regime ambulatorial, desde que em casos criteriosamente selecionados.

Grande parte dos problemas quanto ao procedimento está relacionado à escolha do local da biópsia (GAENSLER e CARRINGTON 1980). Na seleção do local a ser biopsiado, devem-se priorizar zonas intermediárias entre o pulmão são e as zonas de maior alteração, procurando-se evitar formações nodulares rígidas, que podem representar consolidações fibróticas. Para uma adequada representatividade, recomenda-se a coleta de espécimes de pelo menos dois diferentes lobos, sendo um destes de uma área do parênquima com acometimento macroscópico e o outro de uma área com aspecto normal. Isso 
permite ao patologista a análise de diferentes estadios de evolução de determinadas patologias (KIRBY e FELL 1995).

Uma das críticas mais freqüentes contra a realização da biópsia pulmonar cirúrgica é a ausência de tratamento específico para grande parte das entidades diagnosticadas (WARNER e col. 1988). No entanto, em razão do elevado percentual de acurácia diagnóstica, a biópsia pulmonar cirúrgica é um dos melhores meios para se chegar ao diagnóstico, chegando muitas vezes à totalidade de populações estudadas (BOVE e col. 1994; CANVER e MENTZER 1994; BLEWETT e col. 2001), o que permite adequadas medidas de suporte ou a interrupção de tratamentos deletérios (KIRBY e FELL 1995). Alterações da terapêutica ocorreram em percentuais que variaram entre 46 (KRAMER e col. 1998) e 78\% (WAGNER e col. 1992), dependendo em muito da população estudada. O sucesso do procedimento depende, em grande parte, de adequada seleção dos pacientes, considerando-se aqueles que terão benefícios efetivos com o diagnóstico definitivo.

Habitualmente, a biópsia pulmonar cirúrgica é uma técnica bem tolerada até mesmo em pacientes com reserva respiratória bastante restrita e em pacientes críticos, em que o diagnóstico se faz emergencial (LOCICERO e SHIELDS 1989).

Nos últimos anos a toracotomia vem sendo crescentemente substituída pela toracoscopia para o diagnóstico de doença pulmonar intersticial difusa, já que não apresenta desvantagem em relação a amostra tecidual obtida, e por várias outras razões que incluem a possibilidade de obtenção de espécimes de 
mais de um local diferente, a redução no período de internação e no período de drenagem, e por serem menos dolorosas. Além disso, apresenta resultados similares à biópsia pulmonar cirúrgica quanto a acurácia diagnóstica, morbidade e mortalidade (LEWIS e col. 1995; NEUHAUS e MATTAR 1997; BLEWETT e col. 2001; POLETTI e col. 2004;).

Em um estudo randomizado comparativo que levou em consideração parâmetros como a presença da dor, a necessidade de analgésicos, a duração da internação, as complicações e a função pulmonar demonstrou-se que ambas as abordagens não apresentam diferenças significativas de resultados (MILLER e col. 2000). A toracoscopia geralmente necessita de um equipamento mais custoso do que a toracotomia, o que pode, no entanto, ser compensado por períodos mais curtos de internação (BLEWETT e col. 2001).

Embora o primeiro relato de utilização da toracoscopia date de 1922, a sua aplicação remonta a 1910, com a utilização de um cistoscópio rígido introduzido na cavidade pleural através de uma pequena incisão no tórax, usado com a finalidade de debridamento de sinéquias, drenagem de empiemas e biópsia de tumores pleurais. A partir da década de 50 , com o surgimento de medicação antituberculósica, a toracoscopia passou a ser utilizada não só com finalidade diagnóstica, mas terapêutica, no tratamento da tuberculose, promovendo o colapso pleural (KEENAN e col. 1995; LEWIS e col. 1995).

Assim como ocorrera com a broncoscopia, a utilização do mediastinoscópio e do endoscópio por fibra ótica na década de 70 reestimulou o interesse na utilização da técnica. 
A videotoracoscopia tal qual se conhece no presente evoluiu a partir da utilização da videoendoscopia na ginecologia e na ortopedia, na década de 80 . O desenvolvimento de equipamentos óticos e de instrumentação tornou possível a realização de cirurgias cada vez mais complexas (KEENAN e col. 1995; LEWIS e col. 1995).

A técnica operatória da videotoracoscopia é eficiente em casos de infiltrado pulmonar difuso, podendo possibilitar uma excelente visualização de toda a superfície pulmonar e permitindo a escolha de diferentes sítios para biópsia, sendo a língula e o lobo médio os locais de mais fácil acesso (AYED 2003).

A obliteração do espaço pleural em pacientes com história prévia de empiema, tuberculose, toracotomia e, em alguns casos, da própria videotoracoscopia, somada a intolerância à assistência ventilatória unilateral (pacientes que necessitam de altas concentração de fração inspirada de oxigênio e de pressão positiva expiratória final), mesmo em casos agudos, baixa complacência pulmonar (em que o pulmão não pode ser adequadamente colapsado para possibilitar o acesso toracoscópico), descompensação aguda, hipertensão pulmonar e coagulopatias estão entre os principais fatores de contra-indicação da técnica (LEWIS e col. 1995; NEUHAUS e MATTAR 1997; POLETTI e col. 2004).

Embora grande parte dos autores considere a língula como sítio inadequado para a biópsia em virtude de fibrose microscópica e de alterações vasculares que podem estar presentes mesmo na ausência de pneumopatias 
(LOCICERO e SHIELDS 1989; KIRBY e FELL 1995), é o local de biópsia preferido pelos cirurgiões em virtude da facilidade de acesso e de coleta tecidual (BLEWETT e col. 2001). AYED (2003) demonstrou uma alta taxa de sucesso diagnóstico em amostras da língula (96\%), corroborando com dados de outros autores (IMOKE e col. 1983; WENG e col. 1980), em que os percentuais variaram entre 86,1 e $100 \%$. Foi igualmente demonstrado que a coleta de mais de um fragmento pulmonar não apresenta vantagens em relação a biópsia única (FAN e col. 1997).

Ainda que seja realizada através de pequenas incisões torácicas, a videotoracoscopia não deixa de ser um procedimento cirúrgico complexo, requerendo um aparato compatível, com uma taxa de morbidade que varia entre 0 e $25 \%$ em diferentes séries. As complicações imediatas mais comuns associadas ao procedimento são hemorragia e lesão pulmonar, havendo, por vezes, a necessidade de se converter o procedimento para uma toracotomia. Geralmente isso ocorre em casos em que pulmão apresenta consistência bastante aumentada e na presença de sinéquias pleurais (KEENAN e col. 1995; LEWIS e col. 1995). Já no período pós-operatório as complicações mais freqüentes são o escape prolongado de ar, a atelectasia, a pneumonia, o empiema e a arritmia cardíaca (LEWIS e col. 1995). 


\section{$\begin{array}{lllll}\text { 1.6. JUSTIFICANDO A PROPOSTA DE ANALISAR } & \text { A }\end{array}$ QUANTITATIVAMENTE OS PARÂMETROS HISTOLÓGICOS NOS INFILTRADOS PULMONARES DIFUSOS}

A propedêutica armada em pneumologia vem atingindo nas últimas décadas um alto grau de desenvolvimento tecnológico principalmente em função da evolução dos métodos de imagem. No entanto, em razão de seu alto custo, da restrição de sua disponibilidade e pelas próprias limitações dos métodos, em grande número de casos, o exame histopatológico permanece como o "padrão-ouro" para o diagnóstico definitivo (SHAH e col. 1992; DINA e SHEPPARD 1993; KRAMER e col. 1998).

Na rotina de uma unidade de terapia intensiva freqüentemente depara-se com casos cujo diagnóstico se mostra dúbio, mesmo após ampla investigação por métodos não invasivos. Diversas são as entidades que se apresentam com um padrão de infiltrado aos exames de imagem. As principais causas citadas são: tuberculose miliar (sobretudo em nosso meio), pneumoconioses, sarcoidose, lesões reumatóides do pulmão, panbronquiolite difusa, fibrose intersticial pulmonar, infiltrados pulmonares com eosinofilia, infiltração leucêmica, pneumonia por hipersensibilidade, pneumocistose, linfangite carcinomatosa, granuloma eosinofílico, infecções virais e proteinose alveolar (KITAMURA 1990b). Grande parte das causas de infiltrados pulmonares pode ser diagnosticada por meios não invasivos ou minimamente invasivos, tais 
como biópsias transbrônquicas ou transtorácicas. Entretanto, quando estes esforços não fornecem um diagnóstico ou quando o paciente não responde à terapia apropriada, uma biópsia pulmonar cirúrgica pode se fazer necessária, somando esforços ao tratamento. Pacientes com quadro radiológico de infiltrado (inespecífico) difuso, muitas vezes em insuficiência respiratória aguda, geralmente colocam o pneumologista diante de um grande dilema: o tratamento, fornecendo medidas de suporte ao paciente e aguardando a evolução natural da enfermidade, ainda que sem um diagnóstico preciso; ou a realização de uma biópsia pulmonar cirúrgica, sob anestesia geral, que apresenta relativamente altas especificidade e sensibilidade para o diagnóstico preciso em doenças parenquimatosas crônicas difusas (RAY, 1976; GAENSLER e CARRINGTON 1980; WALL e col. 1981; PATEL e col. 2004), mas que se traduz em uma medida de risco, sobrepondo a carga de uma intervenção cirúrgica, ainda que de pequeno porte, a um paciente já debilitado (WALKER 1989; WAGNER 1992).

A literatura médica apresenta controvérsias em relação ao eventual benefício que a biópsia pulmonar cirúrgica pode trazer a tais pacientes, principalmente quando há imunocomprometimento (MCKENNA e col. 1984; MCCABE e col. 1985; MILLER e col. 1995; KRAMER e col. 1998, FLABOURIS e MYBURGH 1999).

Se comprovados os benefícios da biópsia pulmonar cirúrgica em relação a seus riscos, como previamente relatado (THOMAS e col. 1987; SHAH e col. 
1992), preconiza-se a sua realização o mais precocemente possível (CHESON e col. 1985; WARNER e col. 1988; WALKER e col. 1989).

A biópsia pulmonar cirúrgica fornece um diagnóstico em grande parte dos casos, porém há ainda hoje considerável controvérsia a respeito de seu uso rotineiro, considerando-se a informação fornecida. Assim, objetivando-se a efetividade do tratamento, é de geral interesse a identificação, de parâmetros histopatológicos relacionados à limitação do tempo de sobrevida desses pacientes. Parâmetros morfológicos têm sido estudados em espécimes obtidos através de biópsia pulmonar cirúrgica na busca de achados histológicos precoces que poderiam estar relacionados, por exemplo, à recorrência tumoral e à redução da sobrevida (LIPFORD e col. 1984; ELSON e col. 1988; LEE e col. 1989; SHAHAB e col. 1992). Uma vez que abordagens semiquantitativas têm sido consideradas importantes na avaliação da extensão e intensidade de processos patológicos (CHERNIACK e col. 1991; HYDE e col. 1992; KING e col. 2001b; GUTIERREZ e col. 2002), sistemas de escores têm se mostrado como marcadores potencialmente úteis em espécimes provenientes de biópsia pulmonar cirúrgica (WATTERS e col. 1986; GAY e col. 1998). Sistemas de escores histopatológicos têm sido registrados de diferentes maneiras e, em alguns estudos, associam-se significantemente à taxa de sobrevida (KING e col. 2001a; KING e col. 2001b), porém a melhor maneira de se registrar um sistema de escore histopatológico continua sendo motivo de discussão. 


\subsection{EMBASAMENTO CIENTÍFICO PARA ESTUDAR INFILTRADOS PULMONARES DIFUSOS - QUESTÕES NÃO RESOLVIDAS}

A análise de tecido histológico pulmonar pode se fazer necessária na ocorrência de lesões pulmonares solitárias, geralmente quando detectadas por exames de imagem, em doença crônicas intersticiais, em determinadas infecções, especialmente em crianças com incapacidade em produzir secreção, em casos de suspeita de infecções não usuais relacionadas a imunodeficiência e na detecção de fibrose na SARA. Indicações, escolha do tipo de procedimento, avaliação de mortalidade e complicações diferem muito nestas cinco situações (GAENSLER e CARRINGTON 1980).

Desde que a técnica de biópsia pulmonar cirúrgica começou a ser utilizada em 1949 vem sendo indicada quando a doença pulmonar não é diagnosticada após uma adequada investigação por outros métodos não invasivos, ou menos invasivos. Desde então o que vem mudando, na realidade, é a idéia que se tem a respeito do que é uma adequada investigação. Em 1980, GAENSLER e CARRINGTON preconizavam a sua realização tão logo uma adequada anamnese, um exame clínico, testes cutâneos e minuciosa análise do escarro houvessem falhado em fornecer uma pista para o diagnóstico. Preconizava-se também a realização da biópsia mesmo quando a radiografia mostrava-se normal, priorizando os resultados das provas de função pulmonar indicando a presença de doença intersticial. Por outro lado, situações 
como as de pacientes idosos com extenso faveolamento pulmonar sempre foram bons exemplos de que a biópsia pode não fornecer nenhuma contribuição do ponto de vista diagnóstico e ou terapêutico (GAENSLER e CARRINGTON 1980).

Nas últimas duas décadas, informações fornecidas pela tomografia computadorizada de alta resolução em associação aos dados clínicos e outras modalidades investigativas não invasivas, têm incrementado a acurácia do diagnóstico para algumas doenças, como por exemplo, a maior parte dos casos de fibrose pulmonar idiopática (pneumonia intersticial usual), histiocitose de células de Langerhans, linfangioleiomiomatose e silicose, sem a necessidade da biópsia cirúrgica (POLETTI e col. 2004). Após o advento da tomografia computadorizada de alta resolução na prática clínica, o conceito da análise histológica como padrão-ouro vem sendo questionado (HUNNINGHAKE e col. 2003; REMY-JARDIN e col. 2003). Além disso, o repertório de análises imunológicas e moleculares que podem ser realizados com amostras celulares e tissulares cada vez menores vem aumentando consistentemente, o que permite uma melhor acurácia diagnóstica através de amostras teciduais obtidas por métodos minimamente invasivos (POLETTI e col. 2004). A terminologia de doença pulmonar difusa engloba as alterações pulmonares que envolvem infiltração / fibrose ou acúmulo de fluidos em estruturas do lóbulo pulmonar secundário cujo diagnóstico diferencial é extenso e desalentador. Por esta razão, é de grande importância o conhecimento prévio do estado imunológico do indivíduo, uma vez que pacientes imunocomprometidos que desenvolvem 
doença pulmonar difusa apresentam-se em geral com quadro sintomatológico agudo. Nestas circunstâncias, é difícil distinguir entre doença neoplásica infiltrativa, acometimento pulmonar por colagenose, insuficiência cardíaca, infecção oportunística, efeitos tóxicos de quimioterápicos, radioterapia, doença enxerto-versus-hospedeiro, rejeição aguda e crônica e doenças pulmonares idiopáticas (POLETTI e col. 2004). A utilização de técnicas diagnósticas invasivas em pacientes imunocomprometidos tem sido questionada em função de seu baixo impacto na sobrevida (MAYAUD e CADRANEL 2000). No entanto, foi também demonstrado um declínio significativo na mortalidade de pacientes com infecção pulmonar em que o diagnóstico precoce acarretou alteração na terapêutica (RANO e col. 2002). Em pacientes imunocomprometidos, sobretudo, preconiza-se a realização de procedimentos relativamente mais simples, não invasivos, como primeiro passo. Tais procedimentos podem incluir antigenemia para agentes etiológicos específicos, culturas de sangue, de escarro e de lavados nasofaríngeos, assim como aspirados traqueobrônquicos de pacientes em respiração assistida. $\mathrm{O}$ uso de procedimentos não invasivos leva ao diagnóstico em $40 \%$ dos casos e constituem uma boa alternativa para pacientes com contra-indicações para exploração broncoscópica. $\mathrm{Na}$ ausência de contra-indicações, pacientes selecionados devem ser submetidos ao procedimento broncoscópico, com lavado bronco-alveolar, aspiração por agulha transbrônquica e biópsia transbrônquica, antes que se decida pela biópsia pulmonar cirúrgica (POLETTI e col. 2004). 
Ainda que a performance e a tolerância da biópsia pulmonar cirúrgica em pacientes com SARA tenham sido relativamente pouco exploradas, bons resultados têm sido obtidos. O estudo de PAPAZIAN e col. (1998) favorece o uso deste procedimento em pacientes com SARA, podendo ser realizado à beira do leito, na própria unidade de terapia intensiva, quando o uso de ventilação assistida contra-indica o transporte do paciente.

A otimização do procedimento pode ser obtida seguindo-se algumas regras metodológicas: a) o local da biópsia deve ser escolhido levando-se em consideração o quadro observado na tomografia computadorizada de alta resolução; b) colher, quando possível, dois espécimes de diferentes lobos, sendo um destes de uma área obviamente alterada e um de uma área praticamente normal; c) os espécimes devem ser fixados inflados; d) deve se encaminhar uma porção dos fragmentos para cultura, a fim de se assegurar o máximo de informação possível (POLETTI e col. 2004). 
2. OBJETIVOS 


\section{OBJETIVOS}

\subsection{OBJETIVO GERAL}

A) Estudar o impacto da biópsia pulmonar cirúrgica em pacientes portadores de pneumopatias difusas.

\subsection{OBJETIVOS ESPECÍFICOS}

A) Rever os padrões histopatológicos encontrados na biópsia pulmonar cirúrgica e na autópsia dos pacientes que evoluíram para o óbito;

B) Verificar a relação de concordância entre os diagnósticos clínico, de biópsia e de autópsia;

C) Aplicar e validar um sistema de escore histopatológico na biópsia pulmonar cirúrgica e na autópsia;

D) Explorar a relação semiquantitativa entre o escore histopatológico na biópsia e autópsia, fatores epidemiológicos e evolução dos pacientes;

E) Verificar se a presença de determinados achados histopatológicos em biópsias tais como a presença de agente infeccioso, de indícios de aspiração do conteúdo gastroesofageano e de dano alveolar difuso correlaciona-se a menor sobrevida hospitalar;

F) Verificar se a presença de outros fatores nosológicos tais como presença de comorbidade, de imunossupressão e de insuficiência respiratória correlacionase a menor sobrevida hospitalar. 
3. CASUÍSTICA E MÉTODO 


\section{CASUÍSTICA E MÉTOdO}

\subsection{PACIENTES}

O estudo se desenvolveu através da análise retrospectiva dos prontuários, dos laudos anatomopatológicos e dos próprios preparados histopatológicos de espécimes teciduais pulmonares de pacientes selecionados através dos seguintes critérios:

a) pacientes portadores de quadros pulmonares agudos ou crônicos agudizados, internados para diagnóstico e tratamento, submetidos a biópsia pulmonar cirúrgica (“a céu aberto”);

b) presença de quadro de infiltrado pulmonar difuso ao exame radiológico e ou tomográfico;

c) idade superior a 18 anos no momento em que a biópsia foi realizada.

Foram estudados pacientes internados no Instituto Central (ICHC) ou no Instituto do Coração (InCor) do Hospital das Clínicas da Faculdade de Medicina da Universidade de São Paulo (HCFMUSP) cujo período de internação para a realização do procedimento esteve compreendido entre os anos de 1982 e 2003. 
A casuística foi obtida por meio de análise informatizada do banco de dados do Serviço de Arquivamento Médico e Estatístico (SAME) do HCFMUSP, cruzando-se os parâmetros referentes ao tipo de procedimento ("biópsia pulmonar cirúrgica"), à idade (superior a 18 anos), ao período (1982 a 2003) e ao local de internação (enfermarias do Serviço de Pneumologia do HCFMUSP). Dessa forma, foi relacionado um total de 124 procedimentos referentes a 94 pacientes. Cada registro foi então analisado no banco de dados da rede do HCFMUSP ("HCNET"), selecionando-se os números de registro de todos os exames anatomopatológicos dos respectivos pacientes. Constatou-se que 5 dos casos relacionados haviam sido submetidos a autópsia, porém não a biópsia. Embora constassem dos registros hospitalares como biópsias pulmonares cirúrgicas, foi constatado que 17 destas biópsias (de 15 pacientes) eram na verdade transbrônquicas e 7 (de 7 pacientes) eram não pulmonares.

Foram levantados todos os prontuários dos pacientes relacionados, à exceção de 3 casos (os quais foram submetidos a 4 biópsias pulmonares cirúrgicas) que não puderam ser localizados mesmo depois de reiteradas tentativas.

A totalidade de blocos de parafina e lâminas referentes aos casos remanescentes foi então solicitada ao Serviço de Arquivamento da Divisão de Anatomia Patológica do HCFMUSP para análise, porém em 25 exames (referentes a 22 pacientes) nem blocos e nem lâminas foram localizados. Após a análise, dez casos (de 9 pacientes) foram excluídos por não se tratarem de quadros difusos, mas massas tumorais localizadas. 
O Serviço de Patologia da FMUSP confeccionou novos cortes histológicos dos blocos de parafina cuja lâmina original, quando disponível, não apresentava condições de análise. Na indisponibilidade do bloco de parafina, lâminas que não apresentavam condições de análise foram novamente coradas pelo mesmo serviço técnico.

Trinta e três registros referiam-se a pacientes que haviam evoluído para o óbito, sendo que em 22 casos, a autópsia foi realizada no Serviço de Verificação de Óbito Central (SVOC) de São Paulo.

Através da Unidade de Informações Médicas e Hospitalares do InCor, semelhante levantamento de dados foi realizado.

Em virtude de peculiaridades dos bancos de dados do InCor, não permitindo o cruzamento de dados como fora realizado pelo SAME do HCFMUSP, a busca informatizada foi realizada levando-se em consideração apenas o parâmetro relativo ao procedimento realizado: "toracotomia". Dessa forma, 1092 pacientes foram relacionados, tendo sido inicialmente excluídos 569 casos por terem sido submetidos a procedimentos diagnósticos extrapulmonares. Cento e sessenta casos foram também excluídos em virtude de idade inferior a 18 anos. Embora constassem do banco de dados do InCor, 25 casos foram na realidade submetidos a procedimentos no Instituto Central do HC; outros 29 casos não foram localizados nos registros da anatomia patológica do Incor, ainda que constassem do banco de dados como submetidos a biópsia pulmonar cirúrgica. Restaram assim 308 casos dos quais 105 foram excluídos por se tratarem de pacientes submetidos a biópsias outras 
que não do tipo "céu aberto" e a procedimentos cirúrgicos de ressecção pulmonar parcial ou total, sem finalidade diagnóstica. Dentre os 203 casos restantes, diferentemente da seleção utilizada para os casos do ICHC, foram selecionadas ativamente 32 biópsias pulmonares cirúrgicas de 32 pacientes, de acordo com a representatividade histológica observada nas lâminas arquivadas. Os prontuários dos casos cujos cortes histológicos se mostraram representativos foram então analisados para a confirmação de compatibilidade com nossos critérios de inclusão. Dentre os casos selecionados, 18 evoluíram para o óbito, tendo sido realizada autópsia em 15.

Da casuística resultante, de 88 biópsias e 26 autópsias, de 88 pacientes, foram por fim excluídos 25 casos, uma vez que à análise do prontuário constatou-se que tais pacientes haviam sido internados exclusivamente para a realização da biópsia.

Assim, a casuística final constituiu-se de 63 biópsias, de 63 pacientes, 25 dos quais foram também submetidos a autópsia.

Concomitantemente ao levantamento da análise do material histológico, foi realizado levantamento e análise de prontuários arquivados. Para cada um dos 63 casos foram tabulados dados referentes às seguintes variáveis epidemiológicas:
a) idade;
b) sexo;
c) evolução final da internação: alta ou óbito;
d) tempo total de internação (em número de dias); 
e) tempo decorrido (em número de dias) entre a internação e a realização da biópsia;

f) tempo decorrido (em número de dias) entre a biópsia e a alta ou óbito;

g) diagnóstico clínico principal;

h) presença ou ausência de diagnóstico clínico específico;

i) presença ou ausência de doença sistêmica de base (comorbidade);

j) presença ou ausência de fator de imunossupressão;

I) presença ou ausência de insuficiência respiratória comprovada através de dados clínicos e ou gasométricos.

Todos os parâmetros avaliados referem-se à internação em que a biópsia foi realizada.

Definiu-se "diagnóstico clínico específico" toda e qualquer entidade nosológica que tenha sido relacionada dentre as hipóteses diagnósticas no momento da internação do paciente e previamente à realização da biópsia.

Igualmente, definiu-se "comorbidade" como toda e qualquer entidade nosológica sistêmica, de origem não pulmonar, diagnosticada em concomitância ao quadro pulmonar que motivou a biópsia.

Como "fator de imunossupressão", definiu-se as terapias imunossupressoras vigentes por período maior do que 7 dias, no momento em que a biópsia foi realizada, além de neoplasias de acometimento sistêmico.

Os pacientes que apresentaram valores gasométricos prévios à realização da biópsia mostrando $\mathrm{PaO}_{2}<60 \mathrm{mmHg}$ ou $\mathrm{SatO}_{2}<90 \%$ ou, na ausência de dados gasométricos, freqüência respiratória maior do que 28 
inspirações por minuto, foram considerados portadores de insuficiência respiratória lato sensu.

\subsection{MORFOLOGIA}

Do ponto de vista morfológico, além do estudo qualitativo e semiquantitativo que resultou nos "índices histopatológicos", considerados a seguir, foram também avaliadas as seguintes variáveis:

a) diagnóstico histopatológico principal na biópsia;

b) diagnóstico histopatológico pulmonar principal na autópsia;

c) presença ou ausência de agente infeccioso na biópsia;

d) presença ou ausência de diagnóstico específico na biópsia;

e) presença ou ausência de quadro de dano alveolar difuso na biópsia;

f) presença ou ausência de indícios de aspiração de conteúdo gastroesofageano na biópsia.

Foram analisados todos os preparados histológicos corados pelo método da hematoxilina-eosina. Nos casos em que havia suspeita de infecção por micobactéria e ou fungos a partir de parâmetros observados na hematoxilinaeosina, a análise de colorações específicas como os métodos de Ziehl-Neelsen, de Grocott e do ácido periódico de Schiff (PAS) foi também realizada com finalidade diagnóstica. 
Todos os casos foram analisados consensualmente por dois médicos patologistas especializados em patologia pulmonar: o autor e a orientadora do estudo.

Foram considerados representativos os cortes histológicos contendo, ao menos, um compartimento axial bronco-vascular, além do interstício septal, espaços alveolares adjacentes e compartimento intersticial periférico.

A cada caso procurou-se atribuir um diagnóstico histopatológico principal, o mais específico possível. No entanto, em muitos casos somente foi possível um diagnóstico genérico, descritivo, ressaltando as principais características da lesão do tecido pulmonar, para que a mesma pudesse ser interpretada à luz de dados clínicos. Casos em que a não especificidade das alterações não permitiu um diagnóstico preciso, foram classificados em uma categoria patológica, verificando-se o principal compartimento histológico pulmonar acometido.

Os diagnósticos foram divididos em 12 diferentes itens, representados por entidades nosológicas ou categorias diagnósticas, que foram designados "não agregados". Contudo, em virtude da ampla gama de diagnósticos em relação ao tamanho da casuística, para realizar-se a análise estatística descritiva e formal agregou-se também as categorias diagnósticas em quatro grupos maiores, designados como "diagnósticos agregados", conforme mostra a Tabela 3.1 .

O "dano alveolar difuso" foi relacionado como um dos 12 itens por tratarse de terminologia que designa eminentemente uma entidade histopatológica, podendo traduzir diferentes quadros clínicos. 
Além da abordagem com finalidade diagnóstica, procedeu-se à uma minuciosa análise das amostras, em que cada alteração foi tabulada e quantificada segundo um sistema de escores variando de zero a quatro de acordo com a intensidade e extensão de acometimento do parênquima pulmonar: "0": ausência de alterações parenquimatosas;

"1": alterações parenquimatosas em 1 a $25 \%$ do tecido examinado;

"2": alterações parenquimatosas em 26 a 50\% do tecido examinado;

"3": alterações parenquimatosas em 51 a $75 \%$ do tecido examinado;

"4": alterações parenquimatosas em 76 a 100\% do tecido examinado.

Tabela 3.1: Distribuição dos Diagnósticos Histopatológicos “Agregados” e Não-Agregados

\section{Diagnósticos agregados Diagnósticos não agregados}

\begin{tabular}{ll}
\hline A) Pneumopatias infecciosas & Pneumonias infecciosas \\
\hline B) Pneumopatias inflamatórias & Pneumopatias granulomatosas não infecciosas \\
& Doenças das vias aéreas \\
& Pneumonias intersticiais* \\
& Pneumonia por hipersensibilidade \\
& Dano alveolar difuso \\
& Capilarites / vasculites \\
& Amiloidose \\
& Histiocitose X \\
\hline C) Neoplasias & Carcinomas \\
\hline D) Distúrbios circulatórios & Linfomas \\
\hline
\end{tabular}

* à exceção da Pneumonia por hipersensibilidade 
Exceção fez-se ao subitem "homogeneidade temporal" do compartimento alveolar, ao qual foram atribuídos somente os valores zero e um, indicando respectivamente "ausência" ou "presença", não passíveis de quantificação.

Na Tabela 3.2 encontram-se relacionadas em ordem alfabética as principais alterações histopatológicas observadas nos diferentes compartimentos histológicos pulmonares.

Cada um dos achados histopatológicos foi avaliado de acordo com sua extensão dentro de cada compartimento histológico pulmonar. Os números entre parênteses representam as alterações encontradas, conforme a Tabela 3.2, em cada um dos compartimentos histológicos pulmonares abaixo relacionados:

- Interstício axial: (4), (11), (13), (17), (25), (27), (38), (41), (46), (51), (52), (53), (54), (60), (61), (70), (75);

- Interstício septal: (4), (11), (13), (25), (27), (30), (38), (40), (41), (46), (52), (53), (54), (61), (65), (72), (70), (75);

- Interstício periférico: (12), (13), (15), (25), (27), (36), (38), (40), (41), (45), (52), (53), (54), (56), (61), (67), (70), (75);

- Arteríolas pré-acinares: (4), (11), (21), (22), (26), (27), (29), (33), (34), (35), (39), (47), (61), (69), (71), (73), (76), (77);

- Arteríolas pós-acinares: (4), (21), (22), (33), (34), (35), (47), (61), (66), (69), (71), (73), (76), (27), (77);

- Veias e linfáticos: (23), (24), (27), (32), (63), (76); 
- Bronquíolos terminais: (1), (2), (3), (4), (5), (8), (9), (10), (11), (12), (14) (16), (18), (20), (21), (25), (26), (27), (31), (36), (38), (41), (44), (48), (52), (54), (58), (62), (72), (74), (75);

- Bronquíolos respiratórios: (1), (4), (9), (10), (14), (16), (18), (21), (25), (26), (31), (36), (39), (41), (43), (44), (48), (52), (58), (62), (66), (74), (75);

- Alvéolos: (3), (4), (5), (6), (7), (8), (12), (14), (15), (16), (18), (25), (26), (27), (28), (36), (37), (41), (42), (43), (44), (49), (50), (52), (55), (57), (58), (61), (72), (75);

Formações granulomatosas (Tabela 3.3) e alterações de etiologia neoplásica (Tabela 3.4) foram caracterizadas separadamente, independentemente de suas localizações. 
Tabela 3.2: Alterações observadas nos diferentes compartimentos histológicos pulmonares e sua caracterização conforme o caráter evolutivo anatomoclínico
1) Acúmulo de histiócitos (c)
2) Atrofia (c)
3) Bactérias (a)
4) Calcificação distrófica (c)
5) Células neoplásicas
6) Colapso aberto (a)
7) Colapso fechado (a)
8) Corpos estranhos
9) Decapitação epitelial (a)
10) Degeneração epitelial (a)
11) Deposição de amilóide (c)
12) Deposição de fibrina (a)
13) Deposição de hemossiderina (c)
14) Deposição de material amorfo (a)
15) Deposição de material cristalóide (c)
16) Deposição de muco (a)

17) Deposição de poeira mista (c)

18) Descamação (a)

19) Dilatação ou hiperdistensão de ductos58) Metaplasia escamosa (c) alveolares

20) Displasia epitelial (c)

21) Ectasia (c)

22) Ectasia de vasa-vasorum (c)

23) Ectasia de vasos linfáticos (c)

24) Ectasia venosa (c)

25) Edema (a)

26) Efeito citopático (a)

27) Elementos fúngicos

28) Elementos parasitários

29) Embolização gordurosa

30) Enfisema (c)

31) Espasmo (a)

32) Espessamento venoso (c)

33) Exocitose de células mononucleares (sa)

34) Exocitose de eosinófilos (sa)

35) Exocitose de neutrófilos (a)

36) Exsudato (a)

37) Faveolamento (c)

38) Fibrose (c)

39) Granuloma obliterando a luz (c)
40) Granulomas do tipo corpo estranho

41) Hemorragia (a)

42) Hemossiderose (c)

43) Hiperdistensão

44) Hiperplasia de células epiteliais (a)

45) Hiperplasia de células mesoteliais

46) Hiperplasia do BALT (as)

47) Hipertrofia da camada média (c)

48) Hipertrofia da musculatura peribronquiolar (c)

49) Homogeneidade temporal

50) Infarto hemorrágico (a)

51) Infiltração neoplásica

52) Infiltrado de células mononucleares (c)

53) Infiltrado de eosinófilos (sa)

54) Infiltrado de neutrófilos (a)

55) Lambertose (metaplasia colunar do epitélio alveolar) (c)

56) Leucoestase

57) Membranas hialinas (a)

59) Micobactérias

60) Microabscesso (a)

61) Necrose (a)

62) Necrose epitelial (a)

63) Neoangiogênese (c)

64) Nódulo granulomatoso exsudativo

65) Nódulos fibronecróticos calcificados (c)

66) Obliteração (c)

67) Ossificação metaplásica (c)

68) Partículas birrefringentes em granulomas

69) Proliferação adventiceal (c)

70) Proliferação de células alongadas (c)

71) Proliferação fibrointimal (c)

72) Reação gigantocelular (c)

73) Remodelamento plexiforme (c)

74) Suboclusão (c)

75) Tecido de granulação (sa)

76) Trombose vascular

77) Tumefação endotelial (a)

Legenda: (c): crônico; (a): agudo; (sa): subagudo. 
Tabela 3.3: Caracterização das alterações de caráter granulomatoso

\begin{tabular}{ll}
\hline Localização & Zonas axiais \\
& Zonas septais \\
& Zonas periféricas \\
\hline Padrão histopatológico & Completos \\
& Incompletos \\
& Infecciosos \\
& Não infecciosos \\
& Necrotizantes \\
& Não necrotizantes \\
\hline Partículas & Micobactérias \\
& Partículas birrefringentes \\
& Microcalcificações \\
\hline
\end{tabular}

Tabela 3.4: Caracterização das alterações de caráter neoplásico

\begin{tabular}{ll}
\hline Tecido neoplásico de distribuição & Hemorragia \\
vascular & Compressão de estruturas \\
& adjacentes \\
& Necrose \\
& Mucoprodução \\
\hline Tecido neoplásico de distribuição & Hemorragia \\
extravascular & Compressão de estruturas \\
& adjacentes \\
& Necrose \\
& Mucoprodução \\
& Infiltração da parede torácica \\
\hline
\end{tabular}




\subsection{DETERMINAÇÃO DOS "ÍNDICES HISTOPATOLÓGICOS"}

A magnitude da amostra disponível tornaria impossível a análise inferencial, levando-se em conta todos os achados histopatológicos. Assim, foram criados "índices" baseados nos escores histopatológicos. A primeira tentativa foi feita utilizando-se a análise fatorial com e sem rotação varimax (JOHNSON e WICHERN 1998) para se tentar estabelecer "índices" relacionados a cada um dos compartimentos histológicos estudados. Entretanto, tal relação não se mostrou razoavelmente coerente do ponto de vista clínico. Uma vez que os escores histopatológicos estabelecidos são diretamente proporcionais à intensidade de alterações tissulares, postulou-se a utilização de um "índice" que seria calculado a partir da média dos escores para cada um dos compartimentos histológicos. A maior parte dos achados foi subjetivamente classificada de acordo com seu caráter evolutivo anatomoclínico em agudo, crônico ou subagudo (Tabela 3.2).

Achados histopatológicos que, em nossa casuística, mostraram caracteres ora agudos, ora crônicos, como, por exemplo "trombose arteriolar", não foram classificados. Assim, foram elaborados três "índices" denominados respectivamente "crônico", "agudo" e "subagudo", que representariam respectivamente a média dos escores dos achados agudos, crônicos e subagudos (quando presentes) de cada um dos compartimentos histológicos. A 
caracterização e o cálculo dos índices não foram feitos para os achados relacionados a granulomas e tecidos neoplásicos.

Após o cálculo de cada um dos "índices" para os respectivos compartimentos histológicos, foi efetuado o cálculo dos "índices" médios finais agudo e crônico para cada caso. A não utilização do índice "subagudo" justificou-se não somente devido à pequena amostragem de achados subagudos, mas também em razão de sua forte associação com o índice agudo o que não conduziria a inferências estatísticas adequadas.

Vale ressaltar que valores referentes à determinados achados cuja avaliação fidedigna se mostrou muito dificultada, como, por exemplo "obliteração dos bronquíolos respiratórios" em quadros crônicos com amplo remodelamento tecidual, foram descartados para o cálculo das médias compartimentais.

Cada valor final obtido foi então multiplicado por $10 \mathrm{com}$ o intuito de facilitar a interpretação nos possíveis modelos da análise estatística inferencial.

\subsection{ANÁLISE ESTATÍSTICA}

Após a caracterização das variáveis, procedeu-se ao estudo descritivo de concordâncias entre os diagnósticos clínico, de biópsia e de autópsia, além da verificação de outras possíveis relações entre variáveis e concordância 
diagnóstica, como veremos mais adiante. Em seguida, realizou-se o estudo da associação entre as variáveis e o óbito através de análise descritiva.

Foi realizada a análise univariada e, em alguns casos, a análise da relação entre a combinação de duas variáveis com o óbito. Para tanto se utilizou o teste Qui-quadrado, tendo sido também efetuado em alguns casos de forma empírica.

Dessa forma foi possível constatar quais variáveis e quais inter-relações (combinação de duas variáveis) eram importantes, permitindo o início da análise através de regressão logística múltipla.

Para a comparação entre os "índices histopatológicos" de biópsia e de autópsia foi utilizado um teste "t" de Student pareado.

Para se estudar a associação das variáveis com a sobrevida hospitalar, utilizou-se o modelo de regressão logística (HOSMER e LEMESHOW 1989).

Para auxílio das análises estatísticas foi utilizado o programa de computação "SPSS para Windows, versão 10.0", com um limiar de significância para valores de $\alpha<0.05$. 
4. RESULTADOS 


\section{RESULTADOS}

\subsection{ANÁLISE DESCRITIVA}

A análise descritiva foi dividida de acordo com os objetivos do estudo nas seguintes etapas:

- descrição da amostra;

- concordâncias entre os diagnósticos clínico e histopatológico (de biópsia e de autópsia);

- relações das variáveis com a sobrevida hospitalar;

- comparação entre biópsia e autópsia.

\subsubsection{DESCRIÇÃO DA AMOSTRA}

4.1.1.1. Análise descritiva de variáveis epidemiológicas e histopatológicas

Foram estudadas as seguintes variáveis epidemiológicas, cujos resultados encontram-se nas respectivas tabelas, abaixo designadas:

- $\operatorname{sexo}($ Tabela 4.1);

- idade (Tabela 4.2); 
- tempo total de internação, em número de dias (Tabela 4.2);

- tempo decorrido da internação até a biópsia, em número de dias (Tabela 4.2);

- tempo decorrido entre a biópsia e a alta ou óbito, em número de dias (Tabela 4.2);

- presença ou ausência de dano alveolar difuso na biópsia (Tabela 4.3);

- presença ou ausência de doença sistêmica de base (comorbidade) (Tabela 4.3);

- Presença ou ausência de fator de imunossupressão (Tabela 4.3);

- presença ou ausência de quadro clínico e ou gasométrico de insuficiência respiratória(Tabela 4.3);

- diagnósticos "não agregados" principais clínicos, de biópsia e de autópsia (Tabela 4.4).

Na tabela 4.1 é apresentada a distribuição da variável sexo entre os pacientes. Trinta e dois pacientes (51\%) eram do sexo masculino e 31 , do sexo feminino (49\%). A mediana de idade foi 51 anos, variando entre 18 e 92 anos.

O tempo médio de internação foi 39 dias, variando entre 4 e 184 dias. A biópsia foi realizada, em média, 18,2 dias após a internação, tendo o período entre a internação e o referido procedimento variado de zero a 61 dias. Entre a realização da biópsia e a alta ou óbito, o período médio foi de 21,1 dias, variando de 1 a 143 dias (Tabela 4.2). 
Tabela 4.1: Distribuição dos pacientes de acordo com a variável sexo

\begin{tabular}{ccc}
\hline Sexo & \multicolumn{2}{c}{ Freqüência } \\
\hline Masculino & 32 & $(51)$ \\
Feminino & 31 & $(49)$ \\
\hline Total & 63 & $(100)$ \\
\hline
\end{tabular}

* valores entre parênteses representam percentuais

Tabela 4.2: Distribuição dos pacientes de acordo com as variáveis idade e tempo de internação

\begin{tabular}{cccccc}
\hline Estatísticas & $\boldsymbol{N}$ & Média & Desvio-padrão & Mínimo & Máximo \\
\hline Idade & 63 & 49,4 & 17,8 & 18 & 92 \\
$\begin{array}{c}\text { Tempo decorrido entre a } \\
\text { internação e a biópsia }\end{array}$ & 63 & 18,2 & 12,8 & 0 & 61 \\
$\begin{array}{c}\text { Tempo decorrido entre a biópsia } \\
\text { e a alta/óbito }\end{array}$ & 63 & 21,1 & 23,6 & 1 & 143 \\
$\begin{array}{c}\text { Tempo de internação } \\
\text { Temp }\end{array}$ & 63 & 39,0 & 29,0 & 4 & 184 \\
\hline
\end{tabular}

$\mathrm{Na}$ Tabela 4.3. estão distribuídos os pacientes de acordo com as variáveis dano alveolar difuso, doença sistêmica de base, quadro clínico ou gasométrico de insuficiência respiratória e fator de imunossupressão.

Trinta e três dos pacientes estudados (52\%) eram portadores de ao menos um fator de imunossupressão, sendo os demais 30 pacientes $(48 \%)$ imunocompetentes.

Oitenta por cento dos pacientes apresentava quadro clínico e ou gasométrico de insuficiência respiratória e $76 \%$ eram portadores de 
comorbidade. Dano alveolar difuso foi constatado em $51 \%$ das biópsias (Tabela 4.3).

Considerando-se a totalidade da população estudada, o percentual de sobrevida hospitalar, ou seja, de pacientes que receberam alta independentemente do período em que permaneceram hospitalizados, foi de $49 \%$.

Dentre os pacientes imunossuprimidos, $61 \%$ evoluíram para o óbito. Praticamente o mesmo percentual de evolução fatal foi observado dentre os pacientes portadores de insuficiência respiratória e dentre os acometidos por comorbidades. Dos 32 pacientes que apresentaram dano alveolar difuso à biópsia, 69\% evoluíram para o óbito.

Cinqüenta e dois pacientes $(82,5 \%)$ eram portadores de uma a quatro comorbidades. Vinte e três pacientes apresentaram uma única comorbidade e 31 pacientes apresentaram mais de uma, sendo que 4 pacientes apresentaram 3 entidades comórbidas. As doenças cardiovasculares foram as mais freqüentes, acometendo 27 pacientes. Em seguida, maior freqüência foi observada em relação às doenças do sistema hematopoiético, acometendo 15 pacientes, seguidas de nefropatias (10 pacientes) e de quadros infecciosos (10 pacientes).

Em relação a complicações diretamente relacionadas ao procedimento, obtivemos acesso a dados de 33 pacientes, perfazendo aproximadamente $53 \%$ dos casos. Destes, cinco pacientes apresentaram complicações: infecção da 
ferida cirúrgica (1 caso), pneumotórax e atelectasia (1 caso) e enfisema subcutâneo (3 casos).

Tabela 4.3: Distribuição do dano alveolar difuso, doença sistêmica de base, quadro clínico ou gasométrico de insuficiência respiratória e fator de imunossupressão na amostra

\begin{tabular}{cccccccc}
\hline Variáveis & \multicolumn{1}{c}{ Ausência } & Presença & \multicolumn{2}{c}{ Total } \\
\hline Dano alveolar difuso na biópsia & 31 & $(49)$ & 32 & $(51)$ & 63 & $(100)$ \\
Doença de base & 15 & $(24)$ & 48 & $(76)$ & 63 & $(100)$ \\
$\begin{array}{c}\text { Quadro clínico e ou gasométrico de } \\
\text { insuficiência respiratória }\end{array}$ & 10 & $(20)$ & 41 & $(80)$ & 51 & $(100)$ \\
Fator de imunossupressão & 30 & $(48)$ & 33 & $(52)$ & 63 & $(100)$ \\
\hline
\end{tabular}

* valores entre parênteses representam percentuais

$\mathrm{Na}$ Tabela 4.4 estão distribuídos os diagnósticos principais (não agregados) clínicos, de biópsias e de autópsias dos pacientes.

Pouco mais de um terço dos diagnósticos clínicos foram de" pneumopatias infecciosas", seguidas pelas "pneumonias intersticiais" e pelas "pneumopatias granulomatosas não infecciosas". Não houve suspeitas clínicas para os diagnósticos de pneumonia por hipersensibilidade e de amiloidose.

À análise histopatológica de espécimes obtidos através de biópsia, as "doenças de vias aéreas" e as "pneumonias intersticiais" foram os quadros de maior freqüência, seguidos pelas "pneumopatias infecciosas".

Já ao exame necroscópico, as "pneumopatias infecciosas" perfizeram a maior parte dos diagnósticos, aparecendo em segundo lugar o "dano alveolar 
difuso". Como previamente colocado, o "dano alveolar difuso" é mais bem correlacionado à terminologia histopatológica, e, portanto não foi mencionado dentre as hipóteses clínicas.

Morfologicamente, além do estudo semiquantitativo dos achados histopatológicos que resultou nos "índices histopatológicos" previamente citados, diagnósticos histopatológicos principais em biópsia e em autópsia (Tabela 4.4) também foram utilizados como variáveis.

Tabela 4.4: Distribuição dos diagnósticos principais (não agregados) clínico, de biópsia e de autópsia na amostra

\begin{tabular}{|c|c|c|c|c|c|c|}
\hline Diagnósticos & & ico & & osia & & sia \\
\hline Pneumopatias infecciosas (PI) & 22 & (35) & 9 & (14) & 9 & (38) \\
\hline $\begin{array}{l}\text { Pneumopatia granulomatosa não } \\
\text { infecciosa (PGNI) }\end{array}$ & 7 & (11) & 7 & (11) & 1 & (4) \\
\hline Doenças de vias aéreas (VA) & 4 & (6) & 10 & (16) & 1 & (4) \\
\hline Pneumonias intersticiais (PIT) ${ }^{*}$ & 11 & (17) & 10 & (16) & 1 & (4) \\
\hline Distúrbios circulatórios (DC) & 6 & (10) & 7 & (11) & 2 & (8) \\
\hline Carcinomas (CA) & 6 & (10) & 5 & (8) & 3 & (13) \\
\hline $\begin{array}{l}\text { Pneumonia por } \\
\text { hipersensibilidade }(\mathrm{PH})\end{array}$ & & & 2 & (3) & & \\
\hline Dano alveolar difuso (DAD) & & & 7 & (11) & 6 & (25) \\
\hline Capilarites/ vasculites (CV) & 5 & (8) & 4 & (6) & 1 & (4) \\
\hline Amiloidose (AM) & & & 1 & (2) & & \\
\hline Histiocitose $\mathrm{X}(\mathrm{HX})$ & 1 & (2) & & & & \\
\hline Linfoma (LF) & 1 & $(2)$ & 1 & (2) & & \\
\hline Total & 63 & $(100)$ & 63 & $(100)$ & 24 & (100) \\
\hline
\end{tabular}




\subsection{CONCORDÂNCIAS ENTRE OS DIAGNÓSTICOS}

A concordância entre os diagnósticos clínico, de biópsia e de autópsia foi avaliada de acordo com as classificações "não agregada" e "agregada":

A) "Classificação não agregada":

- Diagnósticos clínico e de biópsia (Tabela 4.5): a concordância entre os diagnósticos foi de $48 \%$. Vale ressaltar que o diagnóstico de pneumopatia infecciosa apresenta uma baixa taxa de concordância: dos 22 pacientes diagnosticados clinicamente com pneumopatia infecciosa $(\mathrm{PI})$ apenas 8 (pouco mais de $36 \%$ ), também tiveram o mesmo diagnóstico na biópsia;

- Diagnósticos clínico e de autópsia (Tabela 4.6): descritivamente, ocorre uma maior concordância para a pneumopatia infecciosa $(\mathrm{PI})$ em relação à concordância observada entre os diagnósticos clínico e de biópsia: dos 12 pacientes, em 9 houve concordância. Considerando-se todos os grupos diagnósticos, a concordância observada foi de $62 \%$;

- Diagnósticos de biópsia e de autópsia (Tabela 4.7): novamente a concordância foi relativamente maior para a pneumopatia infecciosa $(\mathrm{PI})$ em relação à concordância encontrada entre os diagnósticos clínico e de biópsia. Considerando-se todas as patologias, houve $58 \%$ de concordância. 


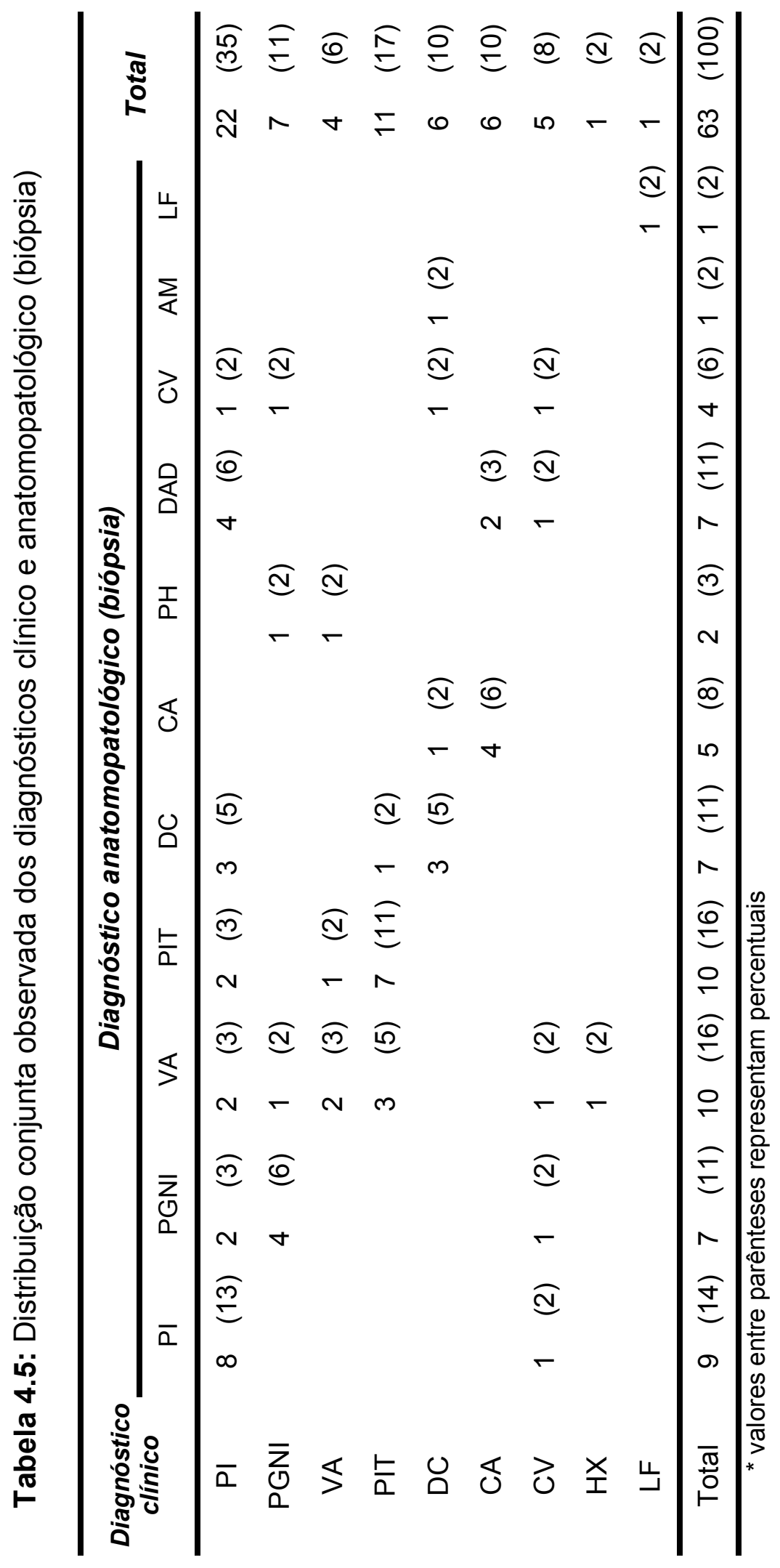




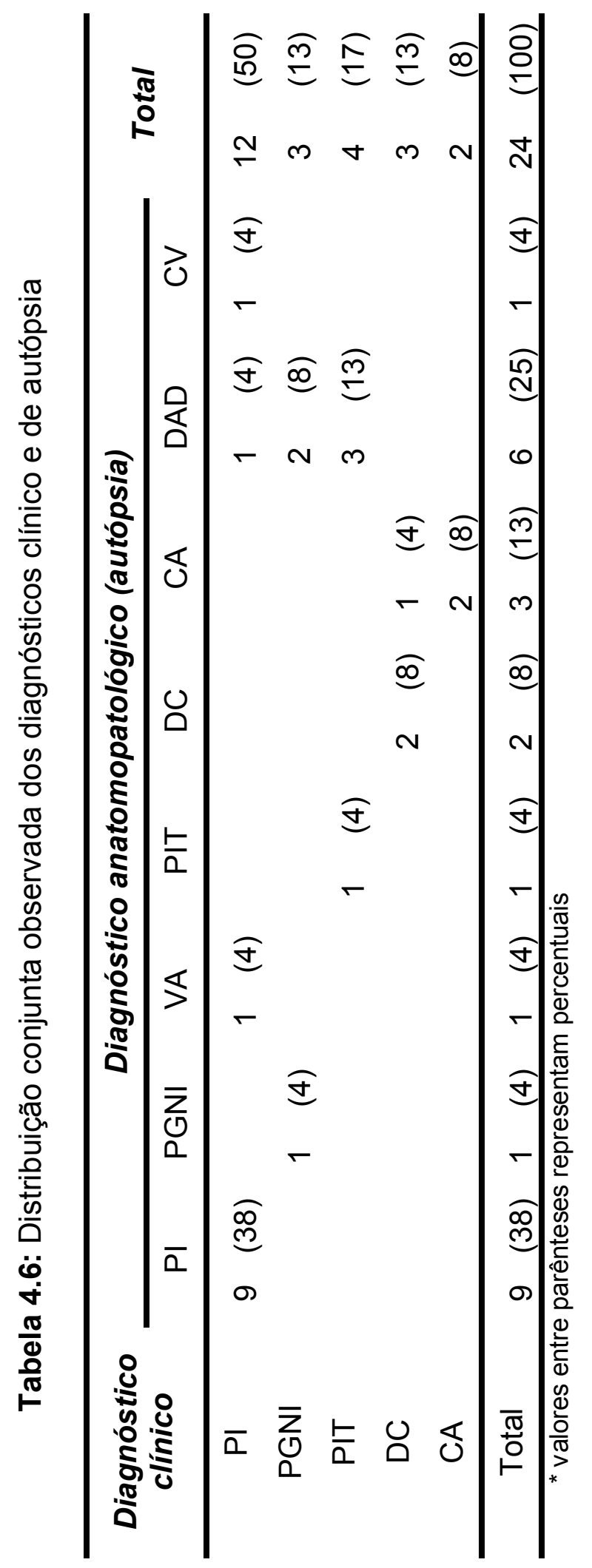




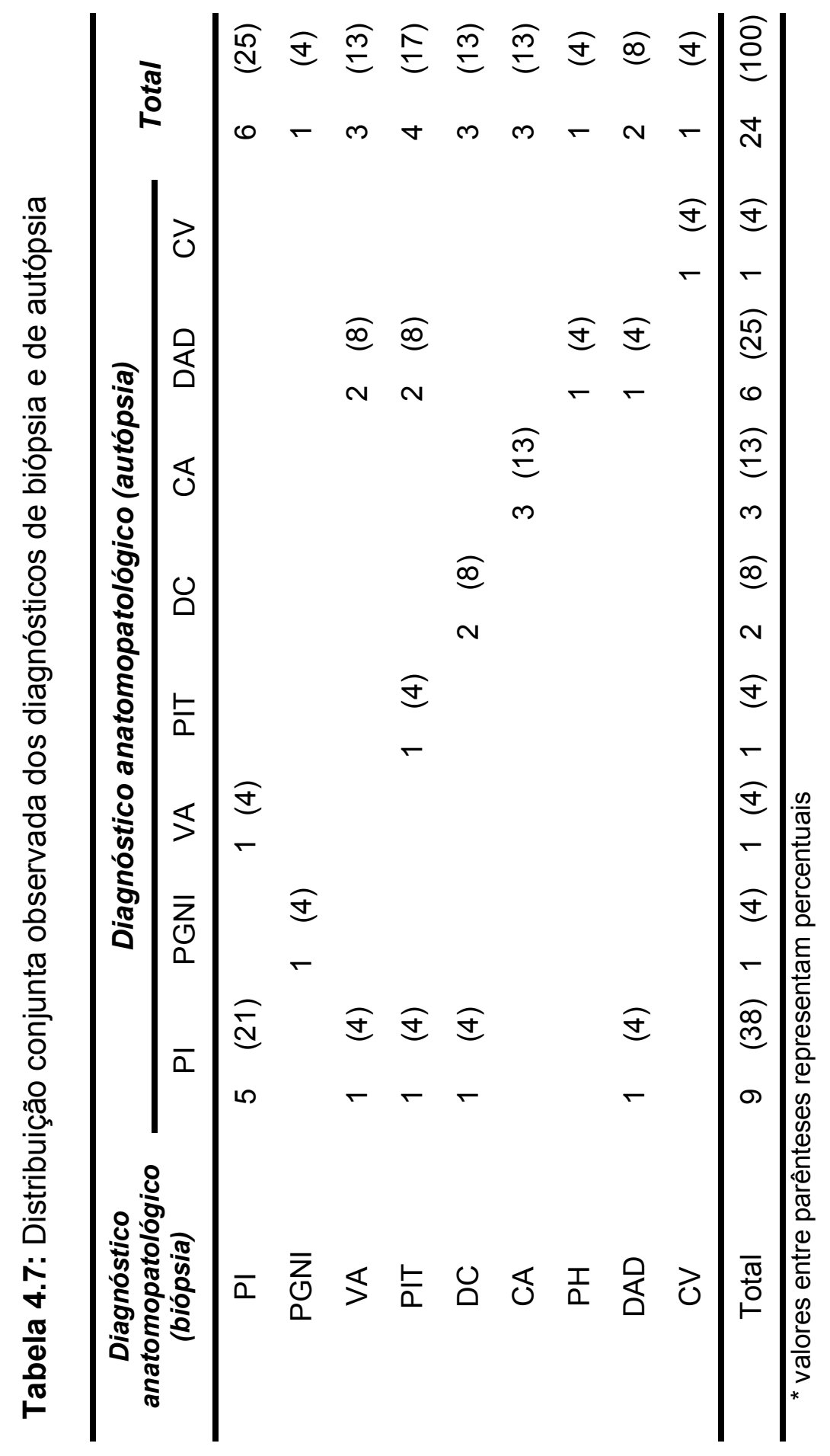


B) "Classificação agregada”:

- Diagnósticos clínico e de biópsia (Tabela 4.8): a concordância neste caso foi de $65 \%$. A Tabela 4.8 mostra mais claramente que a principal discordância se dá entre os diagnósticos das "pneumopatias infecciosas" em relação às "inflamatórias, não infecciosas". Observa-se que dos 26 pacientes classificados clinicamente como "pneumopatias infecciosas" apenas 12 (46\%) apresentaram o mesmo resultado na biópsia;

- Diagnósticos clínico e de autópsia (Tabela 4.9): houve concordância de $75 \%$; mais uma vez aqui o destaque ocorre em relação às "pneumopatias infecciosas": dos 15 pacientes classificados clinicamente com esse grupo de patologias, um terço apresentou diagnóstico de "pneumopatias inflamatórias, não infecciosas" à autópsia;

- Diagnósticos de biópsia e de autópsia (Tabela 4.10): a concordância foi igual a $79 \%$ sendo a principal discordância mais uma vez entre as "pneumopatias infecciosas" e as "inflamatórias, não infecciosas".

Como fora abordado previamente, a "classificação agregada" dos diagnósticos foi elaborada com finalidade exclusiva de tornar possível a análise estatística, utilizando-se os agrupamentos diagnósticos como parte das variáveis de estudo. Assim, passamos a descrever dados relativos tão somente à "classificação agregada" de diagnósticos.

A concordância simultânea entre os diagnósticos clínico, de biópsia e de autópsia foi avaliada (Tabela 4.11). 
Novamente, é possível perceber uma maior discordância quando o diagnóstico clínico é de "pneumopatia infecciosa"; nenhuma discordância foi observada para os casos com diagnóstico clínico de "pneumopatia inflamatória não infecciosa".

As concordâncias entre os diagnósticos clínico e de biópsia, e entre os diagnósticos histopatológicos de biópsia e de autópsia foram avaliadas também segundo o tempo (Tabelas 4.12 e 4.13).

A Tabela 4.12 mostra que a concordância entre os diagnósticos clínico e de biópsia apresentam valores acima de $50 \%$ quando o tempo decorrido até a biópsia é de até 10 dias. Já quando o tempo entre a internação e a biópsia passa a ser maior que 10 dias e menor que 20 dias, a concordância cai para $29 \%$. O percentual de concordância volta, no entanto a subir para o patamar de $50 \%$, quando o tempo decorrido é maior do que 20 dias.

Embora o número de autópsias avaliadas em nosso estudo seja relativamente pequeno, através dos dados apresentados na Tabela 4.13 observa-se que a concordância entre os diagnósticos de biópsia e de autópsia mantêm-se em percentuais semelhantes com o aumento do intervalo entre os procedimentos. Ao se comparar o grupo com intervalo máximo de 7 dias ao grupo cujo intervalo foi maior do que 7 dias, as concordâncias são de $55 \%$ e $62 \%$,respectivamente. 


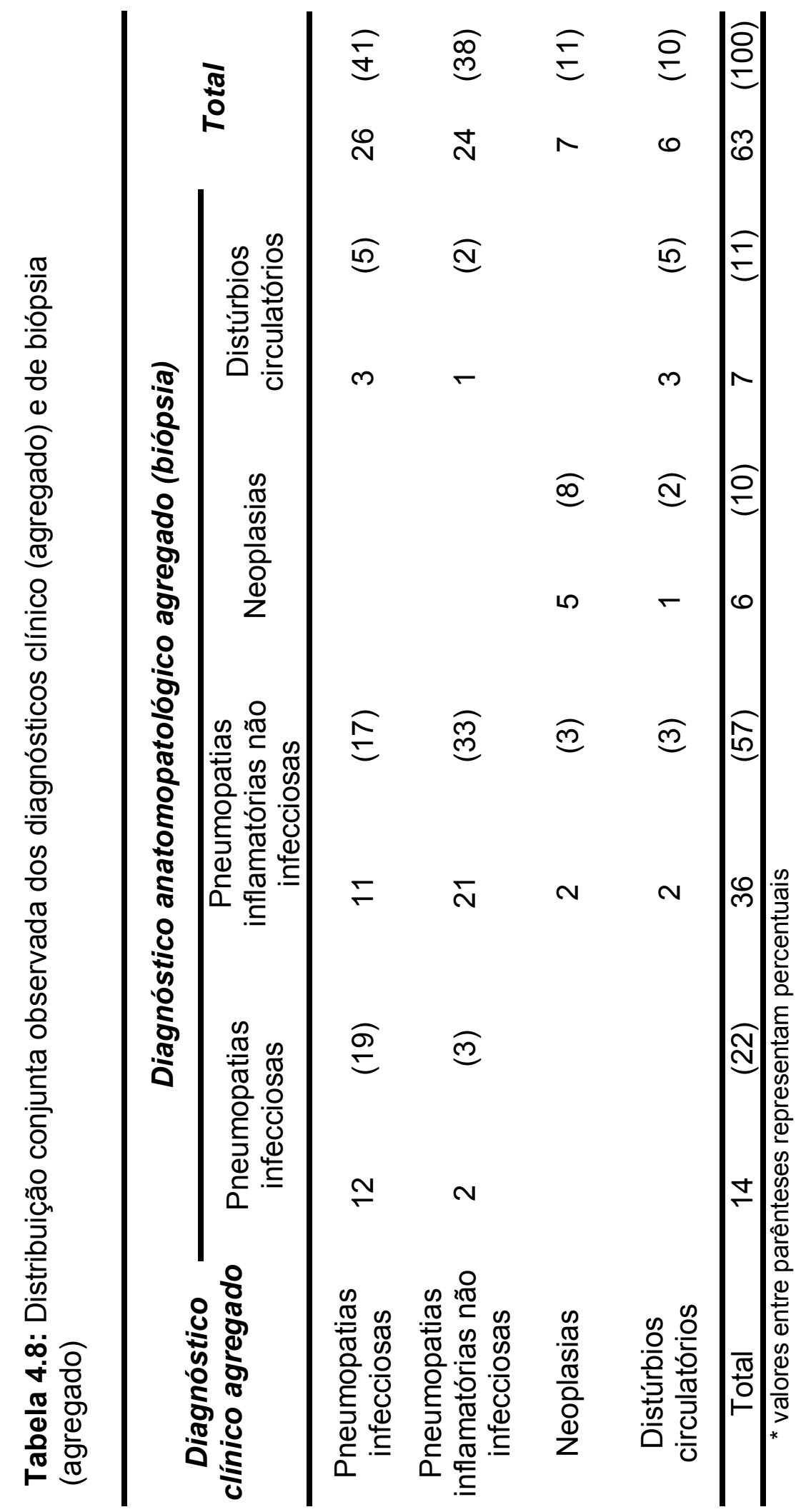


ฌ

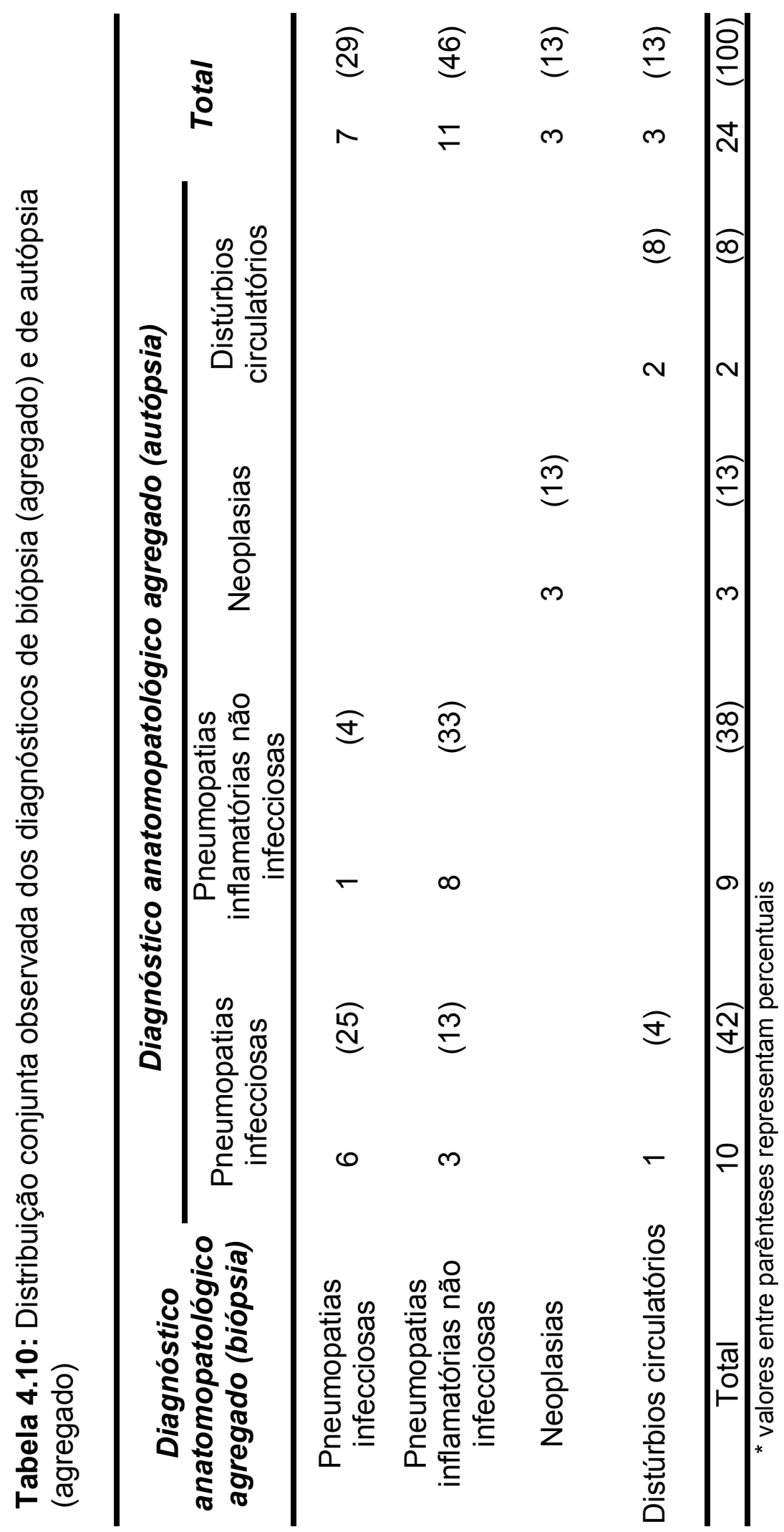




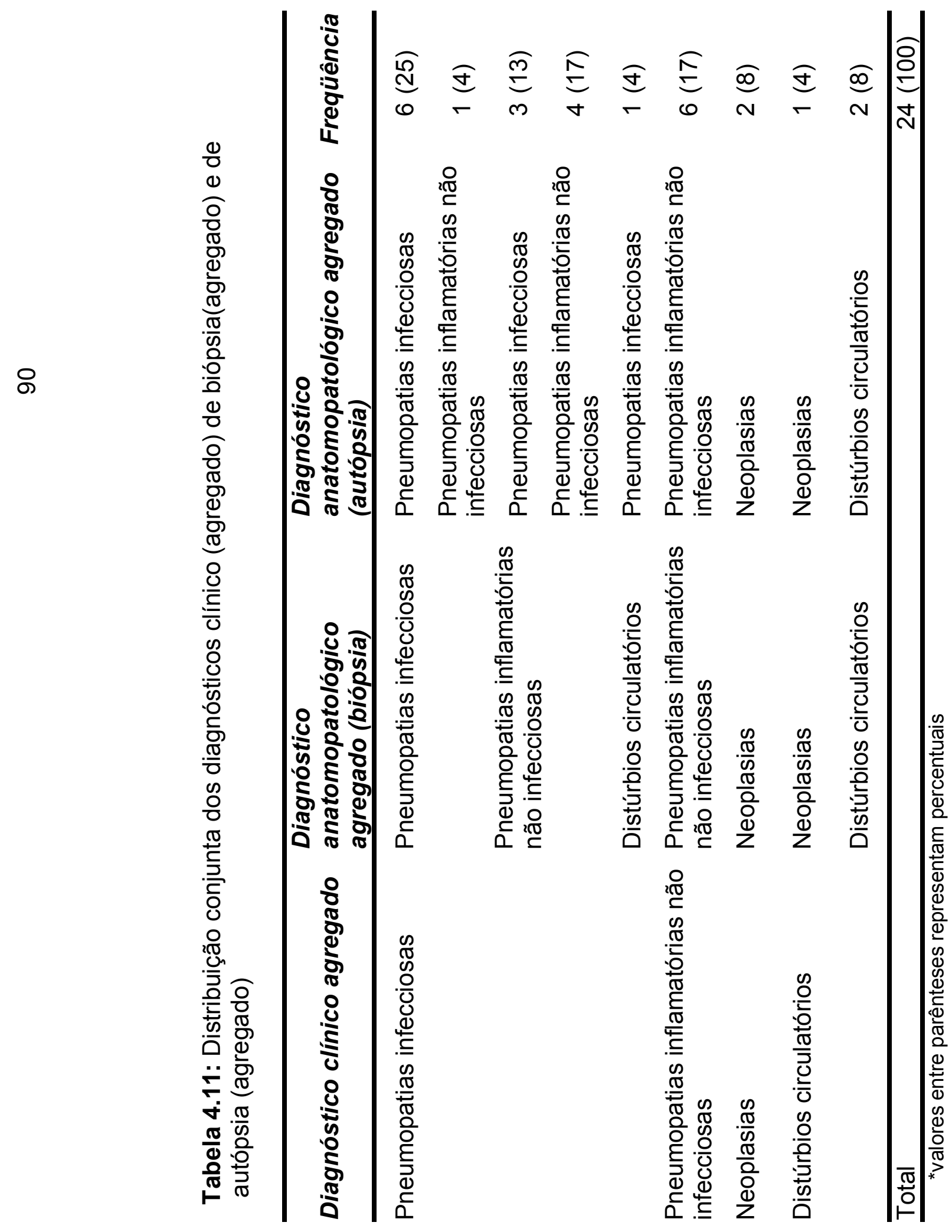


Tabela 4.12: Distribuição da concordância entre os diagnósticos clínico e de biópsia segundo o tempo decorrido até a biópsia

\begin{tabular}{ccccccc}
\hline \multirow{2}{*}{$\begin{array}{c}\text { Tempo decorrido entre } \\
\text { a internação e } \mathbf{a} \\
\text { biópsia }\end{array}$} & $\begin{array}{c}\text { Concordância entre diagnósticos } \\
\text { clínico e de biópsia }\end{array}$ & \multirow{2}{*}{ Total } \\
\cline { 2 - 5 } & \multicolumn{2}{c}{ Ausência } & \multicolumn{2}{c}{ Presença } & & \\
\hline Até 5 dias & 2 & $(25)$ & 6 & $(75)$ & 8 & $(100)$ \\
De 6 a 10 dias & 5 & $(42)$ & 7 & $(58)$ & 12 & $(100)$ \\
De 11 a 20 dias & 15 & $(71)$ & 6 & $(29)$ & 21 & $(100)$ \\
21 dias ou mais & 11 & $(50)$ & 11 & $(50)$ & 22 & $(100)$ \\
\hline Total & 33 & $(52)$ & 30 & $(48)$ & 63 & $(100)$ \\
\hline
\end{tabular}

* valores entre parênteses representam percentuais

Tabela 4.13: Distribuição da concordância entre os diagnósticos de biópsia e de autópsia segundo o tempo decorrido entre a biópsia e o óbito

\begin{tabular}{|c|c|c|c|c|c|c|}
\hline \multirow{3}{*}{$\begin{array}{c}\text { Tempo decorrido entre a } \\
\text { biópsia e a alta ou óbito } \\
\text { clínico }\end{array}$} & \multicolumn{4}{|c|}{$\begin{array}{c}\text { Concordância entre diagnósticos de } \\
\text { biópsia e de autópsia }\end{array}$} & \multirow{2}{*}{\multicolumn{2}{|c|}{ Total }} \\
\hline & \multicolumn{2}{|c|}{ Ausência } & \multicolumn{2}{|c|}{ Presença } & & \\
\hline & 5 & (45) & 6 & (55) & 11 & $(100)$ \\
\hline De 8 a 14 dias & 1 & (25) & 3 & (75) & 4 & (100) \\
\hline De 15 a 21 dias & 1 & (100) & & & 1 & (100) \\
\hline De 22 a 30 dias & 2 & $(40)$ & 3 & $(60)$ & 5 & (100) \\
\hline Acima de 30 dias & 1 & (33) & 2 & (67) & 3 & (100) \\
\hline Total & 10 & (42) & 14 & (58) & 24 & (100) \\
\hline
\end{tabular}

* valores entre parênteses representam percentuais 


\subsection{RELAÇÕES DAS VARIÁVEIS COM A SOBREVIDA HOSPITALAR}

Nesta etapa, como previamente mencionado, realizou-se o estudo da associação entre as variáveis e o óbito através de análise descritiva em que foi efetuada a análise univariada e, em alguns casos, a análise da relação entre a combinação de duas variáveis com o óbito. Para tanto, utilizou-se em alguns casos o teste Qui-quadrado, tendo sido realizada em outros de forma empírica. As variáveis investigadas nesta etapa foram:

- sexo;

- idade;

- tempo decorrido da internação até a biópsia, em número de dias;

- presença ou ausência de dano alveolar difuso na biópsia;

- presença ou ausência de doença sistêmica de base (comorbidade);

- presença ou ausência de fator de imunossupressão;

- presença ou ausência de quadro clínico e ou gasométrico de insuficiência respiratória;

- presença ou ausência de sinais de aspiração do conteúdo gastroesofageano na biópsia;

- concordância entre os diagnósticos clínico e de biópsia;

- “índice agudo";

- “índice crônico". 
A análise dos resultados revelou que o sexo feminino apresentou maior freqüência de sobrevida hospitalar: $61 \%$ versus $38 \%$ em relação ao sexo masculino (Tabela 4.14).

Não houve grandes diferenças entre as freqüências observadas de sobrevida hospitalar para cada faixa etária (Tabela 4.15).

Observou-se que o grupo em que a realização da biópsia ocorreu em até 4 dias após a internação foi aquele que apresentou maior freqüência de sobrevida hospitalar: 71\% (Tabela 4.16). Decorridos mais do que 5 dias, é possível perceber que o patamar de sobrevida hospitalar fica em torno de $50 \%$.

Quanto à concordância do diagnóstico clínico com o de biópsia (Tabela 4.17), havendo concordância, a freqüência de sobrevida hospitalar é um pouco menor (43\% versus os $55 \%$ ) quando comparada à discordância entre os diagnósticos.

A presença de dano alveolar na biópsia (Tabela 4.18) associou-se a menor sobrevida hospitalar (31\%), quando comparada à ausência deste fator $(68 \%)$.

Observou-se também que na presença de doença de base a porcentagem de sobrevida hospitalar é bem menor (40\% versus $80 \%)$ quando comparada à não ocorrência de comorbidade (Tabela 4.19), o mesmo ocorrendo com a presença de fator de imunossupressão (Tabela 4.20) (39\% versus $60 \%$ ) e de quadro clínico e ou gasométrico de insuficiência respiratória aguda (Tabela 4.21$)(39 \%$ versus $70 \%)$. 
Quanto à presença de indícios de aspiração de conteúdo gastroesofageano na biópsia (Tabela 4.22), apenas 4 indivíduos apresentaram tais indícios, sendo que 2 destes sobreviveram. Comparando-se com o grupo onde não houve aspiração, praticamente não ocorre diferença, pois $49 \%$ dos demais pacientes sobreviveram.

Tabela 4.14: Distribuição da sobrevida hospitalar segundo o sexo

\begin{tabular}{|c|c|c|c|c|c|c|}
\hline \multirow{3}{*}{$\begin{array}{c}\text { Sexo } \\
\text { Masculino }\end{array}$} & \multicolumn{4}{|c|}{ Sobrevida hospitalar } & \multirow{2}{*}{\multicolumn{2}{|c|}{ Total }} \\
\hline & \multicolumn{2}{|c|}{ Não } & \multicolumn{2}{|c|}{$\operatorname{Sim}$} & & \\
\hline & 20 & (63) & 12 & (38) & 32 & (100) \\
\hline Feminino & 12 & (39) & 19 & (61) & 31 & (100) \\
\hline Total & 32 & (51) & 31 & (49) & 63 & (100) \\
\hline
\end{tabular}

* valores entre parênteses representam percentuais

Tabela 4.15: Distribuição da sobrevida hospitalar segundo a idade

\begin{tabular}{|c|c|c|c|c|c|c|}
\hline \multirow{2}{*}{ Idade } & \multicolumn{4}{|c|}{ Sobrevida hospitalar } & \multirow{2}{*}{\multicolumn{2}{|c|}{ Total }} \\
\hline & & & & & & \\
\hline Até 40 anos & 10 & (45) & 13 & (55) & 22 & (100) \\
\hline De 41 a 50 anos & 5 & (63) & 3 & (38) & 8 & (100) \\
\hline De 51 a 60 anos & 10 & (59) & 7 & (41) & 17 & (100) \\
\hline 61 anos ou mais & 7 & $(44)$ & 9 & (56) & 16 & (100) \\
\hline Total & 32 & (51) & 31 & (49) & 63 & $(100)$ \\
\hline
\end{tabular}

* valores entre parênteses representam percentuais 
Tabela 4.16: Distribuição da sobrevida hospitalar segundo o tempo decorrido entre a internação e a biópsia

\begin{tabular}{|c|c|c|c|c|c|c|}
\hline \multirow{3}{*}{$\begin{array}{c}\begin{array}{c}\text { Tempo decorrido entre a } \\
\text { internação e a biópsia }\end{array} \\
\text { Até } 4 \text { dias }\end{array}$} & \multicolumn{4}{|c|}{ Sobrevida hospitalar } & \multirow{2}{*}{\multicolumn{2}{|c|}{ Total }} \\
\hline & \multicolumn{2}{|c|}{ Não } & \multicolumn{2}{|c|}{ Sim } & & \\
\hline & 2 & (29) & 5 & (71) & 7 & $(100)$ \\
\hline De 5 a 9 dias & 7 & (64) & 4 & (36) & 11 & (100) \\
\hline De 10 a 19 dias & 11 & (50) & 11 & (50) & 22 & $(100)$ \\
\hline 20 dias ou mais & 12 & (52) & 11 & $(48)$ & 23 & (100) \\
\hline Total & 32 & (51) & 31 & (49) & 63 & (100) \\
\hline
\end{tabular}

${ }^{*}$ valores entre parênteses representam percentuais

Tabela 4.17: Distribuição da sobrevida hospitalar segundo a concordância entre os diagnósticos clínico e de biópsia

\begin{tabular}{cccccccc}
\hline $\begin{array}{c}\text { Concordância entre } \\
\text { diagnósticos clínico e de de } \\
\text { biónsia (aareaado) }\end{array}$ & \multicolumn{3}{c}{ Sobrevida hospitalar } & \multicolumn{2}{c}{ Notal } \\
\cline { 2 - 6 } Não & \multicolumn{2}{c}{ Sim } & & \\
\hline Não concorda & 15 & $(45)$ & 18 & $(55)$ & 33 & $(100)$ \\
Concorda & 17 & $(57)$ & 13 & $(43)$ & 30 & $(100)$ \\
\hline Total & 32 & $(51)$ & 31 & $(49)$ & 63 & $(100)$ \\
\hline
\end{tabular}

${ }^{*}$ valores entre parênteses representam percentuais

Tabela 4.18: Distribuição da sobrevida hospitalar segundo a presença de dano alveolar difuso na biópsia

\begin{tabular}{cccccccc}
\hline \multirow{2}{*}{$\begin{array}{c}\text { Dano alveolar difuso } \\
\text { na biópsia }\end{array}$} & \multicolumn{3}{c}{ Sobrevida hospitalar } & \multicolumn{2}{c}{ Total } \\
\cline { 2 - 6 } & \multicolumn{2}{c}{ Não } & \multicolumn{2}{c}{ Sim } & & \\
\hline Ausência & 10 & $(32)$ & 21 & $(68)$ & 31 & $(100)$ \\
Presença & 22 & $(69)$ & 10 & $(31)$ & 32 & $(100)$ \\
\hline Total & 32 & $(51)$ & 31 & $(49)$ & 63 & $(100)$ \\
\hline
\end{tabular}

* valores entre parênteses representam percentuais 
Tabela 4.19: Distribuição da sobrevida hospitalar segundo a presença de doença de base

\begin{tabular}{cccccccc}
\hline \multirow{2}{*}{ Doença de base } & \multicolumn{3}{c}{ Sobrevida hospitalar } & \multicolumn{2}{c}{ Total } \\
\cline { 2 - 6 } & \multicolumn{3}{c}{ Não } & \multicolumn{2}{c}{ Sim } & & \\
\hline Ausência & 3 & $(20)$ & 12 & $(80)$ & 15 & $(100)$ \\
Presença & 29 & $(60)$ & 19 & $(40)$ & 48 & $(100)$ \\
\hline Total & 32 & $(51)$ & 31 & $(49)$ & 63 & $(100)$ \\
\hline
\end{tabular}

* valores entre parênteses representam percentuais

Tabela 4.20: Distribuição da sobrevida hospitalar segundo a presença de fator de imunossupressão

\begin{tabular}{|c|c|c|c|c|c|c|}
\hline \multirow{2}{*}{$\begin{array}{c}\text { Fator de } \\
\text { imunossupressão }\end{array}$} & \multicolumn{4}{|c|}{ Sobrevida hospitalar } & \multirow{2}{*}{\multicolumn{2}{|c|}{ Total }} \\
\hline & & & & & & \\
\hline Ausência & 12 & $(40)$ & 18 & $(60)$ & 30 & $(100)$ \\
\hline Presença & 20 & (61) & 13 & (39) & 33 & $(100)$ \\
\hline Total & 32 & (51) & 31 & (49) & 63 & (100) \\
\hline
\end{tabular}

* valores entre parênteses representam percentuais

Tabela 4.21: Distribuição da sobrevida hospitalar segundo a presença de quadro clínico e ou gasométrico de insuficiência respiratória

\begin{tabular}{cccccccc}
\hline $\begin{array}{c}\text { Quadro clínico e ou } \\
\text { gasométrico de insuficiência } \\
\text { respiratória }\end{array}$ & \multicolumn{4}{c}{ Sobrevida hospitalar } & \multirow{3}{*}{ Total } \\
\cline { 2 - 6 } & 3 & $(30)$ & 7 & $(70)$ & 10 & $(100)$ \\
\hline Ausência & 25 & $(61)$ & 16 & $(39)$ & 41 & $(100)$ \\
Presença & 28 & $(55)$ & 23 & $(45)$ & 51 & $(100)$ \\
\hline Total & & &
\end{tabular}

* valores entre parênteses representam percentuais 
Tabela 4.22: Distribuição da sobrevida hospitalar segundo a presença de sinais de aspiração de conteúdo gastroesofageano na biópsia

\begin{tabular}{|c|c|c|c|c|c|c|}
\hline \multirow{3}{*}{$\begin{array}{c}\begin{array}{c}\text { Sinais de aspiração de } \\
\text { conteúdo } \\
\text { gastroesofageano na } \\
\text { biópsia }\end{array} \\
\text { Ausência }\end{array}$} & \multicolumn{4}{|c|}{ Sobrevida hospitalar } & \multirow{2}{*}{\multicolumn{2}{|c|}{ Total }} \\
\hline & \multicolumn{2}{|c|}{ Não } & \multicolumn{2}{|c|}{ Sim } & & \\
\hline & 30 & (51) & 29 & $(49)$ & 59 & $(100)$ \\
\hline Presença & 2 & (50) & 2 & (50) & 4 & $(100)$ \\
\hline Total & 32 & (51) & 31 & (49) & 63 & (100) \\
\hline
\end{tabular}

${ }^{*}$ valores entre parênteses representam percentuais

A associação entre a sobrevida hospitalar e todas as alterações histológicas mensuradas nos espécimes obtidos através de biópsia foram investigados. Muitos destes não se mostraram informativos, em virtude da pequena variação que ocorre. No entanto, julgou-se essencial esta análise para que não houvesse erros na proposição de algum índice obtido a partir do estudo histológico. A análise foi dividida de acordo com as regiões ou compartimentos histológicos do parênquima pulmonar, conforme apresentados nas tabelas dos Anexos A1 a A11:

- Interstício Axial (“Anexo A1”);

- Interstício Septal (“Anexo A2”);

- Interstício Periférico (“Anexo A3”);

- Arteríolas pré-acinares ("Anexo A4");

- Arteríolas pós-acinares (“Anexo A5”); 
- Veias e vasos linfáticos (“Anexo A6”);

- Bronquíolos terminais (“Anexo A7");

- Bronquíolos respiratórios (“Anexo A8”);

- Alvéolos (“Anexo A9”);

- Caracterização de granulomas, quando presentes (“Anexo A10”);

- Caracterização de neoplasias, quando presentes ("Anexo A11");

Ainda que em diversos casos nenhuma constatação tenha sido possível, na maior parte, no entanto, observou-se que paradoxalmente ocorre um aumento na proporção de sobrevida hospitalar conforme os escores aumentam. Exceção se fez para os seguintes achados:

- edema em bronquíolos respiratórios (Anexo A8, Tabela A8. 7);

- decapitação epitelial de bronquíolos respiratórios (Anexo A8, Tabela A8. 10);

- efeito citopático em bronquíolos respiratórios (Anexo A8, Tabela A8. 13);

- homogeneidade temporal (Anexo A9, Tabela A9. 5);

- tecido de granulação na luz alveolar (Anexo A9, Tabela A9. 7);

- presença de parasitas na luz alveolar (Anexo A9, Tabela A9. 15);

- exsudato neutrofílico intralveolar (Anexo A9, Tabela A9. 17);

- membranas hialinas na luz alveolar (Anexo A9, Tabela A9. 9). 


\subsubsection{RELAÇÃO DOS ÍNDICES HISTOPATOLÓGICOS AGUDOS E CRÔNICOS COM A SOBREVIDA HOSPITALAR}

A análise da associação entre os "índices histopatológicos" e a sobrevida hospitalar foi feita separadamente para os "índices agudo e crônico". Na Tabela 4.23 é possível contemplar que tais "índices" apresentaram medidas resumo bem parecidas.

A relação dos "índices" com a sobrevida hospitalar foi verificada utilizando-se cada "índice" em separado e também a combinação destes. A distribuição da sobrevida hospitalar segundo o "índice crônico" (Tabela 4.24) indica que a porcentagem de óbito é maior entre os pacientes com valores relativamente menores. Já a distribuição da sobrevida hospitalar segundo o "índice agudo" (Tabela 4.25), mostra que para valores médios e altos a porcentagem de óbito é maior que $50 \%$.

A associação diretamente proporcional encontrada entre o "índice agudo" e a sobrevida hospitalar não se mostra válida quando há concomitância de "índice crônico" elevado. Ao se observar a distribuição da sobrevida hospitalar segundo a associação dos "índices agudo e crônico" (Tabela 4.26) constata-se que a porcentagem de óbito aumenta conforme aumenta o "índice agudo" somente para os grupos com "índice crônico" baixo (até 2,5). Para o grupo com "índice crônico" médio (entre 2,5 e 4,5), ocorre aumento quando são 
comparados valores baixo e médio do "índice agudo"; pequena queda é observada ao se passar de valores médios para altos do "índice agudo". Ao contrário disto, para os pacientes com "índice crônico" alto (acima de 4,5), as maiores porcentagens de óbito ocorrem quando o "índice agudo" é baixo ou médio. Dessa forma, é razoável supor que existe interação entre os "índices agudo e crônico".

Tabela 4.23: Medidas-resumo dos "índices histopatológicos agudo e crônico"

\begin{tabular}{ccc}
\hline Freqüências & Crônico & Agudo \\
\hline $\mathrm{N}$ & 63 & 63 \\
Média & 3,6 & 3,7 \\
Desvio-padrão & 2,0 & 1,8 \\
Mediana & 3,5 & 3,7 \\
Mínimo & 0,1 & 0,4 \\
Máximo & 9,3 & 8,7 \\
\hline
\end{tabular}

Tabela 4.24: Distribuição da sobrevida hospitalar segundo o "índice crônico"

\begin{tabular}{ccccccc}
\hline \multirow{2}{*}{$\begin{array}{c}\text { Índice } \\
\text { crônico }\end{array}$} & \multicolumn{4}{c}{ Sobrevida hospitalar } & \multirow{2}{*}{ Total } \\
\cline { 2 - 6 } & \multicolumn{3}{c}{ Não } & \multicolumn{3}{c}{ Sim } \\
& 14 & $(67)$ & 7 & $(33)$ & 21 & $(100)$ \\
Baixo & 13 & $(57)$ & 10 & $(43)$ & 23 & $(100)$ \\
Médio & 5 & $(26)$ & 14 & $(74)$ & 19 & $(100)$ \\
Alto & 32 & $(51)$ & 31 & $(49)$ & 63 & $(100)$ \\
\hline Total & 32 &
\end{tabular}

${ }^{\text {* } v a l o r e s ~ e n t r e ~ p a r e ̂ n t e s e s ~ r e p r e s e n t a m ~ p e r c e n t u a i s ~}$ 
Tabela 4.25: Distribuição da sobrevida hospitalar segundo o "índice agudo"

\begin{tabular}{|c|c|c|c|c|c|c|}
\hline \multirow{3}{*}{$\begin{array}{l}\text { Índice } \\
\text { agudo }\end{array}$} & \multicolumn{4}{|c|}{ Sobrevida hospitalar } & \multirow{2}{*}{\multicolumn{2}{|c|}{ Total }} \\
\hline & \multicolumn{2}{|c|}{ Não } & \multicolumn{2}{|c|}{ Sim } & & \\
\hline & 7 & (37) & 12 & (63) & 19 & $(100)$ \\
\hline Médio & 14 & (64) & 8 & (36) & 22 & $(100)$ \\
\hline Alto & 11 & (50) & 11 & (50) & 22 & $(100)$ \\
\hline Total & 32 & (51) & 31 & (49) & 63 & (100) \\
\hline
\end{tabular}

* valores entre parênteses representam percentuais

Tabela 4.26: Distribuição da sobrevida hospitalar segundo a associação entre o "índice crônico" e o "índice agudo"

\begin{tabular}{|c|c|c|c|c|c|c|c|}
\hline \multirow{3}{*}{$\frac{\text { Índice crônico }}{\text { Baixo }}$} & \multirow{3}{*}{$\frac{\text { Índice agudo }}{\text { Baixo }}$} & \multicolumn{4}{|c|}{ Sobrevida hospitalar } & \multirow{2}{*}{\multicolumn{2}{|c|}{ Total }} \\
\hline & & \multicolumn{2}{|c|}{ Não } & \multicolumn{2}{|c|}{ Sim } & & \\
\hline & & 5 & (45) & 6 & (55) & 11 & $(100)$ \\
\hline & Médio & 6 & (86) & 1 & (14) & 7 & $(100)$ \\
\hline & Alto & 3 & $(100)$ & & & 3 & $(100)$ \\
\hline & Total & 14 & (67) & 7 & (33) & 21 & $(100)$ \\
\hline \multirow[t]{4}{*}{ Médio } & Baixo & 2 & (33) & 4 & (67) & 6 & $(100)$ \\
\hline & Médio & 4 & (67) & 2 & (33) & 6 & $(100)$ \\
\hline & Alto & 7 & (64) & 4 & (36) & 11 & $(100)$ \\
\hline & Total & 13 & (57) & 10 & (43) & 23 & $(100)$ \\
\hline \multirow[t]{4}{*}{ Alto } & Baixo & & & 2 & $(100)$ & 2 & $(100)$ \\
\hline & Médio & 4 & (44) & 5 & $(56)$ & 9 & $(100)$ \\
\hline & Alto & 1 & (13) & 7 & (88) & 8 & $(100)$ \\
\hline & Total & 5 & (26) & 14 & (74) & 19 & $(100)$ \\
\hline
\end{tabular}

${ }^{*}$ valores entre parênteses representam percentuais 


\subsubsection{Combinação das variáveis com a sobrevida}

hospitalar

Investigando-se as combinações de variáveis duas a duas, foi possível constatar um maior destaque em algumas relações. Para o sexo masculino, a presença de dano alveolar difuso está mais fortemente associada ao óbito, pois o risco de óbito para este grupo é de 4,2 , ao passo que para as mulheres é de 1,8 (Tabela 4.27).

Os resultados sugerem que a presença da doença sistêmica de base (comorbidade) tende a ser de pior prognóstico para as mulheres, uma vez que o risco de óbito para as mulheres acometidas é igual a 5,2 vezes em relação aos pacientes não acometidos. Para os homens esse número cai para 2,8 (Tabela 4.28). Igualmente forte foi a associação entre o óbito e o tempo de internação pré-biópsia maior que 7 dias (Tabela 4.29) nos pacientes com doença de sistêmica base (comorbidade). O quadro clínico e ou gasométrico de insuficiência respiratória aguda (Tabela 4.30) exibe para o sexo masculino o risco de 6, contrastando fortemente com o risco de 2,7 para o sexo feminino que é de 2, Na presença de doença de base, o risco de óbito é praticamente igual ao se comparar os grupos onde houve concordância e discordância entre os diagnósticos, ao passo que, no grupo sem doença de base, o risco de óbito foi menor onde houve discordância entre a biópsia e o diagnóstico clínico o que pode estar ocorrendo em virtude do número reduzido de indivíduos nestes grupos (Tabela 4.31). Por outro lado, a maior porcentagem de óbito ocorreu 
para os indivíduos com doença de base e dano alveolar difuso (Tabela 4.32). Contudo, na vigência de dano alveolar difuso na biópsia e de quadro clínico e ou gasométrico de insuficiência respiratória (Tabela 4.33), as maiores porcentagens de óbito ocorreram para os indivíduos que tinham as duas características presentes, seguido pelos indivíduos com dano alveolar difuso apenas. Na ocorrência de doença sistêmica de base (comorbidade) e quadro clínico e ou gasométrico de insuficiência respiratória (Tabela 4.34), observa-se acentuado aumento na porcentagem de óbito.

Tabela 4.27: Distribuição da sobrevida hospitalar segundo a presença de dano alveolar difuso na biópsia e sexo

\begin{tabular}{|c|c|c|c|c|c|c|c|}
\hline \multirow{3}{*}{$\begin{array}{c}\begin{array}{c}\text { Dano alveolar difuso } \\
\text { na biópsia }\end{array} \\
\text { Ausência }\end{array}$} & \multirow{3}{*}{$\begin{array}{c}\text { Sexo } \\
\text { Masculino }\end{array}$} & \multicolumn{4}{|c|}{ Sobrevida hospitalar } & \multirow{2}{*}{\multicolumn{2}{|c|}{ Total }} \\
\hline & & \multicolumn{2}{|c|}{ Não } & \multicolumn{2}{|c|}{ Sim } & & \\
\hline & & 4 & (36) & 7 & (64) & 11 & $(100)$ \\
\hline & Feminino & 6 & (30) & 14 & (70) & 20 & $(100)$ \\
\hline & Total & 10 & (32) & 21 & (68) & 31 & (100) \\
\hline \multirow[t]{2}{*}{ Presença } & Masculino & 16 & (76) & 5 & (24) & 21 & $(100)$ \\
\hline & Feminino & 6 & (55) & 5 & (45) & 11 & $(100)$ \\
\hline \multicolumn{2}{|l|}{ Total } & 22 & (69) & 10 & (31) & 32 & (100) \\
\hline
\end{tabular}

* valores entre parênteses representam percentuais 
Tabela 4.28: Distribuição da sobrevida hospitalar segundo a presença de doença sistêmica de base e sexo

\begin{tabular}{cccccccc}
\hline \multirow{2}{*}{ Doença de base } & \multirow{2}{*}{ Sexo } & \multicolumn{4}{c}{ Sobrevida hospitalar } & \multirow{2}{*}{ Total } \\
\cline { 2 - 7 } & & \multicolumn{2}{c}{ Não } & \multicolumn{2}{c}{ Sim } & \multicolumn{2}{c}{} \\
\hline \multirow{2}{*}{ Ausência } & Masculino & 3 & $(50)$ & 3 & $(50)$ & 6 & $(100)$ \\
& Feminino & & & 9 & $(100)$ & 9 & $(100)$ \\
\cline { 2 - 7 } & Total & 3 & $(20)$ & 12 & $(80)$ & 15 & $(100)$ \\
\hline \multirow{2}{*}{ Presença } & Masculino & 17 & $(65)$ & 9 & $(35)$ & 26 & $(100)$ \\
& Feminino & 12 & $(55)$ & 10 & $(45)$ & 22 & $(100)$ \\
\cline { 2 - 6 } & Total & 29 & $(60)$ & 19 & $(40)$ & 48 & $(100)$ \\
\hline
\end{tabular}

* valores entre parênteses representam percentuais

Tabela 4.29: Distribuição da sobrevida hospitalar segundo o tempo pré-biópsia maior que 7 dias e a presença da doença sistêmica de base

\begin{tabular}{|c|c|c|c|c|c|c|c|}
\hline \multirow{2}{*}{$\begin{array}{l}\text { Doença } \\
\text { de base }\end{array}$} & \multirow{2}{*}{$\begin{array}{l}\text { Tempo pré- } \\
\text { biópsia maior } \\
\text { que } 7 \text { dias }\end{array}$} & \multicolumn{4}{|c|}{ Sobrevida hospitalar } & \multirow{2}{*}{\multicolumn{2}{|c|}{ Total }} \\
\hline & & \multicolumn{2}{|c|}{ Não } & \multicolumn{2}{|c|}{ Sim } & & \\
\hline & Não & & & 6 & $(100)$ & 6 & (100) \\
\hline \multirow[t]{3}{*}{ Ausência } & Sim & 3 & (33) & 6 & (67) & 9 & (100) \\
\hline & Total & 3 & (20) & 12 & (80) & 15 & (100) \\
\hline & Não & 5 & (63) & 3 & (38) & 8 & (100) \\
\hline \multirow[t]{2}{*}{ Presença } & Sim & 24 & (60) & 16 & (40) & 40 & $(100)$ \\
\hline & Total & 29 & (60) & 19 & (40) & 48 & (100) \\
\hline
\end{tabular}

* valores entre parênteses representam percentuais 
Tabela 4.30: Distribuição da sobrevivência segundo o quadro clínico e ou gasométrico de insuficiência respiratória aguda e o sexo

\begin{tabular}{|c|c|c|c|c|c|c|c|}
\hline \multirow{3}{*}{$\begin{array}{c}\text { Quadro clínico e ou } \\
\text { gasométrico de } \\
\text { insuficiência } \\
\text { respiratória aguda }\end{array}$} & \multirow{2}{*}{ Sexo } & \multicolumn{4}{|c|}{ Sobrevivência } & \multirow{2}{*}{\multicolumn{2}{|c|}{ Total }} \\
\hline & & \multicolumn{2}{|c|}{ Não } & \multicolumn{2}{|c|}{ Sim } & & \\
\hline & Masculino & 2 & (33) & 4 & (67) & 6 & (100) \\
\hline \multirow[t]{2}{*}{ Não } & Feminino & 1 & (25) & 3 & (75) & 4 & (100) \\
\hline & Total & 3 & (30) & 7 & (70) & 10 & (100) \\
\hline Sim & Masculino & 15 & (75) & 5 & (25) & 20 & (100) \\
\hline
\end{tabular}

* valores entre parênteses representam percentuais

Tabela 4.31: Distribuição da sobrevida hospitalar segundo a concordância entre os diagnósticos clínico e de biópsia e a presença de doença sistêmica de base

\begin{tabular}{|c|c|c|c|c|c|c|c|}
\hline \multirow{3}{*}{$\begin{array}{c}\begin{array}{c}\text { Concordância entre } \\
\text { diagnósticos clínico } \\
\text { e de biópsia }\end{array} \\
\text { Ausência }\end{array}$} & \multirow{3}{*}{$\begin{array}{c}\begin{array}{c}\text { Doença de } \\
\text { base }\end{array} \\
\text { Ausência }\end{array}$} & \multicolumn{4}{|c|}{ Sobrevida hospitalar } & \multirow{2}{*}{\multicolumn{2}{|c|}{ Total }} \\
\hline & & \multicolumn{2}{|c|}{ Não } & \multicolumn{2}{|c|}{ Sim } & & \\
\hline & & 2 & (14) & 12 & (86) & 14 & $(100)$ \\
\hline & Presença & 16 & (50) & 16 & $(50)$ & 32 & $(100)$ \\
\hline & Total & 18 & (39) & 28 & (61) & 46 & (100) \\
\hline \multirow[t]{3}{*}{ Presença } & Ausência & 4 & (50) & 4 & (50) & 8 & (100) \\
\hline & Presença & 18 & (53) & 16 & $(47)$ & 34 & (100) \\
\hline & Total & 22 & (52) & 20 & (48) & 42 & (100) \\
\hline
\end{tabular}

${ }^{\text {* } v a l o r e s ~ e n t r e ~ p a r e ̂ n t e s e s ~ r e p r e s e n t a m ~ p e r c e n t u a i s ~}$ 
Tabela 4.32: Distribuição da sobrevida hospitalar segundo a presença de dano alveolar difuso na biópsia e a presença de doença sistêmica de base

\begin{tabular}{|c|c|c|c|c|c|c|c|}
\hline \multirow{3}{*}{$\begin{array}{c}\begin{array}{c}\text { Dano alveolar difuso } \\
\text { na biópsia }\end{array} \\
\text { Ausência }\end{array}$} & \multirow{3}{*}{$\begin{array}{c}\begin{array}{c}\text { Doença de } \\
\text { base }\end{array} \\
\text { Ausência }\end{array}$} & \multicolumn{4}{|c|}{ Sobrevida hospitalar } & \multirow{2}{*}{\multicolumn{2}{|c|}{ Total }} \\
\hline & & \multicolumn{2}{|c|}{ Não } & \multicolumn{2}{|c|}{ Sim } & & \\
\hline & & 1 & (13) & 7 & (88) & 8 & $(100)$ \\
\hline & Presença & 2 & (29) & 5 & (71) & 7 & (100) \\
\hline & Total & 3 & (20) & 12 & $(80)$ & 15 & (100) \\
\hline \multirow[t]{3}{*}{ Presença } & Ausência & 9 & (39) & 14 & (61) & 23 & $(100)$ \\
\hline & Presença & 20 & (80) & 5 & (20) & 25 & (100) \\
\hline & Total & 29 & (60) & 19 & (40) & 48 & (100) \\
\hline
\end{tabular}

* valores entre parênteses representam percentuais

Tabela 4.33: Distribuição da sobrevida hospitalar segundo a presença de dano alveolar difuso na biópsia e a presença de quadro clínico e ou gasométrico de insuficiência respiratória

\begin{tabular}{|c|c|c|c|c|c|c|c|}
\hline \multirow{3}{*}{$\begin{array}{c}\text { Quadro clínico e ou } \\
\text { gasométrico de } \\
\text { insuficiência } \\
\text { respiratória aguda }\end{array}$} & \multirow{2}{*}{$\begin{array}{c}\text { Dano alveolar } \\
\text { difuso na biópsia }\end{array}$} & \multicolumn{4}{|c|}{ Sobrevida hospitalar } & \multirow{2}{*}{\multicolumn{2}{|c|}{ Total }} \\
\hline & & \multicolumn{2}{|c|}{ Não } & \multicolumn{2}{|c|}{$\operatorname{Sim}$} & & \\
\hline & Ausência & & & 5 & $(100)$ & 5 & $(100)$ \\
\hline \multirow[t]{3}{*}{ Não } & Presença & 3 & (60) & 2 & $(40)$ & 5 & (100) \\
\hline & Total & 3 & (30) & 7 & (70) & 10 & (100) \\
\hline & Ausência & 7 & (41) & 10 & (59) & 17 & (100) \\
\hline \multirow[t]{2}{*}{ Sim } & Presença & 18 & (75) & 6 & (25) & 24 & (100) \\
\hline & Total & 25 & (61) & 16 & (39) & 41 & (100) \\
\hline
\end{tabular}

* valores entre parênteses representam percentuais 
Tabela 4.34: Distribuição da sobrevida hospitalar segundo a presença de quadro clínico e ou gasométrico de insuficiência respiratória e a presença de doença sistêmica de base

\begin{tabular}{ccccccccc}
\hline $\begin{array}{c}\text { Quadro clínico e ou } \\
\text { gasométrico de } \\
\text { insuficiência } \\
\text { respiratória }\end{array}$ & $\begin{array}{c}\text { Doença de } \\
\text { base }\end{array}$ & \multicolumn{2}{c}{ Sobrevida hospitalar } & \multirow{2}{*}{ Total } \\
\cline { 2 - 7 } & Ausência & 1 & $(33)$ & 2 & $(67)$ & 3 & $(100)$ \\
\hline Não & Não & \multicolumn{2}{c}{ Sim } & & \\
& Presença & 2 & $(29)$ & 5 & $(71)$ & 7 & $(100)$ \\
\cline { 2 - 7 } & Total & 3 & $(30)$ & 7 & $(70)$ & 10 & $(100)$ \\
\hline \multirow{2}{*}{ Sim } & Ausência & 1 & $(14)$ & 6 & $(86)$ & 7 & $(100)$ \\
& Presença & 24 & $(71)$ & 10 & $(29)$ & 34 & $(100)$ \\
\cline { 2 - 6 } & Total & 25 & $(61)$ & 16 & $(39)$ & 41 & $(100)$ \\
\hline
\end{tabular}

${ }^{*}$ valores entre parênteses representam percentuais

\subsection{COMPARAÇÃO ENTRE ANÁLISES HISTOPATOLÓGICAS DE BIÓPSIA E DE NECRÓPSIA}

Os "índices" histopatológicos para espécimes pulmonares obtidos através de autópsia foram calculados da mesma forma que para as biópsias. Convém ressaltar que somente 25 dos 63 indivíduos foram submetidos a autópsia. Em um destes casos não foi possível obter-se informações do interstício periférico, em outro, das arteríolas pós-acinares e dos bronquíolos respiratórios e em um terceiro, dos bronquíolos respiratórios. Além disso, em 6 
das 24 autópsias, os valores dos bronquíolos respiratórios foram descartados em virtude da ampla modificação do parênquima pulmonar.

Os índices histopatológicos podem ser contemplados na Tabela 4.35, onde se verifica o aumento médio para o "índice agudo", mas não para o "índice crônico", também ilustrados claramente no Gráfico 4.1.

Tabela 4.35: Medidas-resumo da diferença entre a biópsia e a autópsia dos "índices" crônico e agudo

\begin{tabular}{ccc}
\hline \multirow{2}{*}{ Estatísticas } & \multicolumn{2}{c}{ Diferença (biópsia - autópsia) } \\
\cline { 2 - 3 } & Crônico & Agudo \\
\hline $\mathrm{N}$ & 25,00 & 25,00 \\
Média & $-0,16$ & $-1,51$ \\
Desvio-padrão & 1,44 & 2,13 \\
Mediana & $-0,14$ & $-1,88$ \\
Mínimo & $-3,23$ & $-5,42$ \\
Máximo & 2,50 & 2,63 \\
Erro-padrão & 0,29 & 0,43 \\
\hline
\end{tabular}


Gráfico 4.1: Box-plots dos "índices” para autópsia e biópsia

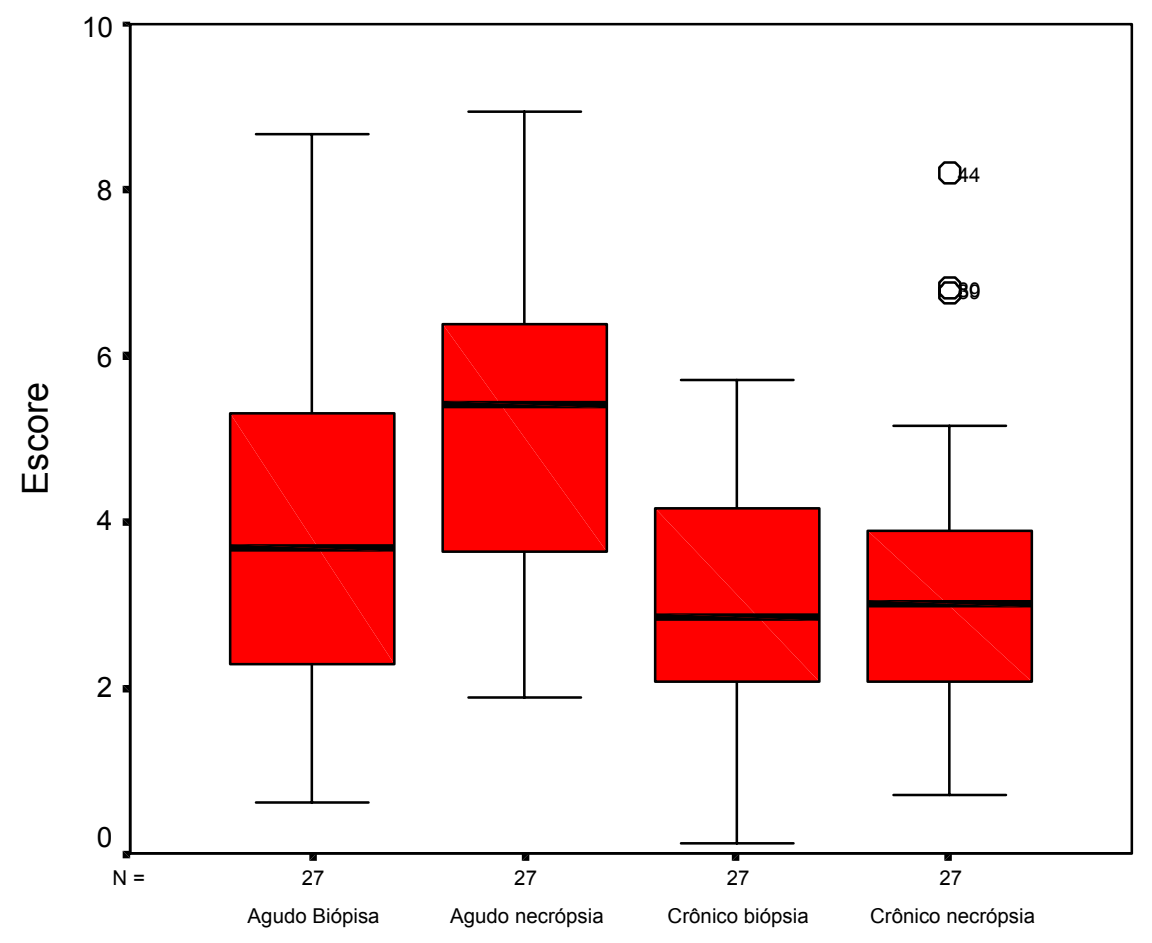

\subsection{ANÁLISE INFERENCIAL}

\subsubsection{ASSOCIAÇÃO DAS VARIÁVEIS COM A SOBREVIDA} HOSPITALAR

Para se estudar a associação das variáveis com a sobrevida hospitalar, utilizou-se o modelo de regressão logística (HOSMER e LEMESHOW 1989). O modelo é apresentado na Tabela 4.36. Foi observada significância estatística em relação ao sexo, dano alveolar difuso na biópsia, comorbidade e "índice 
crônico". Mantidas as demais variáveis constantes, é possível concluir que o risco de óbito foi 6 vezes maior para o sexo masculino em relação ao feminino $(p=0.04)$. A presença na biópsia de dano alveolar difuso aumenta 33 vezes o risco de óbito $(p<0,01)$, enquanto que na presença de comorbidade o risco eleva-se 25 vezes $(p<0,01)$. Em relação ao "índice crônico" foi observado que a cada aumento em uma unidade, o risco de óbito diminui 3 vezes $(p<0,01)$.

Tabela 4.36: Modelo de regressão logística

\begin{tabular}{|c|c|c|c|c|c|c|}
\hline \multirow{2}{*}{ Variáveis } & \multirow{2}{*}{ Coeficiente } & \multirow{2}{*}{$\begin{array}{l}\text { Erro- } \\
\text { padrão }\end{array}$} & \multirow{2}{*}{$p$} & \multirow[t]{2}{*}{ R.C.* } & \multicolumn{2}{|c|}{$\begin{array}{c}\text { Intervalo de Confiança } \\
(95 \%)\end{array}$} \\
\hline & & & & & $\begin{array}{l}\text { Limite } \\
\text { inferior }\end{array}$ & $\begin{array}{l}\text { Limite } \\
\text { superior }\end{array}$ \\
\hline Sexo Feminino & 1,82 & 0,88 & 0,04 & 6,16 & 1,09 & 34,88 \\
\hline $\begin{array}{l}\text { Dano alveolar } \\
\text { difuso }\end{array}$ & $-3,36$ & 1,04 & 0,00 & 0,03 & 0,00 & 0,27 \\
\hline Doença de base & $-3,34$ & 1,08 & 0,00 & 0,04 & 0,00 & 0,29 \\
\hline Índice crônico & 1,10 & 0,30 & 0,00 & 3,01 & 1,67 & 5,43 \\
\hline
\end{tabular}

\subsubsection{COMPARAÇÃO ENTRE ANÁLISES HISTOPATOLÓGICAS} DE BIÓPSIA E DE NECRÓPSIA

Para a comparação entre os "índices histopatológicos" de biópsia e de autópsia foi utilizado um teste "t" de Student pareado, resultando em diferença estatisticamente significante $(p=0,002)$ apenas para o "índice agudo" cujo 
aumento médio foi de 1,5 unidade na autópsia em relação à biópsia (Tabela 4.37).

Tabela 4.37: Teste t pareado para comparação dos "índices agudo e crônico"

\begin{tabular}{|c|c|c|c|c|c|c|}
\hline \multirow{2}{*}{ Índice } & \multirow{2}{*}{$\begin{array}{c}\text { Diferença média } \\
\text { (biópsia - } \\
\text { autópsia) }\end{array}$} & \multirow{2}{*}{$\begin{array}{l}\text { Desvio- } \\
\text { padrão }\end{array}$} & \multirow{2}{*}{$\begin{array}{c}\text { Erro- } \\
\text { padrão }\end{array}$} & \multirow{2}{*}{$p$} & \multicolumn{2}{|c|}{$\begin{array}{c}\text { Intervalo de Confiança } \\
(95 \%)\end{array}$} \\
\hline & & & & & $\begin{array}{c}\text { Limite } \\
\text { inferior } \\
\end{array}$ & $\begin{array}{c}\text { Limite } \\
\text { superior }\end{array}$ \\
\hline Crônico & $-0,16$ & 1,44 & 0,29 & 0,58 & $-0,75$ & 0,43 \\
\hline Agudo & $-1,51$ & 2,13 & 0,43 & 0,00 & $-2,39$ & $-0,63$ \\
\hline
\end{tabular}




\section{DISCUSSÃO}

Os mais diversos aspectos da biópsia pulmonar cirúrgica têm sido extensamente explorados desde a década de 1960, quando duas importantes casuísticas foram publicadas (GAENSLER e col. 1964; KLASSEN e ANDREWS 1967). Ao longo de quase quatro décadas, tal procedimento diagnóstico vem sendo utilizado e estudado de forma crescente nas mais diversas populações: crianças (BOUSSO e col. 1987; FAN e col. 1997) e adultos; pacientes cronicamente enfermos (WALL e col. 1981; BLEWETT e col. 2001) e também aqueles com quadros agudos (FLABOURIS e MYBURGH 1999; PATEL e col. 2004); além de populações imunocompetentes contrastando com imunocomprometidas, seja em virtude de corticoterapia (WALTZER e col. 1980; WEILL e col. 2000), de neoplasia (MCCABE e col. 1985) ou da síndrome da imunodeficiência adquirida (SIDA) (MILLER e col. 1995). Contudo, controvérsias ainda existem a respeito da influência de um diagnóstico específico sobre a mortalidade, principalmente em casos com algum grau de debilidade imunológica (POTTER e col. 1985; HAVERKOS e col. 1983; JAFFE e MAKI 1981; ROSSITER e col. 1979; BOVE e col. 1994).

Ainda hoje, o papel da biópsia pulmonar cirúrgica no tratamento da síndrome da angústia respiratória do adulto (SARA) permanece obscuro. Ainda que revele certa homogeneidade clínica, a SARA pode originar-se de diferentes etiologias como pneumonias infecciosas, pneumonia organizante (OP), 
pneumonia aguda eosinofílica e capilarites pulmonares e, dessa forma, ser tratada de diferentes maneiras (PATEL e col. 2004).

CANVER e MENTZER (1994) estudaram 27 pacientes, entre crianças e adultos, sob suporte ventilatório e demonstraram que gênero, idade, número de dias em ventilação mecânica anteriormente à realização da biópsia e após a instituição do tratamento não influenciaram a sobrevida. Tais dados contrastam com os de WARNER e col. (1988), mostrando que menor taxa de sobrevida está relacionada à faixas etárias relativamente mais baixas e à necessidade de ventilação mecânica pré-operatória. A sobrevida não se mostrou relacionada ao estabelecimento de um diagnóstico específico ou a alterações na terapêutica.

Em 1986, POE e col. realizaram estudo com 99 pacientes, contabilizando 104 biópsias, em que foram abordados eventuais fatores preditivos de mortalidade em pacientes imunocomprometidos com infiltrados pulmonares difusos. Foram estudadas as conseqüências da idade avançada, doença primária, febre, neutropenia, corticoterapia imunossupressora, radiação pulmonar prévia, padrão radiológico, resultado da biópsia pulmonar cirúrgica, $\mathrm{PaO}_{2}$, utilização precoce de ventilação mecânica e presença de comorbidade. Concluiu-se que hipóxia, imunossupressão por corticoterapia e a utilização de ventilação mecânica nas 72 horas iniciais são fatores indicativos de mau prognóstico.

Embora tenham incluído apenas biópsias transbrônquicas em seu estudo, MARTIN e col. (1995) sugeriram que a presença de fibrose em 
espécimes pulmonares é um marcador de mau prognóstico em pacientes com SARA.

PAPAZIAN e col. (1998) mostraram que a biópsia pulmonar cirúrgica é uma técnica segura e útil em pacientes com SARA, em ventilação de suporte, freqüentemente mostrando um diagnóstico que não fora previamente suspeitado e fornecendo valiosa informação para que seja excluída uma infecção pulmonar como uma importante e contínua causa de angústia respiratória. Este conhecimento leva à instituição de terapêutica específica, assim como a descontinuidade de terapêuticas desnecessárias e potencialmente nocivas (PATEL e col. 2004).

Grande ênfase tem sido dada às implicações clínicas da biópsia pulmonar cirúrgica, principalmente quanto a sua contribuição em alterações no prognóstico, através de mudanças na terapêutica, mas também quanto a sua morbimortalidade.

Uma vez que nosso interesse primordial sempre esteve relacionado a uma abordagem predominantemente histopatológica dos espécimes obtidos através de tal procedimento, buscamos abordagens similares em literatura correlata. Surpreendentemente, foram raros os trabalhos encontrados em que a análise histológica ultrapassara o âmbito diagnóstico, sempre utilizada como "padrão ouro" para as hipóteses clínicas no estudo de infiltrados pulmonares difusos (FLABOURIS e MYBURGH 1999). Embora seja sempre cientificamente enriquecedora a multiplicidade de estudos com abordagens similares, permitindo a comparação e a confirmação de resultados, a ausência de estudos 
detalhados de alterações histopatológicas na biópsia pulmonar cirúrgica na literatura foi um incentivo a mais ao nosso projeto.

Acreditamos que muitas das manifestações clínicas ou radiológicas dos pulmões são reflexos de alterações teciduais muitas vezes tão discretas e precoces que podem passar despercebidas em análises com finalidade puramente diagnóstica. Dessa forma, parece-nos de fundamental importância saber se dados adicionais colhidos da clínica e ou da análise histopatológica poderiam auxiliar-nos na identificação do prognóstico através da análise de espécimes pulmonares obtidos através de biópsia cirúrgica. A patologia pulmonar indubitavelmente compreende uma série de reações estereotipadas complexas, dificultando o diagnóstico diferencial baseado somente em abordagens qualitativas. Entretanto, avaliações semiquantitativas podem facilitar a criação de modelos matemáticos que auxiliem na previsão do prognóstico. Em diferentes condições, especialmente em doenças difusas do parênquima pulmonar, sistemas de escores para avaliações quantitativas têm sido utilizados na orientação ou avaliação da terapêutica e do prognóstico (CHERNIACK e col. 1991; HYDE e col. 1992; KING e col. 2001b). No estudo de GAENSLER e CARRINGTON (1980), alterações histológicas em biópsias cirúrgicas de pacientes com infiltrados pulmonares crônicos difusos foram graduadas de acordo com a similitude que guardavam com quadros histopatológicos clássicos. .

Não seria ilógico supor que a avaliação detalhada de biópsias pulmonares cirúrgicas, subdividida de acordo com os diferentes compartimentos 
histológicos, em que alterações são classificadas de acordo com seu caráter agudo ou crônico e semiquantificadas através de um sistema de escores, possa fornecer significativa contribuição prognóstica.

Nesse sentido, o presente estudo procurou detalhar e agrupar as alterações histopatológicas obtidas na biópsia pulmonar cirúrgica, com a finalidade de formular um sistema de escores eficiente que auxiliaria o clínico no diagnóstico e prognóstico de adultos portadores de infiltrados difusos aos exames de imagem, que freqüentemente impõem importantes desafios terapêuticos.

Ainda que tenhamos procurado restringir os critérios de inclusão, os casos selecionados para este estudo apresentam certa heterogeneidade em relação ao caráter evolutivo e ao prognóstico, uma vez que, como fora previamente referido, o padrão de infiltrado difuso pode ser observado nas mais diversas doenças pulmonares. Ainda assim, tal quadro geralmente reflete certa gravidade, indicando a necessidade de intervenção. Infiltrados pulmonares difusos são habitualmente não somente um desafio diagnóstico, mas também o padrão nosológico pulmonar mais severo, quando comparado a quadros focais e nodulares (BOVE e col. 1994).

Além da própria formulação e validação de um sistema de escore histopatológico pulmonar, nossa proposta incluiu um estudo de correlação entre os achados histopatológicos e a evolução final (alta ou óbito) destes pacientes, além da relação entre o sistema de escore histopatológico pulmonar e diferentes variáveis epidemiológicas. 
Dentre as diversas variáveis epidemiológicas inicialmente levantadas, o "tempo de internação" e o "tempo de internação pós-biópsia" foram excluídos da análise estatística por se tratarem de conseqüências das variáveis iniciais, obtidas no momento em que o evento teve início, ou seja, a biópsia foi realizada.

Como previamente demonstrado, o presente estudo foi didaticamente dividido em duas partes principais: a análise descritiva e a análise inferencial. A análise descritiva foi, por sua vez, subdividida em: "descrição da amostra", "concordância entre os diagnósticos", "relações das variáveis com a sobrevida hospitalar" e "comparação entre biópsia e autópsia". Vale ressaltar que os dados apresentados nesta fase do estudo, e que serão discutidos a seguir, simplesmente refletem tendências restritas ao âmbito de nossa população de estudo, não podendo dessa forma serem extrapoladas para a população em geral. A análise descritiva permitiu a seleção de variáveis cuja associação estatisticamente significante com a sobrevida hospitalar foi analisada através do modelo de regressão logística.

Embora se tenha dado ênfase à classificação diagnóstica "agregada" por razões estatísticas, é logicamente a classificação "não agregada" que se mostra mais fidedigna no estudo de concordância entre diagnósticos. Considerando-se a categorização por nós utilizada, nossos dados são similares aos de literatura (NELEMS e col. 1976; WARNER e col. 1988; NEUHAUS e MATTAR 1997; KRAMER e col. 1998), mostrando confirmação de $48 \%$ dos diagnósticos clínicos através da biópsia. O baixo percentual de confirmação histológica do 
diagnóstico clínico de pneumonia infecciosa poderia ser explicado por eventual instituição precoce de terapêutica antimicrobiana, mascarando achados em biópsia. Em pacientes com resultados microbiológicos negativos e quadro clínico mimetizando uma pneumonia nosocomial, a diferenciação entre uma verdadeira infecção e uma resposta inflamatória é dificultada (PAPAZIAN e col. 1998). Infecções bacterianas dos pulmões são habitualmente subdiagnosticadas através da biópsia pulmonar cirúrgica, ao contrário de infecções virais e de quadros organizados exibindo fibrose, mais facilmente diagnosticados em virtude de sua menor heterogeneidade (PAPAZIAN e col. 1998).

A maior parte de nossos diagnósticos consistiu de doenças de vias aéreas e de pneumopatias intersticiais, em igual proporção, seguindo-se de pneumopatias infecciosas, de doenças granulomatosas não infecciosas e de distúrbios circulatórios, o que difere de grande parte de outras casuísticas, cujo quadro mais freqüentemente observado é a fibrose pulmonar (pneumonia intersticial usual) (GAENSLER e CARRINGTON 1980; VENN e col. 1985; SHAH e col. 1992; BOVE e col. 1993; BLEWETT e col. 2001).

Os efeitos da precocidade da realização da biópsia pulmonar cirúrgica sobre a evolução da doença não está claramente definido. ROSSITER e col. (1979), WALKER e col.(1989) e PATEL e col. (2004) sugeriram que a precocidade de sua realização acarretaria uma melhor taxa de sobrevida, principalmente em pacientes imunocomprometidos (ROSSITER e col. 1979). Por outro lado, BOVE e col. (1994) não observaram diferença significativa na 
sobrevida entre grupos em que a biópsia pulmonar cirúrgica foi realizada com diferentes tempos de evolução. POTTER e col. (1985) demonstraram que a realização precoce do referido procedimento em pacientes com câncer, submetidos a quimioterapia e apresentando quadro de infiltrado pulmonar difuso agudo está relacionada a maior morbidade quando comparada à antibioticoterapia empírica.

Nossos dados sugerem que, em um período de até 20 dias, quanto maior o tempo decorrido entre a internação e a realização da biópsia, maior a possibilidade de discordância entre os diagnósticos clínico e histopatológico. Tal fato pode ser, na verdade, um reflexo da dificuldade em se estabelecer o diagnóstico clínico preciso em casos de evolução clínica mais arrastada, em que a biópsia é postergada. Por outro lado, o aumento da concordância observado em períodos maiores do que 20 dias poderia estar refletindo a incapacidade do exame histopatológico em fornecer novos dados após períodos de evolução relativamente mais longos.

A variável "sexo" foi uma das mais importantes de nosso estudo, como constatado pela regressão logística. Amplo predomínio de sobrevida hospitalar do sexo feminino em relação ao sexo masculino foi observado. Além disso, nossos dados apontam para a influência negativa dos quadros de dano alveolar difuso e de insuficiência respiratória, principalmente em homens, e dos quadros de comorbidade principalmente em mulheres.

É de amplo conhecimento que a presença de doenças sistêmicas de origem não pulmonar pode influenciar negativamente na evolução de uma 
pneumopatia e que o quadro de dano alveolar difuso está diretamente relacionado a gravidade clínica. O presente estudo propiciou importantes dados quantitativos referentes a tais parâmetros, mostrando que o risco de óbito é 33 vezes maior na presença de dano alveolar difuso e 25 vezes maior na presença de comorbidade sistêmica em relação a ausência de tais fatores. Haveria provavelmente tendência ainda maior de risco na concomitância de ambos. Dados de literatura sugerem que a mortalidade de pacientes submetidos a biópsia pulmonar cirúrgica depende muito mais da severidade da doença de base e não propriamente de complicações do procedimento (NELEMS e col. 1976; LEIGHT e MICHAELIS. 1978; HIATT e col. 1982; CHESON e col. 1985;).

A constatação estatística que talvez tenha mais bem satisfeito nossos objetivos iniciais foi a significância atingida pelo parâmetro de semiquantificação de alterações histológicas, mais especificamente, o chamado "índice crônico". Entretanto, surpreende-nos resultados que mostraram uma relação de proporcionalidade inversa entre o "índice crônico" e a sobrevida hospitalar. Dessa forma, maior sobrevida relaciona-se ao acréscimo do referido "índice", quando se supunha o contrário, já que o mesmo reflete alterações teciduais de longo período evolutivo. Tal aparente paradoxo poderia ser explicado ao se considerar que pacientes com "índice crônico" elevado são portadores de pneumopatias crônicas, por vezes com acentuada alteração estrutural, não apresentando, no entanto, quadro iminente de óbito durante a internação em que a biópsia foi realizada. Outra possível explicação para tal discrepância estaria em problemas de amostragem, em que o material coletado constitui-se 
de área severamente alterada do parênquima, porém pouco representativa da totalidade dos pulmões.Foi também demonstrada uma tendência de elevação do "índice agudo" diretamente proporcional ao percentual de óbito, além de dados indicativos de possível interação entre os "índices" agudo e crônico. É provável que estudos prospectivos mais amplos, com maior casuística, venham confirmar a factibilidade, a utilidade e a reprodutibilidade deste sistema de escores histopatológicos, podendo vir a aperfeiçoá-lo.

Em relação à concordância entre os diagnósticos clínico e de biópsia, nossos dados fornecem indicações de que o maior percentual de sobrevida observado para os casos em que os diagnósticos se averiguaram discordantes pode ser um indicador de sucesso, não somente pela introdução de terapêutica adequada propiciada pelo diagnóstico histopatológico, mas também de possível interrupção de eventual terapêutica ineficaz.

Embora não se tenha alcançado significância estatística, nossos dados indicam uma menor taxa de sobrevida associada à presença de fatores que contribuam para debilidade imunológica, corroborando dados da literatura (SHAH e col. 1992; BOVE e col. 1993; KRAMER e col. 1998).

Nenhuma variação na sobrevida hospitalar em relação aos diferentes grupos etários foi evidenciada.

Ainda que o presente estudo não tenha priorizado a abordagem epidemiológica do tema, tal qual vem sendo brilhantemente explorado por extensa literatura, cabem aqui considerações relativas a itens freqüentemente abordados. 


\subsection{MORTALIDADE}

A maior parte dos trabalhos refere-se à mortalidade intra-hospitalar nos primeiros 30 dias após a realização da biópsia, considerando ser este o período crítico em que o óbito possa estar relacionado ao procedimento (GAENSLER e CARRINGTON 1980). Considera-se que pacientes que permanecem vivos pelos primeiros 30 dias pós-biópsia, permanecem vivos e em bom estado geral por período maior do que 2 anos (CANVER e MENTZER 1994).

Em nosso estudo o óbito ocorreu em 32 pacientes (aproximadamente $51 \%$ ), a maior parte nos 30 primeiros dias que se sucederam ao procedimento (28 casos, perfazendo aproximadamente $44 \%$ da casuística e $87,5 \%$ do total de óbitos). Uma vez que nossa população constituiu-se de pacientes com quadros agudos e pacientes com quadros crônicos, muitas vezes em surto agudo, foi observada uma grande variação do tempo total de internação e de sua relação com a sobrevida hospitalar. Isto poderia explicar uma taxa de sobrevida relativamente mais alta por nós observada (aproximadamente 49\%), quando comparada à literatura sobre SARA (WARNER e col. 1988; FLABOURIS e MYBURGH 1999; PATEL e col. 2004).

Observa-se na literatura uma nítida diferença entre casuísticas constituídas em sua totalidade ou predominantemente por quadros agudos em relação a outras em que o percentual deste tipo de paciente é menor. Ainda que nosso percentual possa ser considerado elevado, deve-se ressaltar que $52 \%$ dos pacientes por nós estudados eram imunocomprometidos e $80 \%$ 
apresentavam insuficiência respiratória; aproximadamente $61 \%$ dos pacientes de cada um destes grupos evoluíram para o óbito. Tais índices são comparáveis a percentuais de 50\% (WAGNER e col. 1992; PAPAZIAN e col. 1998), 53\% (PATEL e col. 2004), 67\% (FLABOURIS e MYBURGH 1999) e $70 \%$ (WARNER e col. 1988) para populações similares.

Como previamente relatado (WARNER e col. 1988; WALKER e col. 1989 WAGNER e col. 1992), em pacientes agudos e ou imunossuprimidos de nossa casuística a mortalidade esteve mais freqüentemente associada à severidade do quadro de base do indivíduo e não a complicações do procedimento.

LOCICERO e SHIELDS (1994) compararam biópsias pulmonares cirúrgicas realizadas em pacientes HIV positivos e negativos, concluindo que o maior fator preditivo para mortalidade relacionada ao referido procedimento foi o "status" ventilatório do indivíduo.

\subsection{COMPLICAÇÕES}

A avaliação do impacto das complicações pós-operatórias da biópsia pulmonar cirúrgica na evolução dos pacientes deveria ser realizada através de comparação com grupo controle não submetido ao procedimento, como o estudo realizado por POTTER e col. (1985).

Assim como ocorre em relação a mortalidade, o percentual de complicações perioperatórias também varia muito de acordo com a população 
estudada. A maior parte dos estudos publicados referem complicações consideradas "menores", ou seja, de pequena gravidade, sendo raras as menções a complicações importantes, principalmente porque a biópsia pulmonar cirúrgica não afeta de forma significativa a hemodinâmica e nem a fisiologia das trocas gasosas (PATEL e col. 2004).

Há quase trinta anos, em uma das maiores e mais heterogêneas casuísticas já publicadas sobre o tema, RAY e col. (1976) encontraram um elevado percentual de complicações (49\%). No entanto, à sua exceção, são em geral os estudos relacionados a pacientes graves que apresentam as maiores taxas de complicações, como relatado nos estudos de CANVER e MENTZER (1994) e de FLABOURIS e MYBURGH (1999), que incluíram pacientes submetidos a ventilação mecânica, com valores respectivos de $39 \%$ e $40 \%$, sendo o escape de ar prolongado a complicação mais freqüente. De acordo com NEUHAUS e MATTAR (1997), pacientes com função pulmonar diminuída (VEF1 diminuído) apresentaram maior risco para a ocorrência de evento mórbido, porém não observaram correlação entre óbito e "status" ventilatório.

Embora a discussão de tal dado se mostre prejudicada em nossa casuística em virtude do relativamente pequeno número de casos sobre os quais obtivemos informações sobre complicações, o percentual observado de aproximadamente $15 \%$, representado por quadros de pequena gravidade, é comparável a populações similares (CHESON e col. 1985; WALKER e col. 1989; BOVE e col. 1994; PAPAZIAN e col. 1998). 


\subsection{ALTERAÇÕES NA TERAPÊUTICA}

Embora o presente estudo não tenha sido focado em abordagens terapêuticas, o resultado da análise histológica revelou um elevado percentual de casos cujo diagnóstico foi mudado após a realização da biópsia (52\%), o que poderia resultar em alterações na terapêutica.

Foi previamente demonstrado que a biópsia pulmonar cirúrgica pode ser realizada com morbidade relativamente baixa e freqüentemente promove mudanças no tratamento (ROSSITER e col. 1979; WALKER e col. 1989; CANVER e MENTZER 1994; KRAMER e col. 1998; PATEL e col. 2004).

THOMAS e col. (1987) realizaram estudo com 46 pacientes imunocomprometidos (portadores de doenças hematológicas, pacientes submetidos a tratamento quimioterápico e pacientes submetidos a corticoterapia) que apresentavam quadro de infiltrado pulmonar difuso e que foram submetidos a biópsia pulmonar cirúrgica. A terapêutica foi alterada em $59 \%$ dos pacientes, sendo que $40 \%$ respondeu ao tratamento. A sobrevida de um ano foi de $41 \%$. Quarenta e oito por cento $(48 \%)$ dos pacientes em que a terapêutica foi alterada sobreviveu por um ano, comparado a $31 \%$ dos pacientes que não tiveram a terapêutica alterada e sobreviveram igualmente por um ano.

Os benefícios propiciados pela biópsia pulmonar cirúrgica a pacientes imunocompetentes são relativamente menores, uma vez que a gama terapêutica utilizada em tais abordagens é mais restrita, sendo muitas vezes 
representada pela corticoterapia. Já na presença de imunocomprometimento as alterações na terapêutica são mais freqüentes, ainda que a mortalidade seja elevada. Dessa forma, a biópsia pulmonar cirúrgica deveria ser utilizada principalmente em casos em que o diagnóstico histopatológico tenha maior probabilidade de levar a alterações na terapêutica e em que a doença de base tenha um prognóstico relativamente favorável (KRAMER e col. 1998).

\subsection{ACURÁCIA DIAGNÓSTICA E DIAGNÓSTICO ESPECÍFICO}

Embora a biópsia pulmonar cirúrgica seja considerada como o padrãoouro dentre os mais diversos métodos diagnósticos em grande parte das doenças pulmonares, definições a respeito do termo "diagnóstico específico" e do termo "produto diagnóstico" são freqüentemente obscuras na literatura e uma grande variabilidade é observada (WAGNER e col. 1992; CANVER e MENTZER 1994; KRAMER e col. 1998; FLABOURIS e MYBURGH 1999).

A acurácia diagnóstica do procedimento deveria ser utilizada como parâmetro de comparação entre diferentes séries e métodos. No entanto, a própria "acurácia" nem sempre é claramente definida. A proporção de diagnósticos não específicos de uma casuística parece estar relacionada, em grande parte, à maneira como os casos são selecionados, do rigor dos critérios diagnósticos do patologista, mas também da correlação dos achados histopatológicos com dados clínicos, laboratoriais e de imagem (GAENSLER e 
CARRINGTON 1980). Em virtude desta grande disparidade entre categorizações diagnósticas e terminológicas entre autores (GAENSLER e col. 1964; KLASSEN e ANDREWS, 1967; RAY e col. 1976; GAENSLER e CARRINGTON 1980; WALKER e col. 1989; WAGNER e col. 1992), e mesmo entre a terminologia clínica e a histopatológica, decidimos por não abordar a questão da especificidade de forma primordial.

De qualquer forma, a literatura referente a biópsia pulmonar cirúrgica é unânime em apontar uma elevada taxa de obtenção diagnóstica, variando entre 85\% (KRAMER e col. 1998) e 100\% (BOVE e col. 1994).

Em pacientes com doença pulmonar idiopática difusa, dependentes de ventilação mecânica, a probabilidade de se estabelecer o diagnóstico definitivo ou diagnóstico bacteriológico através do uso de métodos não cirúrgicos é pequena. A realização da biópsia pulmonar cirúrgica é um procedimento de alto risco, que, no entanto, pode ser realizado com taxas de morbimortalidade aceitáveis (CANVER e MENTZER 1994).

Em pacientes em situação emergencial, a terapêutica adequada para um caso pode ser bastante nociva para outro. É por esta razão que a severidade de um quadro não pode ser considerada um fator de contra-indicação à realização da biópsia pulmonar cirúrgica (NELEMS e col. 1976). 


\subsection{CONCORDÂNCIA ENTRE ACHADOS HISTOPATOLÓGICOS DE BIÓPSIAS E DE NECRÓPSIAS}

Dados de autópsia de pacientes previamente submetidos a biópsia poderiam trazer dados confiáveis sobre a acurácia da biópsia pulmonar cirúrgica, mas raros estudos têm utilizado informações necroscópicas (CANVER e MENTZER 1994). Em nossa casuística, autópsias foram realizadas em apenas 25 casos (aproximadamente 40\%), confirmando achados de biópsia em aproximadamente $81 \%$.

\subsection{LIMITAÇÕES DO ESTUDO}

Dentre as principais limitações do presente estudo considera-se o próprio tamanho da casuística por nós estudada. Embora não se possa definir um número ideal de casos para semelhante estudo, é provável que uma casuística mais extensa pudesse propiciar maiores conclusões estatisticamente significantes.

Em segundo lugar podemos ressaltar que regras estritas de randomização não foram obedecidas, embora a forma de acesso aos dados tenha permitido certo grau de casualização. Sem uma adequada randomização é impossível concluir se a biópsia pulmonar cirúrgica tem algum efeito na conclusão de um processo terapêutico. Além disso, a ausência de 
randomização não assegura que os pacientes para os quais a biópsia foi indicada façam parte de amostra representativa da população. Porém, ainda que tais fatores possam limitar nossas conclusões, principalmente do ponto de vista clínico, não impedem inferências a respeito da elaboração de um sistema de escore histopatológico para espécimes pulmonares cirúrgicos, uma vez que todos os pacientes estudados apresentavam em comum um quadro de infiltrado difuso ao exame de imagem.

Outro ponto a ser abordado refere-se à natureza retrospectiva do estudo, que não permite avaliar de forma fidedigna se a biópsia pulmonar cirúrgica promove uma significativa alteração da taxa de mortalidade, principalmente fora do âmbito hospitalar, ou da duração da internação.

Embora tenha permitido o tratamento estatístico dos dados, o agregamento de diagnósticos que utilizamos é bastante restrito, não permitindo por vezes a diferenciação entre patologias infecciosas cujos agentes etiológicos e tratamentos são bastante distintos.

Apesar da ênfase de nosso estudo em dados histopatológicos, alterações na terapêutica propiciadas pelo diagnóstico histopatológico, a taxa de complicações tardias do procedimento poderiam ter sido mais bem utilizadas na comparação com estudos prévios.

Os dados relacionados à influência que a comorbidade teria sobre a evolução de tais pacientes mereceria, em especial, novos estudos. Ainda que tenhamos alcançado significância estatística em nosso modelo de regressão logística, grande parte dos pacientes por nós estudados foi atendida no InCor- 
HCFMUSP, instituto especializado em doenças cardiovasculares e que realiza os exames anatomopatológicos do ambulatório de Transplantes de Medula Óssea, contribuindo para um maior número de casos de doenças do sistema hematopoiético. 


\section{CONCLUSÕES}




\section{CONCLUSÕES}

A avaliação detalhada e compartimentalizada de espécimes pulmonares cirúrgicos e de autópsia permite o estabelecimento de um sistema de escores histopatológicos que pode fornecer mais dados do que a avaliação com finalidade puramente classificatória em categorias nosológicas.

O sistema de escores histopatológicos semiquantitativos estabelecido neste estudo permite a comparação estatística de alterações teciduais com dados epidemiológicos e de evolução clínica.

A presença de dano alveolar difuso na amostra tecidual, assim como a presença de comorbidade, são fatores que se correlacionam a uma menor taxa de sobrevida hospitalar.

Novos estudos randomizados prospectivos, com maior casuística, poderiam confirmar e complementar nossas conclusões, validando a avaliação semiquantitativa de espécimes pulmonares através do sistema de escores. Consideramos também de grande importância que tal sistema seja testado em estudos de categorias específicas de doenças pulmonares difusas. 


\section{REFERÊNCIAS}

Andersen HA, Fontana RS. Transbronchoscopic lung biopsy for diffuse pulmonary disease: technique and results in 450 cases. Chest. 1972; 62:125-8.

Ashbaugh DG, Bigelow DB, Petty TL, Levine BE. Acute respiratory distress in adults. Lancet. 1967; 2:319-23.

Ayed AK. Video-assisted thoracoscopic lung biopsy in the diagnosis of diffuse interstitial lung disease. A prospective study. J Cardiovasc Surg (Torino). 2003; 44(1):115-8.

Barroso FC. Estudo da fibrose intersticial pulmonar idiopática. São Paulo, 1994. [Tese de Mestrado - Faculdade de Medicina da Universidade de São Paulo].

Bernard RG, Artigas A, Brigham KL, Carlet J, Falke K, Hudson L e col. The American-European consensus conference on ARDS. Definitions, mechanisms, relevant outcomes, and clinical trial coordination. Am J Respir Crit Care Med. 1994; 149:818-24.

Blewett CJ, Bennett WF, Miller JD, Urschel JD. Open lung biopsy as an outpatient procedure. Ann Thorac Surg. 2001; 71(4):1113-5.

Bousso A, Baldacci ER, Fernandes JC, Fernandes ICO, Cordeiro AMG, Otoch JP e col. Contribuição da biópsia pulmonar cirúrgica na avaliação de pneumopatias difusas e agudas em unidade de terapia intensiva pediátrica. J Pneumol. 1987; 28(1):30-40. 
Bove P, Ranger W, Pursel S, Glover J, Bove K, Bendick P. Evaluation of outcome following open lung biopsy. Am Surg. 1994; 60(8):564-70.

Canver CC, Mentzer RM Jr. The role of open lung biopsy in early and late survival of ventilator-dependent patients with diffuse idiopathic lung disease. J Cardiovasc Surg (Torino). 1994; 35(2):151-5.

Capelozzi VL. Dificuldades na interpretação de biópsias em doenças pulmonares difusas. J Pneumol. 1998; 24(1):30-42.

Carrington C, Gaensler E, Coutu R, Fitzgerald M, Gupta R. Natural history and treated course of usual and desquamative interstitial pneumonia. N Engl J Med.1978; 298:801-9.

Cherniack RM, Colby TV, Flint A, Thurlbeck WM, Waldron J, Ackerson L e col. Quantitative assessment of lung pathology in idiopathic pulmonary fibrosis. Am Rev Respir Dis. 1991; 144(4):892-900.

Cheson BD, Samlowski WE, Tang TT, Spruance SL. Value of open-lung biopsy in 87 immunocompromised patients with pulmonary infiltrates. Cancer. 1985; 55(2):453-9.

Curley FJ, Johal JS, Burke ME, Fraire AE. Transbronchial lung biopsy: can specimen quality be predicted at the time of biopsy? Chest. 1998; 113(4):103741.

Descombes E, Gardiol D, Leuenberger P. Transbronchial lung biopsy: an analysis of 530 cases with reference to the number of samples. Monaldi Arch Chest Dis. 1997; 52(4):324-9. 
Dina R, Sheppard MN. The histological diagnosis of clinically documented cases of cryptogenic organizing pneumonia: diagnostic features in transbronchial biopsies. Histopathology. 1993; 23(6):541-5.

Dreisin RB, Shwarz MI, Theofilopoulos AN, Stanford RE. Circulating immune complex in the idiopatic interstitial pneumonias. N Engl J Med. 1978; 298:353-7.

Drent M, Van Nieerop M, Gerristsen F, Wouters E, Mulder P. A computer program using BALF-analysis results as a diagnostic tool in interstitial lung diseases. Am J Resp Crit Care Med.1996; 153(2):736-41.

Elson CE, Roggli VL, Vollmer RT, Greenberg SD, Fraire AE, Spjut HJ e col. Prognostic indicators for survival in stage I carcinoma of the lung: a histologic study of 47 surgically resected cases. Mod Pathol. 1988; 1(4):288-91.

Fan LL, Kozinetz CA, Wojtczak HA, Chatfield BA, Cohen AH, Rothenberg SS. Diagnostic value of transbronchial, thoracoscopic, and open lung biopsy in immunocompetent children with chronic interstitial lung disease. J Pediatr. 1997; 131(4):565-9.

Fernandez A, Jatene FB, Zamboni M. Diagnosis and staging of lung cancer. J Pneumol. 2002; 28(4):219-28.

Flabouris A, Myburgh J. The utility of open lung biopsy in patients requiring mechanical ventilation. Chest. 1999; 115(3):811-7.

Fraire AE, Cooper SP, Greenberg SD, Rowland LP, Langston C. Transbronchial lung biopsy. Histopathologic and morphometric assessment of diagnostic utility. Chest. 1992; 102:748-52. 
Gaensler EA, Moister MVB, Hamm J. Open-lung biopsy in diffuse pulmonary disease. N Engl J Med. 1964; 270:1319-31.

Gaensler EA, Carrington CB. Open biopsy for chronic diffuse infiltrative lung disease: clinical, roentgenographic, and physiological correlations in 502 patients. Ann Thorac Surg. 1980; 30(5):411-26.

Gay S, Kazerooni EA, Toews GB, Lynch JP 3rd, Gross BH, Cascade PN e col. Idiopathic Pulmonary Fibrosis. Predicting response to therapy and survival. Am J Resp Crit Care Med. 1998; 157(4 Pt 1):1063-72.

Godwin TA. Respiratory system [monograph on line]. Cornell University Medical College. New York; 1995. Available from<URL: http://edcenter.med.cornell.edu/CUMC PathNotes/Respiratory/Respiratory.html $>[2005]$

Grippi MA. Respiratory failure: an overview. In: Fishman AP, Elias JA, Fishman JA, Grippi MA, Kaiser LR, Senior RM, editors. Fishman's pulmonary diseases and disorders. 3rd ed. USA: Mc Graw-Hill; 1998. p. 2525-35.

Gutierrez EB, Zanetta DMT, Saldiva PHN, Capelozzi VL. Autopsy-proven determinants of death in HIV-infected patients treated for pulmonary tuberculosis in Sao Paulo, Brazil. Path Res Pract. 2002; 198:339-46.

Haverkos HW, Dowling JN, Pasculle AW, Myerowitz RL, Lerberg DB, Hakala TR. Diagnosis of pneumonitis in immunocompromised patients by open lung biopsy. Cancer. 1983; 52(6):1093-7.

Hiatt JR, Gong H, Mulder DG, Ramming KP. The value of open lung biopsy in the immunosuppressed patient. Surgery. 1982; 92(2):285-91. 
Hill JD, Ratliff JL, Parrott JC, Lamy M, Fallat RJ, Koeniger E e col. Pulmonary pathology in acute respiratory insufficiency: lung biopsy as a diagnostic tool. $\mathbf{J}$ Thorac Cardiovasc Surg. 1976; 71(1):64-71.

Hosmer DW, Lemeshow S. Applied Logistic Regression. $1^{\text {st }}$ ed. New York: John Wiley \& Sons; 1989.

Hunninghake GW, Lynch DA, Galvin JR, Gross BH, Muller N, Schwartz DA e col. Radiologic findings are strongly associated with a pathologic diagnosis of usual interstitial pneumonia. Chest. 2003; 124(4):1215-23.

Hyde DM, King TE Jr, McDermott T, Waldron JA Jr, Colby TV, Thurlbeck WM e col. Idiopathic pulmonary fibrosis. Quantitative assessment of lung pathology. Comparison of a semiquantitative and a morphometric histopathologic scoring system. Am Rev Respir Dis. 1992; 146(4):1042-7.

Imoke E, Dudgeon DL, Colombani P, Leventhal B, Buck JR, Haller JA. Open lung biopsy in the immunocompromised pediatric patient. J Pediatr Surg. 1983; 18(6):816-21.

Jaffe JP, Maki DG. Lung biopsy in immunocompromised patients: one institution's experience and an approach to management of pulmonary disease in the compromised host. Cancer. 1981; 48(5):1144-53.

Johnson RA, Wichern DW. Applied Multivariate Statistical Analysis. $4^{\text {th }}$ ed. New Jersey: Prentice Hall; 1998.

Keenan RJ, Landreneau RJ, McKneally MF. Video-assisted thoracic surgery. In: Pearson FG, Deslauriers J, Ginsberg RJ, Hiebert CA, Mc Kneally MF, Urschell 
HC Jr., editors. Thoracic Surgery. $1^{\text {st }}$ ed. New York: Churchill Livingstone; 1995. p. $131-40$.

King TE Jr. Diagnostic advances in idiopathic pulmonary fibrosis. Chest. 1991; 100:238-41.

King TE Jr, Schwarz MI, Brown K, Tooze JA, Colby TV, Waldron JA Jr e col. Idiopathic pulmonary fibrosis: relationship between histopathologic features and mortality. Am J Respir Crit Care Med. 2001a; 164(6):1025-32.

King TE Jr, Tooze JA, Schwarz MI, Brown KR, Cherniack RM. Predicting survival in idiopathic pulmonary fibrosis: scoring system and survival model. Am J Respir Crit Care Med. 2001b; 164(7):1171-81.

Kirby TJ, Fell SC. Open lung biopsy. In: Pearson FG, Deslauriers J, Ginsberg RJ, Hiebert CA, Mc Kneally MF, Urschell HC Jr., editors. Thoracic Surgery. $1^{\text {st }}$ ed. New York: Churchill Livingstone; 1995. p. 841-44

Kitamura S. Color atlas of fiberoptic bronchoscopy. $1^{\text {st }}$ ed. St. Louis: MosbyYear Book, Inc.; 1990a. History of bronchoscopy; p. 7-9

Kitamura S. Color atlas of fiberoptic bronchoscopy. $1^{\text {st }}$ ed. St. Louis: MosbyYear Book, Inc.; 1990b. Clinical application of fiberoptic bronchoscopy; p. 10725

Klassen KP, Andrews NC. Biopsy of diffuse pulmonary lesions: a 17-year experience. Ann Thorac Surg. 1967; 4:117-124. 
Kramer MR, Berkman N, Mintz B, Godfrey S, Saute M, Amir G. The role of open lung biopsy in the management and outcome of patients with diffuse lung disease. Ann Thorac Surg. 1998; 65(1):198-202.

Lee TK, Horner RD, Silverman JF, Chen YH, Jenny C, Scarantino CW. Morphometric and morphologic evaluations in stage III non-small cell lung cancers. Prognostic significance of quantitative assessment of infiltrating lymphoid cells. Cancer. 1989; 63(2):309-16.

Leight GS Jr, Michaelis LL. Open lung biopsy for the diagnosis of acute, diffuse pulmonary infiltrates in the immunosuppressed patient. Chest. 1978; 73(4):47782.

Lewis RF, Caccavale RJ, Sisler GE. Video-assisted thoracic surgery. In: Pearson FG, Deslauriers J, Ginsberg RJ, Hiebert CA, Mc Kneally MF, Urschell HC Jr., editors. Thoracic Surgery. $1^{\text {st }}$ ed. New York: Churchill Livingstone; 1995. p. 917-30.

Lipford EH 3rd, Eggleston JC, Lillemoe KD, Sears DL, Moore GW, Baker RR. Prognostic factors in surgically resected limited-stage, nonsmall cell carcinoma of the lung. Am J Surg Pathol. 1984; 8(5):357-65.

LoCicero J 3rd, Shields TW. Surgical diagnostic procedures. In: Shields TW, editor. General Thoracic Surgery. $3^{\text {rd }}$ ed. Philadelphia: Lea e Febiger; 1989. p.265-73.

Mayaud C, Cadranel J. A persistent challenge: the diagnosis of respiratory disease in the non-AIDS immunocompromised host. Thorax. 2000; 55(6):511-7. 
McCabe RE, Brooks RG, Mark JB, Remington JS. Open lung biopsy in patients with acute leukemia. Am J Med. 1985;78(4):609-16.

McKenna RJ Jr, Mountain CF, McMurtrey MJ. Open lung biopsy in immunocompromised patients. Chest. 1984; 86(5):671-4.

Mackenzie JW, Riley DJ. Diagnostic procedures: pulmonary biopsy -- fine needle aspiration, open-lung biopsy, and thoracoscopy. In: Baue AE, Geha AS, Hammond GL, Laks H, Naunheim KS, editors. Glenn's Thoracic and Cardiovascular Surgery. $5^{\text {th }}$ ed. East Norwalk, Connecticut: Appleton e Lange; 1991. p. 169-78.

Martin C, Papazian L, Payan MJ, Saux P, Gouin F. Pulmonary fibrosis correlates with outcome in adult respiratory distress syndrome: a study in mechanically ventilated patients. Chest. 1995; 107(1):196-200.

Matthay RA, Moritz ED. Invasive procedures for diagnosing pulmonary infections: a critical review. Clin Chest Med. 1981; 2:3-18.

Miller RF, Pugsley WB, Griffiths MH. Open lung biopsy for investigation of acute respiratory episodes in patients with HIV infection and AIDS. Genitourin Med. 1995, 71(5):280-5.

Miller JD, Simone C, Kahnamoui K, Thomas J, Bennett WF, Young JE e col. Comparison of videothoracoscopy and axillary thoracotomy for the treatment of spontaneous pneumothorax. Am Surg. 2000; 66(11):1014-5.

Nelems JM, Cooper JD, Henderson RD, Peng T, Phillips MJ. Emergency open lung biopsy. Ann Thorac Surg. 1976; 22(3):260-4. 
Neuhaus SJ, Mattar KS. The efficacy of open lung biopsy. Aust N Z J Surg. 1997; 67(4):181-4.

Papazian L, Thomas P, Bregeon F, Garbe L, Zandotti C, Saux P e col. Openlung biopsy in patients with acute respiratory distress syndrome. Anesthesiology. 1998; 88(4):935-44.

Patel SR, Karmpaliotis D, Ayas NT, Mark EJ, Wain J, Thompson BT e col. The role of open-lung biopsy in ARDS. Chest. 2004; 125(1):197-202.

Poe RH, Wahl GW, Qazi R, Kallay MC, Utell MJ, Morrow GR. Predictors of mortality in the immunocompromised patient with pulmonary infiltrates. Arch Intern Med. 1986; 146(7):1304-8.

Poletti V, Chilosi M, Olivieri D. Diagnostic invasive procedures in diffuse infiltrative lung diseases. Respiration. 2004; 71(2):107-19.

Potter D, Pass HI, Brower S, Macher A, Browne M, Thaler M e col. Prospective randomized study of open lung biopsy versus empirical antibiotic therapy for acute pneumonitis in nonneutropenic cancer patients. Ann Thorac Surg. 1985; 40(5):422-8.

Rano A, Agusti C, Benito N, Rovira M, Angrill J, Pumarola T e col. Prognostic factors of non-HIV immunocompromised patients with pulmonary infiltrates. Chest. 2002; 122(1):253-61.

Raghu G. Idiopathic pulmonary fibrosis: a rational clinical approach. Chest. 1987; 92:148-52. 
Ray JF 3rd, Lawton BR, Myers WO, Toyama WM, Reyes CN, Emanuel DA e col. Open pulmonary biopsy. Nineteen-year experience with 416 consecutive operations. Chest. 1976; 69(1):43-7.

Remy-Jardin M, Campistron P, Amara A, Mastora I, Tillie-Leblond I, Delannoy $\mathrm{V}$ e col. Usefulness of coronal reformations in the diagnostic evaluation of infiltrative lung disease. J Comput Assist Tomogr. 2003; 27(2):266-73.

Rossiter SJ, Miller C, Churg AM, Carrington CB, Mark JB. Open lung biopsy in the immunosuppressed patient. Is it really beneficial? J Thorac Cardiovasc Surg. 1979; 77(3):338-45.

Shah SS, Tsang V, Goldstraw P. Open lung biopsy: a safe, reliable and accurate method for diagnosis in diffuse lung disease. Respiration. 1992; 59(4):243-6.

Shahab I, Fraire AE, Greenberg SD, Johnson EH, Langston C, Roggli VL. Morphometric quantitation of tumor necrosis in stage 1 non-small cell carcinoma of lung: prognostic implications. Mod Pathol. 1992; 5(5):521-4.

Smith CW, Murray GF, Wilcox BR, Starek PJ, Delany DJ. The role of transbronchial lung biopsy in diffuse pulmonary disease. Ann Thorac Surg. 1977; 24(1):54-8.

Thomas JH, Farek PE, Hermreck AS, Pierce GE. Diagnostic value of open lung biopsy in immunocompromised patients. Am J Surg. 1987, 154(6):692-5.

Travis WD, Colby TV, Koss MN, Rosado-De-Christenson ML, Müller NL, King TE Jr. Non-Neoplastic Disorders of the Lower Respiratory Tract. $1^{\text {st }}$ ed. Washington: AFIP/ARP; 2002. Embriology and anatomy; p. 1-15. 
Tuddenham WJ. Glossary of terms for thoracic radiology: recommendations of the Nomenclature Committee of the Fleischner Society. AJR Am J Roentgenol. 1984; 143(3):509-17.

Turner-Warwick M, Burrows B, Johnson A. Cryptogenic fibrosing alveolitis: Clinical features and their influence on survival. Thorax.1980a; 35:171-80.

Turner-Warwick M, Burrows B, Johnson A. Cryptogenic fibrosing alveolitis: response to corticosteroid treatment and effect on survival. Thorax. 1980b; 35:593-9.

Utz JP, Perrella MA, Rosenow EC 3rd. Lung biopsy. Adv Intern Med. 1992; $37: 337-61$.

Venn GE, Kay PH, Midwood CJ, Goldstraw P. Open lung biopsy in patients with diffuse pulmonary shadowing. Thorax. 1985; 40(12):931-5.

Wagner JD, Stahler C, Knox S, Brinton M, Knecht B. Clinical utility of open lung biopsy for undiagnosed pulmonary infiltrates. Am J Surg. 1992; 164(2):104-7.

Walker WA, Cole FH Jr, Khandekar A, Mahfood SS, Watson DC. Does open lung biopsy affect treatment in patients with diffuse pulmonary infiltrates? J Thorac Cardiovasc Surg. 1989; 97(4):534-40.

Wall CP, Gaensler EA, Carrington CB, Hayes JA. Comparison of transbronchial and open biopsies in chronic infiltrative lung diseases. Am Rev Respir Dis. $1981 ; 123(3): 280-5$. 
Waltzer WC, Sterioff S, Zincke H, Bernatz PE, Brewer NS. Open-lung biopsy in the renal transplant recipient. Surgery. 1980; 88(4):601-10.

Warner DO, Warner MA, Divertie MB. Open lung biopsy in patients with diffuse pulmonary infiltrates and acute respiratory failure. Am Rev Respir Dis. 1988; 137(1):90-4.

Watters LC, King TE, Schwarz MI, Waldron JA, Stanford RE, Cherniack RM. A clinical, radiographic, and physiologic scoring system for the longitudinal assessment of patients with idiopathic pulmonary fibrosis. Am Rev Respir Dis. 1986; 133(1):97-103.

Weill D, McGiffin DC, Zorn GL Jr, Alexander CB, Early LJ, Kirklin JK e col. The utility of open lung biopsy following lung transplantation. J Heart Lung Transplant. 2000; 19(9):852-7.

Weng TR, Levison H, Wentworth P, Simpson J, Moes CA. Open lung biopsy in children. Am Rev Respir Dis. 1968; 97(4):673-84. 
8. ANEXOS 


\section{A1. ALTERAÇÕES HISTOLÓGICAS OBSERVADAS NO INTERSTÍCIO AXIAL E SUA RELAÇÃO COM A SOBREVIDA HOSPITALAR}

Tabela A1. 1: Distribuição da sobrevida hospitalar segundo o parâmetro Fibrose do interstício axial

\begin{tabular}{|c|c|c|c|c|c|c|}
\hline \multirow{2}{*}{ Fibrose do interstício axial } & \multicolumn{4}{|c|}{ Sobrevida hospitalar } & \multirow{2}{*}{ Total } & \multirow{2}{*}{$(\%)$} \\
\hline & não & $(\%)$ & $\operatorname{sim}$ & $(\%)$ & & \\
\hline 0 & 18 & (69) & 8 & (31) & 26 & $(100)$ \\
\hline 1 & 9 & (47) & 10 & (53) & 19 & (100) \\
\hline 2 & 3 & (27) & 8 & (73) & 11 & (100) \\
\hline 3 & 1 & (50) & 1 & $(50)$ & 2 & (100) \\
\hline 4 & 1 & (20) & 4 & (80) & 5 & (100) \\
\hline Total & 32 & $(51)$ & 31 & (49) & 63 & $(100)$ \\
\hline
\end{tabular}

Tabela A1. 2: Distribuição da sobrevida hospitalar segundo o parâmetro Tecido de granulação na zona axial

\begin{tabular}{|c|c|c|c|c|c|c|}
\hline \multirow{2}{*}{$\begin{array}{l}\text { Tecido de granulação na zona } \\
\text { axial }\end{array}$} & \multicolumn{4}{|c|}{ Sobrevida hospitalar } & \multirow{2}{*}{ Total } & \multirow{2}{*}{$(\%)$} \\
\hline & não & $(\%)$ & $\operatorname{sim}$ & $(\%)$ & & \\
\hline 0 & 31 & $(54)$ & 26 & (46) & 57 & $(100)$ \\
\hline 1 & & & 3 & (100) & 3 & (100) \\
\hline 3 & & & 1 & $(100)$ & 1 & (100) \\
\hline 4 & 1 & (50) & 1 & $(50)$ & 2 & (100) \\
\hline Total & 32 & (51) & 31 & (49) & 63 & (100) \\
\hline
\end{tabular}

Tabela A1. 3: Distribuição da sobrevida hospitalar segundo o parâmetro Infiltrado de células mononucleares na zona axial

\begin{tabular}{|c|c|c|c|c|c|c|}
\hline \multirow{2}{*}{$\begin{array}{c}\text { Infiltrado de células } \\
\text { mononucleares na zona axial }\end{array}$} & \multicolumn{4}{|c|}{ Sobrevida hospitalar } & \multirow{2}{*}{ Total } & \multirow{2}{*}{$(\%)$} \\
\hline & não & $(\%)$ & $\operatorname{sim}$ & (\%) & & \\
\hline 0 & 8 & (80) & 2 & (20) & 10 & (100) \\
\hline 1 & 18 & (51) & 17 & (49) & 35 & (100) \\
\hline 2 & 6 & (43) & 8 & (57) & 14 & (100) \\
\hline 3 & & & 2 & $(100)$ & 2 & $(100)$ \\
\hline 4 & & & 2 & (100) & 2 & (100) \\
\hline Total & 32 & (51) & 31 & $(49)$ & 63 & (100) \\
\hline
\end{tabular}


Tabela A1. 4: Distribuição da sobrevida hospitalar segundo o parâmetro Infiltrado de neutrófilos na zona axial

\begin{tabular}{|c|c|c|c|c|c|c|}
\hline \multirow{2}{*}{$\begin{array}{c}\text { Infiltrado de neutrófilos na } \\
\text { zona axial }\end{array}$} & \multicolumn{4}{|c|}{ Sobrevida hospitalar } & \multirow{2}{*}{ Total } & \multirow{2}{*}{$(\%)$} \\
\hline & não & $(\%)$ & $\operatorname{sim}$ & $(\%)$ & & \\
\hline 0 & 27 & (52) & 25 & (48) & 52 & (100) \\
\hline 1 & 5 & (50) & 5 & (50) & 10 & (100) \\
\hline 2 & & & 1 & (100) & 1 & (100) \\
\hline Total & 32 & (51) & 31 & $(49)$ & 63 & (100) \\
\hline
\end{tabular}

Tabela A1. 5: Distribuição da sobrevida hospitalar segundo o parâmetro Infiltrado de eosinófilos na zona axial

\begin{tabular}{|c|c|c|c|c|c|c|}
\hline \multirow{2}{*}{$\begin{array}{l}\text { Infiltrado de eosinófilos na } \\
\text { zona axial }\end{array}$} & \multicolumn{4}{|c|}{ Sobrevida hospitalar } & \multirow{2}{*}{ Total } & \multirow{2}{*}{ (\%) } \\
\hline & não & $(\%)$ & sim & $(\%)$ & & \\
\hline 0 & 29 & (58) & 21 & (42) & 50 & (100) \\
\hline 1 & 3 & (23) & 10 & (77) & 13 & (100) \\
\hline Total & 32 & (51) & 31 & (49) & 63 & (100) \\
\hline
\end{tabular}

Tabela A1. 6: Distribuição da sobrevida hospitalar segundo o parâmetro Proliferação de células alongadas na zona axial

\begin{tabular}{|c|c|c|c|c|c|c|}
\hline \multirow{2}{*}{$\begin{array}{l}\text { Proliferação de células } \\
\text { alongadas na zona axial }\end{array}$} & \multicolumn{4}{|c|}{ Sobrevida hospitalar } & \multirow{2}{*}{ Total } & \multirow{2}{*}{$(\%)$} \\
\hline & não & $(\%)$ & $\operatorname{sim}$ & (\%) & & \\
\hline 0 & 17 & (65) & 9 & (35) & 26 & $(100)$ \\
\hline 1 & 11 & (41) & 16 & (59) & 27 & (100) \\
\hline 2 & 3 & (43) & 4 & (57) & 7 & (100) \\
\hline 3 & & & 1 & (100) & 1 & (100) \\
\hline 4 & 1 & (50) & 1 & $(50)$ & 2 & (100) \\
\hline Total & 32 & (51) & 31 & (49) & 63 & (100) \\
\hline
\end{tabular}

Tabela A1. 7: Distribuição da sobrevida hospitalar segundo o parâmetro Edema do interstício axial

\begin{tabular}{|c|c|c|c|c|c|c|}
\hline \multirow{2}{*}{ Edema do interstício axia } & \multicolumn{4}{|c|}{ Sobrevida hospitalar } & \multirow{2}{*}{ Total } & \multirow{2}{*}{$(\%)$} \\
\hline & não & $(\%)$ & $\operatorname{sim}$ & $(\%)$ & & \\
\hline 0 & 27 & (55) & 22 & (45) & 49 & (100) \\
\hline 1 & 5 & (38) & 8 & (62) & 13 & (100) \\
\hline 2 & & & 1 & (100) & 1 & (100) \\
\hline Total & 32 & $(51)$ & 31 & (49) & 63 & $(100)$ \\
\hline
\end{tabular}


Tabela A1. 8: Distribuição da sobrevida hospitalar segundo o parâmetro Deposição de poeira mista na zona axial

\begin{tabular}{|c|c|c|c|c|c|c|}
\hline \multirow{2}{*}{$\begin{array}{c}\text { Deposição de poeira mista na } \\
\text { zona axial }\end{array}$} & \multicolumn{4}{|c|}{ Sobrevida hospitalar } & \multirow{2}{*}{ Total } & \multirow{2}{*}{$(\%)$} \\
\hline & não & $(\%)$ & $\operatorname{sim}$ & $(\%)$ & & \\
\hline 0 & 32 & (51) & 31 & (49) & 63 & (100) \\
\hline Total & 32 & (51) & 31 & (49) & 63 & (100) \\
\hline
\end{tabular}

Tabela A1. 9: Distribuição da sobrevida hospitalar segundo o parâmetro Hiperplasia do BALT no interstício axial

\begin{tabular}{|c|c|c|c|c|c|c|}
\hline \multirow{2}{*}{$\begin{array}{l}\text { Hiperplasia do BALT no } \\
\text { interstício axial }\end{array}$} & \multicolumn{4}{|c|}{ Sobrevida hospitalar } & \multirow{2}{*}{ Total } & \multirow{2}{*}{$(\%)$} \\
\hline & não & $(\%)$ & $\operatorname{sim}$ & $(\%)$ & & \\
\hline 0 & 32 & $(52)$ & 30 & $(48)$ & 62 & (100) \\
\hline 3 & & & 1 & $(100)$ & 1 & $(100)$ \\
\hline Total & 32 & (51) & 31 & (49) & 63 & (100) \\
\hline
\end{tabular}

Tabela A1. 10: Distribuição da sobrevida hospitalar segundo o parâmetro Calcificação distrófica no interstício axial

\begin{tabular}{|c|c|c|c|c|c|c|}
\hline \multirow{2}{*}{$\begin{array}{c}\text { Calcificação distrófica no } \\
\text { interstício axial }\end{array}$} & \multicolumn{4}{|c|}{ Sobrevida hospitalar } & \multirow{2}{*}{ Total } & \multirow{2}{*}{$(\%)$} \\
\hline & não & $(\%)$ & $\operatorname{sim}$ & $(\%)$ & & \\
\hline 0 & 32 & (52) & 30 & (48) & 62 & (100) \\
\hline 1 & & & 1 & (100) & 1 & (100) \\
\hline Total & 32 & (51) & 31 & (49) & 63 & (100) \\
\hline
\end{tabular}

Tabela A1. 11: Distribuição da sobrevida hospitalar segundo o parâmetro Deposição de amilóide no interstício axial

\begin{tabular}{|c|c|c|c|c|c|c|}
\hline \multirow{2}{*}{$\begin{array}{c}\text { Deposição de amilóide no } \\
\text { interstício axial }\end{array}$} & \multicolumn{4}{|c|}{ Sobrevida hospitalar } & \multirow{2}{*}{ Total } & \multirow{2}{*}{$(\%)$} \\
\hline & não & $(\%)$ & $\operatorname{sim}$ & $(\%)$ & & \\
\hline 0 & 32 & (52) & 30 & (48) & 62 & $(100)$ \\
\hline 1 & & & 1 & (100) & 1 & (100) \\
\hline Total & 32 & (51) & 31 & (49) & 63 & (100) \\
\hline
\end{tabular}

Tabela A1. 12: Distribuição da sobrevida hospitalar segundo o parâmetro Deposição de hemossiderina no interstício axial

\begin{tabular}{|c|c|c|c|c|c|c|}
\hline \multirow{2}{*}{$\begin{array}{c}\text { Deposição de hemossiderina } \\
\text { no interstício axial }\end{array}$} & \multicolumn{4}{|c|}{ Sobrevida hospitalar } & \multirow{2}{*}{ Total } & \multirow{2}{*}{$(\%)$} \\
\hline & não & $(\%)$ & $\operatorname{sim}$ & $(\%)$ & & \\
\hline 0 & 32 & (52) & 30 & (48) & 62 & $(100)$ \\
\hline 1 & & & 1 & (100) & 1 & (100) \\
\hline Total & 32 & (51) & 31 & $(49)$ & 63 & (100) \\
\hline
\end{tabular}


Tabela A1. 13: Distribuição da sobrevida hospitalar segundo o parâmetro Hemorragia em zona axial

\begin{tabular}{|c|c|c|c|c|c|c|}
\hline \multirow{2}{*}{ Hemorragia em zona axial } & \multicolumn{4}{|c|}{ Sobrevida hospitalar } & \multirow{2}{*}{ Total } & \multirow{2}{*}{$(\%)$} \\
\hline & não & $(\%)$ & sim & (\%) & & \\
\hline 0 & 31 & $(50)$ & 31 & (50) & 62 & $(100)$ \\
\hline 1 & 1 & $(100)$ & & & 1 & $(100)$ \\
\hline Total & 32 & $(51)$ & 31 & $(49)$ & 63 & $(100)$ \\
\hline
\end{tabular}

Tabela A1. 14: Distribuição da sobrevida hospitalar segundo o parâmetro Infiltração neoplásica na zona axial

\begin{tabular}{|c|c|c|c|c|c|c|}
\hline \multirow{2}{*}{$\begin{array}{c}\text { Infiltração neoplásica na zona } \\
\text { axial }\end{array}$} & \multicolumn{4}{|c|}{ Sobrevida hospitalar } & \multirow{2}{*}{ Total } & \multirow{2}{*}{$(\%)$} \\
\hline & não & $(\%)$ & sim & $(\%)$ & & \\
\hline 0 & 31 & (50) & 31 & $(50)$ & 62 & (100) \\
\hline 2 & 1 & (100) & & & 1 & (100) \\
\hline Total & 32 & (51) & 31 & (49) & 63 & (100) \\
\hline
\end{tabular}

Tabela A1. 15: Distribuição da sobrevida hospitalar segundo o parâmetro Microabscesso na zona axial

\begin{tabular}{|c|c|c|c|c|c|c|}
\hline \multirow{2}{*}{ Microabscesso na zona axial } & \multicolumn{4}{|c|}{ Sobrevida hospitalar } & \multirow{2}{*}{ Total } & \multirow{2}{*}{$(\%)$} \\
\hline & não & $(\%)$ & sim & $(\%)$ & & \\
\hline 0 & 32 & $(51)$ & 31 & $(49)$ & 63 & $(100)$ \\
\hline Total & 32 & (51) & 31 & $(49)$ & 63 & $(100)$ \\
\hline
\end{tabular}

Tabela A1. 16: Distribuição da sobrevida hospitalar segundo o parâmetro Presença de elementos fúngicos na zona axial

\begin{tabular}{|c|c|c|c|c|c|c|}
\hline \multirow{2}{*}{$\begin{array}{l}\text { Presença de elementos } \\
\text { fúngicos na zona axial }\end{array}$} & \multicolumn{4}{|c|}{ Sobrevida hospitalar } & \multirow{2}{*}{ Total } & \multirow{2}{*}{ (\%) } \\
\hline & não & $(\%)$ & $\operatorname{sim}$ & $(\%)$ & & \\
\hline 0 & 32 & (51) & 31 & (49) & 63 & $(100)$ \\
\hline Total & 32 & (51) & 31 & (49) & 63 & $(100)$ \\
\hline
\end{tabular}

Tabela A1. 17: Distribuição da sobrevida hospitalar segundo o parâmetro Necrose em zona axial

\begin{tabular}{|c|c|c|c|c|c|c|}
\hline \multirow{2}{*}{ Necrose em zona axial } & \multicolumn{4}{|c|}{ Sobrevida hospitalar } & \multirow{2}{*}{ Total } & \multirow{2}{*}{$(\%)$} \\
\hline & não & $(\%)$ & $\operatorname{sim}$ & $(\%)$ & & \\
\hline 0 & 32 & $(51)$ & 31 & (49) & 63 & (100) \\
\hline Total & 32 & (51) & 31 & (49) & 63 & (100) \\
\hline
\end{tabular}




\section{A2. ALTERAÇÕES HISTOLÓGICAS OBSERVADAS NO INTERSTÍCIO SEPTAL E SUA RELAÇÃO COM A SOBREVIDA HOSPITALAR}

Tabela A2. 1: Distribuição da sobrevida hospitalar segundo o parâmetro Fibrose do interstício septal

\begin{tabular}{|c|c|c|c|c|c|c|}
\hline \multirow{2}{*}{ Fibrose do interstício septal } & \multicolumn{4}{|c|}{ Sobrevida hospitalar } & \multirow{2}{*}{ Total } & \multirow{2}{*}{$(\%)$} \\
\hline & não & $(\%)$ & $\operatorname{sim}$ & $(\%)$ & & \\
\hline 0 & 13 & (59) & 9 & (41) & 22 & (100) \\
\hline 1 & 9 & (64) & 5 & (36) & 14 & (100) \\
\hline 2 & 5 & (45) & 6 & (55) & 11 & (100) \\
\hline 3 & 4 & (36) & 7 & (64) & 11 & (100) \\
\hline 4 & 1 & (20) & 4 & $(80)$ & 5 & (100) \\
\hline Total & 32 & (51) & 31 & (49) & 63 & (100) \\
\hline
\end{tabular}

Tabela A2. 2: Distribuição da sobrevida hospitalar segundo o parâmetro Tecido de granulação na zona septal

\begin{tabular}{|c|c|c|c|c|c|c|}
\hline \multirow{2}{*}{$\begin{array}{c}\text { Tecido de granulação na } \\
\text { zona septal }\end{array}$} & \multicolumn{4}{|c|}{ Sobrevida hospitalar } & \multirow{2}{*}{ Total } & \multirow{2}{*}{$(\%)$} \\
\hline & não & $(\%)$ & $\operatorname{sim}$ & $(\%)$ & & \\
\hline 0 & 19 & (56) & 15 & (44) & 34 & $(100)$ \\
\hline 1 & 3 & (33) & 6 & (67) & 9 & (100) \\
\hline 2 & 5 & (42) & 7 & (58) & 12 & (100) \\
\hline 3 & 1 & (25) & 3 & (75) & 4 & (100) \\
\hline 4 & 4 & (100) & & & 4 & (100) \\
\hline Total & 32 & $(51)$ & 31 & (49) & 63 & (100) \\
\hline
\end{tabular}

Tabela A2. 3: Distribuição da sobrevida hospitalar segundo o parâmetro Infiltrado de células mononucleares na zona septal

\begin{tabular}{ccccccc}
\hline \multirow{2}{*}{$\begin{array}{c}\text { Infiltrado de células } \\
\text { mononucleares na zona } \\
\text { septal }\end{array}$} & não & $(\%)$ & $\operatorname{sim}$ & $(\%)$ & Total & $(\%)$ \\
\cline { 2 - 5 } & 10 & $(59)$ & 7 & $(41)$ & 17 & $(100)$ \\
1 & 14 & $(74)$ & 5 & $(26)$ & 19 & $(100)$ \\
2 & 6 & $(33)$ & 12 & $(67)$ & 18 & $(100)$ \\
3 & 2 & $(25)$ & 6 & $(75)$ & 8 & $(100)$ \\
4 & 32 & $(51)$ & 31 & $(49)$ & 63 & $(100)$ \\
\hline Total & 32 & & & & & \\
\hline
\end{tabular}


Tabela A2. 4: Distribuição da sobrevida hospitalar segundo o parâmetro Infiltrado de neutrófilos na zona septal

\begin{tabular}{|c|c|c|c|c|c|c|}
\hline \multirow{2}{*}{$\begin{array}{l}\text { Infiltrado de neutrófilos na } \\
\text { zona septal }\end{array}$} & \multicolumn{4}{|c|}{ Sobrevida hospitalar } & \multirow{2}{*}{ Total } & \multirow{2}{*}{$(\%)$} \\
\hline & não & $(\%)$ & $\operatorname{sim}$ & $(\%)$ & & \\
\hline 0 & 25 & (49) & 26 & (51) & 51 & $(100)$ \\
\hline 1 & 6 & (55) & 5 & (45) & 11 & (100) \\
\hline 3 & 1 & (100) & & & 1 & (100) \\
\hline Total & 32 & $(51)$ & 31 & (49) & 63 & $(100)$ \\
\hline
\end{tabular}

Tabela A2. 5: Distribuição da sobrevida hospitalar segundo o parâmetro Infiltrado de eosinófilos na zona septal

\begin{tabular}{|c|c|c|c|c|c|c|}
\hline \multirow{2}{*}{$\begin{array}{c}\text { Infiltrado de eosinófilos na } \\
\text { zona septal }\end{array}$} & \multicolumn{4}{|c|}{ Sobrevida hospitalar } & \multirow{2}{*}{ Total } & \multirow{2}{*}{$(\%)$} \\
\hline & não & $(\%)$ & $\operatorname{sim}$ & $(\%)$ & & \\
\hline 0 & 30 & $(57)$ & 23 & (43) & 53 & (100) \\
\hline 1 & 2 & (22) & 7 & $(78)$ & 9 & $(100)$ \\
\hline 2 & & & 1 & (100) & 1 & $(100)$ \\
\hline Total & 32 & (51) & 31 & (49) & 63 & (100) \\
\hline
\end{tabular}

Tabela A2. 6: Distribuição da sobrevida hospitalar segundo o parâmetro Proliferação de células alongadas na zona septal

\begin{tabular}{|c|c|c|c|c|c|c|}
\hline \multirow{2}{*}{$\begin{array}{l}\text { Proliferação de células } \\
\text { alongadas na zona septal }\end{array}$} & \multicolumn{4}{|c|}{ Sobrevida hospitalar } & \multirow{2}{*}{ Total } & \multirow{2}{*}{$(\%)$} \\
\hline & não & $(\%)$ & $\operatorname{sim}$ & $(\%)$ & & \\
\hline 0 & 9 & (47) & 10 & (53) & 19 & $(100)$ \\
\hline 1 & 11 & (65) & 6 & (35) & 17 & $(100)$ \\
\hline 2 & 6 & (60) & 4 & (40) & 10 & (100) \\
\hline 3 & 2 & (18) & 9 & (82) & 11 & (100) \\
\hline 4 & 4 & (67) & 2 & (33) & 6 & $(100)$ \\
\hline Total & 32 & (51) & 31 & $(49)$ & 63 & $(100)$ \\
\hline
\end{tabular}

Tabela A2. 7: Distribuição da sobrevida hospitalar segundo o parâmetro Edema do interstício septal

\begin{tabular}{|c|c|c|c|c|c|c|}
\hline \multirow{2}{*}{ Edema do interstício septal } & \multicolumn{4}{|c|}{ Sobrevida hospitalar } & \multirow{2}{*}{ Total } & \multirow{2}{*}{$(\%)$} \\
\hline & não & $(\%)$ & $\operatorname{sim}$ & (\%) & & \\
\hline 0 & 17 & (52) & 16 & (48) & 33 & (100) \\
\hline 1 & 12 & (44) & 15 & (56) & 27 & (100) \\
\hline 2 & 2 & (100) & & & 2 & $(100)$ \\
\hline 3 & 1 & $(100)$ & & & 1 & $(100)$ \\
\hline Total & 32 & $(51)$ & 31 & (49) & 63 & (100) \\
\hline
\end{tabular}


Tabela A2. 8: Distribuição da sobrevida hospitalar segundo o parâmetro Enfisema

\begin{tabular}{|c|c|c|c|c|c|c|}
\hline \multirow{2}{*}{ Enfisema } & \multicolumn{4}{|c|}{ Sobrevida hospitalar } & \multirow{2}{*}{ Total } & \multirow{2}{*}{$(\%)$} \\
\hline & não & $(\%)$ & sim & $(\%)$ & & \\
\hline 0 & 29 & (50) & 29 & $(50)$ & 58 & $(100)$ \\
\hline 1 & 1 & (50) & 1 & (50) & 2 & (100) \\
\hline 2 & 1 & (50) & 1 & (50) & 2 & (100) \\
\hline 3 & 1 & $(100)$ & & & 1 & (100) \\
\hline Total & 32 & $(51)$ & 31 & (49) & 63 & $(100)$ \\
\hline
\end{tabular}

Tabela A2. 9: Distribuição da sobrevida hospitalar segundo o parâmetro Hiperplasia do BALT no interstício septal

\begin{tabular}{|c|c|c|c|c|c|c|}
\hline \multirow{2}{*}{$\begin{array}{l}\text { Hiperplasia do BALT no } \\
\text { interstício septal }\end{array}$} & \multicolumn{4}{|c|}{ Sobrevida hospitalar } & \multirow{2}{*}{ Total } & \multirow{2}{*}{$(\%)$} \\
\hline & não & $(\%)$ & sim & $(\%)$ & & \\
\hline 0 & 32 & $(52)$ & 30 & $(48)$ & 62 & (100) \\
\hline 2 & & & 1 & (100) & 1 & (100) \\
\hline Total & 32 & (51) & 31 & (49) & 63 & (100) \\
\hline
\end{tabular}

Tabela A2. 10: Distribuição da sobrevida hospitalar segundo o parâmetro Deposição de hemossiderina no interstício septal

\begin{tabular}{|c|c|c|c|c|c|c|}
\hline \multirow{2}{*}{$\begin{array}{c}\text { Deposição de hemossiderina } \\
\text { no interstício septal }\end{array}$} & \multicolumn{4}{|c|}{ Sobrevida hospitalar } & \multirow{2}{*}{ Total } & \multirow{2}{*}{$(\%)$} \\
\hline & não & $(\%)$ & $\operatorname{sim}$ & $(\%)$ & & \\
\hline 0 & 32 & (52) & 30 & (48) & 62 & $(100)$ \\
\hline 2 & & & 1 & $(100)$ & 1 & $(100)$ \\
\hline Total & 32 & (51) & 31 & (49) & 63 & (100) \\
\hline
\end{tabular}

Tabela A2. 11: Distribuição da sobrevida hospitalar segundo o parâmetro Deposição de amilóide no interstício septal

\begin{tabular}{|c|c|c|c|c|c|c|}
\hline \multirow{2}{*}{$\begin{array}{c}\text { Deposição de amilóide no } \\
\text { interstício septal }\end{array}$} & \multicolumn{4}{|c|}{ Sobrevida hospitalar } & \multirow{2}{*}{ Total } & \multirow{2}{*}{$(\%)$} \\
\hline & não & $(\%)$ & $\operatorname{sim}$ & $(\%)$ & & \\
\hline 0 & 32 & (52) & 30 & (48) & 62 & (100) \\
\hline 1 & & & 1 & $(100)$ & 1 & $(100)$ \\
\hline Total & 32 & (51) & 31 & $(49)$ & 63 & (100) \\
\hline
\end{tabular}

Tabela A2. 12: Distribuição da sobrevida hospitalar segundo o parâmetro Hemorragia no interstício septal

\begin{tabular}{|c|c|c|c|c|c|c|}
\hline \multirow{2}{*}{$\begin{array}{l}\text { Hemorragia no interstício } \\
\text { septal }\end{array}$} & \multicolumn{4}{|c|}{ Sobrevida hospitalar } & \multirow{2}{*}{ Total } & \multirow{2}{*}{$(\%)$} \\
\hline & não & $(\%)$ & sim & $(\%)$ & & \\
\hline 0 & 32 & $(51)$ & 31 & (49) & 63 & $(100)$ \\
\hline Total & 32 & (51) & 31 & (49) & 63 & (100) \\
\hline
\end{tabular}


Tabela A2. 13: Distribuição da sobrevida hospitalar segundo o parâmetro Presença de granulomas do tipo corpo estranho no interstício septal

\begin{tabular}{ccccccc}
\hline $\begin{array}{c}\text { Presença de granulomas do } \\
\text { tipo corpo estranho no } \\
\text { interstício septal }\end{array}$ & não & $(\%)$ & sim & $(\%)$ & Total & $(\%)$ \\
\hline 0 & 32 & $(51)$ & 31 & $(49)$ & 63 & $(100)$ \\
\hline Total & 32 & $(51)$ & 31 & $(49)$ & 63 & $(100)$ \\
\hline
\end{tabular}

Tabela A2. 14: Distribuição da sobrevida hospitalar segundo o parâmetro Presença de calcificação distrófica no interstício septal

\begin{tabular}{|c|c|c|c|c|c|c|}
\hline \multirow{2}{*}{$\begin{array}{c}\text { Presença de calcificação } \\
\text { distrófica no interstício } \\
\text { septal }\end{array}$} & \multicolumn{4}{|c|}{ Sobrevida hospitalar } & \multirow{2}{*}{ Total } & \multirow{2}{*}{$(\%)$} \\
\hline & não & $(\%)$ & $\operatorname{sim}$ & $(\%)$ & & \\
\hline 0 & 32 & (52) & 30 & (48) & 62 & $(100)$ \\
\hline 2 & & & 1 & $(100)$ & 1 & (100) \\
\hline Total & 32 & (51) & 31 & (49) & 63 & (100) \\
\hline
\end{tabular}

Tabela A2. 15: Distribuição da sobrevida hospitalar segundo o parâmetro Presença de nódulos fibronecróticos calcificados no interstício septal

\begin{tabular}{ccccccc}
\hline $\begin{array}{c}\text { Presença de nódulos } \\
\text { fibronecróticos calcificados no } \\
\text { interstício septal }\end{array}$ & não & $(\%)$ & $\operatorname{sim}$ & $(\%)$ & Total & (\%) \\
\hline 0 & 32 & $(51)$ & 31 & $(49)$ & 63 & $(100)$ \\
\hline Total & 32 & $(51)$ & 31 & $(49)$ & 63 & $(100)$ \\
\hline
\end{tabular}

Tabela A2. 16: Distribuição da sobrevida hospitalar segundo o parâmetro Reação gigantocelular a material cristalóide no interstício septal

\begin{tabular}{|c|c|c|c|c|c|c|}
\hline \multirow{2}{*}{$\begin{array}{l}\text { Reação gigantocelular a material } \\
\text { cristalóide no interstício septal }\end{array}$} & \multicolumn{4}{|c|}{ Sobrevida hospitalar } & \multirow{2}{*}{ Total } & \multirow{2}{*}{$(\%)$} \\
\hline & não & $(\%)$ & sim & $(\%)$ & & \\
\hline 0 & 32 & (52) & 30 & (48) & 62 & $\begin{array}{l}(100) \\
\end{array}$ \\
\hline 1 & & & 1 & (100) & 1 & (100) \\
\hline Total & 32 & (51) & 31 & $(49)$ & 63 & (100) \\
\hline
\end{tabular}

Tabela A2. 17: Distribuição da sobrevida hospitalar segundo o parâmetro Necrose em zona septal

\begin{tabular}{|c|c|c|c|c|c|c|}
\hline \multirow{2}{*}{ Necrose em zona septal } & \multicolumn{4}{|c|}{ Sobrevida hospitalar } & \multirow{2}{*}{ Total } & \multirow{2}{*}{$(\%)$} \\
\hline & não & $(\%)$ & $\operatorname{sim}$ & $(\%)$ & & \\
\hline 0 & 31 & $(50)$ & 31 & $(50)$ & 62 & $(100)$ \\
\hline 1 & 1 & (100) & & & 1 & (100) \\
\hline Total & 32 & (51) & 31 & (49) & 63 & $(100)$ \\
\hline
\end{tabular}


Tabela A2. 18: Distribuição da sobrevida hospitalar segundo o parâmetro Presença de elementos fúngicos em zona septal

\begin{tabular}{|c|c|c|c|c|c|c|}
\hline \multirow{2}{*}{$\begin{array}{l}\text { Presença de elementos } \\
\text { fúngicos em zona septal }\end{array}$} & \multicolumn{4}{|c|}{ Sobrevida hospitalar } & \multirow{2}{*}{ Total } & \multirow{2}{*}{$(\%)$} \\
\hline & não & $(\%)$ & $\operatorname{sim}$ & $(\%)$ & & \\
\hline 0 & 32 & (51) & 31 & (49) & 63 & $(100)$ \\
\hline Total & 32 & (51) & 31 & (49) & 63 & (100) \\
\hline
\end{tabular}




\section{A3. ALTERAÇÕES HISTOLÓGICAS OBSERVADAS NO INTERSTÍCIO PERIFÉRICO E SUA RELAÇÃO COM A SOBREVIDA HOSPITALAR}

Tabela A3. 1: Distribuição da sobrevida hospitalar segundo o parâmetro Fibrose do interstício periférico

\begin{tabular}{|c|c|c|c|c|c|c|}
\hline \multirow{2}{*}{ Fibrose do interstício periférico } & \multicolumn{4}{|c|}{ Sobrevida hospitalar } & \multirow{2}{*}{ Total } & \multirow{2}{*}{$(\%)$} \\
\hline & não & $(\%)$ & $\operatorname{sim}$ & $(\%)$ & & \\
\hline 0 & 11 & $(58)$ & 8 & $(42)$ & 19 & $(100)$ \\
\hline 1 & 14 & (70) & 6 & (30) & 20 & (100) \\
\hline 2 & 3 & (21) & 11 & (79) & 14 & $(100)$ \\
\hline 3 & 1 & (33) & 2 & (67) & 3 & (100) \\
\hline 4 & 3 & (43) & 4 & (57) & 7 & (100) \\
\hline Total & 32 & (51) & 31 & (49) & 63 & (100) \\
\hline
\end{tabular}

Tabela A3. 2: Distribuição da sobrevida hospitalar segundo o parâmetro Tecido de granulação na zona periférica

\begin{tabular}{|c|c|c|c|c|c|c|}
\hline \multirow{2}{*}{$\begin{array}{c}\text { Tecido de granulação na } \\
\text { zona periférica }\end{array}$} & \multicolumn{4}{|c|}{ Sobrevida hospitalar } & \multirow{2}{*}{ Total } & \multirow{2}{*}{$(\%)$} \\
\hline & não & $(\%)$ & $\operatorname{sim}$ & $(\%)$ & & \\
\hline 0 & 24 & (59) & 17 & (41) & 41 & $(100)$ \\
\hline 1 & 3 & (27) & 8 & (73) & 11 & (100) \\
\hline 2 & 2 & (40) & 3 & (60) & 5 & (100) \\
\hline 3 & 1 & (50) & 1 & (50) & 2 & (100) \\
\hline 4 & 2 & (50) & 2 & (50) & 4 & (100) \\
\hline Total & 32 & (51) & 31 & (49) & 63 & (100) \\
\hline
\end{tabular}

Tabela A3. 3: Distribuição da sobrevida hospitalar segundo o parâmetro Infiltrado de células mononucleares no interstício periférico

\begin{tabular}{|c|c|c|c|c|c|c|}
\hline \multirow{2}{*}{$\begin{array}{c}\text { Infiltrado de células } \\
\text { mononucleares no interstício } \\
\text { periférico }\end{array}$} & \multicolumn{4}{|c|}{ Sobrevida hospitalar } & \multirow{2}{*}{ Total } & \multirow{2}{*}{$(\%)$} \\
\hline & não & $(\%)$ & $\operatorname{sim}$ & $(\%)$ & & \\
\hline 0 & 10 & (63) & 6 & (38) & 16 & $(100)$ \\
\hline 1 & 19 & (49) & 20 & (51) & 39 & $(100)$ \\
\hline 2 & 3 & $(50)$ & 3 & $(50)$ & 6 & $(100)$ \\
\hline 3 & & & 2 & (100) & 2 & $(100)$ \\
\hline Total & 32 & (51) & 31 & (49) & 63 & $(100)$ \\
\hline
\end{tabular}


Tabela A3. 4: Distribuição da sobrevida hospitalar segundo o parâmetro Infiltrado de neutrófilos no interstício periférico

\begin{tabular}{ccccccc}
\hline \multirow{2}{*}{$\begin{array}{c}\text { Infiltrado de neutrófilos no } \\
\text { interstício periférico }\end{array}$} & não & $(\%)$ & $\operatorname{sim}$ & $(\%)$ & \multirow{2}{*}{ Total } & \multirow{2}{*}{$(\%)$} \\
\hline 0 & 25 & $(48)$ & 27 & $(52)$ & 52 & $(100)$ \\
1 & 7 & $(78)$ & 2 & $(22)$ & 9 & $(100)$ \\
2 & & & 2 & $(100)$ & 2 & $(100)$ \\
\hline Total & 32 & $(51)$ & 31 & $(49)$ & 63 & $(100)$ \\
\hline
\end{tabular}

Tabela A3. 5: Distribuição da sobrevida hospitalar segundo o parâmetro Infiltrado de eosinófilos no interstício periférico

\begin{tabular}{|c|c|c|c|c|c|c|}
\hline \multirow{2}{*}{$\begin{array}{l}\text { Infiltrado de eosinófilos no } \\
\text { interstício periférico }\end{array}$} & \multicolumn{4}{|c|}{ Sobrevida hospitalar } & \multirow{2}{*}{ Total } & \multirow{2}{*}{$(\%)$} \\
\hline & não & $(\%)$ & $\operatorname{sim}$ & $(\%)$ & & \\
\hline 0 & 29 & (54) & 25 & (46) & 54 & (100) \\
\hline 1 & 2 & (40) & 3 & (60) & 5 & (100) \\
\hline 2 & 1 & (33) & 2 & $(67)$ & 3 & (100) \\
\hline 3 & & & 1 & $(100)$ & 1 & (100) \\
\hline Total & 32 & (51) & 31 & $(49)$ & 63 & (100) \\
\hline
\end{tabular}

Tabela A3. 6: Distribuição da sobrevida hospitalar segundo o parâmetro Proliferação de células alongadas na zona periférica

\begin{tabular}{|c|c|c|c|c|c|c|}
\hline \multirow{2}{*}{$\begin{array}{l}\text { Proliferação de células } \\
\text { alongadas na zona periférica }\end{array}$} & \multicolumn{4}{|c|}{ Sobrevida hospitalar } & \multirow{2}{*}{ Total } & \multirow{2}{*}{$(\%)$} \\
\hline & não & $(\%)$ & $\operatorname{sim}$ & $(\%)$ & & \\
\hline 0 & 18 & $(58)$ & 13 & $(42)$ & 31 & (100) \\
\hline 1 & 9 & (43) & 12 & (57) & 21 & (100) \\
\hline 2 & 3 & (43) & 4 & $(57)$ & 7 & (100) \\
\hline 3 & & & 1 & (100) & 1 & (100) \\
\hline 4 & 2 & (67) & 1 & (33) & 3 & (100) \\
\hline Total & 32 & (51) & 31 & (49) & 63 & $(100)$ \\
\hline
\end{tabular}

Tabela A3. 7: Distribuição da sobrevida hospitalar segundo o parâmetro Edema do interstício periférico

\begin{tabular}{|c|c|c|c|c|c|c|}
\hline \multirow{2}{*}{ Edema do interstício periférico } & \multicolumn{4}{|c|}{ Sobrevida hospitalar } & \multirow{2}{*}{ Total } & \multirow{2}{*}{$(\%)$} \\
\hline & não & $(\%)$ & sim & (\%) & & \\
\hline 0 & 14 & (54) & 12 & (46) & 26 & (100) \\
\hline 1 & 11 & (50) & 11 & $(50)$ & 22 & (100) \\
\hline 2 & 5 & (63) & 3 & (38) & 8 & (100) \\
\hline 3 & 1 & (17) & 5 & (83) & 6 & (100) \\
\hline 4 & 1 & $(100)$ & & & 1 & $(100)$ \\
\hline Total & 32 & (51) & 31 & (49) & 63 & (100) \\
\hline
\end{tabular}


Tabela A3. 8: Distribuição da sobrevida hospitalar segundo o parâmetro Hemorragia em zona periférica

\begin{tabular}{|c|c|c|c|c|c|c|}
\hline \multirow{2}{*}{$\begin{array}{l}\text { Hemorragia em zona } \\
\text { periférica }\end{array}$} & \multicolumn{4}{|c|}{ Sobrevida hospitalar } & \multirow{2}{*}{ Total } & \multirow{2}{*}{$(\%)$} \\
\hline & não & $(\%)$ & sim & $(\%)$ & & \\
\hline 0 & 22 & (48) & 24 & (52) & 46 & (100) \\
\hline 1 & 7 & (64) & 4 & (36) & 11 & (100) \\
\hline 2 & 3 & (75) & 1 & (25) & 4 & (100) \\
\hline 3 & & & 2 & (100) & 2 & (100) \\
\hline Total & 32 & (51) & 31 & (49) & 63 & (100) \\
\hline
\end{tabular}

Tabela A3. 9: Distribuição da sobrevida hospitalar segundo o parâmetro Deposição de fibrina em zona periférica

\begin{tabular}{|c|c|c|c|c|c|c|}
\hline \multirow{2}{*}{$\begin{array}{c}\text { Deposição de fibrina em } \\
\text { zona periférica }\end{array}$} & \multicolumn{4}{|c|}{ Sobrevida hospitalar } & \multirow{2}{*}{ Total } & \multirow{2}{*}{$(\%)$} \\
\hline & não & $(\%)$ & $\operatorname{sim}$ & $(\%)$ & & \\
\hline 0 & 27 & (49) & 28 & (51) & 55 & (100) \\
\hline 1 & 2 & (100) & & & 2 & (100) \\
\hline 2 & 2 & $(40)$ & 3 & $(60)$ & 5 & (100) \\
\hline 3 & 1 & (100) & & & 1 & (100) \\
\hline Total & 32 & $(51)$ & 31 & (49) & 63 & (100) \\
\hline
\end{tabular}

Tabela A3. 10: Distribuição da sobrevida hospitalar segundo o parâmetro Leucoestase em vasos da zona periférica

\begin{tabular}{|c|c|c|c|c|c|c|}
\hline \multirow{2}{*}{$\begin{array}{c}\text { Leucoestase em vasos da } \\
\text { zona periférica }\end{array}$} & \multicolumn{4}{|c|}{ Sobrevida hospitalar } & \multirow{2}{*}{ Total } & \multirow{2}{*}{$(\%)$} \\
\hline & não & $(\%)$ & $\operatorname{sim}$ & $(\%)$ & & \\
\hline 0 & 32 & $(52)$ & 30 & $(48)$ & 62 & (100) \\
\hline 3 & & & 1 & (100) & 1 & (100) \\
\hline Total & 32 & (51) & 31 & (49) & 63 & (100) \\
\hline
\end{tabular}

Tabela A3. 11: Distribuição da sobrevida hospitalar segundo o parâmetro Exsudato fibrinoneutrofílico em organização em zona periférica

\begin{tabular}{|c|c|c|c|c|c|c|}
\hline \multirow{2}{*}{$\begin{array}{c}\text { Exsudato fibrino-neutrofílico } \\
\text { em organização em zona } \\
\text { periférica }\end{array}$} & \multicolumn{4}{|c|}{ Sobrevida hospitalar } & \multirow{2}{*}{ Total } & \multirow{2}{*}{$(\%)$} \\
\hline & não & $(\%)$ & $\operatorname{sim}$ & $(\%)$ & & \\
\hline 0 & 31 & (51) & 30 & (49) & 61 & $(100)$ \\
\hline 2 & & & 1 & $(100)$ & 1 & $(100)$ \\
\hline 4 & 1 & $(100)$ & & & 1 & $(100)$ \\
\hline Total & 32 & $(51)$ & 31 & $(49)$ & 63 & $(100)$ \\
\hline
\end{tabular}


Tabela A3. 12: Distribuição da sobrevida hospitalar segundo o parâmetro Deposição de hemossiderina no interstício periférico

\begin{tabular}{|c|c|c|c|c|c|c|}
\hline \multirow{2}{*}{$\begin{array}{c}\text { Deposição de hemossiderina } \\
\text { no interstício periférico }\end{array}$} & \multicolumn{4}{|c|}{ Sobrevida hospitalar } & \multirow{2}{*}{ Total } & \multirow{2}{*}{$(\%)$} \\
\hline & não & $(\%)$ & sim & $(\%)$ & & \\
\hline 0 & 32 & (52) & 30 & (48) & 62 & (100) \\
\hline 1 & & & 1 & (100) & 1 & (100) \\
\hline Total & 32 & (51) & 31 & (49) & 63 & (100) \\
\hline
\end{tabular}

Tabela A3. 13: Distribuição da sobrevida hospitalar segundo o parâmetro Deposição de material cristalóide no interstício periférico

\begin{tabular}{ccccccc}
\hline $\begin{array}{c}\text { Deposição de material } \\
\text { cristalóide no interstício } \\
\text { periférico }\end{array}$ & não & $(\%)$ & $\operatorname{sim}$ & $(\%)$ & Total & (\%) \\
\cline { 2 - 5 } & 32 & $(51)$ & 31 & $(49)$ & 63 & $(100)$ \\
\hline 0 & 32 & $(51)$ & 31 & $(49)$ & 63 & $(100)$ \\
\hline Total & & & & & &
\end{tabular}

Tabela A3. 14: Distribuição da sobrevida hospitalar segundo o parâmetro Presença de granulomas do tipo corpo estranho no interstício periférico

\begin{tabular}{ccccccc}
\hline $\begin{array}{c}\text { Presença de granulomas do } \\
\text { tipo corpo estranho no } \\
\text { interstício periférico }\end{array}$ & não & $(\%)$ & $\operatorname{sim}$ & $(\%)$ & Total & $(\%)$ \\
\hline 0 & 32 & $(51)$ & 31 & $(49)$ & 63 & $(100)$ \\
\hline Total & 32 & $(51)$ & 31 & $(49)$ & 63 & $(100)$ \\
\hline
\end{tabular}

Tabela A3. 15: Distribuição da sobrevida hospitalar segundo o parâmetro Necrose em zona periférica

\begin{tabular}{|c|c|c|c|c|c|c|}
\hline \multirow{2}{*}{ Necrose em zona periférica } & \multicolumn{4}{|c|}{ Sobrevida hospitalar } & \multirow{2}{*}{ Total } & \multirow{2}{*}{$(\%)$} \\
\hline & não & (\%) & $\operatorname{sim}$ & (\%) & & \\
\hline 0 & 31 & (50) & 31 & $(50)$ & 62 & $(100)$ \\
\hline 1 & 1 & $(100)$ & & & 1 & $(100)$ \\
\hline Total & 32 & $(51)$ & 31 & (49) & 63 & $(100)$ \\
\hline
\end{tabular}

Tabela A3. 16: Distribuição da sobrevida hospitalar segundo o parâmetro Presença de elementos fúngicos na zona periférica

\begin{tabular}{ccccccc}
\hline $\begin{array}{c}\text { Presença de elementos } \\
\text { fúngicos na zona } \\
\text { periférica }\end{array}$ & não & $(\%)$ & $\operatorname{sim}$ & $(\%)$ & Total & $(\%)$ \\
\cline { 2 - 5 } & 31 & $(50)$ & 31 & $(50)$ & 62 & $(100)$ \\
1 & 1 & $(100)$ & & & 1 & $(100)$ \\
\hline Total & 32 & $(51)$ & 31 & $(49)$ & 63 & $(100)$ \\
\hline
\end{tabular}


Tabela A3. 17: Distribuição da sobrevida hospitalar segundo o parâmetro Ossificação metaplásica do interstício periférico

\begin{tabular}{|c|c|c|c|c|c|c|}
\hline \multirow{2}{*}{$\begin{array}{l}\text { Ossificação metaplásica do } \\
\text { interstício periférico }\end{array}$} & \multicolumn{4}{|c|}{ Sobrevida hospitalar } & \multirow{2}{*}{ Total } & \multirow{2}{*}{$(\%)$} \\
\hline & não & $(\%)$ & $\operatorname{sim}$ & $(\%)$ & & \\
\hline 0 & 32 & (52) & 30 & (48) & 62 & (100) \\
\hline 1 & & & 1 & (100) & 1 & (100) \\
\hline Total & 32 & (51) & 31 & $(49)$ & 63 & $(100)$ \\
\hline
\end{tabular}

Tabela A3. 18: Distribuição da sobrevida hospitalar segundo o parâmetro Hiperplasia de células mesoteliais

\begin{tabular}{ccccccc}
\hline \multirow{2}{*}{$\begin{array}{c}\text { Hiperplasia de células } \\
\text { mesoteliais }\end{array}$} & \multicolumn{4}{c}{ Sobrevida hospitalar } & \multirow{2}{*}{ Total } & \multirow{2}{*}{$(\%)$} \\
\cline { 2 - 5 } & não & $(\%)$ & sim & $(\%)$ & & $(100)$ \\
\hline 0 & 32 & $(51)$ & 31 & $(49)$ & 63 & $(100)$ \\
\hline Total & 32 & $(51)$ & 31 & $(49)$ & 63 & $(100)$ \\
\hline
\end{tabular}




\section{A4. ALTERAÇÕES HISTOLÓGICAS OBSERVADAS EM ARTERÍOLAS PRÉ-ACINARES E SUA RELAÇÃO COM A SOBREVIDA HOSPITALAR}

Tabela A4. 1: Distribuição da sobrevida hospitalar segundo o parâmetro Ectasia de arteríolas pré-acinares

\begin{tabular}{|c|c|c|c|c|c|c|}
\hline \multirow{2}{*}{$\begin{array}{l}\text { Ectasia de arteríolas pré- } \\
\text { acinares }\end{array}$} & \multicolumn{4}{|c|}{ Sobrevida hospitalar } & \multirow{2}{*}{ Total } & \multirow{2}{*}{$(\%)$} \\
\hline & não & $(\%)$ & $\operatorname{sim}$ & $(\%)$ & & \\
\hline 0 & 31 & $(51)$ & 30 & (49) & 61 & $(100)$ \\
\hline 1 & 1 & $(100)$ & & & 1 & (100) \\
\hline 2 & & & 1 & $(100)$ & 1 & $(100)$ \\
\hline Total & 32 & (51) & 31 & (49) & 63 & (100) \\
\hline
\end{tabular}

Tabela A4. 2: Distribuição da sobrevida hospitalar segundo o parâmetro Trombose de arteríolas pré-acinares

\begin{tabular}{|c|c|c|c|c|c|c|}
\hline \multirow{2}{*}{$\begin{array}{c}\text { Trombose de arteríolas pré- } \\
\text { acinares }\end{array}$} & \multicolumn{4}{|c|}{ Sobrevida hospitalar } & \multirow{2}{*}{ Total } & \multirow{2}{*}{$(\%)$} \\
\hline & não & $(\%)$ & $\operatorname{sim}$ & $(\%)$ & & \\
\hline 0 & 25 & $(47)$ & 28 & (53) & 53 & (100) \\
\hline 1 & 6 & (75) & 2 & (25) & 8 & (100) \\
\hline 2 & 1 & (50) & 1 & (50) & 2 & (100) \\
\hline Total & 32 & $(51)$ & 31 & (49) & 63 & $(100)$ \\
\hline
\end{tabular}

Tabela A4. 3: Distribuição da sobrevida hospitalar segundo o parâmetro Ectasia de vasavasorum de arteríolas pré-acinares

\begin{tabular}{|c|c|c|c|c|c|c|}
\hline \multirow{2}{*}{$\begin{array}{l}\text { Ectasia de vasa-vasorum de } \\
\text { arteríolas pré-acinares }\end{array}$} & \multicolumn{4}{|c|}{ Sobrevida hospitalar } & \multirow{2}{*}{ Total } & \multirow{2}{*}{$(\%)$} \\
\hline & não & $(\%)$ & $\operatorname{sim}$ & $(\%)$ & & \\
\hline 0 & 29 & (53) & 26 & $(47)$ & 55 & $(100)$ \\
\hline 1 & 3 & (38) & 5 & (63) & 8 & (100) \\
\hline Total & 32 & (51) & 31 & (49) & 63 & (100) \\
\hline
\end{tabular}

Tabela A4. 4: Distribuição da sobrevida hospitalar segundo o parâmetro Proliferação adventiceal de arteríolas pré-acinares

\begin{tabular}{|c|c|c|c|c|c|c|}
\hline \multirow{2}{*}{$\begin{array}{l}\text { Proliferação adventiceal de } \\
\text { arteríolas pré-acinares }\end{array}$} & \multicolumn{4}{|c|}{ Sobrevida hospitalar } & \multirow{2}{*}{ Total } & \multirow{2}{*}{$(\%)$} \\
\hline & não & $(\%)$ & $\operatorname{sim}$ & $(\%)$ & & \\
\hline 0 & 19 & (63) & 11 & (37) & 30 & (100) \\
\hline 1 & 7 & (35) & 13 & (65) & 20 & $(100)$ \\
\hline 2 & 6 & (60) & 4 & $(40)$ & 10 & $(100)$ \\
\hline 3 & & & 2 & $(100)$ & 2 & $(100)$ \\
\hline 4 & & & 1 & $(100)$ & 1 & $(100)$ \\
\hline Total & 32 & (51) & 31 & $(49)$ & 63 & (100) \\
\hline
\end{tabular}


Tabela A4. 5: Distribuição da sobrevida hospitalar segundo o parâmetro Hipertrofia da camada média de arteríolas pré-acinares

\begin{tabular}{ccccccc}
\hline $\begin{array}{c}\text { Hipertrofia da camada } \\
\text { média de arteríolas pré- } \\
\text { acinares }\end{array}$ & não & $(\%)$ & $\operatorname{sim}$ & $(\%)$ & Total & $(\%)$ \\
\hline 0 & 4 & $(40)$ & 6 & $(60)$ & 10 & $(100)$ \\
1 & 14 & $(61)$ & 9 & $(39)$ & 23 & $(100)$ \\
2 & 11 & $(58)$ & 8 & $(42)$ & 19 & $(100)$ \\
3 & 2 & $(20)$ & 8 & $(80)$ & 10 & $(100)$ \\
4 & 1 & $(100)$ & & & 1 & $(100)$ \\
\hline Total & 32 & $(51)$ & 31 & $(49)$ & 63 & $(100)$ \\
\hline
\end{tabular}

Tabela A4. 6: Distribuição da sobrevida hospitalar segundo o parâmetro Proliferação fibrointimal de arteríolas pré-acinares

\begin{tabular}{|c|c|c|c|c|c|c|}
\hline \multirow{2}{*}{$\begin{array}{l}\text { Proliferação fibrointimal de } \\
\text { arteríolas pré-acinares }\end{array}$} & \multicolumn{4}{|c|}{ Sobrevida hospitalar } & \multirow{2}{*}{ Total } & \multirow{2}{*}{$(\%)$} \\
\hline & não & $(\%)$ & $\operatorname{sim}$ & $(\%)$ & & \\
\hline 0 & 14 & $(54)$ & 12 & $(46)$ & 26 & (100) \\
\hline 1 & 12 & (63) & 7 & (37) & 19 & (100) \\
\hline 2 & 5 & (36) & 9 & (64) & 14 & (100) \\
\hline 3 & 1 & (25) & 3 & (75) & 4 & (100) \\
\hline Total & 32 & (51) & 31 & (49) & 63 & (100) \\
\hline
\end{tabular}

Tabela A4. 7: Distribuição da sobrevida hospitalar segundo o parâmetro Tumefação endotelial de arteríolas pré-acinares

\begin{tabular}{|c|c|c|c|c|c|c|}
\hline \multirow{2}{*}{$\begin{array}{l}\text { Tumefação endotelial de } \\
\text { arteríolas pré-acinares }\end{array}$} & \multicolumn{4}{|c|}{ Sobrevida hospitalar } & \multirow{2}{*}{ Total } & \multirow{2}{*}{$(\%)$} \\
\hline & não & $(\%)$ & $\operatorname{sim}$ & $(\%)$ & & \\
\hline 0 & 22 & (58) & 16 & $(42)$ & 38 & (100) \\
\hline 1 & 9 & (47) & 10 & (53) & 19 & $(100)$ \\
\hline 2 & 1 & (20) & 4 & (80) & 5 & $(100)$ \\
\hline 3 & & & 1 & $(100)$ & 1 & $(100)$ \\
\hline Total & 32 & (51) & 31 & $(49)$ & 63 & $(100)$ \\
\hline
\end{tabular}

Tabela A4. 8: Distribuição da sobrevida hospitalar segundo o parâmetro Remodelamento plexiforme de arteríolas pré-acinares

\begin{tabular}{|c|c|c|c|c|c|c|}
\hline \multirow{2}{*}{$\begin{array}{l}\text { Remodelamento plexiforme de } \\
\text { arteríolas pré-acinares }\end{array}$} & \multicolumn{4}{|c|}{ Sobrevida hospitalar } & \multirow{2}{*}{ Total } & \multirow{2}{*}{$(\%)$} \\
\hline & não & $(\%)$ & sim & $(\%)$ & & \\
\hline 0 & 29 & (50) & 29 & (50) & 58 & (100) \\
\hline 1 & 3 & (60) & 2 & (40) & 5 & (100) \\
\hline Total & 32 & (51) & 31 & (49) & 63 & $(100)$ \\
\hline
\end{tabular}


Tabela A4. 9: Distribuição da sobrevida hospitalar segundo o parâmetro Exocitose de células mononucleares em arteríolas pré-acinares

\begin{tabular}{ccccccc}
\hline $\begin{array}{c}\text { Exocitose de células } \\
\text { mononucleares em arteríolas } \\
\text { pré-acinares }\end{array}$ & não & $(\%)$ & $\operatorname{sim}$ & $(\%)$ & Total & $(\%)$ \\
\hline 0 & 30 & $(54)$ & 26 & $(46)$ & 56 & $(100)$ \\
1 & 2 & $(29)$ & 5 & $(71)$ & 7 & $(100)$ \\
\hline Total & 32 & $(51)$ & 31 & $(49)$ & 63 & $(100)$ \\
\hline
\end{tabular}

Tabela A4. 10: Distribuição da sobrevida hospitalar segundo o parâmetro Exocitose de neutrófilos em arteríolas pré-acinares

\begin{tabular}{|c|c|c|c|c|c|c|}
\hline Exocitose de neutrófilos & & revida & itala & & & \\
\hline em arteríolas pré-acinares & não & $(\%)$ & $\operatorname{sim}$ & $(\%)$ & Total & $(\%)$ \\
\hline 0 & 32 & (51) & 31 & (49) & 63 & (100) \\
\hline Total & 32 & (51) & 31 & (49) & 63 & (100) \\
\hline
\end{tabular}

Tabela A4. 11: Distribuição da sobrevida hospitalar segundo o parâmetro Exocitose de eosinófilos em arteríolas pré-acinares

\begin{tabular}{ccccccc}
\hline Exocitose de eosinófilos & \multicolumn{4}{c}{ Sobrevida hospitalar } & \multirow{2}{*}{ Total } & \multirow{2}{*}{$(\%)$} \\
\cline { 2 - 5 } em arteríolas pré-acinares & não & $(\%)$ & $\operatorname{sim}$ & $(\%)$ & & \\
\hline 0 & 32 & $(52)$ & 30 & $(48)$ & 62 & $(100)$ \\
2 & & & 1 & $(100)$ & 1 & $(100)$ \\
\hline Total & 32 & $(51)$ & 31 & $(49)$ & 63 & $(100)$ \\
\hline
\end{tabular}

Tabela A4. 12: Distribuição da sobrevida hospitalar segundo o parâmetro Calcificação na periferia de arteríolas pré-acinares

\begin{tabular}{|c|c|c|c|c|c|c|}
\hline \multirow{2}{*}{$\begin{array}{l}\text { Calcificação na periferia de } \\
\text { arteríolas pré-acinares }\end{array}$} & \multicolumn{4}{|c|}{ Sobrevida hospitalar } & \multirow{2}{*}{ Total } & \multirow{2}{*}{$(\%)$} \\
\hline & não & $(\%)$ & $\operatorname{sim}$ & $(\%)$ & & \\
\hline 0 & 32 & $(52)$ & 30 & (48) & 62 & (100) \\
\hline 1 & & & 1 & $(100)$ & 1 & (100) \\
\hline Total & 32 & (51) & 31 & (49) & 63 & $(100)$ \\
\hline
\end{tabular}

Tabela A4. 13: Distribuição da sobrevida hospitalar segundo o parâmetro Deposição de amilóide em arteríolas pré-acinares

\begin{tabular}{|c|c|c|c|c|c|c|}
\hline \multirow{2}{*}{$\begin{array}{l}\text { Deposição de amilóide em } \\
\text { arteríolas pré-acinares }\end{array}$} & \multicolumn{4}{|c|}{ Sobrevida hospitalar } & \multirow{2}{*}{ Total } & \multirow{2}{*}{$(\%)$} \\
\hline & não & $(\%)$ & $\operatorname{sim}$ & (\%) & & \\
\hline 0 & 32 & $(52)$ & 30 & $(48)$ & 62 & $(100)$ \\
\hline 1 & & & 1 & $(100)$ & 1 & (100) \\
\hline Total & 32 & (51) & 31 & (49) & 63 & (100) \\
\hline
\end{tabular}


Tabela A4. 14: Distribuição da sobrevida hospitalar segundo o parâmetro Granulomas em arteríolas pré-acinares

\begin{tabular}{|c|c|c|c|c|c|c|}
\hline \multirow{2}{*}{$\begin{array}{c}\text { Granulomas em arteríolas } \\
\text { pré-acinares }\end{array}$} & \multicolumn{4}{|c|}{ Sobrevida hospitalar } & \multirow{2}{*}{ Total } & \multirow{2}{*}{$(\%)$} \\
\hline & não & $(\%)$ & sim & $(\%)$ & & \\
\hline 0 & 31 & (50) & 31 & (50) & 62 & $(100)$ \\
\hline 2 & 1 & (100) & & & 1 & $(100)$ \\
\hline Total & 32 & $(51)$ & 31 & (49) & 63 & (100) \\
\hline
\end{tabular}

Tabela A4. 15: Distribuição da sobrevida hospitalar segundo o parâmetro Invasão fúngica em arteríolas pré-acinares

\begin{tabular}{|c|c|c|c|c|c|c|}
\hline \multirow{2}{*}{$\begin{array}{l}\text { Invasão fúngica em arteríolas } \\
\text { pré-acinares }\end{array}$} & \multicolumn{4}{|c|}{ Sobrevida hospitalar } & \multirow{2}{*}{ Total } & \multirow{2}{*}{ (\%) } \\
\hline & não & $(\%)$ & sim & $(\%)$ & & \\
\hline 0 & 31 & (50) & 31 & (50) & 62 & (100) \\
\hline 1 & 1 & (100) & & & 1 & (100) \\
\hline Total & 32 & (51) & 31 & (49) & 63 & (100) \\
\hline
\end{tabular}

Tabela A4. 16: Distribuição da sobrevida hospitalar segundo o parâmetro Efeito citopático em células endoteliais de arteríolas pré-acinares

\begin{tabular}{|c|c|c|c|c|c|c|}
\hline \multirow{2}{*}{$\begin{array}{c}\text { Efeito citopático em células } \\
\text { endoteliais de arteríolas pré- } \\
\text { acinares }\end{array}$} & \multicolumn{4}{|c|}{ Sobrevida hospitalar } & \multirow{2}{*}{ Total } & \multirow{2}{*}{$(\%)$} \\
\hline & não & $(\%)$ & sim & $(\%)$ & & \\
\hline 0 & 31 & $(50)$ & 31 & (50) & 62 & $(100)$ \\
\hline 1 & 1 & $(100)$ & & & 1 & (100) \\
\hline Total & 32 & $(51)$ & 31 & (49) & 63 & $(100)$ \\
\hline
\end{tabular}

Tabela A4. 17: Distribuição da sobrevida hospitalar segundo o parâmetro Embolização gordurosa em arteríolas pré-acinares

\begin{tabular}{|c|c|c|c|c|c|c|}
\hline \multirow{2}{*}{$\begin{array}{l}\text { Embolização gordurosa em } \\
\text { arteríolas pré-acinares }\end{array}$} & \multicolumn{4}{|c|}{ Sobrevida hospitalar } & \multirow{2}{*}{ Total } & \multirow{2}{*}{ (\%) } \\
\hline & não & $(\%)$ & sim & $(\%)$ & & \\
\hline 0 & 32 & (52) & 30 & (48) & 62 & $(100)$ \\
\hline 1 & & & 1 & (100) & 1 & (100) \\
\hline Total & 32 & (51) & 31 & (49) & 63 & $(100)$ \\
\hline
\end{tabular}

Tabela A4. 18: Distribuição da sobrevida hospitalar segundo o parâmetro Necrose de arteríolas pré-acinares

\begin{tabular}{|c|c|c|c|c|c|c|}
\hline \multirow{2}{*}{$\begin{array}{l}\text { Necrose de arteríolas pré- } \\
\text { acinares }\end{array}$} & \multicolumn{4}{|c|}{ Sobrevida hospitalar } & \multirow{2}{*}{ Total } & \multirow{2}{*}{$(\%)$} \\
\hline & não & $(\%)$ & $\operatorname{sim}$ & $(\%)$ & & \\
\hline 0 & 32 & (51) & 31 & (49) & 63 & (100) \\
\hline Total & 32 & (51) & 31 & (49) & 63 & $(100)$ \\
\hline
\end{tabular}




\section{A5. ALTERAÇÕES HISTOLÓGICAS OBSERVADAS EM ARTERÍOLAS PÓS-ACINARES E SUA RELAÇÃO COM A SOBREVIDA HOSPITALAR}

Tabela A5. 1: Distribuição da sobrevida hospitalar segundo o parâmetro Ectasia de arteríolas pós-acinares

\begin{tabular}{|c|c|c|c|c|c|c|}
\hline \multirow{2}{*}{$\begin{array}{l}\text { Ectasia de arteríolas pós- } \\
\text { acinares }\end{array}$} & \multicolumn{4}{|c|}{ Sobrevida hospitalar } & \multirow{2}{*}{ Total } & \multirow{2}{*}{$(\%)$} \\
\hline & não & $(\%)$ & $\operatorname{sim}$ & $(\%)$ & & \\
\hline 0 & 31 & $(50)$ & 31 & (50) & 62 & (100) \\
\hline 1 & 1 & (100) & & & 1 & $(100)$ \\
\hline Total & 32 & (51) & 31 & (49) & 63 & (100) \\
\hline
\end{tabular}

Tabela A5. 2: Distribuição da sobrevida hospitalar segundo o parâmetro Trombose de arteríolas pós-acinares

\begin{tabular}{|c|c|c|c|c|c|c|}
\hline \multirow{2}{*}{$\begin{array}{c}\text { Trombose de arteríolas pós- } \\
\text { acinares }\end{array}$} & \multicolumn{4}{|c|}{ Sobrevida hospitalar } & \multirow{2}{*}{ Total } & \multirow{2}{*}{$(\%)$} \\
\hline & não & $(\%)$ & sim & $(\%)$ & & \\
\hline 0 & 30 & (50) & 30 & (50) & 60 & (100) \\
\hline 1 & 2 & (67) & 1 & (33) & 3 & (100) \\
\hline Total & 32 & (51) & 31 & (49) & 63 & (100) \\
\hline
\end{tabular}

Tabela A5. 3: Distribuição da sobrevida hospitalar segundo o parâmetro Ectasia de vasavasorum de arteríolas pós-acinares

\begin{tabular}{|c|c|c|c|c|c|c|}
\hline \multirow{2}{*}{$\begin{array}{l}\text { Ectasia de vasa-vasorum de } \\
\text { arteríolas pós-acinares }\end{array}$} & \multicolumn{4}{|c|}{ Sobrevida hospitalar } & \multirow{2}{*}{ Total } & \multirow{2}{*}{$(\%)$} \\
\hline & não & $(\%)$ & sim & $(\%)$ & & \\
\hline 0 & 32 & (52) & 30 & (48) & 62 & (100) \\
\hline 1 & & & 1 & (100) & 1 & (100) \\
\hline Total & 32 & (51) & 31 & (49) & 63 & (100) \\
\hline
\end{tabular}

Tabela A5. 4: Distribuição da sobrevida hospitalar segundo o parâmetro Proliferação adventiceal de arteríolas pós-acinares

\begin{tabular}{|c|c|c|c|c|c|c|}
\hline \multirow{2}{*}{$\begin{array}{l}\text { Proliferação adventiceal de } \\
\text { arteríolas pós-acinares }\end{array}$} & \multicolumn{4}{|c|}{ Sobrevida hospitalar } & \multirow{2}{*}{ Total } & \multirow{2}{*}{$(\%)$} \\
\hline & não & $(\%)$ & $\operatorname{sim}$ & $(\%)$ & & \\
\hline 0 & 25 & $(60)$ & 17 & $(40)$ & 42 & $(100)$ \\
\hline 1 & 5 & (33) & 10 & (67) & 15 & (100) \\
\hline 2 & 2 & (33) & 4 & (67) & 6 & $(100)$ \\
\hline Total & 32 & (51) & 31 & (49) & 63 & (100) \\
\hline
\end{tabular}


Tabela A5. 5: Distribuição da sobrevida hospitalar segundo o parâmetro Hipertrofia da camada média de arteríolas pós-acinares

\begin{tabular}{ccccccc}
\hline $\begin{array}{c}\text { Hipertrofia da camada } \\
\text { média de arteríolas pós- } \\
\text { acinares }\end{array}$ & não & $(\%)$ & $\operatorname{sim}$ & $(\%)$ & Total & $(\%)$ \\
\hline 0 & 6 & $(35)$ & 11 & $(65)$ & 17 & $(100)$ \\
1 & 14 & $(70)$ & 6 & $(30)$ & 20 & $(100)$ \\
2 & 9 & $(50)$ & 9 & $(50)$ & 18 & $(100)$ \\
3 & 3 & $(38)$ & 5 & $(63)$ & 8 & $(100)$ \\
\hline Total & 32 & $(51)$ & 31 & $(49)$ & 63 & $(100)$ \\
\hline
\end{tabular}

Tabela A5. 6: Distribuição da sobrevida hospitalar segundo o parâmetro Proliferação fibrointimal de arteríolas pós-acinares

\begin{tabular}{|c|c|c|c|c|c|c|}
\hline \multirow{2}{*}{$\begin{array}{l}\text { Proliferação fibrointimal de } \\
\text { arteríolas pós-acinares }\end{array}$} & \multicolumn{4}{|c|}{ Sobrevida hospitalar } & \multirow{2}{*}{ Total } & \multirow{2}{*}{$(\%)$} \\
\hline & não & $(\%)$ & $\operatorname{sim}$ & $(\%)$ & & \\
\hline 0 & 18 & (49) & 19 & (51) & 37 & $(100)$ \\
\hline 1 & 8 & $(50)$ & 8 & $(50)$ & 16 & $(100)$ \\
\hline 2 & 6 & $(60)$ & 4 & $(40)$ & 10 & $(100)$ \\
\hline Total & 32 & (51) & 31 & (49) & 63 & $(100)$ \\
\hline
\end{tabular}

Tabela A5. 7: Distribuição da sobrevida hospitalar segundo o parâmetro Tumefação endotelial de arteríolas pós-acinares

\begin{tabular}{|c|c|c|c|c|c|c|}
\hline \multirow{2}{*}{$\begin{array}{l}\text { Tumefação endotelial de } \\
\text { arteríolas pós-acinares }\end{array}$} & \multicolumn{4}{|c|}{ Sobrevida hospitalar } & \multirow{2}{*}{ Total } & \multirow{2}{*}{$(\%)$} \\
\hline & não & $(\%)$ & $\operatorname{sim}$ & $(\%)$ & & \\
\hline 0 & 22 & $(54)$ & 19 & (46) & 41 & (100) \\
\hline 1 & 8 & $(40)$ & 12 & $(60)$ & 20 & $(100)$ \\
\hline 2 & 2 & $(100)$ & & & 2 & $(100)$ \\
\hline Total & 32 & (51) & 31 & (49) & 63 & (100) \\
\hline
\end{tabular}

Tabela A5. 8: Distribuição da sobrevida hospitalar segundo o parâmetro Remodelamento plexiforme de arteríolas pós-acinares

\begin{tabular}{|c|c|c|c|c|c|c|}
\hline \multirow{2}{*}{$\begin{array}{l}\text { Remodelamento plexiforme de } \\
\text { arteríolas pós-acinares }\end{array}$} & \multicolumn{4}{|c|}{ Sobrevida hospitalar } & \multirow{2}{*}{ Total } & \multirow{2}{*}{$(\%)$} \\
\hline & não & $(\%)$ & $\operatorname{sim}$ & $(\%)$ & & \\
\hline 0 & 31 & (53) & 27 & (47) & 58 & (100) \\
\hline 1 & 1 & (25) & 3 & (75) & 4 & (100) \\
\hline 3 & & & 1 & $(100)$ & 1 & (100) \\
\hline Total & 32 & (51) & 31 & (49) & 63 & (100) \\
\hline
\end{tabular}


Tabela A5. 9: Distribuição da sobrevida hospitalar segundo o parâmetro Exocitose de células mononucleares em arteríolas pós-acinares

\begin{tabular}{ccccccc}
\hline $\begin{array}{c}\text { Exocitose de células } \\
\text { mononucleares em arteríolas pós- } \\
\text { acinares }\end{array}$ & não & $(\%)$ & $\operatorname{sim}$ & $(\%)$ & Total & $(\%)$ \\
\hline 0 & 31 & $(52)$ & 29 & $(48)$ & 60 & $(100)$ \\
1 & 1 & $(33)$ & 2 & $(67)$ & 3 & $(100)$ \\
\hline Total & 32 & $(51)$ & 31 & $(49)$ & 63 & $(100)$ \\
\hline
\end{tabular}

Tabela A5. 10: Distribuição da sobrevida hospitalar segundo o parâmetro Exocitose de neutrófilos em arteríolas pós-acinares

\begin{tabular}{ccccccc}
\hline $\begin{array}{c}\text { Exocitose de neutrófilos } \\
\text { em arteríolas pós- } \\
\text { acinares }\end{array}$ & não & $(\%)$ & $\operatorname{sim}$ & $(\%)$ & Total & $(\%)$ \\
\cline { 2 - 5 } & 32 & $(52)$ & 30 & $(48)$ & 62 & $(100)$ \\
3 & 32 & $(51)$ & 31 & $(49)$ & 63 & $(100)$ \\
\hline Total & 32 & & & $(100)$ & 1 & $(100)$ \\
\hline
\end{tabular}

Tabela A5. 11: Distribuição da sobrevida hospitalar segundo o parâmetro Exocitose de eosinófilos em arteríolas pós-acinares

\begin{tabular}{|c|c|c|c|c|c|c|}
\hline \multirow{2}{*}{$\begin{array}{l}\text { Exocitose de eosinófilos em } \\
\text { arteríolas pós-acinares }\end{array}$} & \multicolumn{4}{|c|}{ Sobrevida hospitalar } & \multirow{2}{*}{ Total } & \multirow{2}{*}{ (\%) } \\
\hline & não & $(\%)$ & $\operatorname{sim}$ & $(\%)$ & & \\
\hline 0 & 32 & (52) & 30 & (48) & 62 & (100) \\
\hline 1 & & & 1 & (100) & 1 & (100) \\
\hline Total & 32 & (51) & 31 & $(49)$ & 63 & $\begin{array}{l}(100) \\
\end{array}$ \\
\hline
\end{tabular}

Tabela A5. 12: Distribuição da sobrevida hospitalar segundo o parâmetro Calcificação na periferia de arteríolas pós-acinares

\begin{tabular}{|c|c|c|c|c|c|c|}
\hline \multirow{2}{*}{$\begin{array}{l}\text { Calcificação na periferia de } \\
\text { arteríolas pós-acinares }\end{array}$} & \multicolumn{4}{|c|}{ Sobrevida hospitalar } & \multirow{2}{*}{ Total } & \multirow{2}{*}{$(\%)$} \\
\hline & não & $(\%)$ & $\operatorname{sim}$ & $(\%)$ & & \\
\hline 0 & 32 & (52) & 30 & (48) & 62 & (100) \\
\hline 2 & & & 1 & (100) & 1 & (100) \\
\hline Total & 32 & (51) & 31 & (49) & 63 & (100) \\
\hline
\end{tabular}

Tabela A5. 13: Distribuição da sobrevida hospitalar segundo o parâmetro Obliteração de arteríolas pós-acinares

\begin{tabular}{|c|c|c|c|c|c|c|}
\hline \multirow{2}{*}{$\begin{array}{l}\text { Obliteração de arteríolas } \\
\text { pós-acinares }\end{array}$} & \multicolumn{4}{|c|}{ Sobrevida hospitalar } & \multirow{2}{*}{ Total } & \multirow{2}{*}{$(\%)$} \\
\hline & não & $(\%)$ & $\operatorname{sim}$ & $(\%)$ & & \\
\hline 0 & 32 & (52) & 30 & (48) & 62 & (100) \\
\hline 4 & & & 1 & (100) & 1 & (100) \\
\hline Total & 32 & (51) & 31 & (49) & 63 & $\begin{array}{l}(100) \\
\end{array}$ \\
\hline
\end{tabular}


Tabela A5. 14: Distribuição da sobrevida hospitalar segundo o parâmetro Invasão fúngica em arteríolas pós-acinares

\begin{tabular}{|c|c|c|c|c|c|c|}
\hline \multirow{2}{*}{$\begin{array}{l}\text { Invasão fúngica em arteríolas } \\
\text { pós-acinares }\end{array}$} & \multicolumn{4}{|c|}{ Sobrevida hospitalar } & \multirow{2}{*}{ Total } & \multirow{2}{*}{$(\%)$} \\
\hline & não & $(\%)$ & $\operatorname{sim}$ & $(\%)$ & & \\
\hline 0 & 31 & (50) & 31 & (50) & 62 & (100) \\
\hline 1 & 1 & (100) & & & 1 & (100) \\
\hline Total & 32 & $(51)$ & 31 & (49) & 63 & $(100)$ \\
\hline
\end{tabular}

Tabela A5. 15: Distribuição da sobrevida hospitalar segundo o parâmetro Necrose de arteríolas pós-acinares

\begin{tabular}{|c|c|c|c|c|c|c|}
\hline \multirow{2}{*}{$\begin{array}{l}\text { Necrose de arteríolas pós- } \\
\text { acinares }\end{array}$} & \multicolumn{4}{|c|}{ Sobrevida hospitalar } & \multirow{2}{*}{ Total } & \multirow{2}{*}{$(\%)$} \\
\hline & não & $(\%)$ & $\operatorname{sim}$ & $(\%)$ & & \\
\hline 0 & 32 & (51) & 31 & (49) & 63 & $(100)$ \\
\hline Total & 32 & (51) & 31 & (49) & 63 & $(100)$ \\
\hline
\end{tabular}




\section{A6. ALTERAÇÕES HISTOLÓGICAS OBSERVADAS EM VEIAS E LINFÁTICOS E SUA RELAÇÃO COM A SOBREVIDA HOSPITALAR}

Tabela A6. 1: Distribuição da sobrevida hospitalar segundo o parâmetro Ectasia de vasos linfáticos

\begin{tabular}{|c|c|c|c|c|c|c|}
\hline \multirow{2}{*}{ Ectasia de vasos linfáticos } & \multicolumn{4}{|c|}{ Sobrevida hospitalar } & \multirow{2}{*}{ Total } & \multirow{2}{*}{$(\%)$} \\
\hline & não & $(\%)$ & $\operatorname{sim}$ & $(\%)$ & & \\
\hline 0 & 20 & (61) & 13 & (39) & 33 & (100) \\
\hline 1 & 5 & (36) & 9 & (64) & 14 & (100) \\
\hline 2 & 2 & (29) & 5 & (71) & 7 & (100) \\
\hline 3 & 3 & (43) & 4 & (57) & 7 & (100) \\
\hline 4 & 2 & (100) & & & 2 & (100) \\
\hline Total & 32 & (51) & 31 & (49) & 63 & (100) \\
\hline
\end{tabular}

Tabela A6. 2: Distribuição da sobrevida hospitalar segundo o parâmetro Ectasia venosa

\begin{tabular}{|c|c|c|c|c|c|c|}
\hline \multirow{2}{*}{ Ectasia venosa } & \multicolumn{4}{|c|}{ Sobrevida hospitalar } & \multirow{2}{*}{ Total } & \multirow{2}{*}{$(\%)$} \\
\hline & não & $(\%)$ & sim & $(\%)$ & & \\
\hline 0 & 19 & (66) & 10 & (34) & 29 & (100) \\
\hline 1 & 10 & (45) & 12 & (55) & 22 & (100) \\
\hline 2 & 3 & (38) & 5 & (63) & 8 & (100) \\
\hline 3 & & & 4 & (100) & 4 & (100) \\
\hline Total & 32 & (51) & 31 & $(49)$ & 63 & (100) \\
\hline
\end{tabular}

Tabela A6. 3: Distribuição da sobrevida hospitalar segundo o parâmetro Trombose venosa

\begin{tabular}{|c|c|c|c|c|c|c|}
\hline \multirow{2}{*}{ Trombose venosa } & \multicolumn{4}{|c|}{ Sobrevida hospitalar } & \multirow{2}{*}{ Total } & \multirow{2}{*}{$(\%)$} \\
\hline & não & $(\%)$ & sim & $(\%)$ & & \\
\hline 0 & 30 & (49) & 31 & (51) & 61 & (100) \\
\hline 1 & 2 & $(100)$ & & & 2 & $(100)$ \\
\hline Total & 32 & $(51)$ & 31 & (49) & 63 & $(100)$ \\
\hline
\end{tabular}

Tabela A6. 4: Distribuição da sobrevida hospitalar segundo o parâmetro Espessamento venoso

\begin{tabular}{|c|c|c|c|c|c|c|}
\hline \multirow{2}{*}{ Espessamento venoso } & \multicolumn{4}{|c|}{ Sobrevida hospitalar } & \multirow{2}{*}{ Total } & \multirow{2}{*}{$(\%)$} \\
\hline & não & $(\%)$ & $\operatorname{sim}$ & $(\%)$ & & \\
\hline 0 & 24 & (55) & 20 & (45) & 44 & $(100)$ \\
\hline 1 & 5 & (36) & 9 & (64) & 14 & (100) \\
\hline 2 & 2 & (67) & 1 & (33) & 3 & (100) \\
\hline 3 & 1 & (50) & 1 & (50) & 2 & (100) \\
\hline Total & 32 & (51) & 31 & (49) & 63 & (100) \\
\hline
\end{tabular}


Tabela A6. 5: Distribuição da sobrevida hospitalar segundo o parâmetro Neoangiogênese

\begin{tabular}{|c|c|c|c|c|c|c|}
\hline \multirow{2}{*}{ Neoangiogênese } & \multicolumn{4}{|c|}{ Sobrevida hospitalar } & \multirow{2}{*}{ Total } & \multirow{2}{*}{$(\%)$} \\
\hline & não & $(\%)$ & sim & $(\%)$ & & \\
\hline 0 & 19 & (53) & 17 & (47) & 36 & (100) \\
\hline 1 & 7 & (58) & 5 & (42) & 12 & (100) \\
\hline 2 & 3 & (43) & 4 & (57) & 7 & (100) \\
\hline 3 & 3 & (43) & 4 & (57) & 7 & (100) \\
\hline 4 & & & 1 & (100) & 1 & (100) \\
\hline Total & 32 & (51) & 31 & (49) & 63 & (100) \\
\hline
\end{tabular}

Tabela A6. 6: Distribuição da sobrevida hospitalar segundo o parâmetro Exocitose neutrofílica em veias

\begin{tabular}{|c|c|c|c|c|c|c|}
\hline \multirow{2}{*}{$\begin{array}{c}\text { Exocitose neutrofílica em } \\
\text { veias }\end{array}$} & \multicolumn{4}{|c|}{ Sobrevida hospitalar } & \multirow{2}{*}{ Total } & \multirow{2}{*}{ (\%) } \\
\hline & não & $(\%)$ & $\operatorname{sim}$ & $(\%)$ & & \\
\hline 0 & 32 & (52) & 30 & (48) & 62 & $(100)$ \\
\hline 1 & & & 1 & (100) & 1 & (100) \\
\hline Total & 32 & (51) & 31 & (49) & 63 & (100) \\
\hline
\end{tabular}

Tabela A6. 7: Distribuição da sobrevida hospitalar segundo o parâmetro Invasão fúngica em veias

\begin{tabular}{|c|c|c|c|c|c|c|}
\hline \multirow{2}{*}{ Invasão fúngica em veias } & \multicolumn{4}{|c|}{ Sobrevida hospitalar } & \multirow{2}{*}{ Total } & \multirow{2}{*}{$(\%)$} \\
\hline & não & $(\%)$ & $\operatorname{sim}$ & $(\%)$ & & \\
\hline 0 & 32 & $(51)$ & 31 & (49) & 63 & $(100)$ \\
\hline Total & 32 & (51) & 31 & (49) & 63 & $(100)$ \\
\hline
\end{tabular}




\section{A7. ALTERAÇÕES HISTOLÓGICAS OBSERVADAS EM BRONQUÍOLOS TERMINAIS E SUA RELAÇÃO COM A SOBREVIDA HOSPITALAR}

Tabela A7. 1: Distribuição da sobrevida hospitalar segundo o parâmetro Ectasia de bronquíolos terminais

\begin{tabular}{|c|c|c|c|c|c|c|}
\hline \multirow{2}{*}{$\begin{array}{c}\text { Ectasia de bronquíolos } \\
\text { terminais }\end{array}$} & \multicolumn{4}{|c|}{ Sobrevida hospitalar } & \multirow{2}{*}{ Total } & \multirow{2}{*}{$(\%)$} \\
\hline & não & $(\%)$ & sim & $(\%)$ & & \\
\hline 0 & 29 & (55) & 24 & (45) & 53 & (100) \\
\hline 1 & 3 & (50) & 3 & (50) & 6 & (100) \\
\hline 2 & & & 3 & (100) & 3 & (100) \\
\hline 3 & & & 1 & $(100)$ & 1 & (100) \\
\hline Total & 32 & (51) & 31 & (49) & 63 & (100) \\
\hline
\end{tabular}

Tabela A7. 2: Distribuição da sobrevida hospitalar segundo o parâmetro Impactação de muco em bronquíolos terminais

\begin{tabular}{|c|c|c|c|c|c|c|}
\hline \multirow{2}{*}{$\begin{array}{l}\text { Impactação de muco em } \\
\text { bronquíolos terminais }\end{array}$} & \multicolumn{4}{|c|}{ Sobrevida hospitalar } & \multirow{2}{*}{ Total } & \multirow{2}{*}{$(\%)$} \\
\hline & não & $(\%)$ & sim & $(\%)$ & & \\
\hline 0 & 25 & (61) & 16 & (39) & 41 & (100) \\
\hline 1 & 5 & (38) & 8 & (62) & 13 & (100) \\
\hline 2 & 1 & (20) & 4 & (80) & 5 & (100) \\
\hline 3 & 1 & (25) & 3 & (75) & 4 & (100) \\
\hline Total & 32 & (51) & 31 & (49) & 63 & $(100)$ \\
\hline
\end{tabular}

Tabela A7. 3: Distribuição da sobrevida hospitalar segundo o parâmetro Sub-oclusão de bronquíolos terminais

\begin{tabular}{|c|c|c|c|c|c|c|}
\hline \multirow{2}{*}{$\begin{array}{c}\text { Suboclusão de bronquíolos } \\
\text { terminais }\end{array}$} & \multicolumn{4}{|c|}{ Sobrevida hospitalar } & \multirow{2}{*}{ Total } & \multirow{2}{*}{$(\%)$} \\
\hline & não & $(\%)$ & sim & (\%) & & \\
\hline 0 & 23 & (49) & 24 & (51) & 47 & (100) \\
\hline 1 & 4 & (50) & 4 & (50) & 8 & (100) \\
\hline 2 & 3 & (60) & 2 & (40) & 5 & (100) \\
\hline 3 & 2 & (67) & 1 & (33) & 3 & (100) \\
\hline Total & 32 & (51) & 31 & (49) & 63 & (100) \\
\hline
\end{tabular}


Tabela A7. 4: Distribuição da sobrevida hospitalar segundo o parâmetro Pelos de tecido de granulação em bronquíolos terminais

\begin{tabular}{ccccccc}
\hline $\begin{array}{c}\text { Pelos de tecido de } \\
\text { granulação em bronquíolos } \\
\text { terminais }\end{array}$ & não & $(\%)$ & $\operatorname{sim}$ & $(\%)$ & Total & $(\%)$ \\
\hline 0 & 31 & $(53)$ & 27 & $(47)$ & 58 & $(100)$ \\
1 & 1 & $(33)$ & 2 & $(67)$ & 3 & $(100)$ \\
2 & 32 & $(51)$ & 31 & $(49)$ & 63 & $(100)$ \\
\hline Total & 32 & & 2 & $(100)$ & 2 & $(100)$ \\
\hline
\end{tabular}

Tabela A7. 5: Distribuição da sobrevida hospitalar segundo o parâmetro Espasmo de bronquíolos terminais

\begin{tabular}{|c|c|c|c|c|c|c|}
\hline \multirow{2}{*}{$\begin{array}{c}\text { Espasmo de bronquíolos } \\
\text { terminais }\end{array}$} & \multicolumn{4}{|c|}{ Sobrevida hospitalar } & \multirow{2}{*}{ Total } & \multirow{2}{*}{$(\%)$} \\
\hline & não & $(\%)$ & $\operatorname{sim}$ & $(\%)$ & & \\
\hline 0 & 16 & $(48)$ & 17 & $(52)$ & 33 & $(100)$ \\
\hline 1 & 9 & (56) & 7 & (44) & 16 & (100) \\
\hline 2 & 4 & (50) & 4 & (50) & 8 & (100) \\
\hline 3 & 3 & $(60)$ & 2 & $(40)$ & 5 & $(100)$ \\
\hline 4 & & & 1 & $(100)$ & 1 & (100) \\
\hline Total & 32 & (51) & 31 & $(49)$ & 63 & (100) \\
\hline
\end{tabular}

Tabela A7. 6: Distribuição da sobrevida hospitalar segundo o parâmetro Exsudato em bronquíolos terminais

\begin{tabular}{ccccccc}
\hline \multirow{2}{*}{$\begin{array}{c}\text { Exsudato em bronquíolos } \\
\text { terminais }\end{array}$} & não & $(\%)$ & sim & $(\%)$ & \multirow{2}{*}{ Total } & \multirow{2}{*}{$(\%)$} \\
\cline { 2 - 5 } & 27 & $(57)$ & 20 & $(43)$ & 47 & $(100)$ \\
1 & 4 & $(40)$ & 6 & $(60)$ & 10 & $(100)$ \\
2 & & & 3 & $(100)$ & 3 & $(100)$ \\
3 & 1 & $(33)$ & 2 & $(67)$ & 3 & $(100)$ \\
\hline 0 & 32 & $(51)$ & 31 & $(49)$ & 63 & $(100)$ \\
\hline Total & & & & & &
\end{tabular}

Tabela A7. 7: Distribuição da sobrevida hospitalar segundo o parâmetro Edema em bronquíolos terminais

\begin{tabular}{|c|c|c|c|c|c|c|}
\hline \multirow{2}{*}{$\begin{array}{c}\text { Edema em bronquíolos } \\
\text { terminais }\end{array}$} & \multicolumn{4}{|c|}{ Sobrevida hospitalar } & \multirow{2}{*}{ Total } & \multirow{2}{*}{$(\%)$} \\
\hline & não & (\%) & $\operatorname{sim}$ & $(\%)$ & & \\
\hline 0 & 24 & (51) & 23 & (49) & 47 & (100) \\
\hline 1 & 7 & (50) & 7 & (50) & 14 & (100) \\
\hline 2 & 1 & (50) & 1 & (50) & 2 & (100) \\
\hline Total & 32 & (51) & 31 & (49) & 63 & (100) \\
\hline
\end{tabular}


Tabela A7. 8: Distribuição da sobrevida hospitalar segundo o parâmetro Hemorragia em bronquíolos terminais

\begin{tabular}{|c|c|c|c|c|c|c|}
\hline \multirow{2}{*}{$\begin{array}{l}\text { Hemorragia em bronquíolos } \\
\text { terminais }\end{array}$} & \multicolumn{4}{|c|}{ Sobrevida hospitalar } & \multirow{2}{*}{ Total } & \multirow{2}{*}{$(\%)$} \\
\hline & não & $(\%)$ & $\operatorname{sim}$ & $(\%)$ & & \\
\hline 0 & 21 & (49) & 22 & (51) & 43 & (100) \\
\hline 1 & 9 & (53) & 8 & (47) & 17 & (100) \\
\hline 2 & 1 & (50) & 1 & (50) & 2 & (100) \\
\hline 3 & 1 & $(100)$ & & & 1 & (100) \\
\hline Total & 32 & $(51)$ & 31 & (49) & 63 & (100) \\
\hline
\end{tabular}

Tabela A7. 9: Distribuição da sobrevida hospitalar segundo o parâmetro Metaplasia escamosa de bronquíolos terminais

\begin{tabular}{|c|c|c|c|c|c|c|}
\hline \multirow{2}{*}{$\begin{array}{l}\text { Metaplasia escamosa de } \\
\text { bronquíolos terminais }\end{array}$} & \multicolumn{4}{|c|}{ Sobrevida hospitalar } & \multirow{2}{*}{ Total } & \multirow{2}{*}{$(\%)$} \\
\hline & não & $(\%)$ & sim & $(\%)$ & & \\
\hline 0 & 26 & (52) & 24 & $(48)$ & 50 & $(100)$ \\
\hline 1 & 5 & (56) & 4 & (44) & 9 & (100) \\
\hline 2 & 1 & (33) & 2 & (67) & 3 & (100) \\
\hline 3 & & & 1 & (100) & 1 & (100) \\
\hline Total & 32 & (51) & 31 & (49) & 63 & $(100)$ \\
\hline
\end{tabular}

Tabela A7. 10: Distribuição da sobrevida hospitalar segundo o parâmetro Decapitação epitelial de bronquíolos terminais

\begin{tabular}{|c|c|c|c|c|c|c|}
\hline \multirow{2}{*}{$\begin{array}{l}\text { Decapitação epitelial de } \\
\text { bronquíolos terminais }\end{array}$} & \multicolumn{4}{|c|}{ Sobrevida hospitalar } & \multirow{2}{*}{ Total } & \multirow{2}{*}{$(\%)$} \\
\hline & não & $(\%)$ & sim & $(\%)$ & & \\
\hline 0 & 11 & (48) & 12 & $(52)$ & 23 & $(100)$ \\
\hline 1 & 16 & (55) & 13 & (45) & 29 & (100) \\
\hline 2 & 3 & (33) & 6 & (67) & 9 & (100) \\
\hline 3 & 2 & (100) & & & 2 & (100) \\
\hline Total & 32 & $(51)$ & 31 & (49) & 63 & (100) \\
\hline
\end{tabular}

Tabela A7. 11: Distribuição da sobrevida hospitalar segundo o parâmetro Descamação de bronquíolos terminais

\begin{tabular}{|c|c|c|c|c|c|c|}
\hline \multirow{2}{*}{$\begin{array}{c}\text { Descamação de bronquíolos } \\
\text { terminais }\end{array}$} & \multicolumn{4}{|c|}{ Sobrevida hospitalar } & \multirow{2}{*}{ Total } & \multirow{2}{*}{$(\%)$} \\
\hline & não & $(\%)$ & $\operatorname{sim}$ & $(\%)$ & & \\
\hline 0 & 10 & (53) & 9 & (47) & 19 & (100) \\
\hline 1 & 13 & (57) & 10 & (43) & 23 & (100) \\
\hline 2 & 8 & (47) & 9 & (53) & 17 & (100) \\
\hline 3 & 1 & (25) & 3 & (75) & 4 & $(100)$ \\
\hline Total & 32 & $(51)$ & 31 & (49) & 63 & $(100)$ \\
\hline
\end{tabular}


Tabela A7. 12: Distribuição da sobrevida hospitalar segundo o parâmetro Hiperplasia epitelial de bronquíolos terminais

\begin{tabular}{|c|c|c|c|c|c|c|}
\hline \multirow{2}{*}{$\begin{array}{l}\text { Hiperplasia epitelial de } \\
\text { bronquíolos terminais }\end{array}$} & \multicolumn{4}{|c|}{ Sobrevida hospitalar } & \multirow{2}{*}{ Total } & \multirow{2}{*}{$(\%)$} \\
\hline & não & $(\%)$ & $\operatorname{sim}$ & $(\%)$ & & \\
\hline 0 & 15 & (68) & 7 & (32) & 22 & $(100)$ \\
\hline 1 & 10 & (38) & 16 & (62) & 26 & (100) \\
\hline 2 & 6 & (46) & 7 & (54) & 13 & (100) \\
\hline 3 & 1 & (50) & 1 & (50) & 2 & (100) \\
\hline Total & 32 & (51) & 31 & (49) & 63 & (100) \\
\hline
\end{tabular}

Tabela A7. 13: Distribuição da sobrevida hospitalar segundo o parâmetro Efeito citopático de bronquíolos terminais

\begin{tabular}{|c|c|c|c|c|c|c|}
\hline \multirow{2}{*}{$\begin{array}{l}\text { Efeito citopático de } \\
\text { bronquíolos terminais }\end{array}$} & \multicolumn{4}{|c|}{ Sobrevida hospitalar } & \multirow{2}{*}{ Total } & \multirow{2}{*}{$(\%)$} \\
\hline & não & $(\%)$ & sim & $(\%)$ & & \\
\hline 0 & 21 & $(50)$ & 21 & (50) & 42 & (100) \\
\hline 1 & 8 & (50) & 8 & (50) & 16 & (100) \\
\hline 2 & 3 & (60) & 2 & (40) & 5 & (100) \\
\hline Total & 32 & (51) & 31 & (49) & 63 & (100) \\
\hline
\end{tabular}

Tabela A7. 14: Distribuição da sobrevida hospitalar segundo o parâmetro Necrose epitelial de bronquíolos terminais

\begin{tabular}{|c|c|c|c|c|c|c|}
\hline \multirow{2}{*}{$\begin{array}{c}\text { Necrose epitelial de } \\
\text { bronquíolos terminais }\end{array}$} & \multicolumn{4}{|c|}{ Sobrevida hospitalar } & \multirow{2}{*}{ Total } & \multirow{2}{*}{$(\%)$} \\
\hline & não & $(\%)$ & sim & $(\%)$ & & \\
\hline 0 & 29 & (54) & 25 & $(46)$ & 54 & (100) \\
\hline 1 & 1 & (25) & 3 & $(75)$ & 4 & (100) \\
\hline 2 & 2 & $(40)$ & 3 & $(60)$ & 5 & $(100)$ \\
\hline Total & 32 & (51) & 31 & (49) & 63 & (100) \\
\hline
\end{tabular}

Tabela A7. 15: Distribuição da sobrevida hospitalar segundo o parâmetro Degeneração epitelial de bronquíolos terminais

\begin{tabular}{|c|c|c|c|c|c|c|}
\hline \multirow{2}{*}{$\begin{array}{l}\text { Degeneração epitelial de } \\
\text { bronquíolos terminais }\end{array}$} & \multicolumn{4}{|c|}{ Sobrevida hospitalar } & \multirow{2}{*}{ Total } & \multirow{2}{*}{$(\%)$} \\
\hline & não & $(\%)$ & $\operatorname{sim}$ & $(\%)$ & & \\
\hline 0 & 31 & (53) & 28 & $(47)$ & 59 & (100) \\
\hline 1 & 1 & (33) & 2 & (67) & 3 & (100) \\
\hline 2 & & & 1 & (100) & 1 & (100) \\
\hline Total & 32 & (51) & 31 & $(49)$ & 63 & $(100)$ \\
\hline
\end{tabular}


Tabela A7. 16: Distribuição da sobrevida hospitalar segundo o parâmetro Infiltrado de células mononucleares em bronquíolos terminais

\begin{tabular}{ccccccc}
\hline \multirow{2}{*}{$\begin{array}{c}\text { Infiltrado de células } \\
\text { mononucleares em } \\
\text { bronquíolos terminais }\end{array}$} & não & $(\%)$ & $\operatorname{sim}$ & $(\%)$ & Total & $(\%)$ \\
\cline { 2 - 6 } & 30 & $(50)$ & 30 & $(50)$ & 60 & $(100)$ \\
1 & 2 & $(100)$ & & & 2 & $(100)$ \\
2 & 32 & $(51)$ & 31 & $(49)$ & 63 & $(100)$ \\
\hline Total & $3100)$ &
\end{tabular}

Tabela A7. 17: Distribuição da sobrevida hospitalar segundo o parâmetro Infiltrado neutrofílico em bronquíolos terminais

\begin{tabular}{|c|c|c|c|c|c|c|}
\hline \multirow{2}{*}{$\begin{array}{l}\text { Infiltrado neutrofílico em } \\
\text { bronquíolos terminais }\end{array}$} & \multicolumn{4}{|c|}{ Sobrevida hospitalar } & \multirow{2}{*}{ Total } & \multirow{2}{*}{$(\%)$} \\
\hline & não & $(\%)$ & sim & (\%) & & \\
\hline 0 & 31 & (50) & 31 & (50) & 62 & (100) \\
\hline 1 & 1 & (100) & & & 1 & (100) \\
\hline Total & 32 & (51) & 31 & (49) & 63 & (100) \\
\hline
\end{tabular}

Tabela A7. 18: Distribuição da sobrevida hospitalar segundo o parâmetro Hipertrofia da musculatura peribronquiolar de bronquíolos terminais

\begin{tabular}{ccccccc}
\hline $\begin{array}{c}\text { Hipertrofia da musculatura } \\
\text { peribronquiolar de } \\
\text { bronquíolos terminais }\end{array}$ & não & $(\%)$ & $\operatorname{sim}$ & $(\%)$ & Total & $(\%)$ \\
\cline { 2 - 5 } & 32 & $(52)$ & 29 & $(48)$ & 61 & $(100)$ \\
2 & 32 & $(51)$ & 31 & $(49)$ & 63 & $(100)$ \\
\hline Total & 32 & & & &
\end{tabular}

Tabela A7. 19: Distribuição da sobrevida hospitalar segundo o parâmetro Presença de células neoplásicas na luz de bronquíolos terminais

\begin{tabular}{|c|c|c|c|c|c|c|}
\hline \multirow{2}{*}{$\begin{array}{l}\text { Presença de células } \\
\text { neoplásicas na luz de } \\
\text { bronquíolos terminais }\end{array}$} & \multicolumn{4}{|c|}{ Sobrevida hospitalar } & \multirow{2}{*}{ Total } & \multirow{2}{*}{$(\%)$} \\
\hline & não & $(\%)$ & $\operatorname{sim}$ & $(\%)$ & & \\
\hline 0 & 32 & $(52)$ & 29 & $(48)$ & 61 & $(100)$ \\
\hline 1 & & & 1 & $(100)$ & 1 & (100) \\
\hline 2 & & & 1 & (100) & 1 & (100) \\
\hline Total & 32 & $(51)$ & 31 & $(49)$ & 63 & $(100)$ \\
\hline
\end{tabular}


Tabela A7. 20: Distribuição da sobrevida hospitalar segundo o parâmetro Agregados de macrófagos na luz de bronquíolos terminais

\begin{tabular}{|c|c|c|c|c|c|c|}
\hline \multirow{2}{*}{$\begin{array}{l}\text { Agregados de macrófagos na } \\
\text { luz de bronquíolos terminais }\end{array}$} & \multicolumn{4}{|c|}{ Sobrevida hospitalar } & \multirow{2}{*}{ Total } & \multirow{2}{*}{$(\%)$} \\
\hline & não & $(\%)$ & sim & $(\%)$ & & \\
\hline 0 & 29 & (49) & 30 & (51) & 59 & (100) \\
\hline 1 & 1 & $(100)$ & & & 1 & (100) \\
\hline 2 & 2 & $(67)$ & 1 & (33) & 3 & (100) \\
\hline Total & 32 & (51) & 31 & (49) & 63 & $(100)$ \\
\hline
\end{tabular}

Tabela A7. 21: Distribuição da sobrevida hospitalar segundo o parâmetro Calcificação na periferia de bronquíolos terminais

\begin{tabular}{|c|c|c|c|c|c|c|}
\hline \multirow{2}{*}{$\begin{array}{l}\text { Calcificação na periferia de } \\
\text { bronquíolos terminais }\end{array}$} & \multicolumn{4}{|c|}{ Sobrevida hospitalar } & \multirow{2}{*}{ Total } & \multirow{2}{*}{ (\%) } \\
\hline & não & $(\%)$ & sim & $(\%)$ & & \\
\hline 0 & 32 & (52) & 30 & (48) & 62 & $(100)$ \\
\hline 1 & & & 1 & (100) & 1 & (100) \\
\hline Total & 32 & (51) & 31 & (49) & 63 & (100) \\
\hline
\end{tabular}

Tabela A7. 22: Distribuição da sobrevida hospitalar segundo o parâmetro Deposição de amilóide em bronquíolos terminais

\begin{tabular}{|c|c|c|c|c|c|c|}
\hline \multirow{2}{*}{$\begin{array}{l}\text { Deposição de amilóide em } \\
\text { bronquíolos terminais }\end{array}$} & \multicolumn{4}{|c|}{ Sobrevida hospitalar } & \multirow{2}{*}{ Total } & \multirow{2}{*}{$(\%)$} \\
\hline & não & $(\%)$ & sim & $(\%)$ & & \\
\hline 0 & 32 & $(52)$ & 30 & $(48)$ & 62 & $(100)$ \\
\hline 3 & & & 1 & $(100)$ & 1 & $(100)$ \\
\hline Total & 32 & $(51)$ & 31 & (49) & 63 & $(100)$ \\
\hline
\end{tabular}

Tabela A7. 23: Distribuição da sobrevida hospitalar segundo o parâmetro Presença de material amorfo com corpos estranhos na luz de bronquíolos terminais

\begin{tabular}{|c|c|c|c|c|c|c|}
\hline \multirow{2}{*}{$\begin{array}{l}\text { Presença de material } \\
\text { amorfo com corpos } \\
\text { estranhos na luz de } \\
\text { bronquíolos terminais }\end{array}$} & \multicolumn{4}{|c|}{ Sobrevida hospitalar } & \multirow[b]{2}{*}{ Total } & \multirow[b]{2}{*}{$(\%)$} \\
\hline & não & $(\%)$ & sim & $(\%)$ & & \\
\hline 0 & 32 & (52) & 29 & $(48)$ & 61 & $(100)$ \\
\hline 1 & & & 1 & (100) & 1 & (100) \\
\hline 3 & & & 1 & $(100)$ & 1 & $(100)$ \\
\hline Total & 32 & (51) & 31 & (49) & 63 & (100) \\
\hline
\end{tabular}


Tabela A7. 24: Distribuição da sobrevida hospitalar segundo o parâmetro Atrofia de bronquíolos terminais

\begin{tabular}{|c|c|c|c|c|c|c|}
\hline \multirow{2}{*}{$\begin{array}{c}\text { Atrofia de bronquíolos } \\
\text { terminais }\end{array}$} & \multicolumn{4}{|c|}{ Sobrevida hospitalar } & \multirow{2}{*}{ Total } & \multirow{2}{*}{$(\%)$} \\
\hline & não & $(\%)$ & sim & $(\%)$ & & \\
\hline 0 & 32 & $(52)$ & 30 & $(48)$ & 62 & $\begin{array}{l}(100) \\
\end{array}$ \\
\hline 3 & & & 1 & $(100)$ & 1 & (100) \\
\hline Total & 32 & (51) & 31 & (49) & 63 & (100) \\
\hline
\end{tabular}

Tabela A7. 25: Distribuição da sobrevida hospitalar segundo o parâmetro Reação gigantocelular a corpos estranhos na luz de bronquíolos terminais

\begin{tabular}{cccccccc}
\hline Reação gigantocelular a corpos & \multicolumn{5}{c}{ Sobrevida hospitalar } & \multirow{2}{*}{ Total } & $(\%)$ \\
\cline { 2 - 6 } $\begin{array}{c}\text { estranhos na luz de bronquíolos } \\
\text { terminais }\end{array}$ & não & $(\%)$ & $\operatorname{sim}$ & $(\%)$ & & \\
\hline 0 & 31 & $(50)$ & 31 & $(50)$ & 62 & $(100)$ \\
1 & 1 & $(100)$ & & & 1 & $(100)$ \\
\hline Total & 32 & $(51)$ & 31 & $(49)$ & 63 & $(100)$ \\
\hline
\end{tabular}

Tabela A7. 26: Distribuição da sobrevida hospitalar segundo o parâmetro Presença de bactérias em bronquíolos terminais

\begin{tabular}{|c|c|c|c|c|c|c|}
\hline \multirow{2}{*}{$\begin{array}{l}\text { Presença de bactérias em } \\
\text { bronquíolos terminais }\end{array}$} & \multicolumn{4}{|c|}{ Sobrevida hospitalar } & \multirow{2}{*}{ Total } & \multirow{2}{*}{$(\%)$} \\
\hline & não & $(\%)$ & sim & $(\%)$ & & \\
\hline 0 & 32 & $(51)$ & 31 & (49) & 63 & $(100)$ \\
\hline Total & 32 & $(51)$ & 31 & $(49)$ & 63 & $(100)$ \\
\hline
\end{tabular}

Tabela A7. 27: Distribuição da sobrevida hospitalar segundo o parâmetro Fibrose da submucosa de bronquíolos terminais

\begin{tabular}{cccccccc}
\hline $\begin{array}{c}\text { Fibrose da submucosa de } \\
\text { bronquíolos terminais }\end{array}$ & \multicolumn{5}{c}{ Sobrevida hospitalar } & Total & \multirow{2}{*}{$(\%)$} \\
\cline { 2 - 5 } & 32 & $(\%)$ & $\operatorname{sim}$ & $(\%)$ & & \\
\hline 0 & 32 & $(51)$ & 31 & $(49)$ & 63 & $(100)$ \\
\hline Total & & 31 & $(49)$ & 63 & $(100)$ \\
\hline
\end{tabular}

Tabela A7. 28: Distribuição da sobrevida hospitalar segundo o parâmetro Invasão fúngica de bronquíolos terminais

\begin{tabular}{|c|c|c|c|c|c|c|}
\hline \multirow{2}{*}{$\begin{array}{l}\text { Invasão fúngica de } \\
\text { bronquíolos terminais }\end{array}$} & \multicolumn{4}{|c|}{ Sobrevida hospitalar } & \multirow{2}{*}{ Total } & \multirow{2}{*}{$(\%)$} \\
\hline & não & $(\%)$ & sim & $(\%)$ & & \\
\hline 0 & 32 & (51) & 31 & (49) & 63 & $(100)$ \\
\hline Total & 32 & (51) & 31 & (49) & 63 & $(100)$ \\
\hline
\end{tabular}


Tabela A7. 29: Distribuição da sobrevida hospitalar segundo o parâmetro Presença de fibrina na luz de bronquíolos terminais

\begin{tabular}{|c|c|c|c|c|c|c|}
\hline \multirow{2}{*}{$\begin{array}{l}\text { Presença de fibrina na luz } \\
\text { de bronquíolos terminais }\end{array}$} & \multicolumn{4}{|c|}{ Sobrevida hospitalar } & \multirow{2}{*}{ Total } & \multirow{2}{*}{$(\%)$} \\
\hline & não & $(\%)$ & sim & $(\%)$ & & \\
\hline 0 & 32 & $(51)$ & 31 & (49) & 63 & $(100)$ \\
\hline Total & 32 & (51) & 31 & (49) & 63 & (100) \\
\hline
\end{tabular}

Tabela A7. 30: Distribuição da sobrevida hospitalar segundo o parâmetro Displasia epitelial de bronquíolos terminais

\begin{tabular}{|c|c|c|c|c|c|c|}
\hline \multirow{2}{*}{$\begin{array}{l}\text { Displasia epitelial de } \\
\text { bronquíolos terminais }\end{array}$} & \multicolumn{4}{|c|}{ Sobrevida hospitalar } & \multirow{2}{*}{ Total } & \multirow{2}{*}{$(\%)$} \\
\hline & não & $(\%)$ & sim & $(\%)$ & & \\
\hline 0 & 32 & $(51)$ & 31 & (49) & 63 & (100) \\
\hline Total & 32 & (51) & 31 & (49) & 63 & (100) \\
\hline
\end{tabular}

Tabela A7. 31: Distribuição da sobrevida hospitalar segundo o parâmetro Presença de material proteináceo amorfo na luz de bronquíolos terminais

\begin{tabular}{ccccccc}
\hline $\begin{array}{c}\text { Presença de material } \\
\text { proteináceo amorfo na luz } \\
\text { de bronquíolos terminais }\end{array}$ & não & $(\%)$ & $\operatorname{sim}$ & $(\%)$ & Total & $(\%)$ \\
\hline 0 & 32 & $(51)$ & 31 & $(49)$ & 63 & $(100)$ \\
\hline Total & 32 & $(51)$ & 31 & $(49)$ & 63 & $(100)$ \\
\hline
\end{tabular}




\section{A8. ALTERAÇÕES HISTOLÓGICAS OBSERVADAS EM BRONQUÍOLOS RESPIRATÓRIOS E SUA RELAÇÃO COM A SOBREVIDA HOSPITALAR}

Tabela A8. 1: Distribuição da sobrevida hospitalar segundo o parâmetro Ectasia de bronquíolos respiratórios

\begin{tabular}{|c|c|c|c|c|c|c|}
\hline \multirow{2}{*}{$\begin{array}{l}\text { Ectasia de bronquíolos } \\
\text { respiratórios }\end{array}$} & \multicolumn{4}{|c|}{ Sobrevida hospitalar } & \multirow{2}{*}{ Total } & \multirow{2}{*}{$(\%)$} \\
\hline & não & $(\%)$ & $\operatorname{sim}$ & (\%) & & \\
\hline 0 & 28 & $(56)$ & 22 & $(44)$ & 50 & $(100)$ \\
\hline 1 & 1 & (100) & & & 1 & (100) \\
\hline Total & 29 & (57) & 22 & (43) & 51 & (100) \\
\hline
\end{tabular}

Tabela A8. 2: Distribuição da sobrevida hospitalar segundo o parâmetro Impactação de muco em bronquíolos respiratórios

\begin{tabular}{|c|c|c|c|c|c|c|}
\hline \multirow{2}{*}{$\begin{array}{l}\text { Impactação de muco em } \\
\text { bronquíolos respiratórios }\end{array}$} & \multicolumn{4}{|c|}{ Sobrevida hospitalar } & \multirow{2}{*}{ Total } & \multirow{2}{*}{$(\%)$} \\
\hline & não & $(\%)$ & $\operatorname{sim}$ & $(\%)$ & & \\
\hline 0 & 27 & (57) & 20 & (43) & 47 & (100) \\
\hline 1 & 2 & (50) & 2 & (50) & 4 & (100) \\
\hline Total & 29 & (57) & 22 & (43) & 51 & (100) \\
\hline
\end{tabular}

Tabela A8. 3: Distribuição da sobrevida hospitalar segundo o parâmetro Sub-oclusão de bronquíolos respiratórios

\begin{tabular}{|c|c|c|c|c|c|c|}
\hline \multirow{2}{*}{$\begin{array}{l}\text { Suboclusão de bronquíolos } \\
\text { respiratórios }\end{array}$} & \multicolumn{4}{|c|}{ Sobrevida hospitalar } & \multirow{2}{*}{ Total } & \multirow{2}{*}{$(\%)$} \\
\hline & não & $(\%)$ & sim & $(\%)$ & & \\
\hline 0 & 24 & (59) & 17 & (41) & 41 & (100) \\
\hline 1 & 4 & (57) & 3 & (43) & 7 & (100) \\
\hline 3 & 1 & $(50)$ & 1 & $(50)$ & 2 & (100) \\
\hline 4 & & & 1 & $(100)$ & 1 & (100) \\
\hline Total & 29 & (57) & 22 & $(43)$ & 51 & $(100)$ \\
\hline
\end{tabular}

Tabela A8. 4: Distribuição da sobrevida hospitalar segundo o parâmetro Pelos em bronquíolos respiratórios

\begin{tabular}{|c|c|c|c|c|c|c|}
\hline \multirow{2}{*}{$\begin{array}{l}\text { Pelos em bronquíolos } \\
\text { respiratórios }\end{array}$} & \multicolumn{4}{|c|}{ Sobrevida hospitalar } & \multirow{2}{*}{ Total } & \multirow{2}{*}{$(\%)$} \\
\hline & não & $(\%)$ & $\operatorname{sim}$ & $(\%)$ & & \\
\hline 0 & 27 & (55) & 22 & (45) & 49 & $(100)$ \\
\hline 1 & 2 & (100) & & & 2 & (100) \\
\hline Total & 29 & $(57)$ & 22 & (43) & 51 & (100) \\
\hline
\end{tabular}


Tabela A8. 5: Distribuição da sobrevida hospitalar segundo o parâmetro Espasmo de bronquíolos respiratórios

\begin{tabular}{|c|c|c|c|c|c|c|}
\hline \multirow{2}{*}{$\begin{array}{l}\text { Espasmo de bronquíolos } \\
\text { respiratórios }\end{array}$} & \multicolumn{4}{|c|}{ Sobrevida hospitalar } & \multirow{2}{*}{ Total } & \multirow{2}{*}{ (\%) } \\
\hline & não & $(\%)$ & sim & $(\%)$ & & \\
\hline 0 & 28 & (57) & 21 & (43) & 49 & $\begin{array}{l}(100) \\
\end{array}$ \\
\hline 1 & 1 & (100) & & & 1 & (100) \\
\hline 3 & & & 1 & (100) & 1 & (100) \\
\hline Total & 29 & (57) & 22 & (43) & 51 & (100) \\
\hline
\end{tabular}

Tabela A8. 6: Distribuição da sobrevida hospitalar segundo o parâmetro Exsudato em bronquíolos respiratórios

\begin{tabular}{ccccccc}
\hline \multirow{2}{*}{$\begin{array}{c}\text { Exsudato em bronquíolos } \\
\text { respiratórios }\end{array}$} & \multicolumn{4}{c}{ Sobrevida hospitalar } & \multirow{2}{*}{ Total } & \multirow{2}{*}{$(\%)$} \\
\cline { 2 - 5 } & não & $(\%)$ & $\operatorname{sim}$ & $(\%)$ & & $(100)$ \\
\hline 0 & 29 & $(59)$ & 20 & $(41)$ & 49 & $(100)$ \\
\hline 1 & & & 2 & $(100)$ & 2 & $(100)$ \\
\hline Total & 29 & $(57)$ & 22 & $(43)$ & 51 & $(100)$ \\
\hline
\end{tabular}

Tabela A8. 7: Distribuição da sobrevida hospitalar segundo o parâmetro Edema em bronquíolos respiratórios

\begin{tabular}{|c|c|c|c|c|c|c|}
\hline \multirow{2}{*}{$\begin{array}{l}\text { Edema em bronquíolos } \\
\text { respiratórios }\end{array}$} & \multicolumn{4}{|c|}{ Sobrevida hospitalar } & \multirow{2}{*}{ Total } & \multirow{2}{*}{$(\%)$} \\
\hline & não & $(\%)$ & $\operatorname{sim}$ & $(\%)$ & & \\
\hline 0 & 24 & (55) & 20 & (45) & 44 & (100) \\
\hline 1 & 4 & (67) & 2 & (33) & 6 & (100) \\
\hline 4 & 1 & $(100)$ & & & 1 & (100) \\
\hline Total & 29 & $(57)$ & 22 & $(43)$ & 51 & (100) \\
\hline
\end{tabular}

Tabela A8. 8: Distribuição da sobrevida hospitalar segundo o parâmetro Hemorragia em bronquíolos respiratórios

\begin{tabular}{|c|c|c|c|c|c|c|}
\hline \multirow{2}{*}{$\begin{array}{l}\text { Hemorragia em bronquíolos } \\
\text { respiratórios }\end{array}$} & \multicolumn{4}{|c|}{ Sobrevida hospitalar } & \multirow{2}{*}{ Total } & \multirow{2}{*}{$(\%)$} \\
\hline & não & $(\%)$ & sim & $(\%)$ & & \\
\hline 0 & 25 & (56) & 20 & $(44)$ & 45 & (100) \\
\hline 1 & 4 & $(80)$ & 1 & (20) & 5 & $(100)$ \\
\hline 2 & & & 1 & $(100)$ & 1 & $(100)$ \\
\hline Total & 29 & $(57)$ & 22 & $(43)$ & 51 & $(100)$ \\
\hline
\end{tabular}


Tabela A8. 9: Distribuição da sobrevida hospitalar segundo o parâmetro Metaplasia escamosa de bronquíolos respiratórios

\begin{tabular}{|c|c|c|c|c|c|c|}
\hline \multirow{2}{*}{$\begin{array}{l}\text { Metaplasia escamosa de } \\
\text { bronquíolos respiratórios }\end{array}$} & \multicolumn{4}{|c|}{ Sobrevida hospitalar } & \multirow{2}{*}{ Total } & \multirow{2}{*}{$(\%)$} \\
\hline & não & $(\%)$ & sim & $(\%)$ & & \\
\hline 0 & 29 & $(57)$ & 22 & (43) & 51 & $(100)$ \\
\hline Total & 29 & (57) & 22 & (43) & 51 & $(100)$ \\
\hline
\end{tabular}

Tabela A8. 10: Distribuição da sobrevida hospitalar segundo o parâmetro Decapitação epitelial de bronquíolos respiratórios

\begin{tabular}{|c|c|c|c|c|c|c|}
\hline \multirow{2}{*}{$\begin{array}{l}\text { Decapitação epitelial de } \\
\text { bronquíolos respiratórios }\end{array}$} & \multicolumn{4}{|c|}{ Sobrevida hospitalar } & \multirow{2}{*}{ Total } & \multirow{2}{*}{$(\%)$} \\
\hline & não & $(\%)$ & sim & $(\%)$ & & \\
\hline 0 & 18 & $(51)$ & 17 & (49) & 35 & (100) \\
\hline 1 & 9 & (64) & 5 & (36) & 14 & (100) \\
\hline 2 & 1 & (100) & & & 1 & (100) \\
\hline 4 & 1 & (100) & & & 1 & (100) \\
\hline Total & 29 & (57) & 22 & (43) & 51 & (100) \\
\hline
\end{tabular}

Tabela A8. 11: Distribuição da sobrevida hospitalar segundo o parâmetro Descamação de bronquíolos respiratórios

\begin{tabular}{|c|c|c|c|c|c|c|}
\hline \multirow{2}{*}{$\begin{array}{l}\text { Descamação de bronquíolos } \\
\text { respiratórios }\end{array}$} & \multicolumn{4}{|c|}{ Sobrevida hospitalar } & \multirow{2}{*}{ Total } & \multirow{2}{*}{$(\%)$} \\
\hline & não & $(\%)$ & sim & $(\%)$ & & \\
\hline 0 & 12 & $(50)$ & 12 & $(50)$ & 24 & (100) \\
\hline 1 & 8 & (62) & 5 & (38) & 13 & (100) \\
\hline 2 & 6 & (75) & 2 & (25) & 8 & (100) \\
\hline 3 & 2 & (50) & 2 & (50) & 4 & (100) \\
\hline 4 & 1 & (50) & 1 & (50) & 2 & (100) \\
\hline Total & 29 & (57) & 22 & (43) & 51 & (100) \\
\hline
\end{tabular}

Tabela A8. 12: Distribuição da sobrevida hospitalar segundo o parâmetro Hiperplasia epitelial de bronquíolos respiratórios

\begin{tabular}{|c|c|c|c|c|c|c|}
\hline \multirow{2}{*}{$\begin{array}{l}\text { Hiperplasia epitelial de } \\
\text { bronquíolos respiratórios }\end{array}$} & \multicolumn{4}{|c|}{ Sobrevida hospitalar } & \multirow{2}{*}{ Total } & \multirow{2}{*}{$(\%)$} \\
\hline & não & $(\%)$ & sim & $(\%)$ & & \\
\hline 0 & 21 & (58) & 15 & $\begin{array}{l}(42) \\
\end{array}$ & 36 & (100) \\
\hline 1 & 6 & (50) & 6 & (50) & 12 & (100) \\
\hline 2 & 2 & (67) & 1 & (33) & 3 & (100) \\
\hline Total & 29 & (57) & 22 & (43) & 51 & (100) \\
\hline
\end{tabular}


Tabela A8. 13: Distribuição da sobrevida hospitalar segundo o parâmetro Efeito citopático em bronquíolos respiratórios

\begin{tabular}{ccccccc}
\hline \multirow{2}{*}{$\begin{array}{c}\text { Efeito citopático em } \\
\text { bronquíolos respiratórios }\end{array}$} & não & $(\%)$ & sim & $(\%)$ & \multirow{2}{*}{ Total } & \multirow{2}{*}{$(\%)$} \\
\hline 0 & 21 & $(51)$ & 20 & $(49)$ & 41 & $(100)$ \\
1 & 7 & $(78)$ & 2 & $(22)$ & 9 & $(100)$ \\
2 & 1 & $(100)$ & & & 1 & $(100)$ \\
\hline Total & 29 & $(57)$ & 22 & $(43)$ & 51 & $(100)$ \\
\hline
\end{tabular}

Tabela A8. 14: Distribuição da sobrevida hospitalar segundo o parâmetro Necrose epitelial de bronquíolos respiratórios

\begin{tabular}{|c|c|c|c|c|c|c|}
\hline \multirow{2}{*}{$\begin{array}{c}\text { Necrose epitelial de } \\
\text { bronquíolos respiratórios }\end{array}$} & \multicolumn{4}{|c|}{ Sobrevida hospitalar } & \multirow{2}{*}{ Total } & \multirow{2}{*}{ (\%) } \\
\hline & não & $(\%)$ & sim & $(\%)$ & & \\
\hline 0 & 27 & (56) & 21 & (44) & 48 & (100) \\
\hline 1 & & & 1 & (100) & 1 & (100) \\
\hline 2 & 1 & (100) & & & 1 & (100) \\
\hline 3 & 1 & (100) & & & 1 & (100) \\
\hline Total & 29 & $(57)$ & 22 & (43) & 51 & $(100)$ \\
\hline
\end{tabular}

Tabela A8. 15: Distribuição da sobrevida hospitalar segundo o parâmetro Degeneração epitelial de bronquíolos respiratórios

\begin{tabular}{|c|c|c|c|c|c|c|}
\hline \multirow{2}{*}{$\begin{array}{l}\text { Degeneração epitelial de } \\
\text { bronquíolos respiratórios }\end{array}$} & \multicolumn{4}{|c|}{ Sobrevida hospitalar } & \multirow{2}{*}{ Total } & \multirow{2}{*}{$(\%)$} \\
\hline & não & $(\%)$ & $\operatorname{sim}$ & $(\%)$ & & \\
\hline 0 & 27 & $(55)$ & 22 & (45) & 49 & $(100)$ \\
\hline 1 & 1 & (100) & & & 1 & (100) \\
\hline 2 & 1 & $(100)$ & & & 1 & (100) \\
\hline Total & 29 & $(57)$ & 22 & (43) & 51 & (100) \\
\hline
\end{tabular}

Tabela A8. 16: Distribuição da sobrevida hospitalar segundo o parâmetro Infiltrado de células mononucleares em bronquíolos respiratórios

\begin{tabular}{cccccccc}
\hline Infiltrado de células mononucleares & \multicolumn{5}{c}{ Sobrevida hospitalar } & \multirow{2}{*}{ Total } & \multirow{2}{*}{ (\%) } \\
\cline { 2 - 6 } em bronquíolos respiratórios & não & $(\%)$ & $\operatorname{sim}$ & $(\%)$ & & \\
\hline 0 & 29 & $(57)$ & 22 & $(43)$ & 51 & $(100)$ \\
\hline Total & 29 & $(57)$ & 22 & $(43)$ & 51 & $(100)$ \\
\hline
\end{tabular}


Tabela A8. 17: Distribuição da sobrevida hospitalar segundo o parâmetro Obliteração de bronquíolos respiratórios

\begin{tabular}{|c|c|c|c|c|c|c|}
\hline \multirow{2}{*}{$\begin{array}{l}\text { Obliteração de bronquíolos } \\
\text { respiratórios }\end{array}$} & \multicolumn{4}{|c|}{ Sobrevida hospitalar } & \multirow{2}{*}{ Total } & \multirow{2}{*}{$(\%)$} \\
\hline & não & $(\%)$ & sim & $(\%)$ & & \\
\hline 0 & 29 & (57) & 22 & (43) & 51 & (100) \\
\hline 4 & 3 & (25) & 9 & (75) & 12 & (100) \\
\hline Total & 32 & (51) & 31 & (49) & 63 & (100) \\
\hline
\end{tabular}

Tabela A8. 18: Distribuição da sobrevida hospitalar segundo o parâmetro Hiperdistensão de bronquíolos respiratórios

\begin{tabular}{|c|c|c|c|c|c|c|}
\hline \multirow{2}{*}{$\begin{array}{l}\text { Hiperdistensão de } \\
\text { bronquíolos respiratórios }\end{array}$} & \multicolumn{4}{|c|}{ Sobrevida hospitalar } & \multirow{2}{*}{ Total } & \multirow{2}{*}{$(\%)$} \\
\hline & não & $(\%)$ & $\operatorname{sim}$ & $(\%)$ & & \\
\hline 0 & 28 & (56) & 22 & (44) & 50 & $(100)$ \\
\hline 3 & 1 & $(100)$ & & & 1 & $(100)$ \\
\hline Total & 29 & (57) & 22 & (43) & 51 & (100) \\
\hline
\end{tabular}

Tabela A8. 19: Distribuição da sobrevida hospitalar segundo o parâmetro Calcificação periferia de bronquíolos respiratórios

\begin{tabular}{|c|c|c|c|c|c|c|}
\hline \multirow{2}{*}{$\begin{array}{l}\text { Calcificação periferia de } \\
\text { bronquíolos respiratórios }\end{array}$} & \multicolumn{4}{|c|}{ Sobrevida hospitalar } & \multirow{2}{*}{ Total } & \multirow{2}{*}{$(\%)$} \\
\hline & não & $(\%)$ & $\operatorname{sim}$ & $(\%)$ & & \\
\hline 0 & 29 & (58) & 21 & (42) & 50 & $(100)$ \\
\hline 1 & & & 1 & (100) & 1 & (100) \\
\hline Total & 29 & $(57)$ & 22 & $(43)$ & 51 & (100) \\
\hline
\end{tabular}

Tabela A8. 20: Distribuição da sobrevida hospitalar segundo o parâmetro Agregados de macrófagos de bronquíolos respiratórios

\begin{tabular}{ccccccc}
\hline $\begin{array}{c}\text { Agregados de macrófagos } \\
\text { de bronquíolos respiratórios }\end{array}$ & não & $(\%)$ & sim & $(\%)$ & Total & \multirow{2}{*}{$(\%)$} \\
\hline 0 & 27 & $(57)$ & 20 & $(43)$ & 47 & $(100)$ \\
1 & 2 & $(50)$ & 2 & $(50)$ & 4 & $(100)$ \\
\hline Total & 29 & $(57)$ & 22 & $(43)$ & 51 & $(100)$ \\
\hline
\end{tabular}

Tabela A8. 21: Distribuição da sobrevida hospitalar segundo o parâmetro Presença de granuloma obliterando na luz de bronquíolos respiratórios

\begin{tabular}{|c|c|c|c|c|c|c|}
\hline \multirow{2}{*}{$\begin{array}{l}\text { Presença de granuloma } \\
\text { obliterando na luz de } \\
\text { bronquíolos respiratórios }\end{array}$} & \multicolumn{4}{|c|}{ Sobrevida hospitalar } & \multirow{2}{*}{ Total } & \multirow{2}{*}{$(\%)$} \\
\hline & não & $(\%)$ & sim & $(\%)$ & & \\
\hline 0 & 28 & $(56)$ & 22 & $(44)$ & 50 & $(100)$ \\
\hline 1 & 1 & (100) & & & 1 & (100) \\
\hline Total & 29 & (57) & 22 & (43) & 51 & $(100)$ \\
\hline
\end{tabular}


Tabela A8. 22: Distribuição da sobrevida hospitalar segundo o parâmetro Hipertrofia da musculatura peribronquiolar de bronquíolos respiratórios

\begin{tabular}{|c|c|c|c|c|c|c|}
\hline \multirow{2}{*}{$\begin{array}{l}\text { Hipertrofia da musculatura } \\
\text { peribronquiolar de } \\
\text { bronquíolos respiratórios }\end{array}$} & \multicolumn{4}{|c|}{ Sobrevida hospitalar } & \multirow{2}{*}{ Total } & \multirow{2}{*}{$(\%)$} \\
\hline & não & $(\%)$ & sim & $(\%)$ & & \\
\hline 0 & 28 & $(56)$ & 22 & $(44)$ & 50 & $(100)$ \\
\hline 4 & 1 & (100) & & & 1 & (100) \\
\hline Total & 29 & $(57)$ & 22 & $(43)$ & 51 & (100) \\
\hline
\end{tabular}

Tabela A8. 23: Distribuição da sobrevida hospitalar segundo o parâmetro Presença de material proteináceo amorfo na luz de bronquíolos respiratórios

\begin{tabular}{ccccccc}
\hline $\begin{array}{c}\text { Presença de material } \\
\text { proteináceo amorfo na luz } \\
\text { de bronquíolos respiratórios }\end{array}$ & não & $(\%)$ & $\operatorname{sim}$ & $(\%)$ & Total & $(\%)$ \\
\hline 0 & 29 & $(57)$ & 22 & $(43)$ & 51 & $(100)$ \\
\hline Total & 29 & $(57)$ & 22 & $(43)$ & 51 & $(100)$ \\
\hline
\end{tabular}




\section{A9. ALTERAÇÕES HISTOLÓGICAS OBSERVADAS EM BRONQUÍOLOS RESPIRATÓRIOS E SUA RELAÇÃO COM A SOBREVIDA HOSPITALAR}

Tabela A9. 1: Distribuição da sobrevida hospitalar segundo o parâmetro Colapso aberto de alvéolos

\begin{tabular}{|c|c|c|c|c|c|c|}
\hline \multirow{2}{*}{$\begin{array}{c}\text { Colapso aberto } \\
\text { de alvéolos }\end{array}$} & \multicolumn{4}{|c|}{ Sobrevida hospitalar } & \multirow{2}{*}{ Total } & \multirow{2}{*}{ (\%) } \\
\hline & não & $(\%)$ & sim & $(\%)$ & & \\
\hline 0 & 13 & (48) & 14 & (52) & 27 & (100) \\
\hline 1 & 10 & (56) & 8 & (44) & 18 & (100) \\
\hline 2 & 7 & (47) & 8 & (53) & 15 & (100) \\
\hline 3 & 1 & (50) & 1 & (50) & 2 & (100) \\
\hline 4 & 1 & (100) & & & 1 & (100) \\
\hline Total & 32 & (51) & 31 & (49) & 63 & (100) \\
\hline
\end{tabular}

Tabela A9. 2: Distribuição da sobrevida hospitalar segundo o parâmetro Colapso fechado de alvéolos

\begin{tabular}{ccccccc}
\hline $\begin{array}{c}\text { Colapso fechado } \\
\text { de alvéolos }\end{array}$ & não & $(\%)$ & sim & $(\%)$ & \multirow{2}{*}{ Total } & \multirow{2}{*}{$(\%)$} \\
\hline 0 & 7 & $(54)$ & 6 & $(46)$ & 13 & $(100)$ \\
1 & 11 & $(55)$ & 9 & $(45)$ & 20 & $(100)$ \\
2 & 9 & $(47)$ & 10 & $(53)$ & 19 & $(100)$ \\
3 & 5 & $(56)$ & 4 & $(44)$ & 9 & $(100)$ \\
4 & & & 2 & $(100)$ & 2 & $(100)$ \\
\hline Total & 32 & $(51)$ & 31 & $(49)$ & 63 & $(100)$ \\
\hline
\end{tabular}

Tabela A9. 3: Distribuição da sobrevida hospitalar segundo o parâmetro Dilatação ou hiperdistensão de ductos alveolares

\begin{tabular}{|c|c|c|c|c|c|c|}
\hline \multirow{2}{*}{$\begin{array}{l}\text { Dilatação ou hiperdistensão } \\
\text { de ductos alveolares }\end{array}$} & \multicolumn{4}{|c|}{ Sobrevida hospitalar } & \multirow{2}{*}{ Total } & \multirow{2}{*}{$(\%)$} \\
\hline & não & $(\%)$ & $\operatorname{sim}$ & $(\%)$ & & \\
\hline 0 & 12 & (48) & 13 & (52) & 25 & $(100)$ \\
\hline 1 & 9 & (47) & 10 & (53) & 19 & (100) \\
\hline 2 & 8 & (57) & 6 & (43) & 14 & (100) \\
\hline 3 & 2 & (50) & 2 & (50) & 4 & (100) \\
\hline 4 & 1 & (100) & & & 1 & (100) \\
\hline Total & 32 & (51) & 31 & (49) & 63 & (100) \\
\hline
\end{tabular}


Tabela A9. 4: Distribuição da sobrevida hospitalar segundo o parâmetro Faveolamento

\begin{tabular}{|c|c|c|c|c|c|c|}
\hline \multirow{2}{*}{ Faveolamento- } & \multicolumn{4}{|c|}{ Sobrevida hospitalar } & \multirow{2}{*}{ Total } & \multirow{2}{*}{$(\%)$} \\
\hline & não & $(\%)$ & sim & $(\%)$ & & \\
\hline 0 & 30 & (57) & 23 & (43) & 53 & (100) \\
\hline 1 & 1 & (50) & 1 & (50) & 2 & (100) \\
\hline 2 & 1 & (50) & 1 & (50) & 2 & (100) \\
\hline 3 & & & 4 & (100) & 4 & (100) \\
\hline 4 & & & 2 & (100) & 2 & (100) \\
\hline Total & 32 & (51) & 31 & (49) & 63 & (100) \\
\hline
\end{tabular}

Tabela A9. 5: Distribuição da sobrevida hospitalar segundo o parâmetro Homogeneidade temporal

\begin{tabular}{|c|c|c|c|c|c|c|}
\hline \multirow{2}{*}{$\begin{array}{l}\text { Homogeneidade } \\
\text { temporal }\end{array}$} & \multicolumn{4}{|c|}{ Sobrevida hospitalar } & \multirow{2}{*}{ Total } & \multirow{2}{*}{ (\%) } \\
\hline & não & $(\%)$ & sim & $(\%)$ & & \\
\hline 0 & 4 & (36) & 7 & (64) & 11 & (100) \\
\hline 1 & 28 & (54) & 24 & (46) & 52 & (100) \\
\hline Total & 32 & (51) & 31 & (49) & 63 & $(100)$ \\
\hline
\end{tabular}

Tabela A9. 6: Distribuição da sobrevida hospitalar segundo o parâmetro Lambertose

\begin{tabular}{|c|c|c|c|c|c|c|}
\hline \multirow{2}{*}{ Lambertose- } & \multicolumn{4}{|c|}{ Sobrevida hospitalar } & \multirow{2}{*}{ Total } & \multirow{2}{*}{$(\%)$} \\
\hline & não & $(\%)$ & sim & $(\%)$ & & \\
\hline 0 & 23 & (66) & 12 & (34) & 35 & (100) \\
\hline 1 & 8 & (44) & 10 & (56) & 18 & (100) \\
\hline 2 & 1 & (20) & 4 & $(80)$ & 5 & (100) \\
\hline 3 & & & 4 & (100) & 4 & (100) \\
\hline 4 & & & 1 & $(100)$ & 1 & (100) \\
\hline Total & 32 & (51) & 31 & $(49)$ & 63 & (100) \\
\hline
\end{tabular}

Tabela A9. 7: Distribuição da sobrevida hospitalar segundo o parâmetro Tecido de granulação na luz de alveolar

\begin{tabular}{ccccccc}
\hline $\begin{array}{c}\text { Tecido de } \\
\text { granulação } \\
\begin{array}{c}\text { na luz de } \\
\text { alveolar }\end{array}\end{array}$ & não & $(\%)$ & sim & $(\%)$ & Total & $(\%)$ \\
\hline 0 & 19 & $(50)$ & 19 & $(50)$ & 38 & $(100)$ \\
1 & 5 & $(42)$ & 7 & $(58)$ & 12 & $(100)$ \\
2 & 5 & $(56)$ & 4 & $(44)$ & 9 & $(100)$ \\
3 & 2 & $(67)$ & 1 & $(33)$ & 3 & $(100)$ \\
4 & 1 & $(100)$ & & & 1 & $(100)$ \\
\hline Total & 32 & $(51)$ & 31 & $(49)$ & 63 & $(100)$ \\
\hline
\end{tabular}


Tabela A9. 8: Distribuição da sobrevida hospitalar segundo o parâmetro Pneumonia organizante

\begin{tabular}{|c|c|c|c|c|c|c|}
\hline \multirow{2}{*}{$\begin{array}{l}\text { Pneumonia } \\
\text { organizante }\end{array}$} & \multicolumn{4}{|c|}{ Sobrevida hospitalar } & \multirow{2}{*}{ Total } & \multirow{2}{*}{$(\%)$} \\
\hline & não & $(\%)$ & sim & $(\%)$ & & \\
\hline 0 & 22 & (51) & 21 & (49) & 43 & $(100)$ \\
\hline 1 & 4 & (40) & 6 & (60) & 10 & (100) \\
\hline 2 & 5 & (63) & 3 & (38) & 8 & (100) \\
\hline 3 & 1 & (50) & 1 & (50) & 2 & (100) \\
\hline Total & 32 & (51) & 31 & (49) & 63 & $(100)$ \\
\hline
\end{tabular}

Tabela A9. 9: Distribuição da sobrevida hospitalar segundo o parâmetro Membranas hialinas

\begin{tabular}{|c|c|c|c|c|c|c|}
\hline \multirow{2}{*}{$\begin{array}{c}\text { Membranas } \\
\text { hialinas }\end{array}$} & \multicolumn{4}{|c|}{ Sobrevida hospitalar } & \multirow{2}{*}{ Total } & \multirow{2}{*}{$(\%)$} \\
\hline & não & $(\%)$ & sim & $(\%)$ & & \\
\hline 0 & 12 & (34) & 23 & (66) & 35 & (100) \\
\hline 1 & 11 & (65) & 6 & (35) & 17 & (100) \\
\hline 2 & 5 & (71) & 2 & (29) & 7 & (100) \\
\hline 3 & 4 & (100) & & & 4 & (100) \\
\hline Total & 32 & (51) & 31 & (49) & 63 & (100) \\
\hline
\end{tabular}

Tabela A9. 10: Distribuição da sobrevida hospitalar segundo o parâmetro Hemorragia intralveolar

\begin{tabular}{|c|c|c|c|c|c|c|}
\hline \multirow{2}{*}{$\begin{array}{l}\text { Hemorragia } \\
\text { intralveolar }\end{array}$} & \multicolumn{4}{|c|}{ Sobrevida hospitalar } & \multirow{2}{*}{ Total } & \multirow{2}{*}{$(\%)$} \\
\hline & não & $(\%)$ & sim & (\%) & & \\
\hline 0 & 6 & (40) & 9 & (60) & 15 & $(100)$ \\
\hline 1 & 17 & (55) & 14 & (45) & 31 & (100) \\
\hline 2 & 9 & (64) & 5 & (36) & 14 & (100) \\
\hline 3 & & & 3 & $(100)$ & 3 & (100) \\
\hline Total & 32 & (51) & 31 & $(49)$ & 63 & (100) \\
\hline
\end{tabular}

Tabela A9. 11: Distribuição da sobrevida hospitalar segundo o parâmetro Edema intralveolar

\begin{tabular}{|c|c|c|c|c|c|c|}
\hline \multirow{2}{*}{$\begin{array}{c}\text { Edema } \\
\text { intralveolar }\end{array}$} & \multicolumn{4}{|c|}{ Sobrevida hospitalar } & \multirow{2}{*}{ Total } & \multirow{2}{*}{$(\%)$} \\
\hline & não & $(\%)$ & sim & $(\%)$ & & \\
\hline 0 & 4 & (33) & 8 & (67) & 12 & $(100)$ \\
\hline 1 & 21 & (60) & 14 & (40) & 35 & (100) \\
\hline 2 & 3 & (38) & 5 & (63) & 8 & (100) \\
\hline 3 & 4 & (57) & 3 & (43) & 7 & (100) \\
\hline 4 & & & 1 & (100) & 1 & (100) \\
\hline Total & 32 & (51) & 31 & (49) & 63 & (100) \\
\hline
\end{tabular}


Tabela A9. 12: Distribuição da sobrevida hospitalar segundo o parâmetro Hiperplasia células alveolares

\begin{tabular}{ccccccc}
\hline $\begin{array}{c}\text { Hiperplasia } \\
\text { células } \\
\text { alveolares }\end{array}$ & não & $(\%)$ & sim & $(\%)$ & Total & $(\%)$ \\
\hline 0 & 10 & $(45)$ & 12 & $(55)$ & 22 & $(100)$ \\
1 & 8 & $(53)$ & 7 & $(47)$ & 15 & $(100)$ \\
2 & 6 & $(50)$ & 6 & $(50)$ & 12 & $(100)$ \\
3 & 5 & $(56)$ & 4 & $(44)$ & 9 & $(100)$ \\
4 & 3 & $(60)$ & 2 & $(40)$ & 5 & $(100)$ \\
\hline Total & 32 & $(51)$ & 31 & $(49)$ & 63 & $(100)$ \\
\hline
\end{tabular}

Tabela A9. 13: Distribuição da sobrevida hospitalar segundo o parâmetro Efeito citopático em células alveolares

\begin{tabular}{|c|c|c|c|c|c|c|}
\hline \multirow{2}{*}{$\begin{array}{c}\text { Efeito } \\
\text { citopático } \\
\text { em } \\
\text { células } \\
\text { alveolares }\end{array}$} & \multicolumn{4}{|c|}{ Sobrevida hospitalar } & \multirow[b]{2}{*}{ Total } & \multirow[b]{2}{*}{$(\%)$} \\
\hline & não & $(\%)$ & $\operatorname{sim}$ & $(\%)$ & & \\
\hline 0 & 11 & (41) & 16 & (59) & 27 & $(100)$ \\
\hline 1 & 10 & (56) & 8 & (44) & 18 & $(100)$ \\
\hline 2 & 4 & (57) & 3 & (43) & 7 & $(100)$ \\
\hline 3 & 5 & (63) & 3 & (38) & 8 & $(100)$ \\
\hline 4 & 2 & $(67)$ & 1 & (33) & 3 & $(100)$ \\
\hline Total & 32 & (51) & 31 & (49) & 63 & $(100)$ \\
\hline
\end{tabular}

Tabela A9. 14: Distribuição da sobrevida hospitalar segundo o parâmetro Componente descamativo intralveolar

\begin{tabular}{ccccccc}
\hline $\begin{array}{c}\text { Componente } \\
\text { descamativo } \\
\text { intralveolar }\end{array}$ & não & $(\%)$ & $\operatorname{sim}$ & $(\%)$ & Total & $(\%)$ \\
\hline 0 & 4 & $(57)$ & 3 & $(43)$ & 7 & $(100)$ \\
1 & 12 & $(52)$ & 11 & $(48)$ & 23 & $(100)$ \\
2 & 13 & $(57)$ & 10 & $(43)$ & 23 & $(100)$ \\
3 & 2 & $(25)$ & 6 & $(75)$ & 8 & $(100)$ \\
4 & 1 & $(50)$ & 1 & $(50)$ & 2 & $(100)$ \\
\hline Total & 32 & $(51)$ & 31 & $(49)$ & 63 & $(100)$ \\
\hline
\end{tabular}


Tabela A9. 15: Distribuição da sobrevida hospitalar segundo o parâmetro Presença de parasitas na luz alveolar

\begin{tabular}{ccccccc}
\hline $\begin{array}{c}\text { Presença de parasitas } \\
\text { na luz alveolar }\end{array}$ & não & $(\%)$ & sim & $(\%)$ & \multirow{2}{*}{ Total } & \multirow{2}{*}{$(\%)$} \\
\cline { 2 - 5 } & 29 & $(48)$ & 31 & $(52)$ & 60 & $(100)$ \\
1 & 1 & $(100)$ & & & 1 & $(100)$ \\
2 & 1 & $(100)$ & & & 1 & $(100)$ \\
3 & 1 & $(100)$ & & & 1 & $(100)$ \\
\hline Total & 32 & $(51)$ & 31 & $(49)$ & 63 & $(100)$ \\
\hline
\end{tabular}

Tabela A9. 16: Distribuição da sobrevida hospitalar segundo o parâmetro Infiltrado linfoplasmocitário intralveolar

\begin{tabular}{|c|c|c|c|c|c|c|}
\hline \multirow{2}{*}{$\begin{array}{c}\text { Infiltrado linfo-plasmocitário } \\
\text { intralveolar }\end{array}$} & \multicolumn{4}{|c|}{ Sobrevida hospitalar } & \multirow{2}{*}{ Total } & \multirow{2}{*}{$(\%)$} \\
\hline & não & $(\%)$ & sim & $(\%)$ & & \\
\hline 0 & 32 & $\begin{array}{l}(51) \\
\end{array}$ & 31 & (49) & 63 & (100) \\
\hline Total & 32 & (51) & 31 & (49) & 63 & (100) \\
\hline
\end{tabular}

Tabela A9. 17: Distribuição da sobrevida hospitalar segundo o parâmetro Exsudato neutrofílico intralveolar

\begin{tabular}{|c|c|c|c|c|c|c|}
\hline \multirow{2}{*}{$\begin{array}{l}\text { Exsudato neutrofílico } \\
\text { intralveolar }\end{array}$} & \multicolumn{4}{|c|}{ Sobrevida hospitalar } & \multirow{2}{*}{ Total } & \multirow{2}{*}{$(\%)$} \\
\hline & não & $(\%)$ & sim & $(\%)$ & & \\
\hline 0 & 27 & $(48)$ & 29 & (52) & 56 & $(100)$ \\
\hline 1 & 1 & (50) & 1 & (50) & 2 & (100) \\
\hline 2 & 2 & (67) & 1 & (33) & 3 & (100) \\
\hline 3 & 2 & $(100)$ & & & 2 & (100) \\
\hline Total & 32 & $(51)$ & 31 & (49) & 63 & (100) \\
\hline
\end{tabular}

Tabela A9. 18: Distribuição da sobrevida hospitalar segundo o parâmetro Infarto hemorrágico do parênquima alveolado

\begin{tabular}{|c|c|c|c|c|c|c|}
\hline \multirow{2}{*}{$\begin{array}{l}\text { Infarto hemorrágico do } \\
\text { parênquima alveolado }\end{array}$} & \multicolumn{4}{|c|}{ Sobrevida hospitalar } & \multirow{2}{*}{ Total } & \multirow{2}{*}{ (\%) } \\
\hline & não & $(\%)$ & $\operatorname{sim}$ & $(\%)$ & & \\
\hline 0 & 30 & (49) & 31 & (51) & 61 & $(100)$ \\
\hline 2 & 2 & (100) & & & 2 & (100) \\
\hline Total & 32 & (51) & 31 & (49) & 63 & (100) \\
\hline
\end{tabular}


Tabela A9. 19: Distribuição da sobrevida hospitalar segundo o parâmetro Corpúsculos calcificados intralveolares

\begin{tabular}{|c|c|c|c|c|c|c|}
\hline \multirow{2}{*}{$\begin{array}{c}\text { Corpúsculos calcificados } \\
\text { intralveolares }\end{array}$} & \multicolumn{4}{|c|}{ Sobrevida hospitalar } & \multirow{2}{*}{ Total } & \multirow{2}{*}{$(\%)$} \\
\hline & não & $(\%)$ & sim & $(\%)$ & & \\
\hline 0 & 32 & (52) & 30 & (48) & 62 & (100) \\
\hline 1 & & & 1 & (100) & 1 & (100) \\
\hline Total & 32 & (51) & 31 & (49) & 63 & $(100)$ \\
\hline
\end{tabular}

Tabela A9. 20: Distribuição da sobrevida hospitalar segundo o parâmetro Reação gigantocelular intralveolar

\begin{tabular}{|c|c|c|c|c|c|c|}
\hline \multirow{2}{*}{$\begin{array}{l}\text { Reação gigantocelular } \\
\text { intralveolar }\end{array}$} & \multicolumn{4}{|c|}{ Sobrevida hospitalar } & \multirow{2}{*}{ Total } & \multirow{2}{*}{$(\%)$} \\
\hline & não & $(\%)$ & sim & $(\%)$ & & \\
\hline 0 & 32 & (52) & 29 & (48) & 61 & (100) \\
\hline 1 & & & 1 & (100) & 1 & (100) \\
\hline 2 & & & 1 & (100) & 1 & (100) \\
\hline Total & 32 & (51) & 31 & (49) & 63 & (100) \\
\hline
\end{tabular}

Tabela A9. 21: Distribuição da sobrevida hospitalar segundo o parâmetro Células neoplásicas intralveolares

\begin{tabular}{|c|c|c|c|c|c|c|}
\hline \multirow{2}{*}{$\begin{array}{c}\text { Células neoplásicas } \\
\text { intralveolares }\end{array}$} & \multicolumn{4}{|c|}{ Sobrevida hospitalar } & \multirow{2}{*}{ Total } & \multirow{2}{*}{ (\%) } \\
\hline & não & (\%) & sim & $(\%)$ & & \\
\hline 0 & 31 & (51) & 30 & (49) & 61 & (100) \\
\hline 1 & 1 & (50) & 1 & (50) & 2 & (100) \\
\hline Total & 32 & (51) & 31 & (49) & 63 & $(100)$ \\
\hline
\end{tabular}

Tabela A9. 22: Distribuição da sobrevida hospitalar segundo o parâmetro Deposição de muco intralveolar

\begin{tabular}{ccccccc}
\hline $\begin{array}{c}\text { Deposição de muco } \\
\text { intralveolar }\end{array}$ & não & $(\%)$ & sim & $(\%)$ & Total & \multirow{2}{*}{$(\%)$} \\
\cline { 2 - 5 } & 30 & $(55)$ & 25 & $(45)$ & 55 & $(100)$ \\
1 & 2 & $(67)$ & 1 & $(33)$ & 3 & $(100)$ \\
2 & & & 3 & $(100)$ & 3 & $(100)$ \\
3 & 32 & $(51)$ & 31 & $(49)$ & 63 & $(100)$ \\
\hline Total & & & & & & \\
\hline
\end{tabular}


Tabela A9. 23: Distribuição da sobrevida hospitalar segundo o parâmetro Plug de fibrina intralveolar

\begin{tabular}{|c|c|c|c|c|c|c|}
\hline \multirow{2}{*}{$\begin{array}{c}\text { Plug de fibrina } \\
\text { intralveolar }\end{array}$} & \multicolumn{4}{|c|}{ Sobrevida hospitalar } & \multirow{2}{*}{ Total } & \multirow{2}{*}{ (\%) } \\
\hline & não & $(\%)$ & $\operatorname{sim}$ & $(\%)$ & & \\
\hline 0 & 30 & (49) & 31 & (51) & 61 & (100) \\
\hline 1 & 1 & (100) & & & 1 & (100) \\
\hline 2 & 1 & (100) & & & 1 & $(100)$ \\
\hline Total & 32 & $(51)$ & 31 & (49) & 63 & $(100)$ \\
\hline
\end{tabular}

Tabela A9. 24: Distribuição da sobrevida hospitalar segundo o parâmetro Metaplasia escamosa do epitélio alveolar

\begin{tabular}{ccccccc}
\hline $\begin{array}{c}\text { Metaplasia escamosa } \\
\text { do epitélio alveolar }\end{array}$ & não & $(\%)$ & Sobrevida & $(\%)$ & \multirow{2}{*}{ Total } & \multirow{2}{*}{$(\%)$} \\
\hline 0 & 32 & $(54)$ & 27 & $(46)$ & 59 & $(100)$ \\
1 & & & 3 & $(100)$ & 3 & $(100)$ \\
2 & 32 & $(51)$ & 31 & $(49)$ & 63 & $(100)$ \\
\hline Total & 32 & & & & & \\
\hline
\end{tabular}

Tabela A9. 25: Distribuição da sobrevida hospitalar segundo o parâmetro Corpos estranhos intralveolares

\begin{tabular}{|c|c|c|c|c|c|c|}
\hline \multirow{2}{*}{$\begin{array}{l}\text { Corpos estranhos } \\
\text { intralveolares }\end{array}$} & \multicolumn{4}{|c|}{ Sobrevida hospitalar } & \multirow{2}{*}{ Total } & \multirow{2}{*}{$(\%)$} \\
\hline & não & $(\%)$ & sim & $(\%)$ & & \\
\hline 0 & 32 & (51) & 31 & (49) & 63 & (100) \\
\hline Total & 32 & (51) & 31 & (49) & 63 & $(100)$ \\
\hline
\end{tabular}

Tabela A9. 26: Distribuição da sobrevida hospitalar segundo o parâmetro Hemossiderose intralveolar

\begin{tabular}{|c|c|c|c|c|c|c|}
\hline \multirow{2}{*}{$\begin{array}{l}\text { Hemossiderose } \\
\text { intralveolar }\end{array}$} & \multicolumn{4}{|c|}{ Sobrevida hospitalar } & \multirow{2}{*}{ Total } & \multirow{2}{*}{$(\%)$} \\
\hline & não & $(\%)$ & sim & $(\%)$ & & \\
\hline 0 & 30 & (51) & 29 & (49) & 59 & (100) \\
\hline 1 & 1 & (100) & & & 1 & (100) \\
\hline 2 & & & 1 & (100) & 1 & (100) \\
\hline 3 & 1 & (100) & & & 1 & (100) \\
\hline 4 & & & 1 & (100) & 1 & (100) \\
\hline Total & 32 & (51) & 31 & (49) & 63 & (100) \\
\hline
\end{tabular}


Tabela A9. 27: Distribuição da sobrevida hospitalar segundo o parâmetro Material cristalóide fagocitado em luz alveolar

\begin{tabular}{|c|c|c|c|c|c|c|}
\hline \multirow{2}{*}{$\begin{array}{c}\text { Material cristalóide fagocitado } \\
\text { em luz alveolar }\end{array}$} & \multicolumn{4}{|c|}{ Sobrevida hospitalar } & \multirow{2}{*}{ Total } & \multirow{2}{*}{ (\%) } \\
\hline & não & (\%) & $\operatorname{sim}$ & $(\%)$ & & \\
\hline 0 & 31 & (52) & 29 & (48) & 60 & (100) \\
\hline 1 & & & 1 & (100) & 1 & (100) \\
\hline 2 & 1 & $(50)$ & 1 & (50) & 2 & (100) \\
\hline Total & 32 & (51) & 31 & (49) & 63 & (100) \\
\hline
\end{tabular}

Tabela A9. 28: Distribuição da sobrevida hospitalar segundo o parâmetro Necrose coagulativa do parênquima alveolado

\begin{tabular}{|c|c|c|c|c|c|c|}
\hline \multirow{2}{*}{$\begin{array}{l}\text { Necrose coagulativa do } \\
\text { parênquima alveolado }\end{array}$} & \multicolumn{4}{|c|}{ Sobrevida hospitalar } & \multirow{2}{*}{ Total } & \multirow{2}{*}{$(\%)$} \\
\hline & não & $(\%)$ & sim & $(\%)$ & & \\
\hline 0 & 31 & $(52)$ & 29 & $(48)$ & 60 & (100) \\
\hline 1 & & & 1 & $(100)$ & 1 & $(100)$ \\
\hline 2 & 1 & $(100)$ & & & 1 & (100) \\
\hline 3 & & & 1 & (100) & 1 & $(100)$ \\
\hline Total & 32 & (51) & 31 & (49) & 63 & (100) \\
\hline
\end{tabular}

Tabela A9. 29: Distribuição da sobrevida hospitalar segundo o parâmetro Deposição de material amorfo na luz alveolar

\begin{tabular}{ccccccc}
\hline $\begin{array}{c}\text { Deposição de material } \\
\text { amorfo na luz alveolar }\end{array}$ & não & $(\%)$ & sim & $(\%)$ & \multirow{2}{*}{ Total } & \multirow{2}{*}{$(\%)$} \\
\hline 0 & 32 & $(52)$ & 30 & $(48)$ & 62 & $(100)$ \\
2 & & & 1 & $(100)$ & 1 & $(100)$ \\
\hline Total & 32 & $(51)$ & 31 & $(49)$ & 63 & $(100)$ \\
\hline
\end{tabular}

Tabela A9. 30: Distribuição da sobrevida hospitalar segundo o parâmetro Elementos fúngicos intralveolares

\begin{tabular}{|c|c|c|c|c|c|c|}
\hline \multirow{2}{*}{$\begin{array}{l}\text { Elementos fúngicos } \\
\text { intralveolares }\end{array}$} & \multicolumn{4}{|c|}{ Sobrevida hospitalar } & \multirow{2}{*}{ Total } & \multirow{2}{*}{$(\%)$} \\
\hline & não & $(\%)$ & sim & $(\%)$ & & \\
\hline 0 & 31 & (50) & 31 & (50) & 62 & (100) \\
\hline 2 & 1 & (100) & & & 1 & (100) \\
\hline Total & 32 & (51) & 31 & (49) & 63 & (100) \\
\hline
\end{tabular}

Tabela A9. 31: Distribuição da sobrevida hospitalar segundo o parâmetro Bactérias intralveolares

\begin{tabular}{ccccccc}
\hline Bactérias & \multicolumn{4}{c}{ Sobrevida hospitalar } & \multirow{2}{*}{ Total } & \multirow{2}{*}{$(\%)$} \\
\cline { 2 - 5 } intralveolares & não & $(\%)$ & sim & $(\%)$ & & \\
\hline 0 & 32 & $(51)$ & 31 & $(49)$ & 63 & $(100)$
\end{tabular}




\begin{tabular}{lllllll}
\hline Total & 32 & $(51)$ & 31 & $(49)$ & 63 & $(100)$ \\
\hline
\end{tabular}




\section{A10. CARACTERIZAÇÃO HISTOPATOLÓGICA DE GRANULOMAS}

Tabela A10. 1: Distribuição da sobrevida hospitalar segundo o parâmetro

\begin{tabular}{|c|c|c|c|c|c|c|}
\hline \multirow{2}{*}{$\begin{array}{c}\text { Granulomas em zonas } \\
\text { axiais }\end{array}$} & \multicolumn{4}{|c|}{ Sobrevida hospitalar } & \multirow{2}{*}{ Total } & \multirow{2}{*}{ (\%) } \\
\hline & não & $(\%)$ & sim & $(\%)$ & & \\
\hline 0 & 30 & (55) & 25 & (45) & 55 & $(100)$ \\
\hline 1 & 1 & (33) & 2 & (67) & 3 & (100) \\
\hline 2 & 1 & (25) & 3 & (75) & 4 & (100) \\
\hline 4 & & & 1 & (100) & 1 & (100) \\
\hline Total & 32 & (51) & 31 & $(49)$ & 63 & (100) \\
\hline
\end{tabular}

Tabela A10. 2: Distribuição da sobrevida hospitalar segundo o parâmetro Granulomas em zonas septais

\begin{tabular}{|c|c|c|c|c|c|c|}
\hline \multirow{2}{*}{ Granulomas em zonas septais } & \multicolumn{4}{|c|}{ Sobrevida hospitalar } & \multirow{2}{*}{ Total } & \multirow[b]{2}{*}{$(\%)$} \\
\hline & não & $(\%)$ & $\operatorname{sim}$ & $(\%)$ & & \\
\hline 0 & 29 & (51) & 28 & (49) & 57 & $(100)$ \\
\hline 1 & 1 & (100) & & & 1 & (100) \\
\hline 2 & 1 & $(25)$ & 3 & (75) & 4 & (100) \\
\hline 3 & 1 & (100) & & & 1 & (100) \\
\hline Total & 32 & (51) & 31 & (49) & 63 & (100) \\
\hline
\end{tabular}

Tabela A10. 3: Distribuição da sobrevida hospitalar segundo o parâmetro Granulomas em zonas periféricas

\begin{tabular}{|c|c|c|c|c|c|c|}
\hline \multirow{2}{*}{$\begin{array}{c}\text { Granulomas em zonas } \\
\text { periféricas }\end{array}$} & \multicolumn{4}{|c|}{ Sobrevida hospitalar } & \multirow{2}{*}{ Total } & \multirow{2}{*}{$(\%)$} \\
\hline & não & $(\%)$ & $\operatorname{sim}$ & $(\%)$ & & \\
\hline 0 & 30 & $(51)$ & 29 & (49) & 59 & (100) \\
\hline 1 & 2 & $(50)$ & 2 & $(50)$ & 4 & $(100)$ \\
\hline Total & 32 & (51) & 31 & (49) & 63 & (100) \\
\hline
\end{tabular}

Tabela A10. 4: Distribuição da sobrevida hospitalar segundo o parâmetro Granulomas de padrão infeccioso

\begin{tabular}{|c|c|c|c|c|c|c|}
\hline \multirow{2}{*}{$\begin{array}{c}\text { Granulomas de padrão } \\
\text { infeccioso }\end{array}$} & \multicolumn{4}{|c|}{ Sobrevida hospitalar } & \multirow{2}{*}{ Total } & \multirow{2}{*}{$(\%)$} \\
\hline & não & $(\%)$ & $\operatorname{sim}$ & $(\%)$ & & \\
\hline 0 & 31 & (54) & 26 & (46) & 57 & (100) \\
\hline 1 & & & 1 & (100) & 1 & (100) \\
\hline 2 & & & 2 & (100) & 2 & (100) \\
\hline 3 & & & 1 & (100) & 1 & (100) \\
\hline 4 & 1 & (50) & 1 & $(50)$ & 2 & (100) \\
\hline Total & 32 & $(51)$ & 31 & (49) & 63 & (100) \\
\hline
\end{tabular}


Tabela A10. 5: Distribuição da sobrevida hospitalar segundo o parâmetro Granulomas de padrão não infeccioso

\begin{tabular}{|c|c|c|c|c|c|c|}
\hline \multirow{2}{*}{$\begin{array}{c}\text { Granulomas de padrão não } \\
\text { infeccioso }\end{array}$} & \multicolumn{4}{|c|}{ Sobrevida hospitalar } & \multirow{2}{*}{ Total } & \multirow{2}{*}{$(\%)$} \\
\hline & não & $(\%)$ & $\operatorname{sim}$ & $(\%)$ & & \\
\hline 0 & 30 & (50) & 30 & (50) & 60 & (100) \\
\hline 2 & 2 & (100) & & & 2 & (100) \\
\hline 4 & & & 1 & $(100)$ & 1 & (100) \\
\hline Total & 32 & (51) & 31 & (49) & 63 & (100) \\
\hline
\end{tabular}

Tabela A10. 6: Distribuição da sobrevida hospitalar segundo o parâmetro Granulomas completos

\begin{tabular}{|c|c|c|c|c|c|c|}
\hline \multirow{2}{*}{ Granulomas completos } & \multicolumn{4}{|c|}{ Sobrevida hospitalar } & \multirow{2}{*}{ Total } & \multirow{2}{*}{$(\%)$} \\
\hline & não & $(\%)$ & $\operatorname{sim}$ & $(\%)$ & & \\
\hline 0 & 29 & (52) & 27 & (48) & 56 & $(100)$ \\
\hline 1 & 1 & (50) & 1 & (50) & 2 & $(100)$ \\
\hline 2 & 1 & (100) & & & 1 & (100) \\
\hline 3 & & & 2 & (100) & 2 & (100) \\
\hline 4 & 1 & $(50)$ & 1 & $(50)$ & 2 & $(100)$ \\
\hline Total & 32 & (51) & 31 & (49) & 63 & $(100)$ \\
\hline
\end{tabular}

Tabela A10. 7: Distribuição da sobrevida hospitalar segundo o parâmetro Granulomas incompletos

\begin{tabular}{|c|c|c|c|c|c|c|}
\hline \multirow{2}{*}{ Granulomas incompletos } & \multicolumn{4}{|c|}{ Sobrevida hospitalar } & \multirow{2}{*}{ Total } & \multirow{2}{*}{$(\%)$} \\
\hline & não & $(\%)$ & $\operatorname{sim}$ & (\%) & & \\
\hline 0 & 31 & (53) & 27 & (47) & 58 & $(100)$ \\
\hline 1 & 1 & (33) & 2 & (67) & 3 & (100) \\
\hline 2 & & & 1 & (100) & 1 & (100) \\
\hline 3 & & & 1 & $(100)$ & 1 & $(100)$ \\
\hline Total & 32 & (51) & 31 & (49) & 63 & $(100)$ \\
\hline
\end{tabular}

Tabela A10. 8: Distribuição da sobrevida hospitalar segundo o parâmetro Granulomas necrotizantes

\begin{tabular}{|c|c|c|c|c|c|c|}
\hline \multirow{2}{*}{ Granulomas necrotizantes } & \multicolumn{4}{|c|}{ Sobrevida hospitalar } & \multirow{2}{*}{ Total } & \multirow{2}{*}{$(\%)$} \\
\hline & não & $(\%)$ & $\operatorname{sim}$ & $(\%)$ & & \\
\hline 0 & 31 & (54) & 26 & $(46)$ & 57 & $(100)$ \\
\hline 1 & & & 1 & (100) & 1 & (100) \\
\hline 2 & & & 2 & (100) & 2 & (100) \\
\hline 3 & & & 2 & (100) & 2 & (100) \\
\hline 4 & 1 & $(100)$ & & & 1 & (100) \\
\hline Total & 32 & $(51)$ & 31 & (49) & 63 & (100) \\
\hline
\end{tabular}


Tabela A10. 9: Distribuição da sobrevida hospitalar segundo o parâmetro Granulomas não necrotizantes

\begin{tabular}{|c|c|c|c|c|c|c|}
\hline \multirow{2}{*}{$\begin{array}{c}\text { Granulomas não } \\
\text { necrotizantes }\end{array}$} & \multicolumn{4}{|c|}{ Sobrevida hospitalar } & \multirow{2}{*}{ Total } & \multirow{2}{*}{$(\%)$} \\
\hline & não & $(\%)$ & $\operatorname{sim}$ & $(\%)$ & & \\
\hline 0 & 30 & $(52)$ & 28 & $(48)$ & 58 & $(100)$ \\
\hline 1 & & & 1 & (100) & 1 & (100) \\
\hline 2 & 2 & (67) & 1 & $(33)$ & 3 & (100) \\
\hline 4 & & & 1 & (100) & 1 & (100) \\
\hline Total & 32 & (51) & 31 & $(49)$ & 63 & (100) \\
\hline
\end{tabular}

Tabela A10. 10: Distribuição da sobrevida hospitalar segundo o parâmetro Nódulo granulomatoso exsudativo

\begin{tabular}{ccccccc}
\hline \multirow{2}{*}{ Nódulo granulomatoso exsudativo } & \multicolumn{4}{c}{ Sobrevida hospitalar } & \multirow{2}{*}{ Total } & \multirow{2}{*}{$(\%)$} \\
\cline { 2 - 6 } & não & $(\%)$ & $\operatorname{sim}$ & $(\%)$ & & \\
\hline 0 & 32 & $(52)$ & 30 & $(48)$ & 62 & $(100)$ \\
1 & & & 1 & $(100)$ & 1 & $(100)$ \\
\hline Total & 32 & $(51)$ & 31 & $(49)$ & 63 & $(100)$ \\
\hline
\end{tabular}

Tabela A10. 11: Distribuição da sobrevida hospitalar segundo o parâmetro Presença de micobactérias

\begin{tabular}{|c|c|c|c|c|c|c|}
\hline \multirow{2}{*}{$\begin{array}{l}\text { Presença de } \\
\text { micobactérias }\end{array}$} & \multicolumn{4}{|c|}{ Sobrevida hospitalar } & \multirow{2}{*}{ Total } & \multirow{2}{*}{$(\%)$} \\
\hline & não & $(\%)$ & $\operatorname{sim}$ & $(\%)$ & & \\
\hline 0 & 32 & $(51)$ & 31 & $(49)$ & 63 & $(100)$ \\
\hline Total & 32 & (51) & 31 & (49) & 63 & (100) \\
\hline
\end{tabular}

Tabela A10. 12: Distribuição da sobrevida hospitalar segundo o parâmetro Presença de partículas birrefringentes em granulomas

\begin{tabular}{cccccccc}
\hline $\begin{array}{c}\text { Presença de partículas } \\
\text { birrefringentes em } \\
\text { granulomas }\end{array}$ & não & $(\%)$ & $\operatorname{sim}$ & $(\%)$ & Total & $(\%)$ \\
\cline { 2 - 5 } & 32 & $(51)$ & 31 & $(49)$ & 63 & $(100)$ \\
\hline 0 & 32 & $(51)$ & 31 & $(49)$ & 63 & $(100)$ \\
\hline Total & & & & &
\end{tabular}

Tabela A10. 13: Distribuição da sobrevida hospitalar segundo o parâmetro Presença de calcificação em granulomas

\begin{tabular}{|c|c|c|c|c|c|c|}
\hline \multirow{2}{*}{$\begin{array}{c}\text { Presença de calcificação } \\
\text { em granulomas }\end{array}$} & \multicolumn{4}{|c|}{ Sobrevida hospitalar } & \multirow{2}{*}{ Total } & \multirow{2}{*}{$(\%)$} \\
\hline & não & $(\%)$ & sim & $(\%)$ & & \\
\hline 0 & 32 & $(51)$ & 31 & $(49)$ & 63 & (100) \\
\hline Total & 32 & (51) & 31 & (49) & 63 & $(100)$ \\
\hline
\end{tabular}




\section{A11. CARACTERIZAÇÃO HISTOPATOLÓGICA DO TECIDO NEOPLÁSICO}

Tabela A11. 1: Distribuição da sobrevida hospitalar segundo o parâmetro Hemorragia em tecido neoplásico de distribuição vascular

\begin{tabular}{ccccccc}
\hline $\begin{array}{c}\text { Hemorragia em tecido } \\
\text { neoplásico de distribuição } \\
\text { vascular }\end{array}$ & não & $(\%)$ & $\operatorname{sim}$ & $(\%)$ & Total & $(\%)$ \\
\cline { 2 - 5 } & 32 & $(51)$ & 31 & $(49)$ & 63 & $(100)$ \\
\hline 0 & 32 & $(51)$ & 31 & $(49)$ & 63 & $(100)$ \\
\hline Total & & & & &
\end{tabular}

Tabela A11. 2: Distribuição da sobrevida hospitalar segundo o parâmetro Compressão de tecidos adjacentes por tecido neoplásico de distribuição vascular

\begin{tabular}{cccccccc}
\hline Compressão de tecidos & \multicolumn{5}{c}{ Sobrevida hospitalar } & Total & $(\%)$ \\
\cline { 2 - 5 } $\begin{array}{c}\text { adjacentes por tecido neoplásico } \\
\text { de distribuição vascular }\end{array}$ & não & $(\%)$ & $\operatorname{sim}$ & $(\%)$ & & \\
\hline 0 & 31 & $(51)$ & 30 & $(49)$ & 61 & $(100)$ \\
1 & 1 & $(50)$ & 1 & $(50)$ & 2 & $(100)$ \\
\hline Total & 32 & $(51)$ & 31 & $(49)$ & 63 & $(100)$ \\
\hline
\end{tabular}

Tabela A11. 3: Distribuição da sobrevida hospitalar segundo o parâmetro Necrose de tecido neoplásico de distribuição vascular

\begin{tabular}{cccccccc}
\hline $\begin{array}{c}\text { Necrose de tecido } \\
\text { neoplásico de distribuição } \\
\text { vascular }\end{array}$ & não & $(\%)$ & $\operatorname{sim}$ & $(\%)$ & Total & $(\%)$ \\
\hline 0 & 32 & $(52)$ & 30 & $(48)$ & 62 & $(100)$ \\
3 & 32 & $(51)$ & 31 & $(49)$ & 63 & $(100)$ \\
\hline Total & & & 1 & $(100)$ & 1 & $(100)$ \\
\hline
\end{tabular}

Tabela A11. 4: Distribuição da sobrevida hospitalar segundo o parâmetro Mucoprodução em tecido neoplásico de distribuição vascular

\begin{tabular}{|c|c|c|c|c|c|c|}
\hline \multirow{2}{*}{$\begin{array}{l}\text { Mucoprodução em tecido } \\
\text { neoplásico de distribuição } \\
\text { vascular }\end{array}$} & \multicolumn{4}{|c|}{ Sobrevida hospitalar } & \multirow{2}{*}{ Total } & \multirow{2}{*}{$(\%)$} \\
\hline & não & $(\%)$ & sim & $(\%)$ & & \\
\hline 0 & 32 & (51) & 31 & (49) & 63 & $(100)$ \\
\hline Total & 32 & (51) & 31 & (49) & 63 & $(100)$ \\
\hline
\end{tabular}


Tabela A11. 5: Distribuição da sobrevida hospitalar segundo o parâmetro Hemorragia em tecido neoplásico de distribuição tecidual

\begin{tabular}{ccccccc}
\hline $\begin{array}{c}\text { Hemorragia em tecido } \\
\text { neoplásico de distribuição } \\
\text { tecidual }\end{array}$ & não & $(\%)$ & $\operatorname{sim}$ & $(\%)$ & Total & $(\%)$ \\
\hline 0 & 31 & $(50)$ & 31 & $(50)$ & 62 & $(100)$ \\
1 & 1 & $(100)$ & & & 1 & $(100)$ \\
\hline Total & 32 & $(51)$ & 31 & $(49)$ & 63 & $(100)$ \\
\hline
\end{tabular}

Tabela A11. 6: Distribuição da sobrevida hospitalar segundo o parâmetro Compressão de tecidos adjacentes por tecido neoplásico de distribuição tecidual

\begin{tabular}{ccccccc}
\hline \multirow{2}{*}{$\begin{array}{c}\text { Compressão de tecidos } \\
\text { adjacentes por tecido neoplásico } \\
\text { de distribuição tecidual }\end{array}$} & não & $(\%)$ & $\operatorname{sim}$ & $(\%)$ & Total & $(\%)$ \\
\hline 0 & 30 & $(52)$ & 28 & $(48)$ & 58 & $(100)$ \\
1 & 1 & $(50)$ & 1 & $(50)$ & 2 & $(100)$ \\
2 & 1 & $(50)$ & 1 & $(50)$ & 2 & $(100)$ \\
3 & & & 1 & $(100)$ & 1 & $(100)$ \\
\hline Total & 32 & $(51)$ & 31 & $(49)$ & 63 & $(100)$ \\
\hline
\end{tabular}

Tabela A11. 7: Distribuição da sobrevida hospitalar segundo o parâmetro Necrose de tecido neoplásico de distribuição tecidual

\begin{tabular}{ccccccc}
\hline $\begin{array}{c}\text { Necrose de tecido } \\
\text { neoplásico de distribuição } \\
\text { tecidual }\end{array}$ & não & $(\%)$ & sim & $(\%)$ & Total & $(\%)$ \\
\hline 0 & 30 & $(51)$ & 29 & $(49)$ & 59 & $(100)$ \\
1 & 1 & $(100)$ & & & 1 & $(100)$ \\
2 & 1 & $(33)$ & 2 & $(67)$ & 3 & $(100)$ \\
\hline Total & 32 & $(51)$ & 31 & $(49)$ & 63 & $(100)$ \\
\hline
\end{tabular}

Tabela A11. 8: Distribuição da sobrevida hospitalar segundo o parâmetro Mucoprodução em tecido neoplásico de distribuição tecidual

\begin{tabular}{|c|c|c|c|c|c|c|}
\hline \multirow{2}{*}{$\begin{array}{l}\text { Mucoprodução em tecido } \\
\text { neoplásico de distribuição } \\
\text { tecidual }\end{array}$} & \multicolumn{4}{|c|}{ Sobrevida hospitalar } & \multirow{2}{*}{ Total } & \multirow{2}{*}{$(\%)$} \\
\hline & não & $(\%)$ & $\operatorname{sim}$ & $(\%)$ & & \\
\hline 0 & 31 & (51) & 30 & $(49)$ & 61 & (100) \\
\hline 2 & 1 & (50) & 1 & (50) & 2 & (100) \\
\hline Total & 32 & (51) & 31 & (49) & 63 & (100) \\
\hline
\end{tabular}


Tabela A11. 9: Distribuição da sobrevida hospitalar segundo o parâmetro Infiltração da parede torácica por tecido neoplásico de distribuição tecidual

\begin{tabular}{ccccccc}
\hline $\begin{array}{c}\text { Infiltração da parede } \\
\text { torácica por tecido } \\
\text { neoplásico de distribuição } \\
\text { tecidual }\end{array}$ & não & $(\%)$ & $\operatorname{sim}$ & $(\%)$ & Total & $(\%)$ \\
\hline 0 & 32 & $(51)$ & 31 & $(49)$ & 63 & $(100)$ \\
\hline Total & 32 & $(51)$ & 31 & $(49)$ & 63 & $(100)$ \\
\hline
\end{tabular}




\section{APÊNDICE 1}

Compilação de dados dos pacientes incluídos no estudo 


\begin{tabular}{|c|c|c|c|c|c|}
\hline Caso & Registro hospitalar & Nome (iniciais) & Sexo & Idade & Evolução \\
\hline 1 & $5046084 \mathrm{~J}$ & AASN & $\mathrm{m}$ & 56 & Óbito \\
\hline 2 & $5089265 A$ & AV & $\mathrm{m}$ & 48 & Óbito \\
\hline 3 & $5172820 \mathrm{~F}$ & $A C$ & $\mathrm{~m}$ & 76 & alta \\
\hline 4 & $2780156 \mathrm{E}$ & ACD & $f$ & 19 & óbito \\
\hline 5 & $3200120 G$ & APG & $m$ & 67 & alta \\
\hline 6 & $3264880 \mathrm{D}$ & ADC & $\mathrm{m}$ & 55 & óbito \\
\hline 7 & 13511156D & $A D$ & $f$ & 52 & alta \\
\hline 8 & $3225973 \mathrm{H}$ & AAS & $\mathrm{m}$ & 48 & óbito \\
\hline 9 & $3169429 \mathrm{~K}$ & AS & $m$ & 66 & alta \\
\hline 10 & $2726527 C$ & AHSG & $f$ & 37 & óbito \\
\hline 11 & $3258127 \mathrm{G}$ & AGN & $\mathrm{m}$ & 34 & óbito \\
\hline 12 & $2608351 \mathrm{~F}$ & BES & $\mathrm{m}$ & 45 & óbito \\
\hline 13 & 13515110B & BMP & $m$ & 52 & alta \\
\hline 14 & 13533244E & DRD & $f$ & 21 & alta \\
\hline 15 & $13545791 \mathrm{~A}$ & DRB & $f$ & 30 & alta \\
\hline 16 & $13544824 I$ & DM & $f$ & 63 & óbito \\
\hline 17 & 2199089J & DS & $\mathrm{m}$ & 37 & óbito \\
\hline 18 & 3044886B & EMN & $f$ & 51 & alta \\
\hline 19 & $3314253 B$ & FRFM & $m$ & 52 & alta \\
\hline 20 & $3360097 \mathrm{~F}$ & IHNR & $f$ & 46 & óbito \\
\hline 21 & $2850450 \mathrm{~J}$ & JMSR & $f$ & 34 & óbito \\
\hline 22 & $2936598 E$ & JOR & $f$ & 49 & alta \\
\hline 23 & $13527509 \mathrm{H}$ & JS & $m$ & 23 & óbito \\
\hline 24 & 2497139J & JFA & $\mathrm{m}$ & 58 & óbito \\
\hline 25 & $5209019 \mathrm{~J}$ & JKAD & $m$ & 77 & óbito \\
\hline 26 & 27934911 & JAB & $\mathrm{m}$ & 36 & óbito \\
\hline 27 & $13520448 C$ & JBPS & $\mathrm{m}$ & 78 & alta \\
\hline 28 & $3248159 \mathrm{~B}$ & JPA & $f$ & 54 & óbito \\
\hline 29 & $13518739 \mathrm{C}$ & $\mathrm{KT}$ & $f$ & 51 & óbito \\
\hline 30 & 5047404B & KM & $\mathrm{m}$ & 57 & óbito \\
\hline 31 & $5229721 \mathrm{H}$ & LMS & $f$ & 21 & alta \\
\hline 32 & 5019779E & LM & $f$ & 74 & óbito \\
\hline 33 & $5065613 A$ & MF & $\mathrm{m}$ & 55 & óbito \\
\hline 34 & $13529832 \mathrm{~F}$ & MFS & $\mathrm{m}$ & 65 & óbito \\
\hline 35 & 13517996G & MAAFM & $f$ & 46 & alta \\
\hline 36 & 13532378D & MCSO & $f$ & 52 & alta \\
\hline 37 & 5197610B & MDF & $f$ & 92 & alta \\
\hline 38 & $3262325 C$ & MESS & $f$ & 26 & óbito \\
\hline 39 & 30501171 & MLD & $f$ & 53 & óbito \\
\hline 40 & $3280695 \mathrm{~A}$ & MDV & $\mathrm{m}$ & 70 & óbito \\
\hline 41 & $13528739 \mathrm{H}$ & MRC & $f$ & 30 & alta \\
\hline 42 & $13540556 \mathrm{H}$ & NAJ & $f$ & 82 & alta \\
\hline 43 & 2948374G & NBC & $f$ & 50 & alta \\
\hline 44 & $13508372 \mathrm{I}$ & NRS & $m$ & 57 & alta \\
\hline 45 & $5104237 \mathrm{H}$ & ORC & $\mathrm{m}$ & 65 & óbito \\
\hline 46 & 5132349B & $\mathrm{PZ}$ & $\mathrm{m}$ & 47 & óbito \\
\hline 47 & $2829573 C$ & PJF & $\mathrm{m}$ & 32 & óbito \\
\hline 48 & $3303274 \mathrm{~F}$ & PA & $f$ & 68 & alta \\
\hline
\end{tabular}




\begin{tabular}{|c|c|c|c|c|c|}
\hline Caso & Registro hospitalar & Nome (iniciais) & Sexo & Idade & Evolução \\
\hline $\mathbf{4 9}$ & 5217496J & RRM & $\mathrm{m}$ & 53 & óbito \\
\hline $\mathbf{5 0}$ & $13516422 \mathrm{~B}$ & RBS & $\mathrm{m}$ & 22 & alta \\
\hline $\mathbf{5 1}$ & $3200666 \mathrm{~B}$ & RJS & $\mathrm{m}$ & 18 & alta \\
\hline $\mathbf{5 2}$ & $5235847 \mathrm{~F}$ & RAC & $\mathrm{f}$ & 76 & óbito \\
\hline $\mathbf{5 3}$ & $13540661 \mathrm{~F}$ & ROS & $\mathrm{f}$ & 55 & óbito \\
\hline $\mathbf{5 4}$ & $5212443 \mathrm{I}$ & RBS & $\mathrm{f}$ & 25 & alta \\
\hline $\mathbf{5 5}$ & $2616072 \mathrm{D}$ & SMS & $\mathrm{f}$ & 38 & alta \\
\hline $\mathbf{5 6}$ & $2867113 \mathrm{~A}$ & SMA & $\mathrm{m}$ & 37 & alta \\
\hline $\mathbf{5 7}$ & $5354737 \mathrm{~J}$ & SCM & $\mathrm{f}$ & 36 & alta \\
\hline $\mathbf{5 8}$ & $13523442 \mathrm{E}$ & SRCA & $\mathrm{f}$ & 36 & alta \\
\hline $\mathbf{5 9}$ & $13534938 \mathrm{D}$ & TVS & $\mathrm{m}$ & 73 & alta \\
\hline $\mathbf{6 0}$ & $2374572 \mathrm{~A}$ & TMN & $\mathrm{f}$ & 52 & alta \\
\hline $\mathbf{6 1}$ & $3081796 \mathrm{E}$ & VAC & $\mathrm{m}$ & 31 & óbito \\
\hline $\mathbf{6 2}$ & $13507026 \mathrm{D}$ & WSM & $\mathrm{m}$ & 28 & alta \\
\hline $\mathbf{6 3}$ & $13504815 \mathrm{~B}$ & WAPR & $\mathrm{f}$ & 73 & alta \\
\hline
\end{tabular}




\begin{tabular}{|c|c|c|c|c|c|c|}
\hline Caso & $\begin{array}{c}\text { Data } \\
\text { Alta/Óbito }\end{array}$ & $\begin{array}{l}\text { Autópsia } \\
\text { no. }\end{array}$ & $\begin{array}{c}\text { Biópsia } \\
\text { no. }\end{array}$ & Internação & Cirurgia & Complicações \\
\hline 1 & $26 / 01 / 96$ & A025-96 & B96-0066 & $06 / 01 / 96$ & $16 / 01 / 96$ & não \\
\hline 2 & $15 / 08 / 01$ & A150-01 & B01-1659 & $13 / 07 / 01$ & $19 / 07 / 01$ & não \\
\hline 3 & $17 / 01 / 03$ & & B02-3213 & $17 / 11 / 02$ & $06 / 12 / 02$ & não \\
\hline 4 & $19 / 08 / 92$ & A301-92 & B92-1736 & $02 / 07 / 92$ & $15 / 08 / 92$ & dados não acessados \\
\hline 5 & $26 / 09 / 97$ & & $30-8585-6$ & $12 / 08 / 97$ & $25 / 08 / 97$ & não \\
\hline 6 & $17 / 11 / 98$ & HC 98/1332 & $36-2684-9$ & $30 / 10 / 98$ & $12 / 11 / 98$ & não \\
\hline 7 & $11 / 08 / 00$ & & $44-3248-7$ & $14 / 07 / 00$ & $03 / 08 / 00$ & não \\
\hline 8 & $25 / 07 / 00$ & $\mathrm{HC} 00 / 0800$ & $44-1103-0$ & $31 / 05 / 00$ & $20 / 07 / 00$ & não \\
\hline 9 & $10 / 02 / 00$ & & B00-0109 & $28 / 12 / 99$ & $14 / 01 / 00$ & $\begin{array}{c}\text { sim (infecção da ferida } \\
\text { cirúrgica) }\end{array}$ \\
\hline 10 & $12 / 08 / 92$ & HC 92/1084 & B92-8583 & $28 / 06 / 92$ & $14 / 07 / 92$ & não \\
\hline 11 & $28 / 09 / 98$ & HC 98/1132 & $35-6191-7$ & $12 / 09 / 98$ & $21 / 09 / 98$ & não \\
\hline 12 & $18 / 11 / 98$ & HC 98/1335 & $36-1809-9$ & $31 / 10 / 98$ & $05 / 11 / 98$ & não \\
\hline 13 & $18 / 09 / 00$ & & $44-8436-3$ & $28 / 08 / 00$ & $12 / 09 / 00$ & dados não acessados \\
\hline 14 & $10 / 08 / 01$ & & $49-1704-9$ & $02 / 07 / 01$ & $23 / 07 / 01$ & $\begin{array}{c}\text { sim (atelectasia e } \\
\text { pneumotórax) }\end{array}$ \\
\hline 15 & $31 / 07 / 01$ & & $48-6579-0$ & $24 / 06 / 01$ & $27 / 06 / 01$ & não \\
\hline 16 & $22 / 06 / 01$ & HC 01/0618 & $48-5667-8$ & $13 / 06 / 01$ & $21 / 06 / 01$ & dados não acessados \\
\hline 17 & $24 / 05 / 95$ & A140-95 & B95-0613 & $06 / 04 / 95$ & $29 / 04 / 95$ & não \\
\hline 18 & $05 / 03 / 01$ & & $46-9919-0$ & $13 / 02 / 01$ & $01 / 03 / 01$ & dados não acessados \\
\hline 19 & $29 / 11 / 99$ & & $40-8695-3$ & $21 / 10 / 99$ & $09 / 11 / 01$ & não \\
\hline 20 & $01 / 07 / 01$ & & $48-5272-9$ & $05 / 06 / 01$ & $19 / 06 / 01$ & dados não acessados \\
\hline 21 & $17 / 05 / 93$ & & B93-0858 & $13 / 05 / 93$ & $13 / 05 / 93$ & não \\
\hline 22 & $10 / 01 / 01$ & & $46-2628-1$ & $21 / 12 / 00$ & $28 / 12 / 00$ & não \\
\hline 23 & $06 / 02 / 01$ & & $46-5522-2$ & $15 / 01 / 01$ & $24 / 01 / 01$ & não \\
\hline 24 & $01 / 10 / 94$ & HC 94/1520 & $18-7683-0$ & $18 / 09 / 94$ & $30 / 09 / 94$ & dados não acessados \\
\hline 25 & $01 / 10 / 95$ & A303-95 & B95-1201 & $16 / 08 / 95$ & $29 / 08 / 95$ & não \\
\hline 26 & $01 / 06 / 92$ & A182-92 & B92-1015 & $11 / 05 / 92$ & $21 / 05 / 92$ & dados não acessados \\
\hline 27 & $17 / 11 / 00$ & & $45-6645-9$ & $30 / 10 / 00$ & $06 / 11 / 00$ & dados não acessados \\
\hline 28 & $12 / 06 / 00$ & & $43-5524-5$ & $03 / 06 / 00$ & $07 / 06 / 00$ & não \\
\hline 29 & $22 / 04 / 01$ & & $45-9123-2$ & $18 / 10 / 00$ & $29 / 11 / 00$ & não \\
\hline 30 & $10 / 07 / 95$ & A208-95 & B95-0928 & $07 / 06 / 95$ & $05 / 07 / 95$ & não \\
\hline 31 & $18 / 04 / 97$ & & $29-1443-3$ & $06 / 03 / 97$ & $01 / 04 / 97$ & dados não acessados \\
\hline 32 & $29 / 11 / 97$ & A330-97 & B97-2246 & $31 / 10 / 97$ & $22 / 11 / 97$ & não \\
\hline 33 & $28 / 06 / 87$ & A237-87 & B87-0455 & $27 / 03 / 87$ & $28 / 05 / 87$ & não \\
\hline 34 & $10 / 04 / 01$ & & $47-1406-7$ & $01 / 02 / 01$ & $12 / 03 / 01$ & não \\
\hline 35 & $21 / 11 / 00$ & & $45-6644-0$ & $06 / 11 / 00$ & $09 / 11 / 00$ & dados não acessados \\
\hline 36 & $07 / 05 / 01$ & & $47-3476-9$ & $21 / 02 / 01$ & $26 / 03 / 01$ & dados não acessados \\
\hline 37 & $30 / 11 / 00$ & & $45-7075-8$ & $06 / 11 / 00$ & $13 / 11 / 00$ & dados não acessados \\
\hline 38 & $15 / 07 / 00$ & & $43-9831-9$ & $18 / 06 / 00$ & $10 / 07 / 00$ & dados não acessados \\
\hline 39 & $31 / 08 / 01$ & HC 01/0887 & $48-2199-8$ & $22 / 05 / 01$ & $28 / 05 / 01$ & não \\
\hline 40 & $15 / 01 / 01$ & & $46-2347-9$ & $28 / 11 / 00$ & $22 / 12 / 00$ & sim (enfisema subcut.) \\
\hline 41 & $28 / 03 / 01$ & & $46-8456-7$ & $23 / 01 / 01$ & $15 / 02 / 01$ & dados não acessados \\
\hline 42 & $31 / 05 / 01$ & & $48-2474-1$ & $08 / 05 / 01$ & $29 / 05 / 01$ & não \\
\hline 43 & $01 / 03 / 96$ & & $23-8560-0$ & $30 / 11 / 95$ & $19 / 12 / 95$ & dados não acessados \\
\hline 44 & $14 / 07 / 00$ & & $43-9048-2$ & $06 / 06 / 00$ & $04 / 07 / 00$ & dados não acessados \\
\hline 45 & $03 / 02 / 95$ & A042-95 & B95-0116 & $26 / 12 / 94$ & $23 / 01 / 95$ & dados não acessados \\
\hline
\end{tabular}




\begin{tabular}{|c|c|c|c|c|c|c|}
\hline Caso & $\begin{array}{c}\text { Data } \\
\text { Alta/Óbito }\end{array}$ & $\begin{array}{c}\text { Autópsia } \\
\text { no. }\end{array}$ & $\begin{array}{c}\text { No. da } \\
\text { biópsia }\end{array}$ & Internação & Cirurgia & Complicações \\
\hline $\mathbf{4 6}$ & $07 / 07 / 91$ & $\mathrm{~A} 216-91$ & $\mathrm{~B} 91-1086$ & $30 / 05 / 91$ & $04 / 07 / 91$ & dados não acessados \\
\hline $\mathbf{4 7}$ & $12 / 06 / 92$ & $\mathrm{~A} 194-92$ & $\mathrm{~B} 92-1177$ & $27 / 05 / 92$ & $10 / 06 / 92$ & s/ dados \\
\hline $\mathbf{4 8}$ & $04 / 01 / 00$ & & $\mathrm{~B} 97-2745$ & $27 / 11 / 99$ & $30 / 12 / 99$ & sim (enfisema subcut.) \\
\hline $\mathbf{4 9}$ & $18 / 05 / 99$ & $\mathrm{~A} 066-99$ & $\mathrm{~B} 99-0872$ & $22 / 04 / 99$ & $03 / 05 / 99$ & não \\
\hline $\mathbf{5 0}$ & $12 / 12 / 00$ & & $45-4138-3$ & $13 / 09 / 00$ & $20 / 10 / 00$ & $\begin{array}{c}\text { sim (enfisema } \\
\text { subcutâneo) }\end{array}$ \\
\hline $\mathbf{5 1}$ & $06 / 10 / 00$ & & $45-1675-3$ & $29 / 09 / 00$ & $02 / 10 / 00$ & dados não acessados \\
\hline $\mathbf{5 2}$ & $10 / 09 / 99$ & $\mathrm{HC} \mathrm{99/1231}$ & $40-0745-0$ & $04 / 08 / 99$ & $04 / 09 / 99$ & dados não acessados \\
\hline $\mathbf{5 3}$ & $25 / 05 / 01$ & $\mathrm{HC} 0505$ & $47-9587-3$ & $08 / 05 / 01$ & $23 / 05 / 01$ & dados não acessados \\
\hline $\mathbf{5 4}$ & $05 / 12 / 95$ & & $\mathrm{~B} 95-1588$ & $18 / 10 / 95$ & $21 / 11 / 95$ & não \\
\hline $\mathbf{5 5}$ & $18 / 10 / 00$ & $\mathrm{HC} 02 / 0344$ & $44-9844-5$ & $06 / 09 / 00$ & $19 / 09 / 00$ & dados não acessados \\
\hline $\mathbf{5 6}$ & $25 / 05 / 93$ & $\mathrm{HC} \mathrm{93/0974}$ & $13-1008-9$ & $01 / 03 / 93$ & $30 / 03 / 93$ & dados não acessados \\
\hline $\mathbf{5 7}$ & $06 / 04 / 01$ & & $47-4068-8$ & $26 / 03 / 01$ & $29 / 03 / 01$ & dados não acessados \\
\hline $\mathbf{5 8}$ & $18 / 12 / 00$ & & $46-0829-1$ & $04 / 12 / 00$ & $11 / 12 / 00$ & dados não acessados \\
\hline $\mathbf{5 9}$ & $23 / 04 / 01$ & & $47-5618-5$ & $19 / 03 / 01$ & $09 / 04 / 01$ & dados não acessados \\
\hline $\mathbf{6 0}$ & $22 / 03 / 85$ & & $\mathrm{~B} 85-1356$ & $16 / 02 / 85$ & $16 / 02 / 85$ & dados não acessados \\
\hline $\mathbf{6 1}$ & $24 / 10 / 00$ & $\mathrm{HC} 00 / 1126$ & $44-8842-3$ & $05 / 09 / 00$ & $13 / 09 / 00$ & dados não acessados \\
\hline $\mathbf{6 2}$ & $11 / 10 / 00$ & $\mathrm{HC} 01 / 0244$ & $44-8475-4$ & $24 / 08 / 00$ & $11 / 09 / 00$ & dados não acessados \\
\hline $\mathbf{6 3}$ & $05 / 04 / 00$ & & $42-3762-5$ & $28 / 02 / 00$ & $14 / 03 / 00$ & dados não acessados \\
\hline
\end{tabular}




\begin{tabular}{|c|c|}
\hline Caso & Hipóteses diagnósticas \\
\hline 1 & $\begin{array}{l}\text { Tx. cardíaco; tabagismo pregresso; pneumopatia a esclarecer; insuficiência } \\
\text { respiratória }\end{array}$ \\
\hline 2 & Pneumopatia intersticial; choque séptico; SARA; IRA ; bcp. \\
\hline 3 & $\begin{array}{l}\text { ICC; IRA; doença pulmonar intersticial c/ fibrose; pneumonia infecciosa a esclarecer; } \\
\text { insuficiência respiratória }\end{array}$ \\
\hline 4 & Anemia aplásica severa; TMO; sepse; pneumopatia intersticial a esclarecer \\
\hline 5 & $\begin{array}{c}\text { Alveolite alérgica extrínseca crônica; sinusopatia crônica; eosinofilia; depressão maior; } \\
\text { pneumonia intersticial (suspeita de aspiração) }\end{array}$ \\
\hline 6 & Tbc(?); histoplasmose(?); bcp(?); sarcoidose(?); quadro reumatológico(?) \\
\hline 7 & Pneumonia intersticial a esclarecer; ICC descompensada \\
\hline 8 & $\begin{array}{l}\text { Doença de Crohn; suboclusão intestinal; pneumopatia por Strongyloides sp.; IRA; } \\
\text { sepse; pneumocistose(?); hemorragia alveolar (vasculite por Crohn?) }\end{array}$ \\
\hline 9 & $\begin{array}{l}\text { HAS; DM; IAM prévio c/ angina instável; doença pulmonar intersticial a esclarecer; } \\
\text { artrite reumatóide; GW }\end{array}$ \\
\hline 10 & LES; insuficiência respiratória; miocardite \\
\hline 11 & $\begin{array}{c}\text { SIDA;SK (?); Pneumocistose(?); CMV pulmonar; Bcp. por acinetobacter(?); } \\
\text { micobacteriose(?) }\end{array}$ \\
\hline 12 & $\begin{array}{l}\text { Pneumopatia a esclarecer; LMC } \\
\end{array}$ \\
\hline 13 & Pneumopatia a esclarecer (silicose? asbestose?) \\
\hline 14 & LNH; aspergilose; herpes genital; PO \\
\hline 15 & Tbc. pulmonar; pneumotórax \\
\hline 16 & Insuficiência respiratória; pneumopatia \\
\hline 17 & Bronquiectasia; hemorragia pulmo \\
\hline 18 & FIPI; artrite reumatóide; 0 \\
\hline 19 & epática \\
\hline 20 & Adenocarcinoma; pneumonia intersticial; \\
\hline 21 & Pneumopatia intersticial ; CMV pulmonar (?); insuficiência respiratória; LMC \\
\hline 22 & CEC pulmonar $\mathrm{c} /$ metástase $\mathrm{p} / \mathrm{SNC}$ \\
\hline 23 & Trauma raquimedular; contusão pulmonar; grande queimado; sepse \\
\hline 24 & Neoplasia maligna pulmonar; pneumonia intersticial a esclarecer \\
\hline 25 & Bcp.; DPOC; neoplasia pulmonar \\
\hline 26 & TMO; pneumopatia a esclarecer (CMV?) \\
\hline 27 & Processo inflamatório granulomatoso pulmonar; pseudotumor inflamatório \\
\hline 28 & $\begin{array}{c}\text { LES; HAS; pneumopatia intersticial: CMV? fungos? bactérias? Tbc.? pneumocistose? } \\
\text { estrongiloidíase }\end{array}$ \\
\hline 29 & GW; IRC; HAS; DM; encefalopatia pós-sarampo; insuficiência respiratória \\
\hline 30 & $\begin{array}{l}\text { IRA; processo inflamatório muscular (reto abdominal); gastrite; esofagite; IAM prévio; } \\
\text { insuficiência respiratória; Bcp. }\end{array}$ \\
\hline 31 & Artrite reumatóide; LES; outra colagenose (?) ; cor pulmonale; hipertensão pulmonar \\
\hline 32 & $\begin{array}{c}\text { Miocardiopatia dilatada; insuficiência de valva aórtica; BAVT; choque cardiogênico; } \\
\text { bcp.; insuficiência respiratória aguda; vasculite a esclarecer; miocardite; IRA; doença } \\
\text { reumatológica a esclarecer; tabagismo pregresso }\end{array}$ \\
\hline 33 & Miocardiopatia dilatada; choque cardiogênico; insuficiência respiratória restritiva \\
\hline 34 & $\begin{array}{c}\text { Tbc (?); sarcoidose (?); bcp (?); micose pulmonar (?); insuficiência coronariana } \\
\text { crônica; fibrilação atrial crônica; IRA }\end{array}$ \\
\hline 35 & $\begin{array}{c}\text { GW; poliangeíte microscópica; bronquiolite; hemorragia alveolar; insuficiência } \\
\text { respiratória; HAS; broncoespasmo }\end{array}$ \\
\hline 36 & TEP c/ infarto infectado; pneumopatia intersticial crônica (PO? FIP?); neoplasia (?) \\
\hline
\end{tabular}




\begin{tabular}{|c|c|}
\hline Caso & Hipóteses diagnósticas \\
\hline 37 & $\begin{array}{c}\text { Nódulos pulmonares a esclarecer; insuficiência respiratória de etiologia a esclarecer } \\
\text { (congestão? linfangite? TEP? Insuficiência coronariana?) }\end{array}$ \\
\hline 38 & LMC; TMO; GVHD (pele e TGI); pneumocistose pulmonar; toxoplasmose pulmonar \\
\hline 39 & $\begin{array}{c}\text { Insuficiência respiratória de etiologia a esclarecer (histiocitose X? Tbc? LAM? } \\
\text { estafilococcia pulmonar?); hepatite C; artrite reumatóide; tabagismo }\end{array}$ \\
\hline 40 & $\begin{array}{l}\text { LNH de baixo grau leucemizado e recidivado pós-QT; neutropenia febril pós-QT; } \\
\text { anemia hemolítica auto-imune; pneumopatia a esclarecer (tbc? aspergilose?) }\end{array}$ \\
\hline 41 & Pneumopatia a esclarecer; colite a esclarecer; tbc. \\
\hline 42 & Pneumopatia a esclarecer; tbc; pneumonia atípica; pneumonia intersticial; neoplasia \\
\hline 43 & Infecção pulmonar; congestão; LES em atividade; pancitopenia febril \\
\hline 44 & FIPI; doença do refluxo gastroesofageano c/ broncoaspiração pulmonar; DM II \\
\hline 45 & $\begin{array}{c}\text { Insuficiência coronariana submetido a revascularização do miocárdio; HAS; DM II; } \\
\text { pneumopatia intersticial }\end{array}$ \\
\hline 46 & Pneumopatia intersticial pós-imunossupressão; LLA; aspergilose pulmonar \\
\hline 47 & LLA; pneumonia bacteriana; sepse \\
\hline 48 & pneumopatia intersticial a esclarecer; TEP; HAS \\
\hline 49 & $\begin{array}{l}\text { Miocardiopatia chagásica; tx. cardíaco; pneumonia bilateral; IRA; fístula broncopleural } \\
\text { à direita. }\end{array}$ \\
\hline 50 & LLA; aspergilose pulmonar (?) \\
\hline 51 & LH (esclerose nodular) c/ comprometimento pulmonar; TMO; LLA; GVHD \\
\hline 52 & $\begin{array}{l}\text { Insuficiência respiratória aguda (tbc? neoplasia?); ICC descompensada.; HAS; } \\
\text { hipertireoidismo; fibrilação atrial crônica; AVCI prévio; nódulo mamário ä direita } \\
\text { sugestivo de neoplasia }\end{array}$ \\
\hline 53 & $\begin{array}{c}\text { Nódulos pulmonares a esclarecer; TVP; TEP; insuficiência respiratória; derrames } \\
\text { pleural e pericárdico; tabagismo }\end{array}$ \\
\hline 54 & Hemoptise a esclarecer (fístula arteriovenosa ? doença de Behçet? vasculite?) \\
\hline 55 & FIP \\
\hline 56 & $\begin{array}{l}\text { LMC; tbc. miliar (?); pneumonia intersticial viral (?); infecção polimicrobiana (?) } \\
\text { (Klebsiella? Pseudomonas?) }\end{array}$ \\
\hline 57 & $\begin{array}{c}\text { Insuficiência cardíaca direita; hipertensão pulmonar; sarcoidose (?); doença veno- } \\
\text { oclusiva pulmonar (?) }\end{array}$ \\
\hline 58 & Pneumopatia a esclarecer (neoplasia metastática? tbc? histoplasmose?) \\
\hline 59 & Pneumopatia intersticial a esclarecer (silicose?); enfisema; tabagismo \\
\hline 60 & Pneumopatia intersticial a esclarecer (malaria?) \\
\hline 61 & $\begin{array}{c}\text { LES; tbc. miliar; IRC; HAS; AVCI prévio; sangramento a esclarecer; pneumopatia } \\
\text { intersticial }\end{array}$ \\
\hline 62 & Anemia aplásica grave em tratamento; IRA; aspergilose pulmonar \\
\hline 63 & Pneumopatia intersticial a esclarecer \\
\hline
\end{tabular}




\begin{tabular}{|c|c|c|c|c|c|c|c|}
\hline Caso & $\begin{array}{c}\text { Data da } \\
\text { gasometria }\end{array}$ & pH & $\mathrm{PO}_{2}$ & $\mathrm{PCO}_{2}$ & Sat $\mathrm{O}_{2}$ & $\begin{array}{l}\text { Freqüência } \\
\text { respiratória }\end{array}$ & $\begin{array}{c}\text { Data da } \\
\text { IOT }\end{array}$ \\
\hline 1 & $17 / 01 / 96$ & 7,36 & 100 & 30 & 97 & $32(15 / 01 / 96)$ & $18 / 01 / 96$ \\
\hline 2 & $18 / 07 / 01$ & 7,08 & 73 & 70 & 90 & 30 & $08 / 08 / 01$ \\
\hline 3 & $19 / 11 / 02$ & 7,45 & 33 & 35 & 59,9 & & \\
\hline 4 & $14 / 08 / 92$ & 7,31 & 56 & 31 & 85,6 & 16 & $02 / 07 / 92$ \\
\hline 5 & $02 / 07 / 97$ & 7,39 & 66 & 44,9 & 92,9 & & \\
\hline 6 & $09 / 11 / 98$ & & & & $\begin{array}{l}80 \text { (máscara: } 8 \mathrm{l} / \mathrm{min} \text {; } \\
\text { cateter nasal: } 3 \mathrm{l} / \mathrm{min} \text { ) }\end{array}$ & 54 & $09 / 11 / 98$ \\
\hline 7 & $15 / 07 / 00$ & 7,38 & 51,8 & 42 & 85 & & \\
\hline 8 & $30 / 06 / 00$ & & & & 88 (masc. $\mathrm{O}_{2}$ 2l./min.) & 28 & $22 / 07 / 00$ \\
\hline 9 & $15 / 01 / 00$ & 7,36 & 120 & 36 & 96,3 & & $14 / 01 / 00$ \\
\hline 10 & $30 / 06 / 92$ & 7,43 & & 50,1 & 86,9 & 34 & $07 / 07 / 92$ \\
\hline 11 & $13 / 09 / 98$ & 7,46 & 51 & 28,6 & 86 & $38(12 / 09 / 98)$ & $18 / 09 / 98$ \\
\hline 12 & $04 / 11 / 98$ & 7,22 & 57,9 & 62,4 & 88,2 & 46 & $04 / 11 / 98$ \\
\hline 13 & $20 / 08 / 00$ & 7,39 & 58,2 & 40,3 & 89,6 & & \\
\hline 14 & $04 / 07 / 01$ & 7,43 & 125,9 & 19,5 & 98,8 & & \\
\hline 15 & $25 / 06 / 01$ & 7,44 & 45,3 & 27,5 & 82,5 & & \\
\hline 16 & $14 / 06 / 01$ & 7,5 & 46,3 & 29 & 86,7 & 24 & $21 / 06 / 01$ \\
\hline 17 & $29 / 04 / 95$ & 7,35 & 29 & 40 & 49,1 & & \\
\hline 18 & não realizada & & & & & & \\
\hline 19 & $08 / 11 / 99$ & & & & 87 & & \\
\hline 20 & $05 / 06 / 01$ & 7,51 & 48,3 & 26,3 & 88,4 & & \\
\hline 21 & $13 / 05 / 93$ & 7,56 & 67 & 25 & 95,6 & & \\
\hline 22 & $22 / 12 / 00$ & & & & 83 & & \\
\hline 23 & $21 / 01 / 01$ & 7,375 & 54 & 40,7 & 86,6 & & $22 / 01 / 01$ \\
\hline 24 & $18 / 09 / 94$ & & & & 68 & 32 & $22 / 09 / 94$ \\
\hline 25 & $17 / 08 / 95$ & 7,42 & 80 & 27 & 96,2 & & $18 / 09 / 95$ \\
\hline 26 & $15 / 05 / 92$ & 7,48 & 43 & 29 & 80 & 12 & $15 / 05 / 92$ \\
\hline 27 & não realizada & & & & & & \\
\hline 28 & $04 / 06 / 00$ & 7,4 & 27,2 & 37,2 & 49,9 & & \\
\hline 29 & $18 / 11 / 00$ & 7,43 & 71,7 & 32,1 & 94,6 & & \\
\hline 30 & $23 / 06 / 95$ & 7,41 & 36,5 & 42,5 & 70,1 & & \\
\hline 31 & $10 / 03 / 97$ & & 41,5 & 33 & 77,5 & 30 & \\
\hline 32 & $04 / 11 / 97$ & 7,44 & 35,5 & 38 & 70,8 & & \\
\hline 33 & $29 / 03 / 87$ & 7,48 & 57 & 36 & 92 & & $27 / 06 / 87$ \\
\hline 34 & $04 / 03 / 01$ & 7,433 & 44,5 & 44,8 & 82,4 & 40 & \\
\hline 35 & $08 / 11 / 00$ & & & & 87 & & \\
\hline 36 & $31 / 05 / 01$ & & & & 88 & 28 & \\
\hline 37 & $\begin{array}{c}\text { dados } \\
\text { incompletos }\end{array}$ & & & & & & \\
\hline 38 & $19 / 06 / 00$ & 7,422 & 30,9 & 28,4 & 59,6 & & \\
\hline 39 & $28 / 08 / 01$ & 7,28 & 48,1 & 29 & 76,2 & & $24 / 08 / 01$ \\
\hline 40 & $\begin{array}{c}\text { dados } \\
\text { incompletos }\end{array}$ & & & & 96 & 12 & $22 / 12 / 00$ \\
\hline 41 & $14 / 02 / 01$ & 7,42 & 50,6 & 34,7 & 86,2 & 14 & $14 / 02 / 01$ \\
\hline 42 & não realizada & & & & & & \\
\hline 43 & $18 / 12 / 95$ & 7,42 & 52 & 25 & 88,3 & 27 & $18 / 12 / 95$ \\
\hline
\end{tabular}




\begin{tabular}{|c|c|c|c|c|c|c|c|}
\hline Caso & $\begin{array}{c}\text { Data da } \\
\text { gasometria }\end{array}$ & $\mathrm{pH}$ & $\mathrm{PO}_{2}$ & $\mathrm{PCO}_{2}$ & Sat $\mathrm{O}_{2}$ & $\begin{array}{l}\text { Freqüência } \\
\text { respiratória }\end{array}$ & $\begin{array}{c}\text { Data da } \\
\text { IOT }\end{array}$ \\
\hline 44 & $\begin{array}{l}15 / 06 / 00 \text { (cate- } \\
\text { ter } \mathrm{O}_{2} 11 / \mathrm{min} \text { ) }\end{array}$ & 7,43 & 51,1 & 36,8 & $87,2\left(84\right.$ sem $\left.\mathrm{O}_{2}\right)$ & & \\
\hline 45 & $29 / 12 / 94$ & 7,46 & 59,5 & 37 & 92 & & \\
\hline 46 & $03 / 07 / 91$ & 7,33 & 47 & 46,5 & 79,5 & 40 & \\
\hline 47 & $10 / 06 / 92$ & 7,03 & 49 & 87 & 63,1 & 25 & $10 / 06 / 92$ \\
\hline 48 & $29 / 12 / 99$ & & & & 90 & 32 & \\
\hline 49 & $18 / 05 / 99$ & 7,13 & 65 & 63 & 85,8 & 15 & $05 / 05 / 99$ \\
\hline 50 & $13 / 09 / 00$ & & & & 96 & 28 & \\
\hline 51 & não realizada & & & & & & \\
\hline 52 & $31 / 08 / 99$ & 7,37 & 42,8 & 23,5 & 75,7 & 30 & \\
\hline 53 & $\begin{array}{c}08 / 05 / 01 \text { (cate- } \\
\text { ter } \mathrm{O}_{2} 7 \mathrm{l} / \mathrm{min} \text { ) }\end{array}$ & 7,47 & 59,8 & 29,6 & 92,4 & 29 & \\
\hline 54 & $21 / 11 / 95$ & 7,36 & 40 & 46 & 72 & & \\
\hline 55 & não realizada & & & & & & \\
\hline 56 & $01 / 03 / 03$ & 7,44 & 38,9 & 33,8 & 75,8 & 40 & $02 / 03 / 93$ \\
\hline 57 & $24 / 11 / 03$ & & & & 80 & & \\
\hline 58 & não realizada & & & & & & \\
\hline 59 & $19 / 03 / 01$ & 7,49 & 87,1 & 23,9 & 97,3 & 20 & \\
\hline 60 & $15 / 02 / 85$ & 7,49 & 45,2 & 37,2 & 85 & 32 & \\
\hline 61 & $\begin{array}{c}01 / 10 / 00 \\
\text { (ventil. mec.) }\end{array}$ & 7,1 & 79 & 54 & 88 & & $13 / 09 / 00$ \\
\hline 62 & $03 / 03 / 01$ & 7,23 & 105,9 & 20,4 & 96,3 & 14 & $03 / 03 / 01$ \\
\hline 63 & $02 / 03 / 00$ & 7,43 & 52,2 & 38 & 87,8 & 32 & \\
\hline
\end{tabular}




\begin{tabular}{|c|c|}
\hline Caso & Diagnósticos de biópsias \\
\hline 1 & DAD (fase exsudativa) associado a capilarite e hemorragia alveolar. \\
\hline 2 & DAD (fase exsudativa). Broncopneumonia. Broncoaspiração (refluxo ?) \\
\hline 3 & DAD (fase proliferativa) associado a PO. \\
\hline 4 & $\begin{array}{l}\text { Bronquiolite crônica focal e discreta. Hemorragia e edema focais e discretos em } \\
\text { espaços alveolares }\end{array}$ \\
\hline 5 & Pneumonia aspirativa com fibrose centrolobular (pós-refluxo) \\
\hline 6 & PH crônica em surto de DAD \\
\hline 7 & UIP \\
\hline 8 & DAD induzido por infestação parasitária (estrongiloidíase) \\
\hline 9 & Processo inflamatório crônico granulomatoso necrosante (provável origem infecciosa) \\
\hline 10 & DAD (fase proliferativa). PO focal \\
\hline 11 & DAD induzido por infestação parasitária (pneumocistose). Infarto hemorrágico focal. \\
\hline 12 & NSIP em surto agudo \\
\hline 13 & PH crônica (alveolite de hipersensibilidade) \\
\hline 14 & NSIP \\
\hline 15 & Processo inflamatório crônico granulomatoso (tbc?) \\
\hline 16 & $\begin{array}{c}\text { Adenocarcinoma metastático (linfangite carcinomatosa). ALI. Esclerose vascular (HP } \\
\text { grau II). Trombose arteriolar focal c/ infarto }\end{array}$ \\
\hline 17 & HP tromboembólica, grau III. CPC com hemorragia alveolar. focal. Enfisema discreto. \\
\hline 18 & UIP em surto agudo \\
\hline 19 & TEP c/ infarto hemorrágico. DAD incipiente \\
\hline 20 & DAD (fase exsudativa) \\
\hline 21 & Pneumonite aguda por CMV \\
\hline 22 & DAD (fase proliferativa). \\
\hline 23 & Bronquiolite crônica com áreas de PO. Pleurite fibrino-neutrofílica em organização. \\
\hline 24 & Adenocarcinoma bem diferenciado (linfangite carcinomatosa). DAD. \\
\hline 25 & CEC moderadamente diferenciado. UIP. ALI. \\
\hline 26 & DAD (fase exsudativa) associado a infecção pelo CMV \\
\hline 27 & Vasculite crônica granulomatosa (não necrosante; não infecciosa) \\
\hline 28 & DAD induzido por infestação parasitária (pneumocistose). \\
\hline 29 & $\begin{array}{c}\text { Vasculite crônica granulomatosa necrosante. Hemorragia alveolar antiga e recente. ALI. } \\
\text { PO. }\end{array}$ \\
\hline 30 & Enfisema pulmonar panacinar. Trombose venosa focal. ALI incipiente \\
\hline 31 & Síndrome hemorrágica pulmonar c/ intensa hemossiderose e congestão vascular \\
\hline 32 & $\begin{array}{c}\text { DAD (fase proliferativa) com áreas de PO. Pleurite fibrinosa em organização. } \\
\text { Bronquiolite crônica. }\end{array}$ \\
\hline 33 & Congestão passiva crônica. HP passiva. \\
\hline 34 & Processo inflamatório crônico granulomatoso (sarcoidose?). Enfisema. HP. ALI focal \\
\hline 35 & Bronquiolite folicular. Bloqueio do efluxo venoso pulmonar (CPC). \\
\hline 36 & Adenocarcinoma bem diferenciado do tipo bronquíolo-alveolar \\
\hline 37 & Amiloidose micronodular \\
\hline 38 & DAD (fase proliferativa) de origem pulmonar. \\
\hline 39 & Bronquiolite respiratória. TEP. Congestão passiva crônica pulmonar. Edema pulmonar. \\
\hline 40 & Pneumonia aspirativa com DAD \\
\hline 41 & Tbc. miliar pulmonar \\
\hline 42 & Doença vascular com componente de via aérea. HP \\
\hline 43 & Micobacteriose forma nodulo-exsudativa \\
\hline 44 & Fibrose centrolobular pós-refluxo gástrico \\
\hline 45 & UIP em surto agudo \\
\hline
\end{tabular}




\begin{tabular}{|c|c|}
\hline Caso & Diagnósticos de biópsias \\
\hline $\mathbf{4 6}$ & Aspergilose pulmonar angioinvasiva \\
\hline $\mathbf{4 7}$ & ALI (edema e hemorragia alveolares) \\
\hline $\mathbf{4 8}$ & UIP em surto agudo \\
\hline $\mathbf{4 9}$ & DAD (fase exsudativa). Trombose arteriolar aguda focal \\
\hline $\mathbf{5 0}$ & TEP c/ infarto focal \\
\hline $\mathbf{5 1}$ & LH (celularidade mista) \\
\hline $\mathbf{5 2}$ & Bronquiolite respiratória. Pleurite crônica discreta. \\
\hline $\mathbf{5 3}$ & Carcinoma metastático. Bronquiolite respiratória. Esclerose vascular. \\
\hline $\mathbf{5 4}$ & DAD incipiente (ALI) \\
\hline $\mathbf{5 5}$ & UIP em surto agudo \\
\hline $\mathbf{5 6}$ & DAD (fase exsudativa). Hemorragia alveolar. Áreas de PO. Bronquiolite crônica em surto \\
& agudo \\
\hline $\mathbf{5 7}$ & Bloqueio do efluxo venoso pulmonar. Hemorragia alveolar focal. Enfisema \\
\hline $\mathbf{5 8}$ & Adenocarcinoma papilífero moderadamente diferenciado infiltrando tecido pulmonar \\
\hline $\mathbf{5 9}$ & UIP em surto agudo (DAD) \\
\hline $\mathbf{6 0}$ & Processo inflamatório crônico granulomatoso necrosante (provável origem infecciosa) \\
\hline $\mathbf{6 1}$ & Tbc. miliar pulmonar \\
\hline $\mathbf{6 2}$ & Alveolo-bronquiolite crônica folicular \\
\hline $\mathbf{6 3}$ & Doença de pequenas vias aéreas (bronquiolite). Enfisema. DAD incipiente \\
\hline
\end{tabular}




\begin{tabular}{|c|c|}
\hline Caso & $\begin{array}{l}\text { Diagnósticos de autópsia } \\
\end{array}$ \\
\hline 1 & $\begin{array}{l}\text { TEP de repetição com infarto focal. DAD (fase exsudativa). Bcp. CPC c/ hemorragia } \\
\text { alveolar. }\end{array}$ \\
\hline 2 & DAD (fase proliferativa). BO \\
\hline 3 & \\
\hline 4 & DAD (fase exsudativa). Microabscesso focal do parênquima pulmonar \\
\hline 5 & \\
\hline 6 & $\begin{array}{c}\text { DAD associado a PO e a hemorragia alveolar focal. Bronquite crônica agudizada, com } \\
\text { bronquiectasia e metaplasia escamosa. }\end{array}$ \\
\hline 7 & \\
\hline 8 & \\
\hline 9 & \\
\hline 10 & DAD em organização. \\
\hline 11 & Pneumonite aguda focalmente necrosante por $P$. carinii \\
\hline 12 & DAD incipiente. Bronquiolite crônica. \\
\hline 13 & \\
\hline 14 & \\
\hline 15 & \\
\hline 16 & $\begin{array}{c}\text { Adenocarcinoma metastático (linfangite carcinomatosa). ALI. Trombose arteriolar focal } \\
\mathrm{c} / \text { infarto }\end{array}$ \\
\hline 17 & $\begin{array}{l}\text { TEP crônica e aguda. Bloqueio do efluxo venoso (CPC). Bronquite aguda. purulenta c/ } \\
\text { bcp. Edema e hemorragia alveolar extensas. Cisto broncogênico. }\end{array}$ \\
\hline 18 & \\
\hline 19 & \\
\hline 20 & \\
\hline 21 & \\
\hline 22 & \\
\hline 23 & \\
\hline 24 & Adenocarcinoma infiltrando tecido pulmonar, com embolização de vasos linfáticos. \\
\hline 25 & Bronquiectasia com bronquite aguda purulenta e bcp. DAD. \\
\hline 26 & $\begin{array}{c}\text { Pneumonia aspirativa evoluindo com DAD (fase exsudativa). Bronquiolite constritiva. } \\
\text { Toxoplasmose (?) }\end{array}$ \\
\hline 27 & \\
\hline 28 & \\
\hline 29 & \\
\hline 30 & $\begin{array}{l}\text { PO.Áreas de DAD (fase exsudativa).CPC c/ hemorragia alveolar focal. Bronquiolite } \\
\text { aguda exsudativa }\end{array}$ \\
\hline 31 & \\
\hline 32 & Pneumonia aspirativa com hemorragia alveolar \\
\hline 33 & $\begin{array}{c}\text { DAD (fase exsudativa). Bcp.(presença de diplococos em bronquíolos e alvéolos). } \\
\text { Trombose arteriolar em organização. CPC }\end{array}$ \\
\hline 34 & \\
\hline 35 & \\
\hline 36 & \\
\hline 37 & \\
\hline 38 & \\
\hline 39 & $\begin{array}{c}\text { DAD (fase exsudativa) associado a bcp. Reação gigantocelular a material estranho em } \\
\text { espaços alveolares e parede venosa. }\end{array}$ \\
\hline 40 & \\
\hline 41 & \\
\hline
\end{tabular}




\begin{tabular}{|c|c|}
\hline Caso & Diagnósticos de autópsia \\
\hline \multicolumn{2}{|l|}{42} \\
\hline \multicolumn{2}{|l|}{43} \\
\hline \multicolumn{2}{|l|}{44} \\
\hline 45 & DAD (fase exsudativa). Áreas de fibrose intersticial. Bcp incipiente (Drogas ?) \\
\hline 46 & DAD (fase exsudativa) associado a aspergilose angioinvasiva \\
\hline 47 & Necrose (infarto?) focal. Edema e hemorragia alveolares focais. \\
\hline \multicolumn{2}{|r|}{ ( } \\
\hline 49 & $\begin{array}{l}\text { DAD (fase exsudativa) associado a broncoalveolite viral de provável etiologia } \\
\text { herpética. Bronquite herpética }\end{array}$ \\
\hline \multicolumn{2}{|r|}{ ( } \\
\hline \multicolumn{2}{|l|}{51} \\
\hline 52 & DAD em fase proliferativa, em surto agudo (?) \\
\hline 53 & Carcinoma metastático (linfangite carcinomatosa) \\
\hline \multicolumn{2}{|r|}{${ }^{2}$} \\
\hline \multicolumn{2}{|l|}{55} \\
\hline 56 & Pulmão em estadio terminal (UIP) em surto agudo. Pneumonia aguda necrosante. \\
\hline \multicolumn{2}{|r|}{ ( } \\
\hline \multicolumn{2}{|l|}{58} \\
\hline \multicolumn{2}{|l|}{59} \\
\hline \multicolumn{2}{|l|}{60} \\
\hline 61 & $\begin{array}{c}\text { Processo inflamatório crônico granulomatoso (provável tbc.); PO; bronquiolite crônica } \\
\text { descamativa; DIP }\end{array}$ \\
\hline 62 & $\begin{array}{c}\text { Aspergilose angioinvasiva com infarto pulmonar extenso, associado a DAD (fase } \\
\text { exsudativa). Bronquiolite crônica descamativa. }\end{array}$ \\
\hline 63 & \\
\hline
\end{tabular}




\section{APÊNDICE 2}

Protocolo utilizado na tabulação de dados histopatológicos 
CASO No.:

DIAGNÓSTICO:

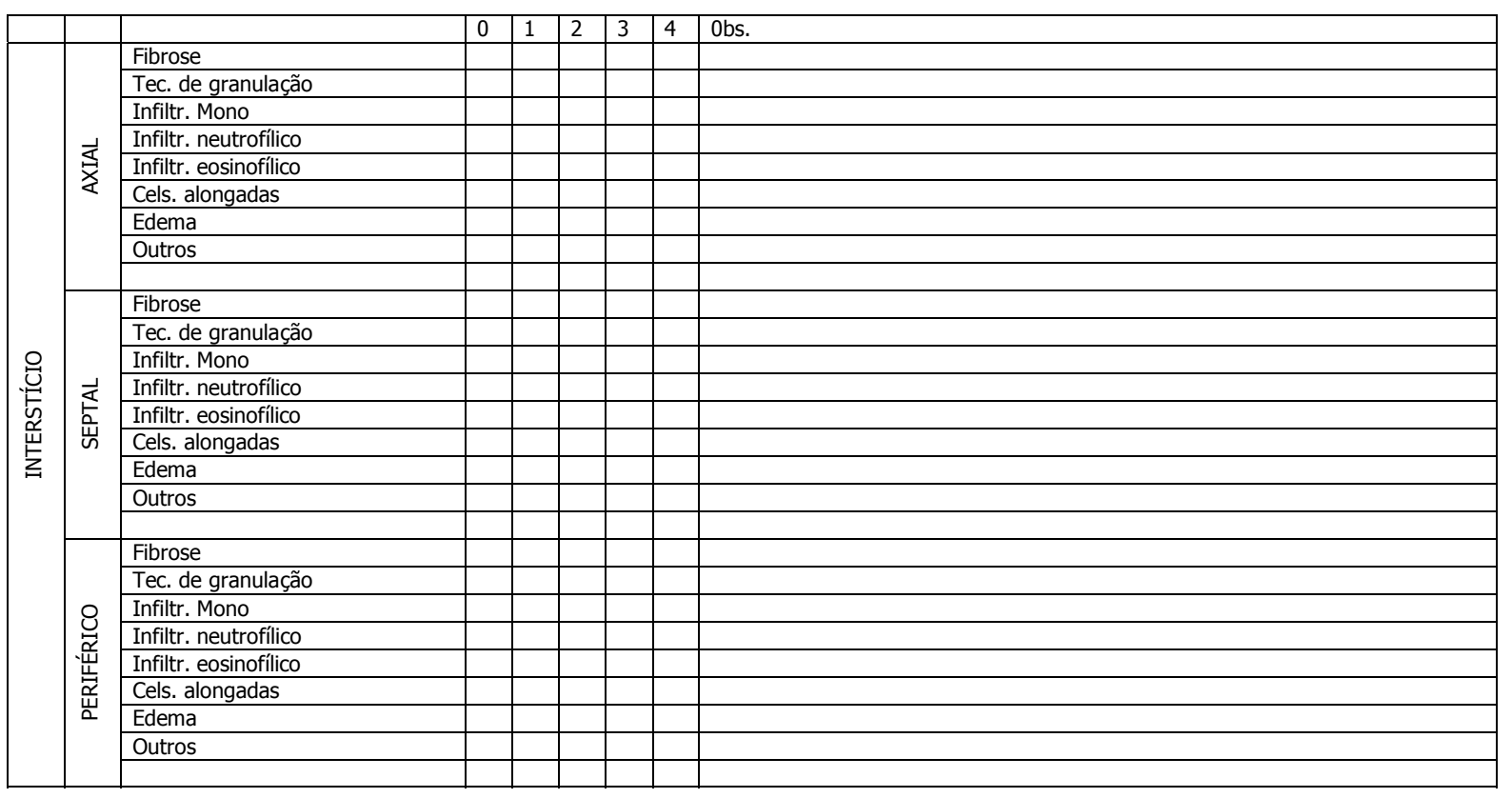

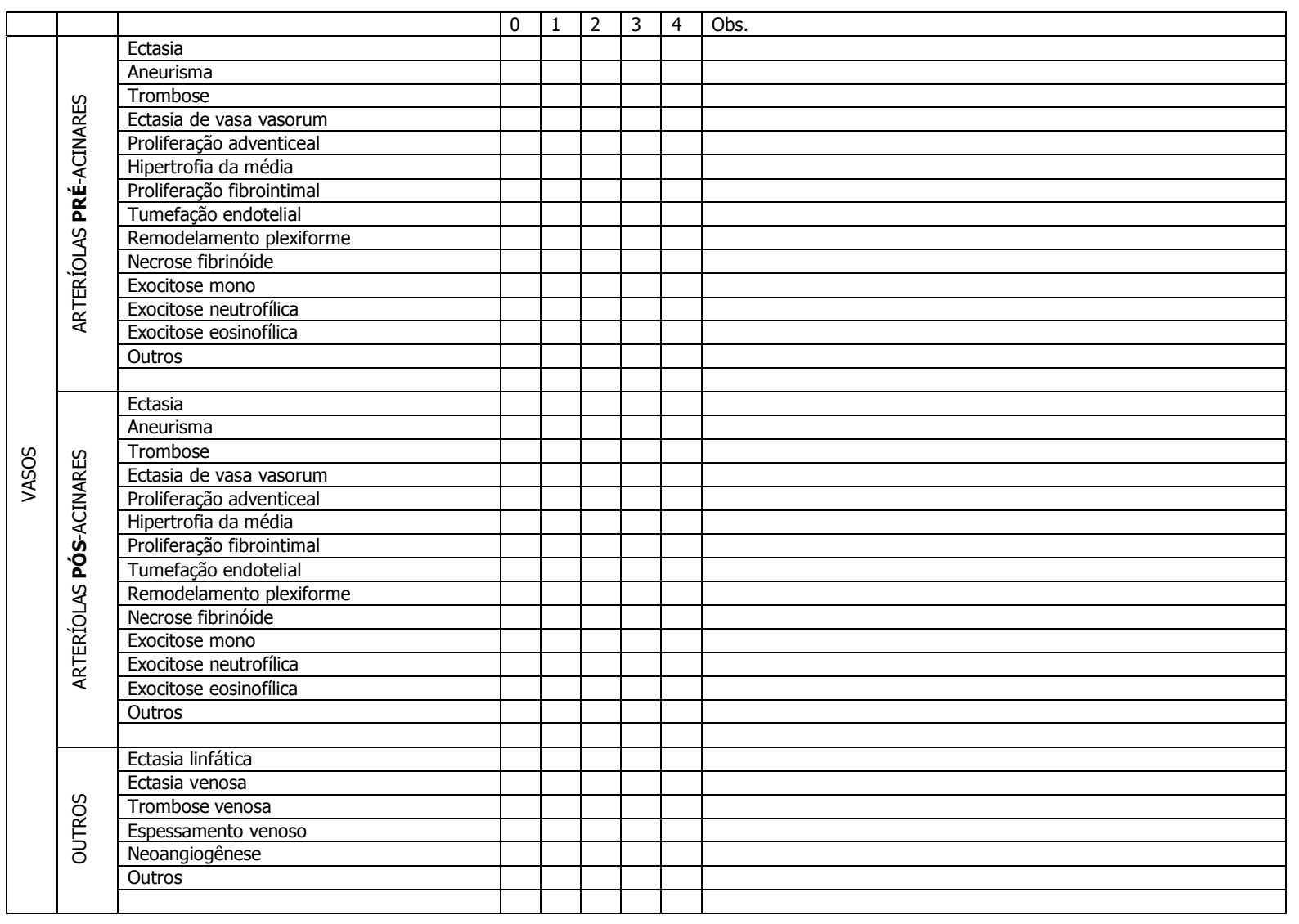




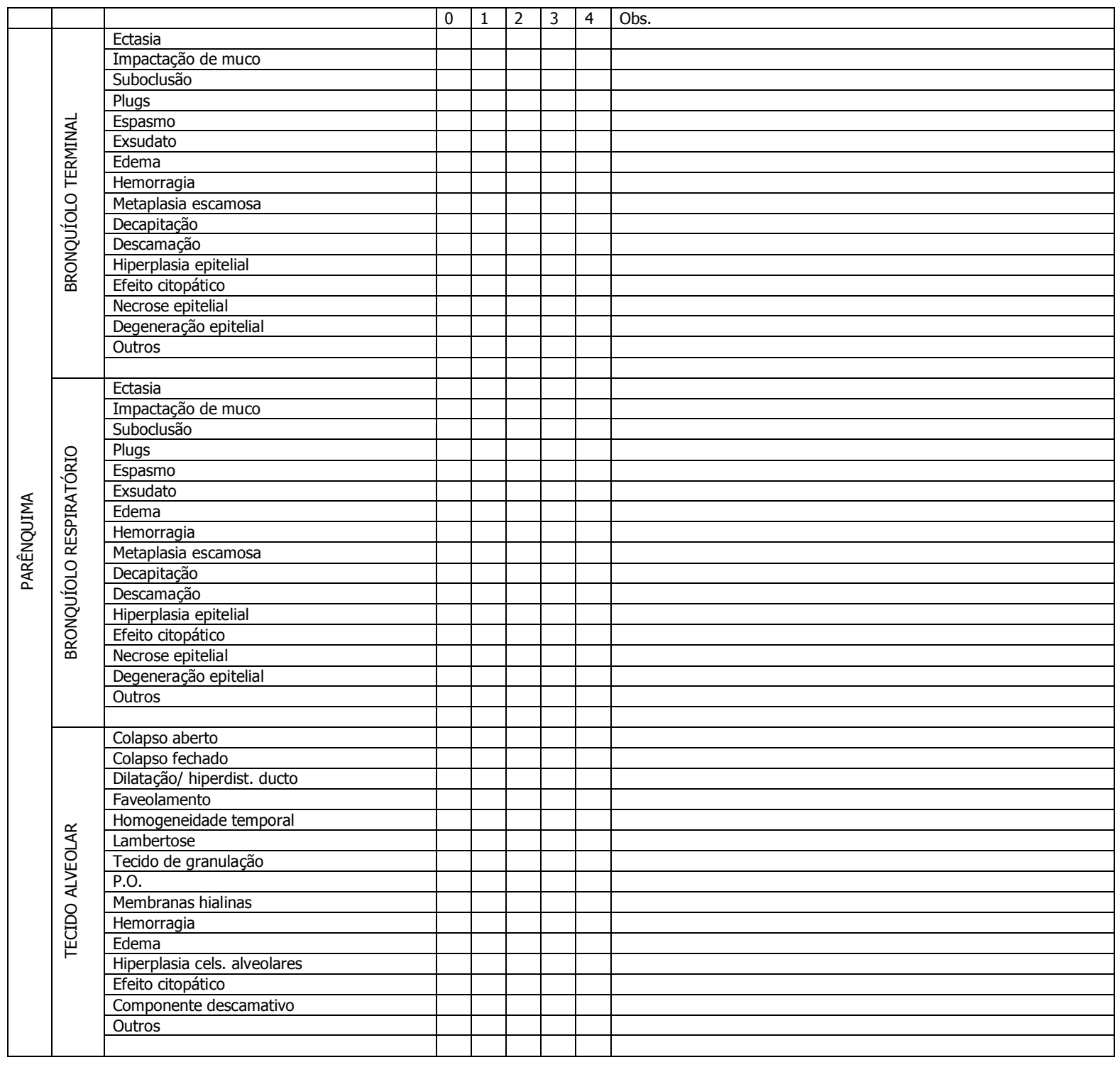
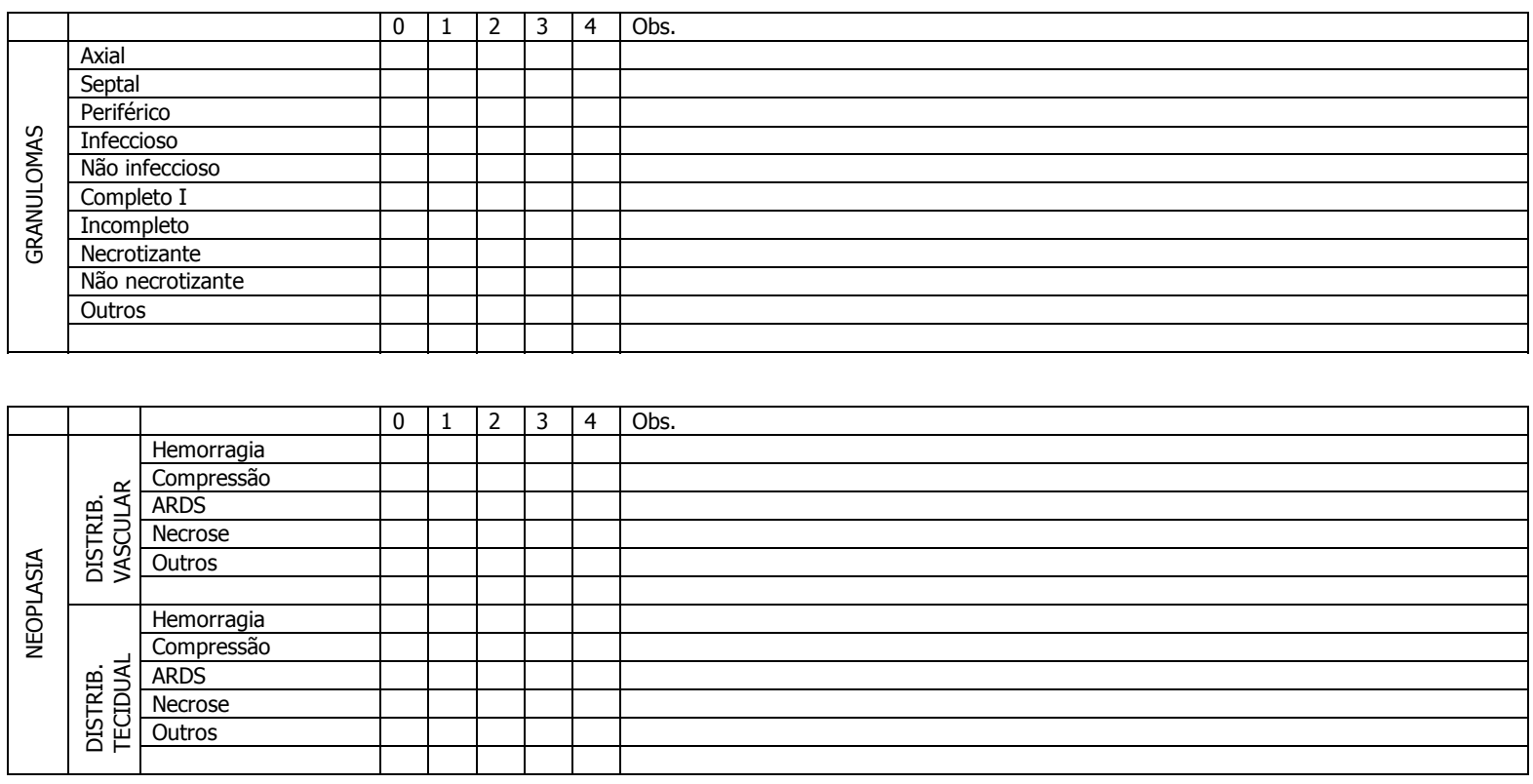


\section{APÊNDICE 3}

Poster apresentado na $100^{\mathrm{a}}$. Conferência Internacional da "American Thoracic Society (ATS)", realizada entre 21 e 26 de maio de 2004, em Orlando, EUA (CANZIAN, Mauro ; SOEIRO, A M ; BARBAS, C S V ; CARVALHO, C R R ; KAIRALLA, R ; CAPELOZZI, $V L$. Diffuse Pulmonary infiltrates in patients with acute respiratory failure: impact of open lung biopsy with autopsy correlation. In: 100th ATS International Conference, 2004, Orlando. Am J Respir Crit Care Med. 2004; 169: A349.) 


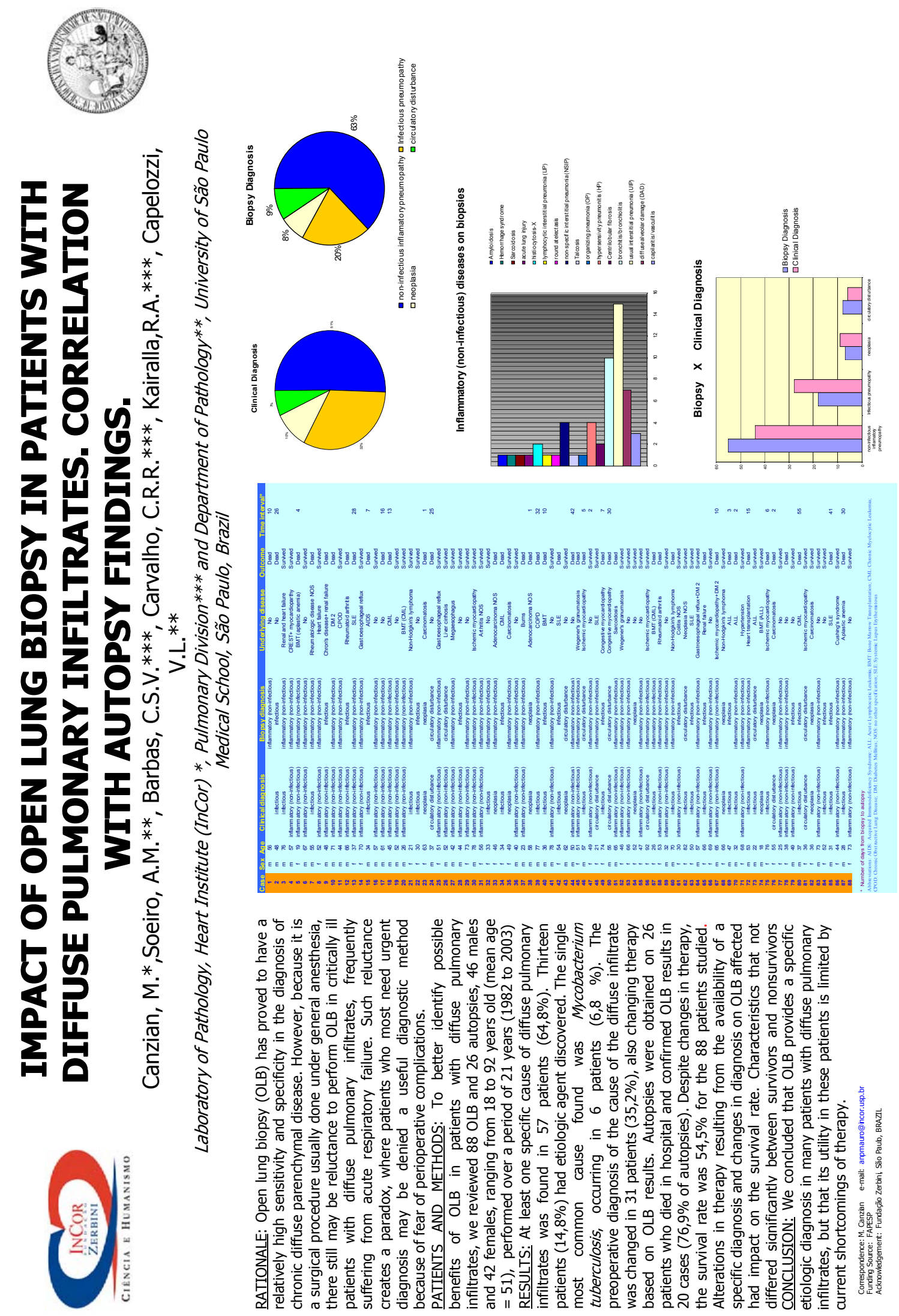




\title{
APÊNDICE 4
}

\author{
Trabalho submetido para publicação
}


SEMIQUANTITATIVE ASSESSMENT OF OPEN LUNG BIOPSY: PREDICTIVE VALUE AND IMPACT ON PROGNOSIS OF PATIENTS WITH DIFFUSE PULMONARY INFILTRATES.

Mauro Canzian, $\mathrm{MD}_{1}{ }^{1}$ Alexandre de Matos Soeiro, Medical Student, ${ }^{2}$ Marcel Frederico de Lima Taga, ${ }^{1}$ Carmen Silvia Valente Barbas, MD, PhD, ${ }^{1}$ Vera Luiza Capelozzi, MD, PhD ${ }^{2}$

From the ${ }^{1}$ Divisions of Respiratory Diseases and Pathology, Heart Institute (InCor),

${ }^{2}$ Department of Pathology, School of Medicine, University of São Paulo, SP, Brazil.

This study was supported by the following Brazilian agencies: the National Council for Scientific and Technological Development [CNPq 300430/95-7]; the Foundation for the Support of Research of the State of São Paulo [FAPESP 00-14336-0 and 02/09949-9]; and the Laboratories for Medical Research [LIM-05], "Hospital das Clínicas", School of Medicine, University of Sao Paulo.

\section{Address for correspondence:}

Vera Luiza Capelozzi

Associate Professor of Lung Pathology

Department of Pathology, School of Medicine, University of São Paulo.

Av. Dr. Arnaldo 455; ZIP CODE - 01246-903, São Paulo, SP, Brazil.

Phone - (11)3066-7427; FAX - (11)5096-0761

E-mail - vcapelozzi@lim05.fm.usp.br 
São Paulo, Brazil, April, 27, 2005.

To

L. Henry Edmunds, Jr, MD

\section{Editor of The Annals of Thoracic Surgery}

The Annals of Thoracic Surgery Editorial Office

5000 Ravdin Court, Hospital of University of Pennsylvania

3400 Spruce Street

Philadelphia, PA 19104-4283

Tel: (215) 349-5542

Fax: (215) 614-0416

E-mail:ats@uphs.upenn.edu

Please find enclosed the manuscript "SEMIQUANTITATIVE ASSESSMENT OF OPEN LUNG BIOPSY: PREDICTIVE VALUE AND IMPACT ON PROGNOSIS OF PATIENTS WITH DIFFUSE PULMONARY INFILTRATES", which is being submitted for possible publication in The Annals of Thoracic Surgery. The work represents original investigation and will not be submitted to any other journal until your decision is made.

Faithfully yours, Vera Luiza Capelozzi

Associate Professor of Lung Pathology

Department of Pathology

Faculdade de Medicina da Universidade de São Paulo. 


\section{ABSTRACT}

Background: The therapeutical approach of diffuse pulmonary infiltrates represents a challenge for clinicians. Open lung biopsy (OLB) has been studied in distinct populations, mostly concerning only histopathological diagnostic information in diffuse infiltrates, beyond clinical data. However, detailed tissue analyses in this situation have barely been exploited. The present study was delineated to provide detailed tissue analysis in diffuse infiltrates. Thus, a semiquantitative score system was applied to a histologic OLB findings in order to evaluate intensity and extension of pathological process, providing prognostic information.

Methods: We examined open lung biopsies of 63 patients older than 18 years, with diffuse infiltrates, most of them presenting respiratory failure, from 1982 to 2003. Pulmonary specimens were divided into 4 anatomical compartments - interstitium, vessels, airways and alveolar spaces. Severity of each pathological alteration was semiquantitatively rated following a histological score system varying from 0 (zero) to 4. "Acute" and "chronic" "indices" were then histologically established.

Results: Statistically significant association occurred between hospital survival and sex $(p<=0.04)$, presence of underlying diseases, presence of diffuse alveolar damage and "histopathological index" $(p<0.01)$. Death risk for men was six times higher than women's risk and it is 25 times and 33 times higher for the groups presenting underlying diseases and diffuse alveolar damage, respectively. For each unit increased in "chronic index", death risk was 3 times lower. 
Conclusion: Detailed histological analysis of histological specimens can provide more than nosological diagnosis. This approach can bring valuable information concerning prognosis. Greater study in a randomized and prospective trial could finalize and confirm this conclusion.

\section{INTRODUCTION}

Diffuse pulmonary disease of uncertain etiology presents a diagnostic and therapeutic challenge in general population. The majority of causes of pulmonary infiltrates can be diagnosed by noninvasive or minimally invasive means, such as transbronchial or transthoracic needle biopsies. However, when these efforts fail to provide a diagnosis or when a patient does not respond to appropriate therapy, an open lung biopsy (OLB) may be required to assist in treatment efforts. OLB provides a histologic diagnosis in almost every case, but considerable controversy exists whether the information provided justifies its routine use. Thus, similarly to the approach of previous tumor recurrence studies [1-5] and aiming for the effectiveness of treatment, there is great interest to identify, as soon as possible, morphological parameters on OLB associated to shortening of patient's life.

As semiquantitative approaches have been thought to be important in evaluating intensity and extension of pathologic processes [6-9], a scoring system has been considered as potentially useful OLB specimens markers $[10,11]$. Several parenchymal alterations related to necrosis, degeneration, hyperplasia, neoplasia, 
inflammation/remodeling (fibrin and hyaline membranes deposition, polymorphnuclear and mononuclear cell infiltration, granulation tissue, granuloma, fibrocellular proliferation) and circulatory changes (edema, hemorrhage, congestion, thrombosis) have shown promise as useful markers.

Scoring system has also been found to be significantly associated to survival $[8,12]$, but there has been uncertainty about how best to record scoring system. Hence, this project was proposed to validate the importance of a scoring system and to explore the semiquantitative relationship between this factor and outcome as well as the relationship between a scoring system and other epidemiological factors.

\section{METHODS}

Patients. We examined the medical records of all patients who underwent OLB at our institution from 1982 to 2003 . From this group were selected those patients older than 18 years, showing diffuse infiltrates on chest roentgenogram, whose hospitalization has not been exclusively motivated for biopsy procedure.

Epidemiological Variables. Included age, sex, total hospitalization time, days from admission to biopsy, outcome, main clinical diagnosis, underlying disease, respiratory failure proven through clinical and or gasometrical data (respiratory rate over 28 breaths per minute and or $\mathrm{PaO}_{2}<60 \mathrm{mmHg}$ and or $\mathrm{SpO}_{2}>90 \mathrm{mmHg}$, while breathing room air). Details about the patients are summarized in Table 1. 
Pulmonary Tissue. Pulmonary tissue was derived from the routine formalin-fixed pathological samples taken from the resected or autopsied lung specimens and after routine pathological studies had been completed. The cases were observed consensually by two experienced pathologists in pulmonary pathology (MC and VLC). The lung parenchyma was histologically divided into 4 anatomical compartments of reference: a) interstitium (septal, peripheral, axial); b) airways (terminal and respiratory bronchioles); c) vessels (arteries, veins and lymphatics); and c) alveolar spaces (including alveolar ducts).

Parenchymal alterations throughout the 4 anatomical compartments were then evaluated: a) tissue injury (necrosis; degeneration; hyperplasia; neoplasia; inflammation/remodeling findings such as fibrin deposition, hyaline membranes, polymorphnuclear cells, mononuclear cells, granulation tissue, granuloma, fibrocellular proliferation; and circulatory changes such as edema, hemorrhage, congestion, thrombosis); b) extension and distribution of the pathological process.

Other histological variables included main histopathological diagnosis at biopsy, main histopathological diagnosis at autopsy, presence or absence of infectious agent at biopsy, of diffuse alveolar damage and of histological signs of gastroesophageal content aspiration at biopsy. At first analysis specimens were classified into twelve histopathologic features, which were then separated into four sections (Table 2): a)inflammation/remodeling; b) infectious disease; c) circulatory changes; d) neoplasia.

Semiquantitative Assessment of Pulmonary Tissue. Extension, intensity and distribution of the above parenchymal alterations were inhomogeneous along the 
anatomic compartments. Thus, the severity of the various pathological processes was rated semiquantitatively according to the amount and severity of disease by the following histological score:

0: absence of parenchymal alterations

1: parenchymal alterations in 1 to $25 \%$ of the tissue examined;

2: parenchymal alterations in 26 to $50 \%$ of the tissue examined;

3: parenchymal alterations in 51 to $75 \%$ of the tissue examined;

4: parenchymal alterations in $76 \%$ to $100 \%$ of the tissue examined.

Histopathological findings were divided according to its acute or chronic pathologic course. So, an "acute" and a "chronic" pathological "scores" were created, representing respectively the average of acute and chronic findings of each one of the histological compartments, respectively. The average of total acute and chronic scores (comprising all 4 histological compartments) were then calculated, creating an "acute" and a "chronic" "indices". Values of each "index" were then multiplied by 10 to facilitate the interpretation in the possible models of the inferencial analysis.

Statistical Analysis. Initial analyses were done to investigate association between "acute" and "chronic" "indices" with epidemiological variables (days from admission to biopsy, clinical diagnosis, hospital survival, underlying diseases, respiratory failure proven through clinical and or gasometrical data) and histological variables (biopsy diagnosis, infectious agent, diffuse alveolar damage, aspiration of gastroesophageal content). 
Multiple logistic regression model was used to test the relationship between each of the "indices" and the factors above. All analysis were done with SPSS for Windows 10.0 statistical software. The threshold for statistical significance was chosen considering $a=0.05$.

\section{RESULTS}

Patients Characteristics. Over the period examined, 1,657 open lung biopsies were performed at our institution; 63 patients (3.8\%) met our study criteria. Thirty-two patients (51\%) were male and 31 (49\%) were female, with a mean age of $49 \mathrm{yr}$. (range, 18 to $92 \mathrm{yr}$.). Arterial blood samples for gas analyses taken during inspiration of room air in the $24 \mathrm{~h}$ preceding OLB were obtained in 51 patients (81\%) and 41 of them showed signs of acute respiratory failure. Table 1 lists the preexisting medical conditions in the study population. Thirty-three patients (52\%) were immunocompromised and 48 (76\%) had, at least, one underlying disease. The mean time from admission to OLB was 18 days (range, 0 to 61 ). The mean interval from OLB to hospital discharge or death was 18 days (range, 1 to 143 ) and the mean total hospitalization time was 39 days (range, 4 to 184). The overall death rate was 49\%. Amongst immunocompromised patients, $61 \%$ died $(p>0.05)$. Similar percentages were found to the groups presenting respiratory failure or underlying diseases. Death occurred in $69 \%$ of patients presenting diffuse alveolar damage No variation related to age groups was observed. 
Diagnostic Results. The diagnostic results of OLB are shown in Table 2. All biopsies specimens exhibited abnormalities. Diagnoses were subdivided into specific and nonspecific categories. Thirty-nine patients (62\%) had specific diagnoses established by OLB: $51 \%$ had specific benign/inflammatory etiologies; $26 \%$ had infectious causes, $15 \%$ had infiltrates directly or indirectly due to neoplastic process and $8 \%$ had circulatory disturbances. Thirty-one patients (38\%) had nonspecific diagnoses: most of them showing pneumonitis or pulmonary edema as the cause of their infiltrates. The diagnoses found in clinical, biopsy and necropsy patients were compared. In this situation, the preoperative diagnosis of the cause of diffuse pulmonary infiltrate was changed in 33 patients (52\%). . A low percentage of confirmation of clinically diagnosed infectious lung diseases was observed (36\%). The most frequent biopsy diagnoses were airway diseases and interstitial pneumopathies, followed by infectious lung diseases, as shown on Table 2. The highest percentages of discordance from clinical to biopsy diagnoses were found when the interval from hospitalization to biopsy was less than 10 days and over 20 days (approximately 50\%). Our data also suggest a higher hospital survival rate for the cases presenting discordant clinical and biopsy diagnoses $(p>0,05)$. Autopsies were obtained in 24 patients who died in hospital and confirmed OLB results in 14 cases (58\%). Days from hospitalization to OLB in these patients ranged from 5 to 61 days and the preoperative diagnosis of the cause of diffuse pulmonary infiltrate was changed in more than $42 \%$ of the patients

Quantitative Assessment. The mean for "acute index" was 3.7 (range, 0.4 to 8.7) and 3.6 (range, 0.1 to 9.3) for "chronic index" (Table3). Investigation of the association 
between scoring system and variables such as age, sex, days from admission to biopsy, pattern of lung disease, presence of infectious agent at biopsy, diffuse alveolar damage at biopsy, presence of underlying disease and acute respiratory failure was accomplished through multiple logistic regression model (Table 4). Statistically significant association occurred between hospital survival and factors such as sex $(p<=0.04)$, diffuse alveolar damage $(p<0.01)$, underlying disease $(p<0.01)$ and "histopathological index" $(p<0.01)$. Thus, death risk for male sex is 6 times higher compared to women. Presence of diffuse alveolar damage at biopsy increases death risk in 33 times and the occurrence of at least one underlying disease increases death risk in 25 times. A paradoxical relationship was found to "histopathological index": for each unit increased in "chronic index" death risk is 3 times lower. It was also demonstrated a trend of increasing of "acute index" values directly proportional to death risk ( $p>0.05)$.

\section{DISCUSSION}

Diffuse infiltrates are usually a diagnostic challenge and also the most severe pulmonary nosologic pattern when compared to focal and nodular ones [13].

Until now, the hole of OLB on Acute Respiratory Distress Syndrome (ARDS) management remains obscure. Albeit it reveals some clinical homogeneity, ARDS can originate from different etiologies like infectious pneumonias, organizing pneumonia 
(BOOP), acute eosinofilic pneumonia and pulmonary capilaritis and so be treated by different ways [14].

Several studies have been published concerning different aspects of OLB in distinct populations with diffuse infiltrates $[15,16]$.Clinical implications of OLB have been greatly exploited, mostly concerning its contribution on prognosis through therapeutic changes, but also because of its morbidity. It has been demonstrated that OLB can be carried out with relatively small morbidity and frequently promotes changes in treatment [17-20].

The accuracy of OLB may be evaluated by changes in diagnosis and consequent changes in patient's therapy. In this situation, autopsy data from patients previously submitted to biopsy could supply reliable information about accuracy of OLB, but rare studies have included such approach [19].

Our study has not focused therapeutical approaches, but we found an elevated percentage of changes in diagnoses after histological analysis (52\%), that might result in therapeutical changes.

Autopsy was performed in 24 cases (about $38 \%$ ) of our casuistry, confirming OLB findings in approximately $58 \%$ of the cases.

Clearly, most part of studies concerning OLB takes into account only diagnostic information provided by histological analysis, usually regarded as the gold-standard for clinical hypotheses in diffuse infiltrates [21], beyond clinical data. OLB histopathological data have rarely and barely been exploited in detail [22]. The likely reason that OLB frequently fails to provide information in routine use is because histopathologic details 
have not yet been detected by either routine clinical or pathological analysis. Frequently clinical or radiological findings can reflect so minimal tissue changes that can be misdiagnosed at diagnostic approaches. The question of interest is whether additional, more technological information gathered from OLB or clinical records can help us to identify patient's outcome by OLB analysis. Lung pathology undoubtedly comprises a series of complex stereotyped reactions, which make difficult differential diagnosis only on qualitative approaches. However, semiquantitative assessment is thought to be important because facilitates to create mathematical models to predict outcome. In a variety of conditions, especially diffuse pulmonary parenchymal diseases, a scoring system for quantitative assessment has been associated with guidance or evaluation of therapy response and prognosis [6-8]. Thus, for all these reasons, we should not be surprised to learn that detailed pulmonary analysis into the different histological compartments, where alterations are classified in accordance to its acute or chronic character and semiquantified through a system of scores, can provide significant prognostic contribution.

Farther on acknowledging a scoring system, our purpose includes correlation of histopathological findings to data concerning outcome and to epidemiological parameters.

Descriptive analyses helped in selecting useful information which statistical significance was verified through multiple logistic regression.

As our population was composed by acute patients, but also by some chronic ones, sometimes presenting acute crisis, a great variation of the total inhospital time 
and its relation to hospital survival was observed. However, approximately $49 \%$ of the patients were alive at discharge, similarly to previous studies about ARDS $[14,21,23]$.

Considering the diagnostic categorization used in this study, confirmation of clinical diagnosis by biopsy was found in $48 \%$ of the cases, similarly to literature [20,23-25]. The low percentage of confirmation of clinical diagnosis of infectious pneumonia could be explained by early treatment, masking biopsy findings.

Concerning concordance between clinical and biopsy diagnoses, our study shows the higher percentage of hospital survival observed in discordant cases could be interpreted as an indicator of success, not only by the introduction of proper therapy, but also by the withdrawal of a harmful one.

Most part of our diagnoses included airways diseases at the same proportion to interstitial lung diseases; other studies found a higher percentage of idiopathic pulmonary fibrosis [13,16,26-28,].

The effects of precocity of the OLB procedure on outcome are not clearly defined. Some studies suggest a higher survival associated to early biopsy, mainly in immunocompromised patients $[14,17,18]$. On the other hand, BOVE et al. [13] did not observe significant difference between groups biopsied at distinct evolution time. POTTER et al. [15] showed a higher morbidity rate on early biopsies in cancer patients when compared to empiric antibiotictherapy

Our data suggest that in a period up to 20 days, the longer the delay from hospitalization to biopsy, the higher the possibility of discordance from clinical to biopsy diagnosis, reflecting the difficulty in establishing a precise clinical diagnosis in longer 
evolutions. Increasing in concordance, observed in a period longer than 20 days could be the expression of incapacity of histological analysis in providing new information in longer evolutions.

The parameter "sex" was one of the most important of our study, with a large predominance of female. Moreover, we found a negative influence of diffuse alveolar damage and respiratory failure, mainly on men and of underlying diseases mainly on women $(p>0.05)$.

It is largely known that presence of underlying diseases has a deleterious influence on the outcome of a pneumopathy and that diffuse alveolar damage is related to critical clinical pictures. Nevertheless, our study provided important quantitative information concerning these parameters showing an increase of death risk in 33 times in the presence of diffuse alveolar damage and of 25 times in the presence of underlying diseases. An even higher risk could be observed in the concurrence of these factors. Maybe, according to the objective of this study, the most important evidence was the association of the "histopathological index", more specifically "chronic index", to hospital survival. However, there was a surprising inverse association, showing increasing hospital survival in the presence of higher values of "chronic index". Such paradox could be the reflex of the existence of patients with chronic lung diseases, with evident histological changes, but free of death risk during the hospitalization when OLB was carried out, in our casuistry. Other possible interpretation could be done by surgical sampling of a very diseased area, not representative of the whole organ. 
Although without statistical significance, our data indicates a lower percentage of hospital survival associated to factors of immunocompromising, according to previous studies $[13,20,28]$.

Our results now confirm the prognostic importance of histopathological evaluation in OLB. This is probably the first study concerning OLB with emphasis on such detailed histological findings.

Although further studies are required, our results suggest that quantitative assessment, used as scoring system, provides more prognostic information than does routine clinical and pathological approaches.

Restrictions of our results are related to some heterogeneity of the sample , including immunocompetent and immunocompromised, acute and chronic patients. Chronic cases, even that under acute crisis, tend to have shorter inhospital time and to be alive at discharge, besides some procedure complication.

As a retrospective study, conclusions about real benefits of open lung biopsy on mortality beyond hospital scope are not quite reliable.

Although the emphasis of our study is on histopathological findings, changes on therapy resulted from biopsy diagnosis and eventually the rate of late complications of the procedure could have been compared to previous studies.

In addition, clustering 12 different diagnoses into only 4 categories allows statistical analysis, but can lead to mistaken conclusions about successful changes in treatment. 
In conclusion, detailed histological analysis of histological specimens can provide more than nosological diagnosis. This approach can bring valuable information concerning prognosis. Greater study in a randomized and prospective trial could finalize end confirm this conclusion. We also believe that it is important to validate our semiquantitative assessment by a scoring system, as well as to extend it to other histological types of diffuse pulmonary diseases, by studying scoring system in additional patients.

\section{REFERENCES}

1. Lipford EH 3rd, Eggleston JC, Lillemoe KD, Sears DL, Moore GW, Baker RR. Prognostic factors in surgically resected limited-stage, nonsmall cell carcinoma of the lung. Am J Surg Pathol 1984; 8(5):357-65.

2. Elson $\mathrm{CE}$, Roggli VL, Vollmer RT et al. Prognostic indicators for survival in stage $\mathrm{I}$ carcinoma of the lung: a histologic study of 47 surgically resected cases. Mod Pathol. $1988 ; 1(4): 288-91$.

3. Lee TK, Horner RD, Silverman JF, Chen YH, Jenny C, Scarantino CW. Morphometric and morphologic evaluations in stage III non-small cell lung cancers. Prognostic significance of quantitative assessment of infiltrating 
lymphoid cells. Cancer 1989; 63(2):309-16.

4. Kodama T, Nishiyama $H$, Nishiwaki $Y$. Histology and prognosis in lung cancer treatment. Nihon Kyobu Shikkan Gakkai Zasshi 1990; 28(2):216-24.

5. Shahab I, Fraire AE, Greenberg SD, Johnson EH, Langston C, Roggli VL. Morphometric quantitation of tumor necrosis in stage 1 non-small cell carcinoma of lung: prognostic implications. Mod Pathol 1992; 5(5):521-4.

6. Cherniack RM, Colby TV, Flint A et al. Quantitative assessment of lung pathology in idiopathic pulmonary fibrosis. The BAL Cooperative Group Steering Committee. Am Rev Respir Dis 1991;144(4):892-900.

7. Hyde DM, King TE Jr, McDermott T et al. Idiopathic pulmonary fibrosis. Quantitative assessment of lung pathology. Comparison of a semiquantitative and a morphometric histopathologic scoring system. Am Rev Respir Dis 1992; 146(4):1042-7.

8. King TE Jr, Tooze JA, Schwarz MI, Brown KR, Cherniack RM. Predicting survival in idiopathic pulmonary fibrosis: scoring system and survival model. Am J Respir Crit Care Med. 2001;164(7):1171-81. 
9. Gutierrez EB, Zanetta DM, Saldiva PH, Capelozzi VL. Autopsy-proven determinants of death in HIV-infected patients treated for pulmonary tuberculosis in Sao Paulo, Brazil. Path Res Pract 2002; 198:339-346.

10. Watters LC, King TE, Schwarz MI, Waldron JA, Stanford RE, Cherniack RM. A clinical, radiographic, and physiologic scoring system for the longitudinal assessment of patients with idiopathic pulmonary fibrosis. Am Rev Respir Dis. 1986;133(1):97-103.

11. Gay SE, Kazerooni EA, Toews GB et al. Idiopathic pulmonary fibrosis: predicting response to therapy and survival. Am J Respir Crit Care Med 1998;157(4 Pt 1):1063-72.

12. King TE Jr, Schwarz MI, Brown K et al. Idiopathic pulmonary fibrosis: relationship between histopathologic features and mortality. Am J Respir Crit Care Med. 2001; 164(6):1025-32.

13. Bove P, Ranger W, Pursel S, Glover J, Bove K, Bendick P. Evaluation of outcome following open lung biopsy. Am Surg. 1994;60(8):564-70.

14. Patel, SR; Karmpaliotis,D; Ayas, NT, et al. The role of open-lung biopsy in ARDS. Chest 2004, 125(1):197-202. 
15. Potter D, Pass HI, Brower S et al. Prospective randomized study of open lung biopsy versus empirical antibiotic therapy for acute pneumonitis in nonneutropenic cancer patients. Ann Thorac Surg. 1985; 40(5):422-8.

16. Blewett CJ, Bennett WF, Miller JD, Urschel JD. Open lung biopsy as an outpatient procedure. Ann Thorac Surg. 2001;71(4):1113-5.

17. Rossiter SJ, Miller C, Churg AM, Carrington CB, Mark JB. Open lung biopsy in the immunosuppressed patient. Is it really beneficial? J Thorac Cardiovasc Surg. 1979; 77(3):338-45.

18. Walker WA, Cole FH Jr, Khandekar A, Mahfood SS, Watson DC. Does open lung biopsy affect treatment in patients with diffuse pulmonary infiltrates? J Thorac Cardiovasc Surg. 1989; 97(4):534-40.

19. Canver CC, Mentzer RM Jr. The role of open lung biopsy in early and late survival of ventilator-dependent patients with diffuse idiopathic lung disease. J Cardiovasc Surg (Torino). 1994;35(2):151-5.

20. Kramer, MR; Berkman, N; Mintz, B, et al. The role of open lung biopsy in the management and outcome of patients with diffuse lung disease. Ann Thorac Surg 1998, 65(1): 198-202. 
21. Flabouris A, Myburgh J. The utility of open lung biopsy in patients requiring mechanical ventilation. Chest. 1999;115(3):811-7.

22. Papazian $\mathrm{L}$, Thomas $\mathrm{P}$, Bregeon $\mathrm{F}$ et al. Open-lung biopsy in patients with acute respiratory distress syndrome. Anesthesiology. 1998;88(4):935-44.

23. Warner DO, Warner MA, Divertie MB. Open lung biopsy in patients with diffuse pulmonary infiltrates and acute respiratory failure. Am Rev Respir Dis. 1988; 137(1):904.

24. Nelems JM, Cooper JD, Henderson RD, Peng T, Phillips MJ. Emergency open lung biopsy. Ann Thorac Surg. 1976; 22(3):260-4.

25. Neuhaus SJ, Mattar KS. The efficacy of open lung biopsy. Aust N Z J Surg. 1997; 67(4):181-4.

26. Gaensler EA, Carrington CB. Open biopsy for chronic diffuse infiltrative lung disease: clinical, roentgenographic, and physiological correlations in 502 patients. Ann Thorac Surg. 1980; 30(5):411-26. 
27. Venn GE, Kay PH, Midwood CJ, Goldstraw P. Open lung biopsy in patients with diffuse pulmonary shadowing. Thorax. 1985; 40(12):931-5.

28. Shah SS, Tsang V, Goldstraw P. Open lung biopsy: a safe, reliable and accurate method for diagnosis in diffuse lung disease. Respiration. 1992; $59(4): 243-6$. 
Table 1: Epidemiological data of the 63 patients studied

\begin{tabular}{|c|c|c|c|c|c|c|}
\hline Case & Sex & Age & $\begin{array}{c}\text { Total } \\
\text { Hospitalization } \\
\text { Time (days) } \\
\end{array}$ & Underlying disease & $\begin{array}{c}\text { Presence of } \\
\text { immunossupression } \\
\text { factor }\end{array}$ & Outcome \\
\hline 1 & $\mathrm{~m}$ & 56 & 20 & No & No & Dead \\
\hline 2 & $\mathrm{~m}$ & 48 & 32 & No & No & Dead \\
\hline 3 & $\mathrm{~m}$ & 76 & 60 & Renal and heart failure & No & Survived \\
\hline 4 & $f$ & 19 & 47 & BMT (aplastic anemia) & Yes & Dead \\
\hline 5 & $\mathrm{~m}$ & 67 & 44 & No & No & Survived \\
\hline 6 & $\mathrm{~m}$ & 55 & 17 & Rheumatologic disease NOS & No & Dead \\
\hline 7 & $f$ & 52 & 27 & Heart failure & No & Survived \\
\hline 8 & $\mathrm{~m}$ & 48 & 55 & Crohn's disease+ renal failure & No & Dead \\
\hline 9 & $\mathrm{~m}$ & 66 & 42 & Rheumatoid arthritis & No & Dead \\
\hline 10 & $f$ & 37 & 44 & SLE & No & Dead \\
\hline 11 & $\mathrm{~m}$ & 34 & 16 & AIDS & Yes & Dead \\
\hline 12 & $\mathrm{~m}$ & 45 & 18 & $\mathrm{CML}$ & Yes & Dead \\
\hline 13 & $\mathrm{~m}$ & 52 & 20 & No & No & Survived \\
\hline 14 & $f$ & 21 & 38 & Non-Hodgkin's lymphoma & Yes & Survived \\
\hline 15 & $f$ & 30 & 37 & No & No & Survived \\
\hline 16 & $f$ & 63 & 9 & Carcinomatosis & Yes & Dead \\
\hline 17 & $\mathrm{~m}$ & 37 & 48 & No & No & Dead \\
\hline 18 & $f$ & 51 & 22 & Gastroesophageal reflux & No & Survived \\
\hline 19 & $\mathrm{~m}$ & 52 & 38 & Liver cirrhosis & No & Survived \\
\hline 20 & $f$ & 46 & 26 & Adenocarcinoma NOS & No & Dead \\
\hline 21 & $f$ & 34 & 4 & $\mathrm{CML}$ & Yes & Dead \\
\hline 22 & $f$ & 49 & 19 & Carcinomatosis & Yes & Survived \\
\hline 23 & $\mathrm{~m}$ & 23 & 21 & Burns & No & Dead \\
\hline 24 & $\mathrm{~m}$ & 58 & 13 & Adenocarcinoma NOS & Yes & Dead \\
\hline 25 & $\mathrm{~m}$ & 77 & 45 & COPD & Yes & Dead \\
\hline 26 & $\mathrm{~m}$ & 36 & 20 & BMT & Yes & Dead \\
\hline 27 & $\mathrm{~m}$ & 78 & 17 & No & Yes & Survived \\
\hline 28 & $f$ & 54 & 9 & SLE & No & Dead \\
\hline 29 & $f$ & 51 & 184 & Wegener's granumatosis & No & Dead \\
\hline 30 & $\mathrm{~m}$ & 57 & 33 & Ischemic myocardiopathy & No & Dead \\
\hline 31 & $f$ & 21 & 42 & SLE & No & Survived \\
\hline 32 & $f$ & 74 & 16 & Congestive myocardiopathy & No & Dead \\
\hline 33 & $\mathrm{~m}$ & 55 & 91 & Congestive myocardiopathy & No & Dead \\
\hline 34 & $\mathrm{~m}$ & 65 & 69 & Sarcoidosis & No & Dead \\
\hline 35 & $f$ & 46 & 15 & Wegener's granumatosis & No & Survived \\
\hline 36 & $f$ & 52 & 76 & No & Yes & Survived \\
\hline 37 & $f$ & 92 & 24 & Ischemic myocardiopathy & No & Survived \\
\hline 38 & $f$ & 26 & 27 & $\mathrm{BMT}(\mathrm{CML})$ & Yes & Dead \\
\hline 39 & $f$ & 53 & 98 & Rheumatoid arthritis & No & Dead \\
\hline 40 & $\mathrm{~m}$ & 70 & 47 & Non-Hodgkin's lymphoma & Yes & Dead \\
\hline 41 & $f$ & 30 & 65 & Colitis NOS & No & Survived \\
\hline 42 & $f$ & 82 & 22 & Neoplasia NOS & Yes & Survived \\
\hline 43 & $f$ & 50 & 91 & SLE & Yes & Survived \\
\hline 44 & $\mathrm{~m}$ & 57 & 38 & Gastroesophageal reflux+DM 2 & No & Survived \\
\hline 45 & $\mathrm{~m}$ & 65 & 37 & Ischemic myocardiopathy+DM 2 & No & Dead \\
\hline 46 & $\mathrm{~m}$ & 47 & 37 & ALL & Yes & Dead \\
\hline 47 & $\mathrm{~m}$ & 32 & 16 & ALL & Yes & Dead \\
\hline 48 & $f$ & 68 & 37 & Hypertension & No & Survived \\
\hline 49 & $\mathrm{~m}$ & 53 & 26 & Heart transplantation & Yes & Dead \\
\hline 50 & $\mathrm{~m}$ & 22 & 89 & ALL & Yes & Survived \\
\hline
\end{tabular}




\begin{tabular}{ccccccc}
\hline $\mathbf{5 1}$ & $\mathrm{m}$ & 18 & 7 & BMT (ALL) & Yes & Survived \\
$\mathbf{5 2}$ & $\mathrm{f}$ & 76 & 36 & Ischemic myocardiopathy & No & Dead \\
Dead \\
$\mathbf{5 3}$ & $\mathrm{f}$ & 55 & 17 & Carcinomatosis & Yes & Survived \\
$\mathbf{5 4}$ & $\mathrm{f}$ & 25 & 47 & No & No & Dead \\
$\mathbf{5 5}$ & $\mathrm{f}$ & 38 & 42 & No & Yes & Dead \\
$\mathbf{5 6}$ & $\mathrm{m}$ & 37 & 84 & $\mathrm{CML}$ & No & Survived \\
$\mathbf{5 7}$ & $\mathrm{f}$ & 36 & 10 & Ischemic myocardiopathy & Yes & Survived \\
$\mathbf{5 8}$ & $\mathrm{f}$ & 36 & 14 & Carcinomatosis & No & Survived \\
$\mathbf{5 9}$ & $\mathrm{m}$ & 73 & 34 & No & No & Survived \\
$\mathbf{6 0}$ & $\mathrm{f}$ & 52 & 36 & No & No & Dead \\
$\mathbf{6 1}$ & $\mathrm{m}$ & 31 & 49 & SLE & Yes & Dead \\
$\mathbf{6 2}$ & $\mathrm{m}$ & 28 & 48 & Aplastic anemia & No & Survived \\
$\mathbf{6 3}$ & $\mathrm{f}$ & 73 & 37 & No & & \\
\hline
\end{tabular}

Abbreviations: AIDS: Acquired Immunodeficiency Syndrome; ALL: Acute Lymphocytic Leukemia; BMT: Bone Marrow Transplantation; CML: Chronic Myelocytic Leukemia; CPOD: Chronic Obstructive Lung Disease; DM: Diabetes Mellitus; NOS: no other specification; SLE: Systemic Lupus Erythematous 
Table 2: Distribution of clinical, biopsy and necropsy diagnoses

\begin{tabular}{|c|c|c|c|c|c|c|}
\hline Diagnoses & \multicolumn{2}{|c|}{ Clinical } & \multicolumn{2}{|c|}{ Biopsy } & \multicolumn{2}{|c|}{ Necropsy } \\
\hline Infectious lung disease & 22 & (35) & 9 & (14) & 9 & (38) \\
\hline Granulomatous (non-infectious) lung disease & 7 & (11) & 7 & (11) & 1 & (4) \\
\hline Airway diseases & 4 & (6) & 10 & (16) & 1 & (4) \\
\hline Interstitial pneumonia & 11 & (17) & 10 & (16) & 1 & (4) \\
\hline Circulatory disturbance & 6 & (10) & 7 & (11) & 2 & (8) \\
\hline Carcinoma & 6 & (10) & 5 & (8) & 3 & (13) \\
\hline Hypersensitivity pneumonia & & & 2 & (3) & & \\
\hline Diffuse alveolar damage & & & 7 & (11) & 6 & (25) \\
\hline Capilaritis/ vasculitis & 5 & (8) & 4 & (6) & 1 & (4) \\
\hline Amyloidosis & & & 1 & (2) & & \\
\hline Histiocytosis X & 1 & (2) & & & & \\
\hline Lymphoma & 1 & (2) & 1 & $(2)$ & & \\
\hline & & $(100$ & & & & \\
\hline Total & 63 & ) & 63 & $(100)$ & 24 & (100) \\
\hline
\end{tabular}


Table 3: Quantitative assessment for "acute" and "chronic" "indices"

\begin{tabular}{ccc}
\hline Statistical parameters & Chronic & Acute \\
\hline $\mathrm{N}$ & 63 & 63 \\
Mean & 3,6 & 3,7 \\
Standard error & 2,0 & 1,8 \\
Median & 3,5 & 3,7 \\
Minimum & 0,1 & 0,4 \\
Maximum & 9,3 & 8,7 \\
\hline
\end{tabular}


Table 4: Multiple linear regression model

\begin{tabular}{ccccccc}
\hline Factors & Coefficient Std.error & $\mathbf{p}$ & $\mathbf{0 . R}$. & \multicolumn{2}{c}{ Confidence interval (95\%) } \\
\cline { 6 - 7 } & & & & & Inferior Limit Superior Limit \\
\hline $\begin{array}{c}\text { Female sex } \\
\text { Diffuse alveolar } \\
\quad \text { damage }\end{array}$ & $-3,82$ & 0,88 & 0,04 & 6,16 & 1,09 & 34,88 \\
$\begin{array}{c}\text { Underlying } \\
\text { disease }\end{array}$ & $-3,34$ & 1,04 & 0,00 & 0,03 & 0,00 & 0,27 \\
"Chronic index" & 1,10 & 0,30 & 0,00 & 3,01 & 1,67 & 5,43 \\
\hline O.R.= odds ratio & & & & & &
\end{tabular}

